Florida International University FIU Digital Commons

\title{
Understanding the Organizational Factors that Impact Police-Community Relations
}

Andrea Marie Headley

Florida International University, ahead004@fiu.edu

DOI: 10.25148 /etd.FIDC006817

Follow this and additional works at: https://digitalcommons.fiu.edu/etd

Part of the Criminology Commons, Public Administration Commons, Public Affairs Commons, and the Race and Ethnicity Commons

\section{Recommended Citation}

Headley, Andrea Marie, "Understanding the Organizational Factors that Impact Police-Community Relations" (2018). FIU Electronic Theses and Dissertations. 3816.

https://digitalcommons.fiu.edu/etd/3816

This work is brought to you for free and open access by the University Graduate School at FIU Digital Commons. It has been accepted for inclusion in FIU Electronic Theses and Dissertations by an authorized administrator of FIU Digital Commons. For more information, please contact dcc@fiu.edu. 


\section{FLORIDA INTERNATIONAL UNIVERSITY}

Miami, Florida

\section{UNDERSTANDING THE ORGANIZATIONAL FACTORS THAT IMPACT POLICE-COMMUNITY RELATIONS}

A dissertation submitted in partial fulfillment of

the requirements for the degree of

DOCTOR OF PHILOSOPHY

in

PUBLIC AFFAIRS

by

Andrea Marie Headley 
To: Dean John F. Stack, Jr.

Green School of International and Public Affairs

This dissertation, written by Andrea Marie Headley, and entitled Understanding the Organizational Factors that Impact Police-Community Relations, having been approved in respect to style and intellectual content, is referred to you for judgment.

We have read this dissertation and recommend that it be approved.

Robert Guerette

Mohamad Alkadry

Alexander Kroll

Timothy Goddard, Co-Major Professor

Nazife Emel Ganapati, Co-Major Professor

Date of Defense: May 30, 2018

The dissertation of Andrea Marie Headley is approved.

Dean John F. Stack, Jr. Green School of International and Public Affairs

Andrés G. Gil

Vice President for Research and Economic Development and Dean of the University Graduate School

Florida International University, 2018 
C Copyright 2018 by Andrea Marie Headley

All rights reserved. 


\section{DEDICATION}

This dissertation is dedicated to my mother and father, Lucia and Menthor

Headley; my sister, Rene Headley; and my grandmother, Gloria Headley. All of you have walked on this journey side by side with me and dreamt with me. 


\section{ACKNOWLEDGMENTS}

To my dissertation committee members, Dr. N. Emel Ganapati, Dr. Tim Goddard, Dr. Alexander Kroll, Dr. Mohamad G. Alkadry, and Dr. Rob T. Guerette, you have remained with me through this academic journey and have shaped my intellectual development. Thank you for the support, encouragement, and continuous substantive feedback. To my co-chairs, Dr. Ganapati and Dr. Goddard, you have both encouraged me, celebrated with me, and most importantly challenged me to consistently do better, for that I am forever grateful.

To all of the faculty and staff in the Department of Public Policy and Administration, you have each impacted my doctoral journey by providing immense support throughout this process. This has truly been a pleasurable experience and I thank you. To the faculty in the Department of Criminal Justice, thank you for accepting me as your own.

I am thankful for the many organizations, scholars, and practitioners who have helped facilitate my dissertation research along the way. First, I would like to acknowledge the gracious financial support that I have been fortunate to receive during my doctoral process. There are two organizations in particular that have provided substantial financial support towards my doctoral education and my dissertation research. First, to the Florida Education Fund McKnight Doctoral Fellowship, I am thankful for the monetary support, the emotional support, and the professional development opportunities. Second, to the Bureau of Justice Statistics, Office of Justice Programs, U.S. Department of Justice, thank you for awarding me with the Graduate Research Fellowship for Criminal Justice Statistics (Award No. 2015-R2-CX-K030), which provided me the 
freedom and opportunity to investigate research questions that I am passionate about. However, I acknowledge that the opinions, findings, and conclusions or recommendations expressed herein are those of the author and do not necessarily represent the views of the U.S. Department of Justice.

I am especially thankful for Chief James Rovella and the Hartford Police Department. During a time when the practice and culture of policing in America has been intensely scrutinized, it could have been easy for you to close your doors to me. Rather, you chose to open your doors even wider. Thank you to the entire department for the countless hours that you all spent with me during meetings, interviews, ride-alongs and more, all of which allowed me to conduct this research. To the Miami-Dade County Association of Chiefs of Police, the National Association of Chiefs of Police, and the National Association of Police Organizations, thank you for the letters written in support of my dissertation research endeavors.

To Dr. Laura Kohn-Wood, my undergraduate professor and one of my mentors, thank you for exposing me to social science research, encouraging me to pursue a Ph.D., believing in my potential, and always looking far beyond what I could only imagine. To Mildred Duprey de Robles, the experience you provided me with during my time interning at the U.S. Department of Justice, Community Relations Service has shaped my dissertation research. Thank you for allowing me to learn from you and continuing to serve as one of my mentors.

To all of my fellow graduate students (both inside and outside of my department) who have become my dearest friends along the way. You have uplifted me, motivated me, laughed with me, traveled with me, exposed me to new cultures and broadened my 
perspective. In five short years, we have created memories that I will cherish for a lifetime.

Outside of academe, there are many people that I am particularly appreciative for. To my Apostle and church, you have prayed for me, encouraged me and nurtured me throughout my entire undergraduate and graduate experience. Thank you for instilling in me hope and faith in Jesus Christ, both of which were essential for me throughout this process. To the friends that have become family, the ones that have known me for over ten years, thank you for being a continual presence in my life. Thank you for standing with me as I pursued my doctoral degree.

Lastly, to my mother and father, the love, guidance, patience, encouragement, and experiences that you have provided to and for me have truly made me a better person, scholar, and educator. Words fall short in expressing my sentiments of gratitude. To my sister, you continue to show me what a heart of kindness and generosity looks like. Thank you for always believing in me and inspiring me to do this work. To my grandmother, you have embodied what it means to persevere. Thank you for so generously passing that along to me. 


\section{ABSTRACT OF THE DISSERTATION \\ UNDERSTANDING THE ORGANIZATIONAL FACTORS THAT IMPACT POLICE-COMMUNITY RELATIONS}

by

Andrea Marie Headley

Florida International University, 2018

Miami, Florida

\section{Professor Nazife Emel Ganapati, Co-Major Professor \\ Professor Timothy Goddard, Co-Major Professor}

There has been a significant amount of attention refocused on problems surrounding police and communities of color. The most consistent remedy identified has been reforming police departments, which is an organizational-level solution. However, only minimal strides have been made in empirical research to understand the organizational correlates associated with police-community relations. Thus, this research investigated the impact that police departments' organizational and managerial characteristics have on police-community relations.

The key contributions of this research to the literature are three-fold. First, a composite indicator of police-community relations was developed by compiling a large nationwide dataset of local police-departments. This multidimensional indicator includes citizen complaints, police use of force, assaults against police officers, and civilian deaths by police. Second, the role that specific organizational characteristics-communityoriented policing, passive representation, professionalism, and control mechanismshave on police-community relations was estimated using ordinary least squares 
regression analyses from over 250 police departments. The findings portrayed that only specific (and very few) organizational and managerial characteristics of police departments impact police-community relations. Specifically, police departments that had formal partnerships with the community, dedicated beat patrol officers, and minority representation were found to have lower levels of use of force. Police departments with higher numbers of officers dedicated to problem-solving activities in the community had lower levels of citizen complaints; in contrast, departments that were more formalized had higher levels of citizen complaints.

Lastly, to understand the causal mechanisms undergirding organizational factors and police-community relations, an in-depth case study was conducted in Hartford, Connecticut. The case study included (a) 88 interviews with police officers, public officials, and community leaders, (b) 67.7 hours of participant observations, and (c) a review of secondary sources. A thematic content analysis of the data underscored the importance of police departments cultivating soft skills, investing in human resources, and being intentional about engaging the community. Specifically, police departments can influence police-community relations by impacting the level and quality of service provision and/or officer attitudes and behavior. Taken as a whole, this study adds to the knowledge base of organizational behavior, public management, and policing studies while also providing implications for policy and practice. 


\section{TABLE OF CONTENTS}

CHAPTER

PAGE

CHAPTER 1: The Need for an Organizational Approach: Examining PoliceCommunity Relations in Light of History, Police Reform, and Previous Literature ..........1

Historical Context of Policing in America: Policing Paradigms ..........................5

Historical Context of Police Reform in America.................................................9

Literature Review on Organizational Studies of Police Departments ..................16

Studies of police use of force ................................................... 18

Studies of citizen complaints ......................................................22

Studies of assaults against officers ..................................................24

Qualitative studies on police organizations ...................................27

Purpose and Significance of the Study....................................................29

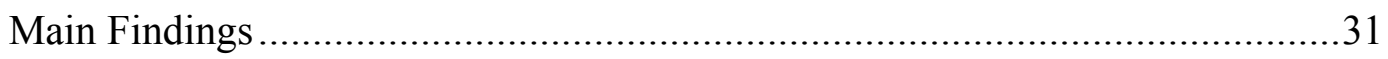

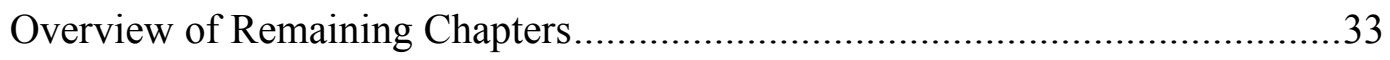

CHAPTER 2: Where They Fall: A Comparative Assessment of Police Performance in Terms of Police-Community Relations Across United States Cities ..........................36

Conceptualizing and Operationalizing Police-Community Relations .................39

What is a Composite Indicator? ........................................................ 42

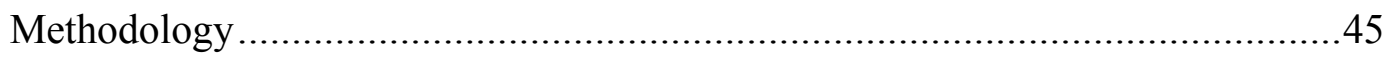

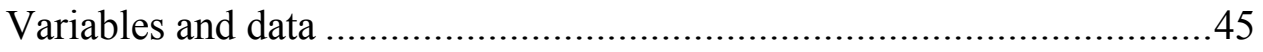

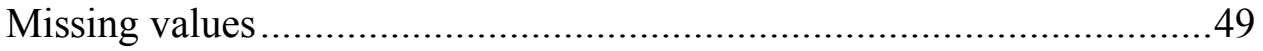

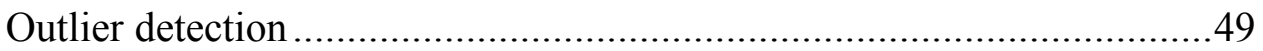

Data transformation and normalization ...........................................50

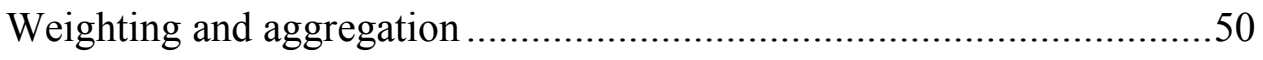

Multiplicative scoring (geometric aggregation) .......................51

Principal components analysis............................................53

Sensitivity and uncertainty analyses...........................................5

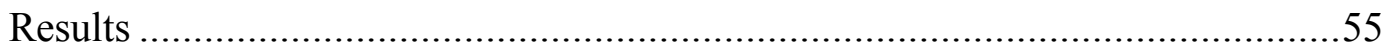

Comparing composite indicators...................................................56

The geography of police-citizen conflict ......................................58 
Conclusion .65

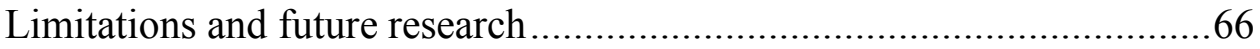

Implications.

CHAPTER 3: Can Organizational and Managerial Strategies Solve Negative PoliceCommunity Relations? An Analysis of United States City Police Departments. .71

Literature Review: Police-Community Relations and Police-Citizen Conflict.....74

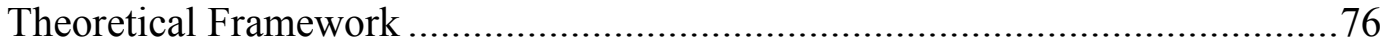

Community-oriented policing .........................................................

Administrative responsibility and accountability ....................................79

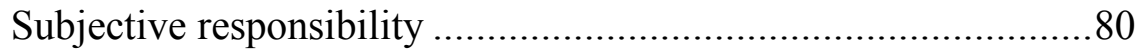

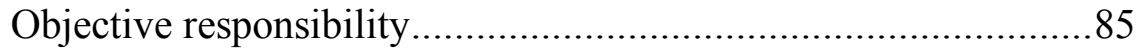

Research Design and Methodology ............................................................... 88

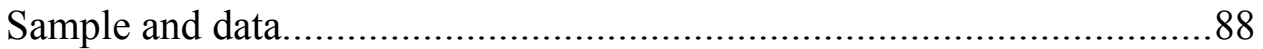

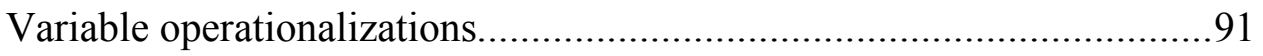

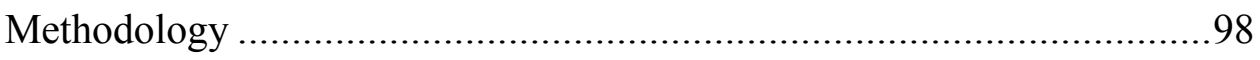

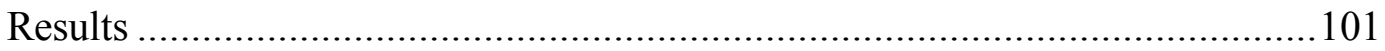

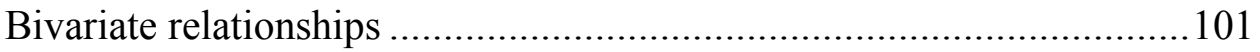

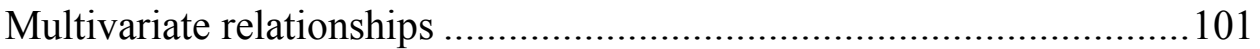

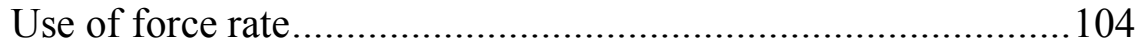

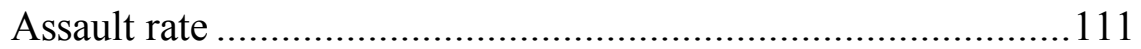

Citizen complaint rate ......................................................... 112

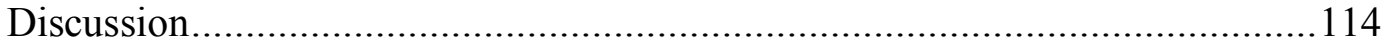

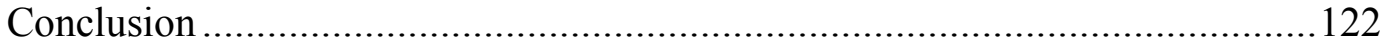

Limitations and future research.........................................................123

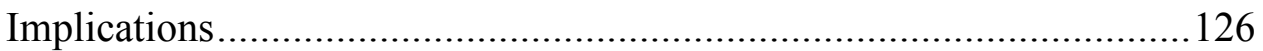

CHAPTER 4: Why and How: Untangling the Causal Mechanisms Undergirding Organizational and Managerial Factors and Police-Community Relations.

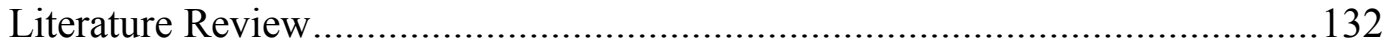

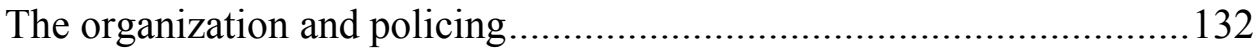

Qualitative research and police-community relations ............................133

Filling the gap ................................................................................ 136 


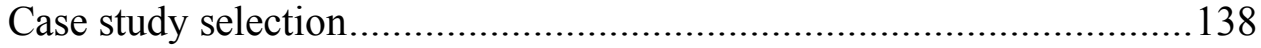

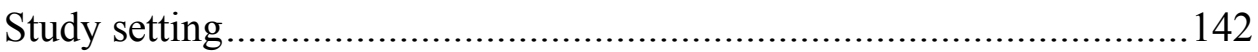

Hartford Police historical context ..............................................143

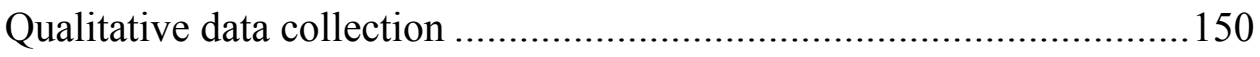

Semi-structured interviews .......................................................150

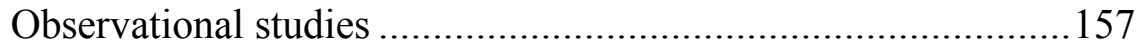

Review of secondary sources.................................................... 160

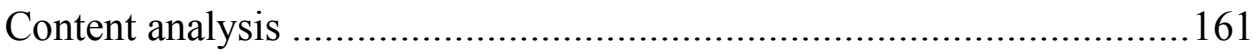

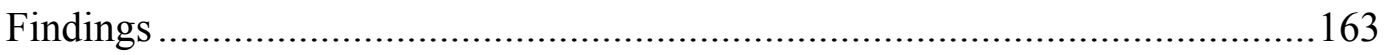

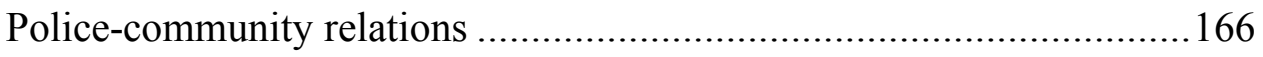

Defining police-community relations: It takes two to tango,

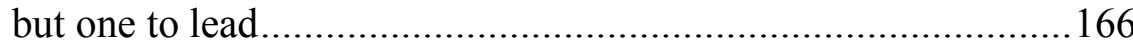

Where you stand depends on where you sit: Differing perspectives on the current state of police-community relations

Cultivating soft skills

Winning the community one person at a time: Individual-level

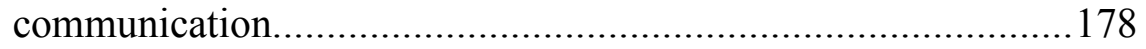

Organizational communication as a means to keep the community informed.

Not by the color of your skin, but by the content of your character: The link between officer character traits and behavior.

Investing in human resources.

Tell me and I forget, teach me and I may remember, involve me and I learn: Training officers to deal with diverse populations.

Time spent on hiring is time well spent: Inadequate staffing levels diminish police-community relations

Intentionally engaging

Bringing the community in: Broadening community understanding of police activities and internal challenges

Getting the police out: Police engaging in community-oriented activities. 
The whole is greater than the sum of its parts: Partnering to impact police-community relations.

A dream deferred: External accountability mechanisms in place but enforcement lacking ..........................................225

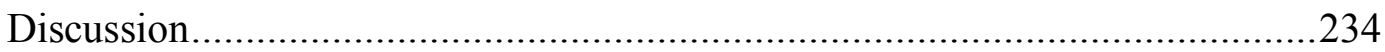

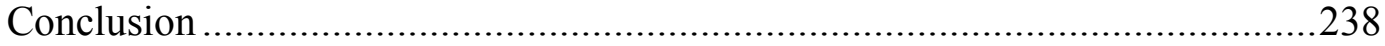

Limitations and future research ...............................................239

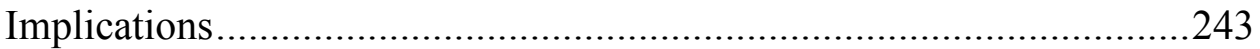

CHAPTER 5: Where, What, Why, and How? Reconciling the Quantitative and Qualitative Findings to Better Understand Police-Community Relations.....................246

Summary of the Dissertation Chapters......................................................246

Integrating the Quantitative and Qualitative Findings .................................250

Strengths and Limitations...................................................................2. 255

Implications and Future Research ........................................................2256

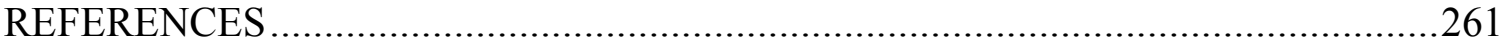

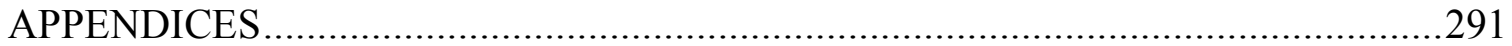

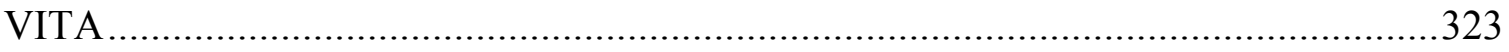




\section{LIST OF TABLES}

TABLE

PAGE

1. Principal Component Analysis of Police-Citizen Conflict ..................................52

2. Index Correlations with Three Key Socio-Economic Variables ..............................55

3. Listing Police Departments with the Highest and Lowest Police-Citizen Conflict Scores.....

4. Comparing Police Departments with High and Low Police-Citizen Conflict Scores.....

5. Police Departments' Rank Across Individual Police-Citizen Conflict Indicators ......65

6. Results of One-sample T-test and Descriptive Statistics for Force Model ................92

7. Results of One-sample T-test and Descriptive Statistics for Assault Model .............93

8. Results of One-sample T-test and Descriptive Statistics for Complaint Model.........94

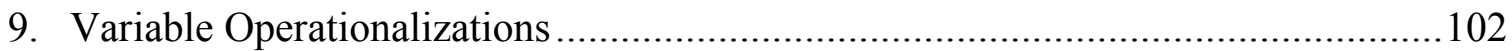

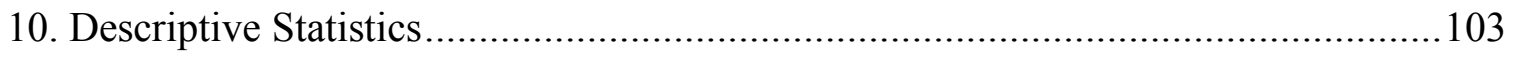

11. Bivariate Correlations for Force and Assault Rate ......................................... 105

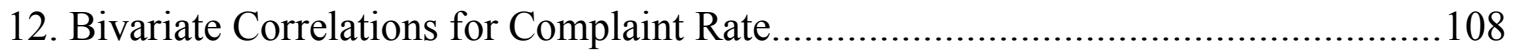

13. Ordinary Least Squares Regression Results............................................. 110

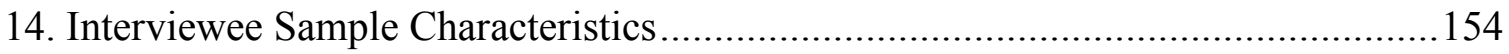




\section{LIST OF FIGURES}

FIGURE

PAGE

1. Police-citizen conflict in cities across the contiguous United States. .60

2. Police-citizen conflict and minoritized populations across the contiguous United States

3. Conceptual framework .81

4. Hartford Police Department organizational chart 144

5. Hartford neighborhood maps 145

6. Police representatives: Division of labor 156

7. Police respondent's tenure (in years of service) at the police department. 156

8. Word frequency cloud of qualitative interviews 164

9. The impact of communication on police-community relations. 184

10. The impact of character traits on police-community relations 188

11. The impact of training on police-community relations...... 195

12. The impact of manpower on police-community relations

13. The impact of collaborative relationships on police-community relations .205

14. The impact of external accountability on police-community relations .232

15. The processes by which organizational and managerial factors impact policecommunity relations 


\section{ABBREVIATIONS AND ACRONYMS}

ACLU

ACS

CALEA

CI

$\mathrm{CP}$

$\mathrm{CSO}$

DOJ

FBI

GM

IACP

KMO

LEMAS

LEOKA

NACOLE

NRZ

NYPD

OLS

ORI

PAL

PCA

PCC

PCR
American Civil Liberties Union

American Community Survey

Commission on Accreditation for Law Enforcement Agencies

Composite Indicator

Community-Oriented Policing

Community Service Officer

Department of Justice

Federal Bureau of Investigation

Geometric Mean

International Association of Chiefs of Police

Kaiser-Meyer-Olkin

Law Enforcement Management and Administrative Statistics

Law Enforcement Officers Killed and Assaulted

National Association of Civilian Oversight of Law Enforcement

Neighborhood Revitalization Zones

New York City Police Department

Ordinary Least Squares

Originating Agency Identifier

Police Activities League

Principle Component Analysis

Police-Citizen Conflict

Police-Community Relations 
PD

SARA

UCR

UNDP
Police Department

Scanning, Analysis, Response, and Assessment

Uniform Crime Report

United Nations Development Programme 


\section{CHAPTER 1}

\section{The Need for an Organizational Approach: Examining Police-Community Relations in Light of History, Police Reform, and Previous Literature}

In July 2014, Eric Garner was approached by the New York City Police Department due to suspicion that he was selling untaxed single cigarettes, also referred to as "loosies." Within minutes, an altercation between Mr. Garner and police officers ensued that ultimately led to multiple New York City police officers holding Mr. Garner to the ground and Officer Pantaleo's arms around Mr. Garner's neck (what appears to some as a chokehold ${ }^{1}$ ). The video footage that was subsequently released depicted Mr. Garner repeatedly stating "I can't breathe" as he lay on the ground. Soon thereafter, Mr. Garner lost consciousness and was pronounced dead an hour later after arriving at a hospital.

A month following this incident, Michael Brown, a Black male, was shot to death by law enforcement officers in Ferguson, Missouri. Mr. Brown was a suspect in a reported convenience store robbery. After Mr. Brown was approached by the police, a tussle immediately ensued between Mr. Brown and Officer Wilson. Within three minutes, Michael Brown was shot at least six times and killed.

Controversy followed shortly after each of these incidents as they both involved unarmed Black males who died at the hand of law enforcement. Despite the geographical distance between these incidents, both were displayed and discussed via social media and

\footnotetext{
${ }^{1}$ The New York Police Department's policy prohibits the use of chokeholds by their officers. However, following this case, some speculation arose as to what constitutes a chokehold.
} 
resulted in public outcry. Consequently, following the grand jury decisions to indict neither Officer Pantaleo nor Officer Wilson, many cities across the United States experienced protests, demonstrations, disruption, looting, and destruction.

It is important to note that in many communities across the county, such deadly force encounters have not necessarily been the sole cause of demonstrations, but rather the spark that ignited years of growing tensions between police and communities. For instance, a subsequent investigation into the Ferguson Police Department found a history of deeply embedded unconstitutional police practices (e.g., unreasonable use of force, racial bias, an overwhelming emphasis on revenue over public safety) that often impacted the racially minoritized and impoverished communities (U.S. Department of Justice, 2015).

Likewise, these tensions are not new and often date back decades. For instance, Stoughton (2015) noted that "of the ten most destructive and violent riots in United States history, fully half were responses to perceived police abuses" (para. 9). As of 2011, the list of the ten most destructive riots included the following (listed in chronological order):

1. 1863, New York City: Irish immigrants protested the Union's institution of the Civil War draft;

2. 1965, Watts neighborhood of Los Angeles: residents protested perceived racist police behavior;

3. 1967, Detroit: residents reacted to police raids of an unlicensed business and rumors of excessive police force;

4. 1967, Newark: riots sparked by a false rumor that police killed a Black taxicab driver; 
5. 1968, Chicago: city residents responded with outcry to the assassination of Martin Luther King, Jr.;

6. 1973, Oklahoma State Penitentiary prison: riot arose among correctional officers and inmates;

7. 1977, New York City: citywide riots and looting prompted by an overnight city blackout, amid a serious financial crisis and sweltering summer temperatures;

8. 1992, Los Angeles: "the Rodney King riots" erupted in protest of police abuse and brutality;

9. 1999, Seattle: anti-globalization activist riot in protest of the World Trade Organization Ministerial Conference; and

10. 2001, Cincinnati: "urban riots" occurred in reaction to a fatal police shooting of a young Black male.

These incidents were characterized as the most destructive riots due to the damages incurred both in money and livelihood (Bukszpan, 2011), five of which were in direct response to police actions - Cincinnati (2001), the 1992 Rodney King riots, the 1967 riots in Detroit and Newark, and in 1965 in Watts Los Angeles.

However, the violence was not one-sided; there have also been horrific assaults and deaths of police by the members of the public. In July 2016, five Dallas police officers (Officers Ahrens, Krol, Smith, Thompson, and Zamarripa) were shot and killed in what authorities have characterized as a sniper ambush. Likewise, in December 2017, Officer Miosotis Familia, a New York City police officer, was fatally shot while she was sitting in her police vehicle. While these acts may represent the rare extremes of police- 
community violence, they represent just a few out of many, and exemplify the devastating impacts and strains that such incidents have on building relationships between police and communities.

One of the biggest differences with police-citizen conflict now compared to many years ago is the prolific impact of the internet and media as a result of media's instantaneous nature and wide-scale dissemination. Thus, while the service provision aspect of policing is at the local level, attention and impacts can be felt nationwide. Thus, recent - yet recurrent — national attention has been focused on problems within police and community relationships, particularly as it surrounds issues of use of force and negative relations with communities of color.

Policing is an integral part of public service delivery and provision, and law enforcement may often operate as the face of local government within certain communities. Law enforcement officers are public sector employees, working at the local, state, or even federal level and are considered to be front-line workers. They operate within para-military command structures with highly bureaucratized and politicized environments (Lipsky, 2010). They implement policy directives and have high levels of administrative discretion when engaging with the public (Maynard-Moody \& Musheno, 2003). Further, public safety overall makes up a substantial part of government expenditures and, at times, its revenue. Thus, it is imperative to understand and develop solutions to the ongoing issues between the police and the community in light of public affairs, administration, and management contexts.

This chapter proceeds by providing an overview of the historical context of policing in America, while devoting significant attention to policing paradigms. It then 
leads into a discussion of police reform efforts that have occurred at predominantly national (but also local) levels. After laying the foundation for the importance of understanding policing from an organizational perspective, the chapter delves into the empirical literature in policing that has utilized an organizational lens. This chapter emphasizes the purpose and significance of this research to further research, practice, and policy on how organizational and managerial characteristics impacts police-community relations. The concluding portions of this chapter provide an overview of the contents and substance of the dissertation research, methods, and findings.

\section{Historical Context of Policing in America: Policing Paradigms}

Policing in the United States has traditionally borrowed approaches from the British system, particularly England. Prior to the $19^{\text {th }}$ century, policing as a large, bureaucratic, and organized institution was nonexistent. However, mechanisms were still in place to ensure safety and security, such as night watches and slave patrols (Potter, 2013). With the turn of the $19^{\text {th }}$ century, the United States faced various problems as it pertained to industrialization, migration, and urbanization, all of which resulted in poverty, crime and disorder, poor sanitation, and other social ills. These societal problems led to many challenges during the early 1800 s, which in turn demonstrated the need for larger, organized police forces (Langworthy \& Travis, 1999). The first centralized municipal police department was established in Boston, Massachusetts in 1838. Within the next 20 years, police departments were also created in New York City, Chicago, New Orleans, Cincinnati, Philadelphia, Newark, and Baltimore (Potter, 2013).

Historians and other scholars typically refer to policing in the United States as defined by Kelling and Moore's framework, which identified three policing eras seen 
over time: the political era, the reform era, and the community era (Kelling \& Moore, 1988). It is important to note that the typology identified by Kelling and Moore is limited in that it applies to the typical majority of the population. Thus, some scholars have argued that this framework does not offer a holistic guideline for analyzing police relations in regard to urban, communities of color (Williams \& Murphy, 1990). Further, in practice, the strategies utilized within each policing era have typically built upon the previous era, rather than replacing it. Thus, each era should not be discussed in a vacuum or as separate and distinct from the others.

The first attempt at an organized and large police force began with the political era from the 1830s to the 1920s. During this time, policing gained its legitimacy and power from politics and the political process. The focus of policing was on order maintenance and on gaining political and citizen satisfaction by providing direct services to the community. Police mirrored the racial and/or ethnic background of the dominant political group (i.e., White) and they would typically reside within the communities they foot patrolled. During this time period, Blacks lacked both political power and influence, and thus they had little to no input in policing strategy or policy (Williams \& Murphy, 1990). This era ultimately evolved with the realization that ties too close to the political process, a rampant spoils system, and a lack of oversight and supervision produced an ineffective and corrupt police force.

Following this era was a movement to professionalize the police bureaucracy. Professionalization was seen as particularly important as it related to the detachment from political influences as well as to the hiring and promotional standards for officers. The professional-reform era of policing lasted approximately from the 1920s to the 1960s and 
1970s. This era was characterized by a more professional police force focused on crime fighting (i.e., controlling crime and making arrests), with police legitimacy derived from criminal law alone. The professional era came to an end due to the social and environmental changes that were occurring. For instance, during the 1960s there were civil rights and women's rights movements, efforts to end poverty and social inequality (e.g., Poor People's Campaign), changes in the profile of the national population (with more youth involvement), increased oversight of police via the court system, heightened fears of crime, and deinstitutionalization and decriminalization movements. Moreover, as Black urban violence rose, it became evident that police were not as politically detached or professional as hoped for, and that racially prejudiced and discriminatory behavior was occurring. Therefore, the police lost legitimacy as a controlling force and were thus unable to control the riots that arose. Many of the riots that occurred in communities of color were the result of injustice, brutality, and abuse of authority by law enforcement agents, and double standards in the law (Williams \& Murphy, 1990).

The community-oriented era gained prominence in the 1970s because of the evident need to have a police force that was not only given power through legislation, but that was also backed by the community it was policing (Alpert \& Dunham, 1997). The previous era had demonstrated the importance of working with communities in intimate and close relations. Therefore, officers in the community-oriented era took a more proactive approach, and focused on preventing crime, solving community problems, gathering information from the community, providing direct services, and maintaining public order. The goals of this era were to improve citizen satisfaction with policing services, restore citizen trust in the police, and improve police attitudes towards and 
perceptions of the community. Achieving these goals were essential because police needed the community in order to effectively do their job. The primary policing tactics employed included returning to foot patrol, providing victim services and counseling, organizing in the community, educating the community, and establishing beat patrols, neighborhood teams, and precinct stations. Additionally, community-oriented policing brought custom-tailored policing strategies and approaches to community problems by soliciting and gathering community input. Williams and Murphy (1990) indicated that although this era brought many changes pertinent to policing racially minoritized communities such as increased representation on the police force, open complaint procedures, and administrative policies to limit officer abuse of force, there were still significant problems with police practices.

From 2001 onwards, less attention has been given to the role of community policing by local law enforcement due to the competing demands that the post-9/11 era brought as it pertained to focusing on citizen safety as well as anti- and counter-terrorism (Oliver, 2006). Oliver (2006) classified this time as "the homeland security era of policing." This current era focuses on passive measures to safeguard against community vulnerabilities to terrorist attacks as well as on more active steps, such as intelligence analysis, information gathering, and local threat assessments. Oliver (2006) has argued that crime prevention and community engagement are still features of this approach, though they may take a back seat to the other pressing demands. Moreover, it can be argued that this approach has deteriorated relationships between racially minoritized populations and the police due to imbalances between intelligence gathering priorities and civil liberty and privacy protections. This imbalance has been evidenced through 
many cases of wrongful profiling of certain communities or groups. Problems have also arisen as this approach has led to apprehension among immigrant communities for working with the police to provide intelligence information due to their fears of deportation (Jones \& Supinski, 2010).

\section{Historical Context of Police Reform in America}

A discussion of the history of law enforcement in the United States is incomplete without mentioning pivotal police reforms. Such reforms have often been aimed at improving the practices of police departments through organizational, administrative, managerial, and/or programmatic changes. The history of organized police reform in the United States dates back to the early 1900s and includes various federal and local interventions. These reform interventions have ranged from conducting external investigations of police departments and providing subsequent recommendations to filing law suits and obtaining forced compliance. ${ }^{2}$

The first ever federal review of law enforcement dates back to the 1931 report released by the National Commission on Law Observance and Enforcement ("the Wickersham Commission”), which was established by President Herbert Hoover. The

\footnotetext{
${ }^{2}$ There are also significant Supreme Court cases that have been vital in impacting the performance and operations of police departments; however, these cases have often been focused more on officer behavioral responses and not necessarily on the police department as an organization. Thus, an extensive review of such court cases is beyond the scope of this research. Nevertheless, some of the landmark cases include: (1) Brown v. Mississippi (1936) on police violence used to gain confession as a violation of the Due Process clause; (2) Mapp v. Ohio (1961) held that evidence obtained in violation of the Fourth Amendment (i.e., without a warrant) is not admissible in court; (3) Escobedo v. Illinois (1964) validated a person's right to speak to an attorney when held in police custody; (4) Miranda v. Arizona (1966) held that prisoners must be advised of their rights prior to being questioned by police; (5) Terry v. Ohio (1968), added the reasonable suspicion standard as a way to avoid violating Fourth Amendment rights when making police stops; and (6) Tennessee v. Garner (1985), maintained that police cannot use deadly force on a fleeing suspect merely to prevent escape when there is no significant threat posed by the suspect.
} 
Wickersham Commission primarily focused on the national alcohol prohibition and the lack of compliance thereof; however, the commission also examined police practices. The commission highlighted two notable points pertaining to policing. First, it found widespread corruption in police ranks. It also noted that police interrogation practices often included excessive force and abuse of power in order to gain confession from suspects. Second, the commission recommended more aggressive policing tactics to obtain compliance with prohibition laws.

Just over 30 years later, two of the more prominently known commissions were established by President Lyndon B. Johnson: The President's Commission on Law Enforcement and Administration of Justice and the National Advisory Commission on Civil Disorder ("the Kerner Commission"). The President's Commission on Law Enforcement and Administration of Justice (1967) was a response to widespread beliefs of unfair criminal justice practices and rising crime (whether perceived or real). The commission's focus was largely on crime and crime control, and encompassed a wide variety of crimes (e.g., narcotics, juvenile delinquency, organized crime) as well as all aspects of the criminal justice system (police, courts, and corrections). It included recommendations with regard to crime prevention as it related specifically to policing (e.g., the use of predictive policing models to allocate manpower more effectively and efficiently in order to prevent crime). The commission acknowledged the tension between police and poor urban communities in particular, and thus recommended a heightened focus on building community relations and partnerships, increasing community trust, and improving communications between the police and the community. The commission also 
addressed the need to improve police departments' human resources with suggestions pertaining to hiring, education, and training standards of police personnel.

The Kerner Commission, which released its report in 1968, was established in response to the rebellions and riots that were occurring in urban communities across the United States during this time period, particularly around issues of race (United States National Advisory Commission on Civil Disorders, 1968). After surveying 20 cities, the commission formally acknowledged the plight of the Black experience (relative to that of Whites) due to the various socio-economic disadvantages faced. Among many of the problems surrounding poverty, unemployment, and insufficient public services (such as education and housing), there were also many issues of police brutality. Specifically, the commission found that immediately prior to many of the riots, instances of police brutality transpired, which ignited piles of widespread and longstanding racial issues. Regarding police-community relations, the commission indicated that aggressive policing tactics only exacerbated conditions in poor urban communities rather than effectively resolving the high demand of community ills. When community members tried to hold police officers accountable for such behavior, the lack of effective complaint systems and processes further complicated issues of police brutality. The recommendations by the Kerner Commission included local external reviews of police operations; equitable accountability mechanisms and complaint procedures; improved policies to guide officer behavior and decision-making; community relations programs; the development of personnel performance standards; the recruitment, retention, and promotion of Blacks onto the police force; and enhanced relations between police and the media (United States National Advisory Commission on Civil Disorders, 1968). 
In 1979, the four major law enforcement membership associations (International Association of Chiefs of Police, National Organization of Black Law Enforcement Executives, National Sheriffs Association, and Police Executive Research Forum) created an independent accreditation organization known as the Commission on Accreditation for Law Enforcement Agencies (CALEA). While law enforcement has always been primarily a localized responsibility, these associations acknowledged the role that national standards could play in enhancing law enforcement as a profession and in improving the delivery of public services. Thus, CALEA has maintained formalized management and administrative procedures and guidelines to improve crime prevention and order maintenance, to institute impartial and unbiased personnel practices, to enhance both personnel and community perceptions, as well as to facilitate interagency cooperation (CALEA, 2012). While not mandatory, accreditation is highly esteemed and well-respected in the law enforcement community as a means of ensuring that police departments are operating with the most current best practices.

In 1994, the Violent Crime Control and Law Enforcement Act was authorized as a bipartisan act of Congress (U.S. Department of Justice, 1994). This act was passed under President Bill Clinton as a result of the Rodney King beating by police officers in 1991 and the ensuing Los Angeles riots. The act gave the U.S. Department of Justice (DOJ) the ability to thoroughly investigate and intervene (via lawsuits) in police departments that portrayed a "pattern or practice" of police misconduct. The DOJ has primarily relied on consent decrees or memoranda of agreements (MOAs) to address police departments that have exhibited extreme misconduct. Both consent decrees and MOAs are formal documents used to strong-arm reform policies, procedures, and practices as well as 
implement federal monitoring and conduct outcome assessments. As of early 2017, a total of 40 police reform agreements, 20 of which were court enforced consent decrees, had been issued. Walker (2017) argued that the DOJ had been instrumental in detailing best practices in police accountability, particularly pertaining to laying out use of force policies, requiring the filing and review of detailed and coherent use of force reports, implementing early intervention systems to gauge problematic officer performance, and ensuring fair citizen complaint processes. More recently, the DOJ released an interactive guide on a variety of reform issues including civilian stops, searches, and arrests; the handling of public protests and demonstrations; mental health and crisis intervention; bias in policing; officer support, wellness, and equipment; and accountability and oversight mechanisms.

In 2011, the U.S. DOJ Office of Community Oriented Policing Services started the Collaborative Reform Initiative for Technical Assistance. Unlike the DOJ "pattern or practice" investigations and consent decrees, which are adversarial, costly, and binding reform tactics, this program is voluntary. Local police departments proactively initiate requests to the federal government for technical assistance, which entails organizational transformation in order to address key issues. Such key issues may include crime analysis, performance management, information sharing, deterrence, proactive policing, problem-solving techniques, de-escalation, gangs, mass demonstration responses, crisis intervention, community engagement, and so forth. While participation in the program is voluntary, police departments that opt to participate receive tailored recommendations for improving service delivery and community trust, and are then monitored to ensure compliance (Office of Community Oriented Policing Services, 2016, 2018). 
A more recent police reform initiative is the President's Task Force on $21^{\text {st }}$ Century Policing (2015) established under President Barack Obama. This task force convened after a string of police shooting incidents occurred and subsequent community unrest followed - most notably in Ferguson and New York. The goal of the task force was to gather information from various community, law enforcement, and government stakeholders to identify best practices and standards in law enforcements operations. The final report comprised six key topical areas, with multiple recommendations under each area. First, the task force identified the need for trust and legitimacy to be built through accountability, transparency, and citizen engagement. Second, a focus on policy and oversight was recommended to ensure that community values were reflected in policies (particularly those policies that addressed key issues such as use of force, public demonstrations, and de-escalation). Third, the task force identified technology and social media as key tools that provide opportunities to improve police-community relations by increasing transparency. Fourth, they called for a recommitment to community policing to build relations and reduce crime. Fifth, the task force emphasized the need for consistent and effective training and education standards. Lastly, they highlighted the importance of officer wellness and safety for job performance and for preventing officer injuries and deaths.

As a result of the 2016 U.S. presidential elections transitions occurred in the administration of the federal government, which resulted in departures from prior police reform initiatives (Sessions, 2017). Under President Donald Trump, there have been official statements released by the DOJ stating that the Collaborative Reform Initiative, mentioned above, would be scaled back (U.S. Department of Justice, 2017). This 
reduction represents a shift toward prioritizing officer safety and morale while limiting federal-level interventions into local law enforcement practices.

While the aforementioned police reform initiatives typically refer to federal-level interventions, reform attempts at the individual local-level have also been made by police departments themselves, local government officials, and nonprofit advocacy organizations. For instance, the Commission to Investigate Alleged Police Corruption, also referred to as the Knapp Commission (1972), was formed by Mayor John V. Lindsay to investigate corruption in the New York City Police Department. After finding extensive corruption embedded throughout the entire department, the commission recommended more hierarchical accountability between supervisors and subordinates, established Internal Affairs field offices, and amplified personnel screening and selection methods. The American Civil Liberties Union's (ACLU) Criminal Law Reform Program has worked with police departments at the local level to create departmental reform and also pursue litigation against police departments that demonstrate unconstitutional practices used in communities. Between 2005 and 2017, the ACLU pursued 15 court cases surrounding issues of discrimination, equality, privacy, equal protection, searches and seizures, and the rights of the poor in order to improve negative and hostile relations between police departments and communities (American Civil Liberties Union, n.d.).

Taken as a whole, police effectiveness has been a concern at all levels of government, as evidenced by the numerous reform efforts undertaken over the years. More often than not, reforms were initiated as a result of the state of police-community relations in various locations across the country at the time (in some cases tensions were demonstrated through riots and protests). Salient issues to most, if not all, aforementioned 
reforms are those of police abuse of force, race relations, equitable and fair practices, accountability mechanisms, improving the trust of the community, and hiring and training standards. Despite the long history of police reform, empirical research that evaluates and confirms the effectiveness of these organizational, administrative, managerial, and programmatic reform mechanisms and suggestions has been insufficient. Hereafter, organizational, administrative, managerial, and programmatic characteristics are all referred to as either "organizational" or "organizational and managerial" factors and/or characteristics.

\section{Literature Review on Organizational Studies of Police Departments}

Organizational studies often include understanding both administrative characteristics and managerial strategies of organizations. These factors have been theorized to have a relatively large impact on policing and can be beneficial in terms of controlling police behavior and impacting policy (Gustafson, 2010; Reiss, 1992;

Skolnick, 1966; Skolnick \& Fyfe, 1993; Wilson, 1968). Scholars have long advocated for measuring the organizational impact on policing (see Bayley, 1992; Sherman, 1980), thus such studies are long overdue. In 1980, Sherman noted that there is "a managerial assumption that police behavior is influenced by the way police departments are organized and administered" (p. 85). However, only recently has the application of organization theory to policing gained significant attention (Brooks, 2015). Maguire (2009) noted that scholars have attempted to examine how organizational characteristics impact specific policing outcomes (such as arrest rates, clearance rates, use of force, and citizen complaints); however, the literature has not advanced much towards actually 
explaining the impact that police departments' organizational structures has on officer performance .

The few studies that do exist do not always detail which organizational characteristics contribute to positive or negative outcomes or under which circumstances these outcomes occur (Klahm \& Tillyer, 2010). Moreover, the research has demonstrated a lack of conclusive findings in that some studies suggest organizational variables do have an impact on policing outcomes and behavior, while others conclude there is no relationship (see for example Alpert \& MacDonald, 2001; Chappell, MacDonald, \& Manz, 2006; Eitle, D’Alessio, \& Stolzenberg, 2014; Eitle, Stolzenberg, \& D’Alessio, 2005; Hickman \& Piquero, 2009; Maguire, 2009; Mastrofski, 2004). Further, the organizational factors that appear to have an impact on police officer behavior have varied extensively across studies both in type and significance.

Within the literature, some consistent administrative, management, and human resource predictors have been tested repeatedly across studies, despite the inconclusive evidence of their impact. These variables include but are not limited to racial diversity and/or representation (Eitle et al., 2005; Gustafson, 2010; Smith \& Holmes, 2003), administrative policy and judicial controls (Cao \& Huang, 2000; Ferdik, Kaminski, Cooney, \& Sevigny, 2014; Nowacki, 2011), police department size (Maguire, 2003; Willits \& Nowacki, 2014), education levels (Cao \& Huang, 2000; Smith, 2004; Willits \& Nowacki, 2014), hiring requirements and training (Lee, Jang, Yun, Lim, \& Tushaus, 2010; Smith, 2004), and community policing programs (Barrick, Hickman, \& Strom, 
2014; Shjarback \& White, 2015; Smith \& Holmes, 2014). ${ }^{3}$ Unfortunately, the literature has produced mixed results in trying to understand the organizational factors of police departments that impact specific outcomes and behaviors, let alone police-citizen conflict more broadly (which is inclusive of but not limited to police behavior).

The majority of the published research has focused solely on identifying correlates via quantitative methods and less on understanding causal mechanisms through qualitative research. Nonetheless, the next sections of this chapter focus on empirical literature that has assessed three of the most common police-citizen conflict measurespolice use of force, citizen complaints, and assaults against police—with attention devoted specifically to organizational impacts (see Appendix A for a tabular display of the literature review).

Studies of police use of force. Police use of force is one of the measures employed to assess police behavior. Often, use of force statistics can provide a way to understand negative or violent police behavior. Walker (2005) noted that use of force statistics can be a risk indicator of problematic officer behavior such as abuse of force in specific neighborhoods, thus sustaining and perpetuating negative police-community relations. While communities with higher crime rates have been associated with problematic police-community relations (Brunson \& Gau, 2015), this relationship is often a reflection of the quality of policing and police behavior exhibited (Brunson, 2007; Gau \& Brunson, 2010; Sobol, 2010). "In [police officers'] efforts to fight crime in these [high-

\footnotetext{
${ }^{3}$ While this research is focused on police-citizen conflict in particular, the studies listed here have examined a variety of policing outcomes, including but not limited to case attrition, use of force, arrests, misconduct, discretion, complaints, violence against the police, and overall police performance.
} 
crime] communities, police tend to typify residents as troublemakers" which then leads to officers "act[ing] aggressively towards them. The result is that verbal and physical abuse, unjustified stops of people on the street, and corrupt activities are much more likely to occur" (Weitzer \& Tuch, 2004, p. 309).

Police use of force is measured on a continuum, with incremental steps in between the absence of force on one end to the presence of lethal force on the other end. Force may include verbal commands, physical restraint tactics, use of pepper spray or Taser, and so forth. When studying use of force, scholars have at times studied specific types of force, such as lethal force due to its severity despite how rare it may be (see Eitle et al., 2005; Falcone, Wells, \& Weisheit, 2002; Ferdik et al., 2014; Nowacki, 2011; Smith, 2004; Willits \& Nowacki, 2014). Other differences in the research have emerged with regard to the type of data used to measure the force incidents. Whereas some studies have used complaints as a proxy for use of force (Holmes, 2000; Phillips \& Smith, 2000), others have relied on official police documentation via officer self-reports (Boivin \& Lagacé, 2016; Lawton, 2007; Terrill, Leinfelt, \& Kwak, 2008), observational studies (Paoline \& Terrill, 2007; Sun \& Payne, 2004; Terrill \& Mastrofski, 2002) and surveys of officers, suspects, and/or the general public (Edwards, 2000; Langan, Greenfield, Smith, Durose, \& Levin, 2001). Each of these measurements contains strengths and weaknesses in terms of accuracy and/or biases presented for understanding use of force (see Garner, Maxwell, \& Heraux, 2002, for in-depth discussion).

Variations have also been found in regard to identifying statistically significant correlates of police use of force. The scholars who have assessed use of force have done so at the individual officer level, the situational (or encounter) level, the organizational 
level, and the community level. At the individual level, scholars apply a psychological approach to study offenders and/or officers and the characteristics thereof that contribute to the use of force occurrence (Brandl \& Stroshine, 2012; Lawton, 2007; McCluskey, Terrill, \& Paoline, 2005; McElvain \& Kposowa, 2004; Sun \& Payne, 2004). Often the individual characteristics — particularly officer demographics (e.g., race, age, gender, education) — have been found to have minimal relationship to use of force, and studies often portray mixed findings regarding such correlations (Bolger, 2015; Klahm \& Tillyer, 2010).

A sociological approach is often employed at the situational (or encounter) level as well as at the community level for understanding the circumstances surrounding what factors led to certain levels of force. Situational factors refer to factors that are specific to the encounter or incident between the officer and the citizen. The situational level has often produced the most consistent findings regarding police use of force. Particularly, at the situational level, scholars have found that the level of intoxication, citizen resistance, the presence of a weapon, the presence of bystanders, and whether an arrest is being made all impact levels of force used (Bolger, 2015; Engel, Sobol, \& Worden, 2000; Garner et al., 2002; Lawton, 2007; McCluskey et al., 2005; Novak, Frank, Smith, \& Engel, 2002; Terrill \& Mastrofski, 2002). Next, at the community level, scholars have often examined characteristics that describe the specific neighborhood or community that a use of force incident occurred in (e.g., poverty rates, racial and ethnic makeup, crime rates; see Kane, 2002; Lee, Jang, et al., 2010; Smith, 1986; Sun, Payne, \& Wu, 2008; Terrill \& Reisig, 2003). 
While primarily studying the situational- and individual-level characteristics, Terrill and Mastrofski (2002) found higher rates of force in Indianapolis than in St. Petersburg, Florida, to which they attributed more aggressive tactical and enforcement policies in Indianapolis. They also noted the need for better organizational frameworks to understand use of force rather than solely relying on the psychological or sociological theoretical frameworks. However, studies examining the organizational characteristics of police departments have been rare (Bolger, 2015).

The few organizational studies conducted have examined various administrative features of police departments involved in regulating police behavior. Organizational variables included in such analyses were the presence of a citizen complaint board, an internal affairs unit, the use of performance monitoring systems, the number of restrictive policies, the level of community policing efforts, the size of the police department in relation to the community, and hiring requirements (Alpert \& MacDonald, 2001; Lee, Jang, et al., 2010; Nowacki, 2015; Smith, 2004; White, 2000, 2001; Worden, 1995). Nonetheless, scholars have produced mixed findings in identifying correlates and determining the impact of such variables on police use of force. For instance, Alpert and MacDonald (2001) found that police departments that require supervisors to complete officer use of force reports (on behalf of their subordinates) have lower rates of force compared to departments where patrol officers fill out reports themselves. Administrative policy that limits discretion was found to be correlated with police use of lethal force (Nowacki, 2015; White, 2001). Smith (2004) found only one organizational factor-the number of hours of field training - to be positively correlated with lethal force for cities with populations of 100,000 or more, which is quite a counter-intuitive outcome. Willits 
and Nowacki (2014) identified various organizational factors of police departments that have different impacts on small and large city police departments. For instance, organizational context and complexity were significant only for large police departments, and professionalism was related to deadly force only in smaller cities. Worden (1995) compared 24 law enforcement organizations on the extent of bureaucratization and reported that more bureaucratic police departments use more force.

Studies of citizen complaints. Citizen complaints are one way to understand police-citizen conflict from the perspective of the citizen toward the police. While complaints have often been used as an indicator of police use of force (Ajilore \& Shirey, 2017; Smith \& Holmes, 2014) or police misconduct (Hong, 2017), they also show the citizen displeasure with their police force (Cao \& Huang, 2000; Terrill \& Paoline, 2015). In measuring complaints, there have been slight variations: studies have either measured specific types of citizen complaints (e.g., use of force complaints), sustained complaints, or the total level of complaints.

When assessing citizen complaints, scholars have investigated both micro- and macro-level factors that impact complaints. At the micro-level, scholars have often focused on internal aspects of police departments, with greater attention directed towards specific communities, complainants, and/or officers. For instance, studies have assessed overall community stakeholder perceptions of complaint processes and systems (Buffone, Chenier, Schulenberg, \& Sycz, 2017; Prenzler, Mihinjac, \& Porter, 2013; Schulenberg, Chenier, Buffone, \& Wojciechowski, 2017) as well as specific complainant experiences, perceptions, and/or outcomes (Ajilore \& Shirey, 2017; Bartels \& Silverman, 2005; De Angelis, 2009; Dunn, 2010; Headley, D’Alessio, \& Stolzenberg, 2017; Prenzler, Allard, 
Curry, \& MacIntyre, 2010; Schaible, De Angelis, Wolf, \& Rosenthal, 2013; Smith, 2009; Terrill \& Ingram, 2016). The micro-level studies that have focused more on the police officer typically fall into one of two groups. First, some research has analyzed officers' personal demographics, backgrounds, and/or years and types of experience as they correlate with citizen complaints (Brandl, Stroshine, \& Frank, 2001; Harris, 2010; Hassell \& Archbold, 2010; Kappeler, Sapp, \& Carter, 1992; Lersch, 2002; McElvain \& Kposowa, 2004; Terrill \& Ingram, 2016). Whereas, fewer studies have focused on officer experiences, perceptions, and attitudes towards the complaint process and/or system (Bartels \& Silverman, 2005; De Guzman, 2004; Schaible et al., 2013; Wells \& Schafer, 2007).

At the macro-level, organizational and/or community level factors are often assessed to understand the frequency or occurrence of citizen complaints (Cao, Deng, \& Barton, 2000; Cao \& Huang, 2000; Hickman \& Piquero, 2009; Holmes, 2000; Hong, 2017; Schuck \& Rabe-Hemp, 2014; Shjarback, 2015; Shjarback \& White, 2015; Smith \& Holmes, 2003, 2014; Trochmann \& Gover, 2016). This body of literature, though limited, has demonstrated that organizational characteristics do correlate with the type and frequency of citizen complaints. Specifically, Cao and Huang (2000) noted that both organizational characteristics and organizational behavior impact citizen complaints. However, there are discrepancies as to which organizational variables matter. For instance, studies have found that spatial differentiation (Hickman \& Piquero, 2009), education levels (Shjarback \& White, 2015), training (Cao et al., 2000), citizen review (Smith \& Holmes, 2003), internal affairs units (Hickman \& Piquero, 2009), and the racial makeup of the police department (Schuck \& Rabe-Hemp, 2014; Smith \& Holmes, 2014; 
Trochmann \& Gover, 2016) are each correlated with the levels of use of force complaints in a police department. When examining sustained and/or substantiated complaints, studies have found that the level of formalization (Hickman \& Piquero, 2009) as well as the racial makeup of the police department (Hong, 2017) both have an impact. Alternatively, a host of studies have assessed similar variables for both the level of complaints overall as well as for sustained/substantiated complaints specifically and found no effect.

Aside from the mixed results on organizational characteristics and citizen complaints, it is important to note that citizen complaints, when used as a variable in isolation, are often criticized for not presenting a complete and coherent understanding of the issue due to the lack of uniformity across police departments in terms of collection and reporting requirements (Alpert \& Dunham, 2004). However, thus far the research literature has continued to suggest that organizational characteristics do impact citizen complaints (see Cao \& Huang, 2000). So, while assessing citizen complaints is important, it is imperative to also incorporate other measures when operationalizing police-citizen conflict.

Studies of assaults against officers. Violence or aggression against the police has gained a significant amount of attention in recent years due to the negative relations between the police and the community. While it is not appropriate to say which "comes first," it is evident that felonious assaults against and/or killings of the police are, at the very least, indicative of negative police-community relations. Barrick and colleagues specified that such acts of violence are usually in "protest of injustice and political subordination" (Barrick et al., 2014, p. 194). Violence against the police, also referred to 
as "officer victimization," is an officer-related outcome measuring citizen behavior and thus sheds light on citizen sentiment.

In comparison to other indicators of police-citizen conflict such as police use of force, officer victimization data can be accessed more readily and accurately from the Federal Bureau of Investigation (FBI) Law Enforcement Officers Killed and Assaulted (LEOKA) database (Shjarback \& White, 2015; Uchida \& King, 2002). Although this data is more readily available, historically researchers have given more attention to police use of force instead. It is only more recent scholarship that has devoted significant attention to violence against the police. Additionally, a majority of scholars have focused on specific types of assaults against officers, such as only those that led to officer deaths in the line of duty (e.g., Blair, Fowler, Betz, \& Baumgardner, 2016; Gibbs, Ruiz, \& Klapper-Lehman, 2014; Kachurik, Ruiz, \& Staub, 2013; Kaminski, 2008; Kaminski \& Stucky, 2009; Kent, 2010; Maguire, Nix, \& Campbell, 2017; Swedler, Kercher, Simmons, \& Pollack, 2014). This narrow view neglects the fact that officer assaults leading to injuries are more common than those resulting in death (Covington, HuffCorzine, \& Corzine, 2014), and thus the former deserve equal, if not more, attention in the literature. Officer injuries also lead to a host of undesirable impacts apart from safety and well-being, such as economic implications (e.g., officers being out of work, medical costs).

Scholars have primarily focused on the community level and/or situational level correlates of violence against the police (e.g., Bierie, Detar, \& Craun, 2016; Caplan, Marotta, Piza, \& Kennedy, 2014; Covington et al., 2014; Gibbs, Lee, Moloney, \& Olson, 2017; Gibbs et al., 2014; Kaminski, Jefferis, \& Gu, 2003; Rabe-Hemp \& Schuck, 2007). 
While this research has been beneficial for police departments for risk assessment purposes, relatively few factors of the community environment and/or situational peculiarities are within an officer's control. Gibbs et al. (2017) highlighted the need to identify the organizational processes by which structural conditions impact violence against the police, because although officers do not have control over certain community factors (e.g., poverty), they can work within the government to make change internally. Thus, reflecting inward on the police organizations themselves would yield specific results that can be applied directly by and for their members.

Relatively few scholars have assessed the organizational department-level correlates of violence against the police (see Barrick et al., 2014; Fridell, Faggiani, Taylor, Brito, \& Kubu, 2009; Ozkan, Worrall, \& Piquero, 2016; Shjarback \& White, 2015; Willits, 2014; Wilson \& Zhao, 2008 for exceptions). Some of the findings have suggested that officer education requirements (Ozkan et al., 2016; Shjarback \& White, 2015), levels of force accountability (Fridell et al., 2009), and community policing and higher police-citizen ratios (Wilson \& Zhao, 2008) are all negatively correlated with assaults against the police. In contrast, aggressive enforcement of drug laws (Wilson \& Zhao, 2008), racial representation within police departments (Barrick et al., 2014), and body armor policies (Fridell et al., 2009) have been positively correlated with assaults against the police.

When taken as a whole, these studies have presented mixed findings on the actual impact of the organization on violence against the police. There is no consistent evidence either to suggest which specific organizational factors help to prevent and/or reduce 
violence against the police or to understand the mechanisms by which such factors operate.

Qualitative studies on police organizations. Despite the quantitative studies conducted in the organizational policing literature, scholars have long noted the importance of qualitative research for providing insights into understanding the intricacies of police work, the experiences of officers, and the overall functioning of police departments and programs. Numerous early works sought to qualitatively examine police departments. For instance, Wilson (1968) took an ethnographic approach to understanding the role of the patrolman within his organizational context, in the community, and in the larger political environment. Toch, Grant, and Galvin (1975) provided insight to a police reform initiative that focused on training and problem-solving in the Oakland Police Department. Reiss (1971) conducted an ethnography to investigate the ways in which the police and public interact.

To date, the research identifying the ways in which organizational and managerial factors impact police-community relations has focused primarily on specific organizational features. These studies have often been program and/or performance evaluations to assess the implementation and effectiveness of individual organizational factors. For instance, Brunson, Braga, Hureau, and Pegram (2013) focused on how partnerships between the police and religious leaders impact police legitimacy and violence. Walker, Alpert, and Kenney (2001) took a mixed methods approach including case studies to understand the effectiveness and impacts of early warning systems in police departments. Likewise, Hanafi and colleagues assessed the effectiveness of crisis intervention training for police officers (Hanafi, Bahora, Demir, \& Compton, 2008). 
These studies, among others, have yielded fruitful insights into the specific programs and/or practices under investigation. However, such studies neither fully capture or describe the complexities within police departments nor the variety of organizational factors and managerial strategies that are often interrelated. Further, these studies do not always detail the processes by which such programs and/or practices impact policecommunity relations.

Thus, suggestions to incorporate qualitative methods as a means to more fully understand policing contexts and processes have been continuously recommended by scholars. For instance, Fielding and Innes (2006) suggested that conducting interviews and incorporating community perspectives of police can be fruitful measures of police performance. Willits (2014) suggested that case studies can provide understandings of the connections between the organizational characteristics of police departments and officer assaults. Gill and colleagues acknowledged in their meta-analysis of community oriented policing strategies that "a qualitative understanding of the nature and context of collaborative problem-solving initiatives is crucial" (Gill, Weisburd, Telep, Vitter, \& Bennett, 2014, p. 420). Paoline and Terrill (2011) used surveys to assess attitudinal beliefs of officers and suggested that "future approaches might focus on extended interviews with patrol officers to gain deeper insight..." (p. 187). Lastly, in Engel, Tillyer, Klahm, and Frank's (2012) analysis of citizen demeanor from recorded traffic stop data, they noted "future research...that incorporates qualitative data, is needed to better understand these issues. Observations, interviews, and focus groups with officers and citizens may be a good starting point" (p. 678). However, this need and demand for such research has not yet been met. 


\section{Purpose and Significance of the Study}

While many of the police-community tensions present today have existed for years, concrete solutions to such problems have been minimal. This dearth of solutions can partly attributed to a lack of understanding (a) the problem and/or (b) the effectiveness of potential solutions. This gap has been a longstanding "wicked problem." Wicked problems are often characterized by their complex nature, changing circumstances, and lasting impact as well as the incomplete information regarding the issue —all of which pose difficulties for solving such problems (Rittel \& Webber, 1973; Weber \& Khademian, 2008). Not only does the domain of police-community relations entail numerous complexities, but there is also a lack of effective solutions for reducing tension and improving relations. As evidenced above, more often than not, police reform strategies have served as immediate knee-jerk responses to problematic relations between police and the communities they serve (often communities of color) without adequate support from proper evaluations and tools. This study seeks to first understand what organizational and managerial factors impact police-community relations and then identify why and/or how such factors have impacts. A mixed methods approach was necessary to examine the research questions of interest since wicked problems involve multiple stakeholders, have complexities pertaining to context and history, and encompass an evolving nature.

Focusing on the organization is important because that is where policy and practice have been aimed at reforming. When the U.S. Department of Justice has conducted investigations of police departments and issued consent decrees, policymakers have proposed legislation and funding for police body-worn cameras, and activists have 
called for the abolition of police departments all together, all of these actions have been aimed at the organizational level. Some neighborhoods and communities have even proposed sweeping reform proposals. For instance, in the Watts neighborhood of Los Angeles — a predominantly Black neighborhood where riots against police brutality occurred in the $1960 \mathrm{~s}$ - there have been new policies enacted pertaining to the hiring and promotion practices of police departments. Examples of such policies include mandatory residency requirements of officers, community engagement to assist in the screening process of officers prior to hiring decisions being made, and evaluating officers on the quality of their police-citizen contacts (Calhoun, 2016).

In the current era of evidence-based policy, these historic and current organizational efforts beg the question: What does the research show relating to organizational and managerial reform effectiveness? Thus far, there have been problems evident in public service delivery that have been addressed using organizational solutions, yet the empirical and scholarly research has not followed. Further, the importance of studying such organizational and managerial factors is ineffable because although police departments are not due all of the blame, they are structured such that (at least hypothetically) they can be changed via policy more easily than can larger societal issues or culture. Lastly, organizational characteristics have been theorized to have a relatively large impact on police outcomes, yet the empirical literature has only recently gained meaningful attention (Brooks, 2015; Maguire, 2009).

The findings of this research study yield the possibility of improving criminal justice policy and practice as it pertains to policing, public safety, and officer safety. In understanding the organizational factors that impact negative police-community relations 
in particular, this research yields policy implications for local government officials and police departments relevant to reorganization and restructuring to improve relationships. Positive relationships with the community enable police departments to successfully respond to and/or prevent community problems (Alpert \& Moore, 1993; Hunter \& Barker, 2010; U.S. Department of Justice, 1999). Additionally, positive relations facilitate establishing order and control within a community. Specifically, identifying the organizational factors that lead to decreased police-citizen conflict and then putting policies in place to prevent police-citizen conflict can in turn promote both public and officer safety as well as reduce community tension, mass unrest, and mobilization against the police.

\section{Main Findings}

This study addresses two research questions. First, what are the organizational characteristics and managerial strategies of police departments that impact police-citizen conflict while accounting for contextual community differences? The quantitative findings demonstrated that organizational and managerial factors, as a whole, were not significant correlates of police use of force, citizen complaints, or assaults against officers. Only a few factors appeared to be significantly correlated with these outcomes, none of which had equivalent impacts across police-citizen conflict outcomes. Thus, the relevance of specific organizational and managerial factors depends on the specific outcome being measured.

Of all of the organizational and managerial factors included in the models, only three correlated with police departments' use of force rates, none correlated with assault rates, and two correlated with complaint rates. The presence of partnerships between the 
police and the community, the percentage of officers assigned to patrol specific geographic areas, and the level of minority representation were all negatively correlated with police departments' use of force rates within the study sample. The percentage of police officers dedicated to problem-solving responsibilities was negatively correlated with the complaint rate of police departments, whereas the extent to which a police department was formalized (as indicated by the number of formal policies a department has to direct officer behavior) portrayed positive correlations with the complaint rate. Seeing as the majority of hypothesized variables included in the models were not statistically significant correlates of the outcomes, it is important that future research identify the factors that hold explanatory value. Policy proposals to improve the practice and outcomes associated with policing should be mindful of the lack of significant findings of organizational and managerial factors.

The second question asks why and how organizational characteristics and managerial strategies impact police-community relations? "Police-community relations" was first defined, and then an assessment of the current state of relations in Hartford, Connecticut, was presented. Subsequently, three main factors and two primary mechanisms by which these factors impact police-community relations were identified through the qualitative research. First, cultivating soft skills in the police department is critical. Both communication skills and efforts as well as officers' character traits were found to impact the relationships between police and the community. Second, police departments must invest in their human resources. Hands-on training and sufficient staffing were identified as two important ways to invest in the personnel of the police department to positively impact police-community relations. Third, there must be 
intentional engagement between the police and the community. Intentional engagement manifested in two primary ways: through collaborative relationships and external accountability.

The two mechanisms by which the aforementioned factors impacted policecommunity relations were (a) through direct interventions regarding officer attitudes and/or behavior or (b) through increasing the level and/or quality of service provision by the police department. Both of these mechanisms had direct consequences on citizen attitudes and perceptions. The qualitative findings shed light on the reasons why and processes by which organizational and managerial factors affect police-community relations. Providing this in-depth insight allows for greater understanding as to how strategies influence outcomes.

\section{Overview of Remaining Chapters}

In the following chapter, Chapter 2, attention is drawn to the lack of consistency in the literature when discussing the term "police-community relations." This chapter illustrates that the concept of police-community relations is multidimensional; its multidimensionality necessitates a composite measure of police-community relations. This chapter is primarily focused on creating a composite index of negative policecommunity relations (also referred to as "police-citizen conflict"). The index provided a comparative assessment of relations across the country and highlighted the cities that had been experiencing relatively high levels of police-citizen conflict. Four variables comprised the index: police use of force, police killings of citizens, assaults against law enforcement, and citizen complaints. Two methods of index creation were compared: multiplicative scoring and principal components analysis. The index created using 
multiplicative scoring was then used to make comparisons across police departments and cities within the United States. This chapter ends with a discussion of the utility and implications of creating a police-citizen conflict index.

In Chapter 3, organizational theories are applied to police-community relations in order to conduct an ordinary least squares (OLS) regression that estimates the effects of organizational and managerial characteristics on police-citizen outcomes. There were three key police-citizen conflict outcomes of interest: use of force, citizen complaints, and assaults against law enforcement officers. Data was compiled from the following administrative, community, and survey data sources: the Bureau of Justice Statistics' Law Enforcement Management and Administrative Statistics survey, the Federal Bureau of Investigation's statistics on Law Enforcement Officers Killed and Assaulted, the Federal Bureau of Investigation's Uniform Crime Report, the National Association of Civilian Oversight of Law Enforcement, and the Census American Community Survey. Three separate ordinary least squares regression models were estimated (with clustered robust standard errors). Doing so allowed for the relationships between organizational correlates and police-community outcomes to be disentangled while also accounting for any statelevel variations.

Chapter 4 considers how and why organizational characteristics impact policecommunity relations. Attention is drawn to the limited amount of research distinguishing the causal mechanisms undergirding the correlations found in quantitative analyses. To appropriately address this gap in the literature, a qualitative exploration is presented. This chapter reports on the findings from an explanatory case study of police-community relations in Hartford, Connecticut. An explanatory case study is one that seeks to explore 
a phenomenon in order to understand, describe, and explain causal relationships (Yin, 2009). Utilizing a case study approach provided a better understanding of the relationship between a police department and the community it serves while potentially adding to theory on police-community relations. The case study included data collection from indepth semi-structured interviews, participant observations, and a review of secondary sources. Content analysis was performed in order to identify themes and build explanations.

Chapter 5 concludes with an overarching perspective on organizational and managerial factors and police-community relations. A summary of each of the individual chapters is provided, followed by a discussion of the contributions this research has for the literature at large. The strengths and limitations of this research are also provided. Lastly, the implications for policy, practice, and future research are considered. 


\section{CHAPTER 2}

\section{Where They Fall: A Comparative Assessment of Police Performance in Terms of Police-Community Relations Across United States Cities}

Police departments normally make news headlines for problematic practices such as police misconduct, discriminatory behavior, or excessive use of force incidents. The imbalance of attention devoted to negative aspects of police practices in comparison to more positive aspects can have detrimental impacts on the public perceptions of police performance. For instance, in 2015, a Gallup poll showed that overall public confidence in the police had been at its lowest in 20 years (Jones, 2015) and further gaps exist when accounting for both racial and political differences (Fingerhut, 2017). Due to the contentious relations evidenced between police departments and urban communities across the country in recent years, there have been resounding calls to bring transparency to police practices and behavior. For instance, in 2012, the Center for Police Equity began building a National Justice Database to track police behavior across the country. Likewise, in 2017, the Federal Bureau of Investigation piloted a National Use-of-Force Data collection program due to the lack of nationwide data on police-involved shootings and police use of force.

These recent data collection efforts reflect a shift in measuring the performance of law enforcement from traditional crime-centered measures (e.g., crime clearance or response time rates) towards indicators of police-community relations (e.g., community satisfaction). It is important that police departments maintain strong relationships with the communities they serve, beyond merely responding to and/or preventing criminal 
activity. Cooperation and collaboration between the police and the community enables problem-solving, resolves criminal cases, and helps to ensure public order. The absence of effective working relationships between communities and their police departments can pose complications for effectively ensuring the safety of community members as well as police officers. Thus, continuously monitoring the relationships between the police and the communities they serve can help to prevent negative relations from taking root and also create a culture of mutual respect.

Monitoring police-community relations may entail conducting community surveys, gauging perceptions and satisfaction with services (e.g., Rosenbaum, Lawrence, Hartnett, McDevitt, \& Posick, 2015; Weitzer, Tuch, \& Skogan, 2008), or assessing the presence of disparities across various police outcomes, such as arrests, citations, or use of force (e.g., Fryer, 2016; Gau, Mosher, \& Pratt, 2009; Kochel, Wilson, \& Mastrofski, 2011; Mitchell \& Caudy, 2013; Novak \& Chamlin, 2008). However, no singular method of measuring police-community relations can sufficiently capture the complex nature of this multidimensional concept. Attempts at measuring police-community relations are not entirely new, however; scholars have routinely relied on the use of singular indicators to operationalize police-community relations (e.g., measuring police use of force alone). Relying solely on a single measure of police-community relations fails to capture the multiple dimensions as well as dynamic nature of such relationships. Thus, employing multiple measures of police-community relations is essential.

This chapter presents a multidimensional composite indicator of policecommunity relations that was created over the course of this research project. The index comprised four variables: use of force, citizen complaints, assaults against officers, and 
civilian deaths by police. The police use of force and citizen complaint data were taken from the Bureau of Justice Statistics' Law Enforcement Management and Administrative Statistics survey. The data on assaults against law enforcement officers was taken from the Federal Bureau of Investigation's Law Enforcement Officers Killed and Assaulted database. Civilian deaths by police officers were compiled from the Fatal Encounters Database. To create the police-citizen conflict index, two methods of index creation were compared as a sensitivity check: multiplicative scoring and principal components analysis.

This research serves as a starting point for future scholars to build upon as more data become available and accessible. It provides scholars with the ability to identify organizational, community, and situational correlates that explain interagency variations of police-community relations. The index provides ease of analysis in understanding the relative performance of police departments across the country. Government agencies can use this index to identify police departments and communities that are in need of assistance and/or resources to improve police-community relation outcomes. Using a composite index to continuously monitor the performance of police departments' by measuring police-community relations can help to prevent problematic situations from arising.

The remaining sections of this chapter conceptualize and operationalize policecommunity relations and highlight the importance of devoting attention specifically to police-citizen conflict. It is argued herein that police-citizen conflict is one aspect of problematic police-community relations. Then, a composite indicator is explained, along with the data and methods used to develop this indicator. Finally, to assess the utility of 
the police-citizen conflict index, the geographic distribution of police-citizen conflict is mapped and its trends with other community-level socio-economic measures are discussed. Overall, creating an index of police-citizen conflict was found to be feasible, practical, and geographically consistent with preconceived notions of heightened conflict occurring in areas with higher rates of poverty, unemployment, violent crime, racially minoritized populations, younger populations, and renter-occupied and/or vacant housing. This chapter concludes with a discussion of the limitations and directions for future research.

\section{Conceptualizing and Operationalizing Police-Community Relations}

The term "police-community relations" has often been ambiguously defined in empirical research, yet it is frequently used in the literature. When referring to policecommunity relations, scholars have also interchangeably used the term "community policing." Though community policing is a strategy used to promote positive policecommunity relations, it is not sufficient to accurately or comprehensively capture the broader concept of "police-community relations." One working definition identified two important features of police-community relations as those that are (a) continuous and not constant and (b) multifaceted, including both the positive and negative aspects of policing (Hunter \& Barker, 2010).

It is also essential to understand the bidirectional relationship between the police and the community in order to offer effective suggestions for reform. In a report on police-community relations, the International Association of Chiefs of Police (IACP) acknowledged the need to address the shared perspective of both the police and the community, noting that it is often a tale of two diverse perspectives (IACP, 2015). 
Evaluating these distinct perspectives has often been conducted by measuring perceptions, trust, and/or satisfaction. Such measurements are important for understanding how the service recipients (i.e., the community) evaluate service provision and delivery as well as the challenges service providers (i.e., the police) may be facing. Despite this need, there is not yet a standardized way to capture perceptions of the public or of law enforcement on a national level across jurisdictions. The lack of such standardization poses difficulties for comparing police departments and their respective communities across the country. Further, measuring perceptions may not accurately capture the actual behavior that occurs during police-citizen interactions.

An alternative way to operationalize police-community relations has been to identify the factors that impact perceptions, satisfaction levels, or trust between community members and the police. One of the impacting factors of such perceptions is negative interactions between the police and the community (see Weitzer et al., 2008). Weitzer et al. (2008) used levels of "police-citizen conflict" within communities as a proxy for measuring negative interactions and gauging police-community relations. There is little agreement in the literature about police-citizen conflict as an overarching term or concerning its correlates. Despite the importance of this work, few attempts have been made to date to develop larger theoretical or conceptual understandings on comparative indicators of police-citizen conflict.

However, some scholars have identified individual indicators of police-citizen conflict (see Gustafson, 2010; Johnson, 2013; Long, 2012; Shjarback \& White, 2015; and Trochmann \& Gover, 2016). Gustafson (2010) measured police-citizen conflict by including "the number of police-initiated fatal shootings of citizens and felonious killings 
and assaults of police" (p. 47). Johnson (2013) operationalized "police-citizen aggression" using assaults on officers, lethal force by police, and citizen complaints. Shjarback and White (2015) included complaints and the number of officers assaulted. Long (2012) and Trochmann and Gover (2016) both focused solely on citizen complaints as the measure of conflict between police and their respective communities. The aforementioned studies neither included all of the identified conflict measures in one analysis nor as a comprehensive indicator. ${ }^{4}$ Though police-citizen conflict may occur infrequently, these incidents leave a tremendous impact on the relationships between communities and the police. It has been these conflict situations (e.g., police use of force or assaults against the police) that have fueled much of the uproar and protest surrounding police-community relations and police reform. For instance, in recent years, videos have surfaced that exposed individuals dying at the hands of law enforcement officers from places across the nation such as Alton Sterling in Falcon Heights, Minnesota; Michael Brown in Ferguson, Missouri; Philando Castile in Baton Rouge, Louisiana; and Eric Garner in Staten Island, New York.

Measuring the frequency and severity of police-citizen conflict may also serve as a measure of police performance. More recent efforts suggest that community relations should be included as an organizational performance measure of police departments (Barrett \& Greene, 2016). Traditional measures of police performance have focused on arrest rates, clearance rates, crime pattern analyses, and response times (Innes, Fielding,

\footnotetext{
${ }^{4}$ While Johnson (2013) did include three measures, he examined lethal force by police specifically rather than including all types of police use of force. He also made note of the limitation that lethal force is the highest end of the spectrum of police aggression.
} 
\& Cope, 2005). Scholars have long argued that focusing solely on these traditional measures of performance are inadequate for understanding the multiple layers of policing activities. Police are also responsible for improving the quality-of-life in a community, performing their duties fairly and equitably, and positively engaging with the community in non-enforcement capacities (Fielding \& Innes, 2006; Rosenbaum et al., 2015). Some scholars have gone even further and argued that without appropriate performance monitoring systems in place, police accountability cannot be assured (Moore \& Braga, 2003).

One well-known deviation from traditional police performance measures is CompStat, which refers to computer comparison statistics. CompStat was originally developed by the New York City Police Department in the early 1990s. It is a performance management system that aims to prevent crime, promote informationsharing, identify and effectively address community problems, allocate resources efficiently, and increase accountability (Police Executive Research Forum, 2013). Since its inception, CompStat has been widely received by police departments across the country. However, in its current form, CompStat is not being used to capture policecitizen conflict measures. Thus, this study is the first attempt to understand policecommunity relations by creating a composite indicator of police-citizen conflict using a combination of measures.

\section{What is a Composite Indicator?}

A composite indicator (CI), commonly referred to as an index, is composed of multiple individual indicators and provides a numerical score to comparatively understand performance across geographical units and/or organizations (Alam, Dupras, \& 
Messier, 2016). As opposed to solely focusing on individual measures and trying to identify common threads throughout, these indices take complex concepts and measure the multiple dimensions that encompass them. CIs address the interrelated and interdependent nature of individual indicators and are particularly useful for cases in which one indicator alone cannot capture the complexities associated with a larger phenomenon (Kitchin, Lauriault, \& McArdle, 2015). ${ }^{5}$

More recently, CIs have been used in a variety of practical settings to understand the environment (de Sherbinin, Reuben, Levy, \& Johnson, 2013; Hsu, Lloyd, \& Emerson, 2013), health (Halpern et al., 2012), human development (UNDP, 2014), neighborhoodlevel deprivation (Messer et al., 2006), wellbeing (Prescott-Allen, 2001), income inequality (Silber, 1989), and other multifaceted concepts. Cities across the country have been using indicators more frequently for descriptive and/or informative purposes to track performance, to shape policy, and/or to rank and compare cities (Kitchin et al., 2015; Tofallis, 2014).

Regarding policing in particular, some index methods exist to measure police efficiency. In these studies, investigators have relied heavily on assessing police departments in terms of crime, clearance rates, response times, and arrests in relation to police department expenditures and personnel. One study assessed police effectiveness by measuring citizen satisfaction using a multidimensional indicator (Verschelde \& Rogge, 2012). The majority of these studies have been conducted in international settings such as Taiwan (Wu, Chen, \& Yeh, 2010), Slovenia (Aristovnik, Seljak, \& Mencinger,

\footnotetext{
5 "Composite indicator" will also be used interchangeably with "composite index" throughout the paper.
} 
2013, 2014), Belgium (Verschelde \& Rogge, 2012), India (Verma \& Gavirneni, 2006), and the United Kingdom (Drake \& Simper, 2005). The two studies that were conducted in the United States focused solely on police efficiency (Gorman \& Ruggiero, 2008; Nyhan \& Martin, 1999). Each of the aforementioned studies highlighted the importance of multidimensionality and relative comparability. Yet, most of these scholars narrowly operationalized police performance in terms of police efficiency without accounting for other aspects of performance such as the relationships between the police and the community.

The CI created herein is used as a performance benchmark for assessing and comparing how police departments and their respective cities are faring with regard to police-citizen conflict (Huggins, 2009). Benchmarking is a process that entails continuously measuring an organization's progress and performance against competitors and/or pre-identified target performance standards. Typically, it entails an evaluation of policies, processes, practices and outcomes. Competitive benchmarking has frequently been utilized in the private-sector (e.g., Min \& Min, 2013; Monkhouse, 1995). However, some attempts have been made to apply the benchmarking process to other sectors, such as the public sector (Curry, 1999), or to units of analysis such as cities (Arribas-Bel, Kourtit, \& Nijkamp, 2013; Kitchin et al., 2015; Luque-Martinez \& Munoz-Leiva, 2005). Thus far, no measures have been used to comparatively assess and rank policecommunity relations across multiple dimensions. In practice, the ranking of communities and police departments has often been discussed in terms of safety (e.g., identifying locations with high crime rates). However, two departures from these traditional crime measures include a ranking of cities based on social media sentiment towards police 
departments (Danois, 2015) and a list of police departments' racial representation in reflection to their respective cities (Ashkenas \& Park, 2015; Maciag, 2015). These latter attempts have neither been empirical nor do they directly measure police-citizen conflict.

\section{Methodology}

Data was compiled from a variety of sources to measure police-citizen conflict. Creating a composite index rather than relying solely on individual measures can capture cities' overall variation and allow for inter-city comparisons. Two statistical procedures to create the composite indicator and reduce the data were used and compared:

multiplicative scoring (or geometric aggregation) and principal components analysis. Using both methods also allowed for an additional sensitivity check.

Variables and data. Due to the practical importance of improving fraught police-community relations, the focus of this research was on police-citizen conflict as an indicator of negative police-community relations. The unit of analysis was the police department. However, the geographic unit of observation was at the city level. The sample was the subset of city police departments in the Bureau of Justice Statistics Law Enforcement Management and Administrative Statistics (LEMAS) 2013 database that had 100 or more full-time sworn employees $(n=481)$. The police-citizen conflict index score was created for the corresponding city of each police department.

This research utilized four indicators of police-citizen conflict: police use of force, police killings of civilians (i.e., deaths by police), violence against the police, and citizen complaints about use of force. Police use of force and police killings of civilians were both key behaviors of law enforcement that have been identified in the literature as risk indicators for officers (Walker, 2005) and as having a negative influence on public 
perception and/or satisfaction (Skogan, 2005). Citizen complaints have often been used as an indicator of police misconduct (Hong, 2017) as well as public perceptions (Cao \& Huang, 2000; Terrill \& Paoline, 2015). Violence against the police (i.e., assaults against officers) is indicative of negative police-community relations, as such acts of violence are usually in "protest of injustice and political subordination" (Barrick et al., 2014, p. 194). Taken together, these measures were used to represent the reciprocal behavior between the community and the police. These four measures of police-citizen conflict have been commonly used independently and are considered valid in the current policing literature as measurements of conflict and/or community relations (e.g., Gustafson, 2010; Long, 2012; Shjarback \& White, 2015; Trochmann \& Gover, 2016). However, these measures have not been combined as an index to provide a global measure of police-citizen conflict that more fully informs the relative standing of police departments. Thus, this policecitizen conflict index has face validity in that the composite index consisted of indicators that made theoretical and intuitive sense for the concept being measured.

Police use of force was operationalized as the number of total use of force incidents reported by a police department per 100,000 population. The data for use of force was retrieved from the 2013 Law Enforcement Administrative and Management Statistics survey. The LEMAS survey asked police departments to report the total number of use of force incidents and/or the total number of separate use of force reports per officer filed. Some police departments reported both the number of incidents and the number of reports, whereas other police departments reported only one of those measures. The primary interest here was the number of use of force incidents regardless of how many separate reports were filed per officer on scene for an incident. However, 
the number of incidents and number of reports were highly correlated $(r=0.9744)$. Thus, a regression imputation was used to estimate the number of use of force incidents for those police departments that only provided a number for separate use of force reports. Of the 278 police departments with 100 or more sworn full-time employees included in the sample, 99 of them were replaced with these estimated force values.

Police killings of citizens were compiled from the Fatal Encounters database ${ }^{6}$ and operationalized as the total number of deaths caused by law enforcement from 2011 to 2013 per 100,000 population. Despite the relative infrequency of police killings, these occurrences have lasting impacts on the community. Since the killing of civilians by police officers is rare, a three-year span was used in order to have stability in the measurement and conduct a meaningful analysis. A summed measure across the span of multiple years has been used prior by scholars such as Nowacki (2011) and Smith (2004). The data to measure violence against the police was taken from the Law Enforcement Officers Killed and Assaulted database. This variable included all assaults against law enforcement (including those that led to injury and/or felonious death as well

\footnotetext{
${ }^{6}$ The fatal encounters measure of killings by police is an alternative data source in comparison to the other mentioned "official data sources" provided by government agencies. However, the importance of compiling statistics on civilians killed by police from alternative sources is ineffable. "Scholars have noted for several years, however, that there is no national-level system for measuring police use of force - deadly or otherwise - and, in fact, commonly used data sources for measuring the phenomenon have substantial limitations" (Shjarback \& White, 2015, p. 4). The inadequacy of official counts of civilians killed by police (apart from mere justifiable homicide counts) available at a national level has led to various data attempts to create such an archive. Furthermore, these unofficial data sources provide information more indicative of actual counts of civilians killed by police for all police departments, rather than just those departments that voluntarily report to the supplementary homicide report. Additionally, data on killings that yield ongoing investigations and that are unjustifiable are included in the archives (Fischer-Baum, 2014). As mentioned in the literature review, similar methods for compiling this data has been used by Ferdik et al. (2014), in a smaller magnitude. Moreover, as of October 2015 the justice department began a trial system to count killings by police mirrored off of two open-source archiving attempt, which shows the growing acceptance to such alternative archival methods (Laughland, Swaine, McCarthy \& Lartey, 2015).
} 
as those that did not). It was calculated as the average number of assaults against law enforcement officers per year (summed over a three-year period from 2011 to 2013, then divided by three) per 100 officers. This calculation for the average rate of assaults was adapted from Wilson and Zhao (2008) due to the relative infrequent nature of these events. Raw data is reported by police departments each month to the Federal Bureau of Investigation, however, many departments fail to provide consistent monthly data. For the police departments that did not report all 36 months of data, the assaults were weighted by the number of months reported using the formula outlined in Wilson \& Zhao (2008, p. 463): $C \times 36 / M$, where $C=$ the summed number of reported assaults and $M=$ the number of months reported. Only police departments that reported data for at least half of the 36 month timeframe (i.e., 18 months or more) were weighted and included, whereas the departments that reported less than half were not included in the final dataset. After the summative and weighting processes, the average number of assaults per year was calculated by summing across all the assaults over the 3 year period, dividing by 3 years, then dividing by the number of officers on the police force and multiplying that final number by 100 .

Lastly, citizen complaints about use of force were compiled from the 2007 Law Enforcement Administrative and Management Statistics survey. This measure included the total number of complaints filed (including those sustained and those not) per 100 officers. This data from 2007 represents the most recent civilian complaint data available. It is important to note the gap in the number of years between 2007 and 2013 when comparing the complaint variable to the other police-citizen conflict variables included in this analysis. However, scholars have noted that there is not much structural change that 
occurs in police departments because it is an organization that is often slow and resistant to change (Maguire, 1997). Further, Schuck \& Rabe-Hemp (2014) looked at citizen complaints across the same police departments in 2003 and 2007 (a 4-year period) and found on average the number of complaints and the rate of complaints increased. Thus, if anything, using the 2007 complaint numbers may provide more conservative estimates than would otherwise be provided if more current data were available.

Missing values. Methodological and/or analytical problems may occur when data is not missing at random because bias may be introduced into the equation. Nonetheless, a variety of methods are available for dealing with missing data (e.g., case deletion, single imputation, multiple imputation). Case deletion of data that was missing on any of the key indicator variables was used herein. Only those police departments with complete data for all four of the indicator variables were retained for this analysis. The purpose of creating this index was solely to make comparisons across police departments, and thus it was more important to preserve actual values and data. After combining data from all aforementioned sources, full data was available for a total of 278 police departments. As of 2008, the Bureau of Justice Statistics' Census of State and Local Law Enforcement Agencies reported there were approximately 582 city police departments with 100 or more full-time sworn officers. Thus, approximately $47.8 \%$ of the total population of city police departments with 100 or more full time sworn officers was represented in the police-citizen conflict index sample.

Outlier detection. An assessment of the data for potential outliers was conducted using mahalanobis distance. However, all data was retained regardless of whether it was considered an outlier. Again, the purpose herein was to preserve actual numbers and 
identify cases that were higher or lower on the index (i.e., best or worse cases). Thus, being able to identify "extremes" was important. Observations should not be omitted unless there is strong evidence to show that data points are false.

Data transformation and normalization. The creation of the geometric aggregation index relied on the raw rates for each variable. When calculating a geometric mean there is no need to normalize variables (see Tofallis, 2014 for an in-depth explanation). On the other hand, in order to conduct principal components analysis, the raw rates for each variable were log transformed (after adding a base of 1 to the raw rates) because of the skewed nature of the data. ${ }^{7}$ After the transformations, each variable was standardized using $z$ scores. Standardizing helps to account for the variance in the dataset as well as the cases with extreme values. It also corrects for potential scale effects due to different units of measurement used for each of the variables included in the index. $^{8}$

Weighting and aggregation. Weighting indicators is particularly important if each of the variables is expected to represent police-citizen conflict differently. If some indicators describe the overall concept more or less than others, then the weight that variable carries in the overall composite should be reflected accordingly. Aggregation is the final step in creating a composite index. This includes aggregating the normalized and weighted indicators to create a composite score. A variety of methods can be utilized to aggregate data; however, two common methods of aggregation (and their respective

\footnotetext{
${ }^{7}$ Adding the base of 1 for all cases was important to account for the many zeros that cannot be log transformed, whereas when you log a 1 it goes back to 0 .

${ }^{8}$ If each indicator was measured using the same standard, then there would be no need for normalization.
} 
weighting procedures) are discussed below and applied here in the context of policecitizen conflict.

Multiplicative scoring (geometric aggregation). To create the index based on geometric aggregation, equal weights were assigned to each of the indicator variables. Equal weighting does not mean that no weights were assigned, but rather that all indicators held the same weight when comprising the composite indicator. Geometric aggregation was chosen rather than linear aggregation because the latter is compensatory — meaning one indicator's high performance can account for another indicator's lower performance-whereas geometric aggregation offers a less compensatory approach (Giambona \& Vassallo, 2014). Multiplicative scoring has already been advocated for and used in practice as well (see Tofallis, 2014 for in-depth discussion). For instance, the United Nations Development Programme recently transitioned to using a geometric mean as opposed to an arithmetic mean to create the Human Development Index. ${ }^{9}$ They justified this transition by stating "as a basis for comparisons of achievements, this method is also more respectful of the intrinsic differences across the dimensions than a simple average" (Human Development Reports, 2016, para. 1).

The geometric mean is defined as:

\footnotetext{
${ }^{9}$ While this police-citizen conflict index measures aspects completely different than the Human Development Index (HDI), there are some important similarities. The HDI was created as a deprivation indicator for each country; rather than measuring how well a country is doing, this index was created to examine the country's shortfalls and as a measure of relative performance across countries (Anand \& Sen, 1994). Similarly, the police-citizen conflict index is used to understand police-community relations, though not necessarily by looking at how well the police department is doing, but rather by looking at the shortfalls of the department, while also using it to compare police departments.
} 


$$
\operatorname{GM}\left(\mathrm{x}_{1}, \mathrm{x}_{2}, \ldots, \mathrm{x}_{\mathrm{N}}\right)=\left(\mathrm{x}_{1} \cdot \mathrm{x}_{2} \cdots \mathrm{x}_{\mathrm{N}}\right)^{1 / \mathrm{N}}
$$

where $x$ represents the different indicators and $N$ is the total number of indicators. The geometric mean is invariant to normalizations. ${ }^{10}$ Thus, to calculate the geometric index, the raw rates for each indicator variable were used. Three of the four indicator variables were increased to a baseline of 1 (instead of 0 ) so that the multiplicative nature of the index would not be overpowered by an indicator having a 0 . In calculating the geometric mean, the four indicators are multiplied, and the fourth root is taken of the product:

$$
P C C 1_{i}=\left(F R_{i} \times C R_{i} \times A R_{i} \times K R_{i}\right)^{1 / 4},
$$

where $P C C 1_{i}$ is the first composite police-citizen conflict index value of the $i$ city composed of the geometric mean of the police use of force rate, $F R_{i}$, citizen complaint rate, $C R_{i}$, rate of assaults against police, $A R_{i}$, and the rate of killings by police $K R_{i}$, for each city, $i$.

\section{Table 1}

Principal Component Analysis of Police-Citizen Conflict

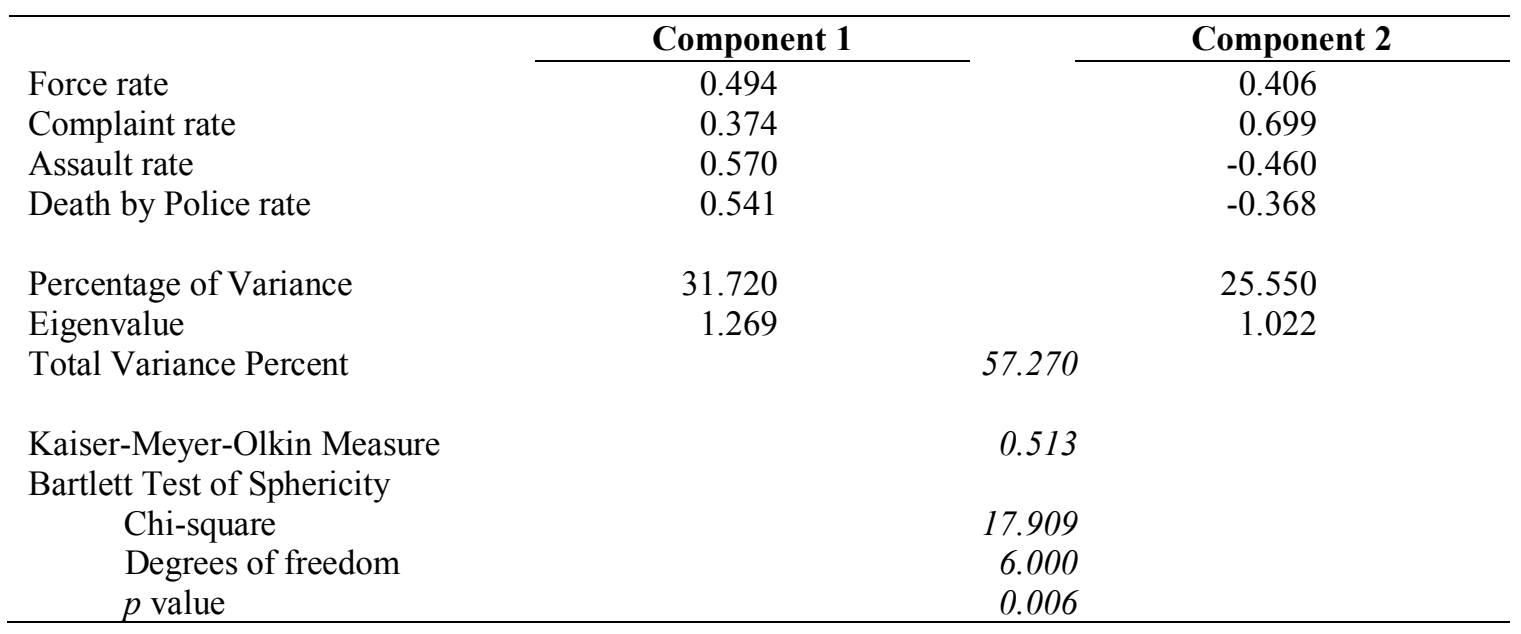

\footnotetext{
${ }^{10}$ When using the arithmetic mean, a normalization method must be accounted for. However, the subsequent rankings would then depend on the normalization method chosen, whereas ranking with the geometric mean does not depend on the normalization reference (Simon, 2012).
} 
Principal components analysis. To create the index using principal components analysis (PCA) and an additive model, a weighted score was calculated based on the two components' cumulative significance (see Table 1). However, prior to running the PCA, the Kaiser-Meyer-Olkin (KMO) value and Bartlett's test were both used to test the appropriateness of the data for the PCA method. The KMO value was 0.513 , and the $p$ value of the Bartlett's test was 0.006 , both of which indicated that conducting PCA was acceptable. ${ }^{11}$ Two components with eigenvalue $>1$ were extracted from the original four police-citizen conflict variables, which accounted for almost $60 \%$ of the total variance (the cumulative variance of the two components totaled 57.27\%). For Component 1, assaults against law enforcement officers and killings by police showed the largest positive factor loadings on this component. For Component 2, police use of force and citizen complaints about use of force showed the largest positive factor loadings. Component 1 held a larger weight of $31.72 \%$, whereas Component 2 held a weight of $25.55 \%$. The values of these weights reflected the magnitude of variance across cities given the data.

In order to create the composite measure, the percentage of total variance accounted for by each component was used as a weight:

$$
P C A_{i}=W^{m} \sum_{i=1}^{278} I_{i}^{m}
$$

\footnotetext{
${ }^{11}$ The Cronbach's alpha is a measure of the internal consistency of a latent variable. It was found that the value of the Cronbach's alpha for the four variables was relatively low (0.3041). However, this result was not a major issue. First, the low value was probably due to the small number of items (only four variables). Also, if there data on complaints was more up to date, the alpha may be higher. Second, in this study, a police-citizen conflict index was constructed as a weighted composite index rather than a single latent variable. The alpha level would be more problematic if running a regression analysis on the data, rather than simply comparing across cities.
} 
where $I_{i}^{m}$ is the component score $m$ in a given city $i(i=1,2,3 \ldots 47)$ and $W^{m}$ is the contributing variance of each component $I_{i}^{m}(m=1,2)$. Thus, the following index based on a weighted sum of the two component scores was calculated as: ${ }^{12}$

$$
P C C 2_{i}=\left(31.72 \% \times I_{1 i}\right)+\left(25.55 \% \times I_{2 i}\right),
$$

where $P C C 2_{i}$ is the second composite police-citizen conflict index value of the $i$ city composed of the weighted percent of predicted scores based on Component $1, I_{1 i}$, and Component 2, $I_{2 i}$.

Sensitivity and uncertainty analyses. Sensitivity and uncertainty analyses are imperative to ensure confidence in the index created. A sensitivity analysis is designed to gauge how the output of an index may vary depending upon data selection and inclusion as well as on methodological choices. An uncertainty analysis quantifies the overall uncertainty in city rankings due to any issues with the model input. Both are necessary to "gauge the robustness of the composite indicator ranking, to increase its transparency, [and] to identify which [cities] are favored or weakened under certain assumptions to help frame a debate around the index" (Joint Research Centre-European Commission, 2008, p. 117).

Comparing the two aforementioned index methods served as a sensitivity analysis to determine how different normalization procedures, aggregation methods, and weighting of indicator variables impacted the outcomes. In comparing the index results and ranking (see Appendix B), it is clear that there was some sensitivity to change that was exhibited. However, Pearson's correlation coefficient, $r$, for the actual index scores

\footnotetext{
${ }^{12}$ This method was taken from Chen (2016) in measure of a fiscal stress index.
} 
(PCC1 and PCC2) was 0.8893 , and the correlation for the relative rankings assigned from each score was 0.9195 . The level of statistical significance ( $p$ value) of both correlation coefficients was 0.0000 , demonstrating the convergent validity of the indices since there was a statistically significant and strong positive association between them. Further, when comparing the two indices, they both had correlation trends similar to other key socio-economic, community-level variables such as violent crime, poverty, and unemployment (albeit they were significant correlations, but not high correlations; see Table 2).

Table 2

Index Correlations with Three Key Socio-Economic Variables

\begin{tabular}{lcccccc}
\hline & \multicolumn{2}{c}{ Principal Components Analysis Index } & & \multicolumn{2}{c}{ Multiplicative Aggregation Index } \\
\cline { 2 - 3 } \cline { 6 - 6 } \cline { 5 - 6 } Vearson's $r$ & $p$ level & & & Pearson's $r$ & $p$ level \\
\cline { 2 - 3 } \cline { 5 - 6 } Violent crime rate & 0.297 & 0.000 & & 0.294 & 0.000 \\
Poverty level & 0.238 & 0.000 & & 0.315 & 0.000 \\
Unemployment rate & 0.160 & 0.007 & & 0.190 & 0.002 \\
\hline
\end{tabular}

\section{Results}

To understand the relative performance of police departments and their respective cities, the rankings for each are presented. Once the police-citizen conflict score was generated, there was little meaning (with regard to interpretation) of the raw numbers in the respective indices for cities. However, a higher score on either index meant more police-citizen conflict and thus negative police-community relations. Appendix B lists the 
total police-citizen conflict score, or PCC, for each of the 278 cities. The individual indicator values (for each of the four indicators) can be found in Appendix C. ${ }^{13}$

Comparing composite indicators. In comparing the two CIs, it was evident that some rankings varied based on the standardization, normalization, and aggregation methods chosen (as noted above in the sensitivity and uncertainty analyses sub-section). The range for the first index, $P C C l$, which used the geometric aggregation method, was from a low police-citizen conflict of 1.874 (Hoover Police Department in Alabama) to a high police-citizen conflict of 37.347 (Oakland Police Department in California), with a mean of $11.392(S D=5.513)$ for all cities included in the sample. The range for the second index, $P C C 2$, which used principal components analysis, was from a low policecitizen conflict of -1.295 (Hoover Police Department in Alabama) to a high police-citizen conflict of 1.395 (Oakland Police Department in California), with a mean of 0.012 ( $S D=$ 0.437 ) for all cities included in the sample. While the lowest and highest identified police departments remained the same for the two CI creation methods, there was some variability when comparing the relative ranks of police departments throughout. For both indices, a higher score was synonymous with places with higher police-citizen conflict, whereas a lower score represented places with lower police-citizen conflict.

Table 3 presents side-by-side comparisons of the top five highest and lowest police-citizen conflict scores for each index $P C C 1$ and $P C C 2$. The top five locations with the highest police-citizen conflict scores according to the geometric aggregation method were as follows:

\footnotetext{
${ }^{13}$ This table includes the raw rates of each indicator prior to the baseline of 1 being added to the entire sample.
} 
1. Oakland Police Department (CA)

2. Wilmington Police Department (NC)

3. Farmington Police Department (NM)

4. Rapid City Police Department (SD)

5. Hartford Police Department (CT).

The top five highest police-citizen conflict scores according to the principal component analysis method were as follows:

1. Oakland Police Department (CA)

2. Wilmington Police Department (NC)

3. Wichita Falls Police Department (TX)

4. Hartford Police Department (CT)

5. College State Police Department (TX).

Of the top five within both indices, three police departments were consistently identified:

Oakland, Wilmington, and Hartford.

The five police departments with the lowest police-citizen conflict scores (see Table 3) per the geometric aggregation were as follows:

1. Hoover Police Department (AL)

2. Union City Police Department (NJ)

3. Rio Rancho Police Department (NM)

4. Peoria Police Department (AZ)

5. Richardson Police Department (TX). 
Table 3

Listing Police Departments with the Highest and Lowest Police-Citizen Conflict Scores

\begin{tabular}{|c|c|c|c|}
\hline & Geometric Aggregation Method & & Principal Component Analysis Method \\
\hline \multicolumn{4}{|c|}{ Highest Police-Citizen Conflict Scores } \\
\hline 1 & Oakland Police Department (CA) & 1 & Oakland Police Department (CA) \\
\hline 2 & Wilmington Police Department (NC) & 2 & Wilmington Police Department (NC) \\
\hline 3 & Farmington Police Department (NM) & 3 & Wichita Falls Police Department (TX) \\
\hline 4 & Rapid City Police Department (SD) & 4 & Hartford Police Department (CT) \\
\hline 5 & Hartford Police Department (CT) & 5 & College State Police Department (TX) \\
\hline \multicolumn{4}{|c|}{ Lowest Police-Citizen Conflict Scores } \\
\hline 1 & Hoover Police Department (AL) & 1 & Hoover Police Department (AL) \\
\hline 2 & Union City Police Department (NJ) & 2 & Richardson Police Department (TX) \\
\hline 3 & Rio Rancho Police Department (NM) & 3 & Peoria Police Department (AZ) \\
\hline 4 & Peoria Police Department (AZ) & 4 & Boca Raton Police Department (FL) \\
\hline 5 & Richardson Police Department (TX) & 5 & Rio Rancho Police Department (NM) \\
\hline
\end{tabular}

The five departments with the lowest police-citizen conflict scores per the principal components analysis were as follows:

1. Hoover Police Department (AL)

2. Richardson Police Department (TX)

3. Peoria Police Department (AZ)

4. Boca Raton Police Department (FL)

5. Rio Rancho Police Department (NM).

Of the top five within both indices, four police departments were consistently identified as having low police-citizen conflict: Hoover, Rio Rancho, Peoria, and Richardson.

The geography of police-citizen conflict. Since the two indices, $P C C 1$ and PCC2, were highly correlated, it was deemed appropriate to continue with only displaying one index for ease of analysis. The geometric aggregation index can be a more practical indicator for police departments as well as for public service professionals to 
replicate and use. Further, while PCA was used here more as a sensitivity check, it is important to note that PCA is usually used for scales that are reflective. In reflective scales, the respective indicators are a reflection of an underlying construct, which is why correlation across indicators is particularly imperative (see footnote 11). However, the police-citizen conflict index herein is formative, in that the various indicators are theoretically and/or conceptually linked, but represent different aspects of police-citizen conflict as a whole and when taken together equal the sum. Thus, for ease of analysis, the geometric aggregation index, $P C C l$, is more suitable to use to further understand the geographical distributions and characteristics of the police departments in this study.

Most of the police departments and their corresponding cities included in this sample had low to moderate levels of police-citizen conflict. The police-citizen conflict scores were mapped, using ArcGIS, based on standard deviations from the mean (see Figure 1). Conflict scores were divided into six levels ranging from the lower end of 1.0 standard deviation below the mean to the upper end of 1.5 standard deviations above the mean. Using standard deviations helps to assess how the scores are distributed from either side of a mean. Other scholars have also used standard deviations when comparing composite indicator scores to allow for easier comparisons of data in clusters or groups (e.g., Cutter, Boruff, \& Shirley, 2003 in mapping social vulnerability). Figure 1 displays all police departments included in the sample with their relative categories according to standard deviations. On the other hand, Figure 2 includes not only categorical information pertaining to police-citizen scores, but also the percentage of the population that is Black and/or Hispanic for a given city. 


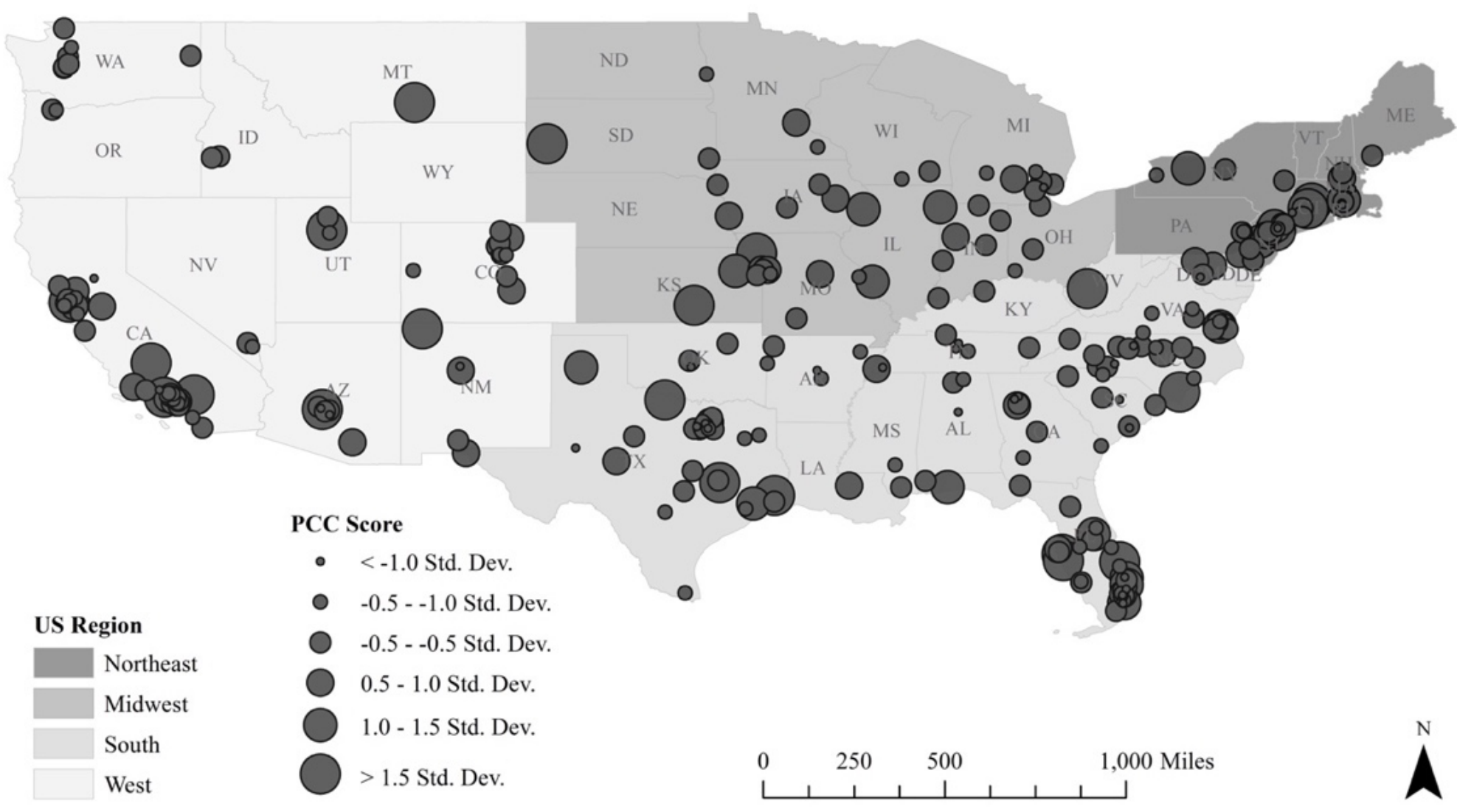

Figure 1. Police-citizen conflict in cities across the contiguous United States 


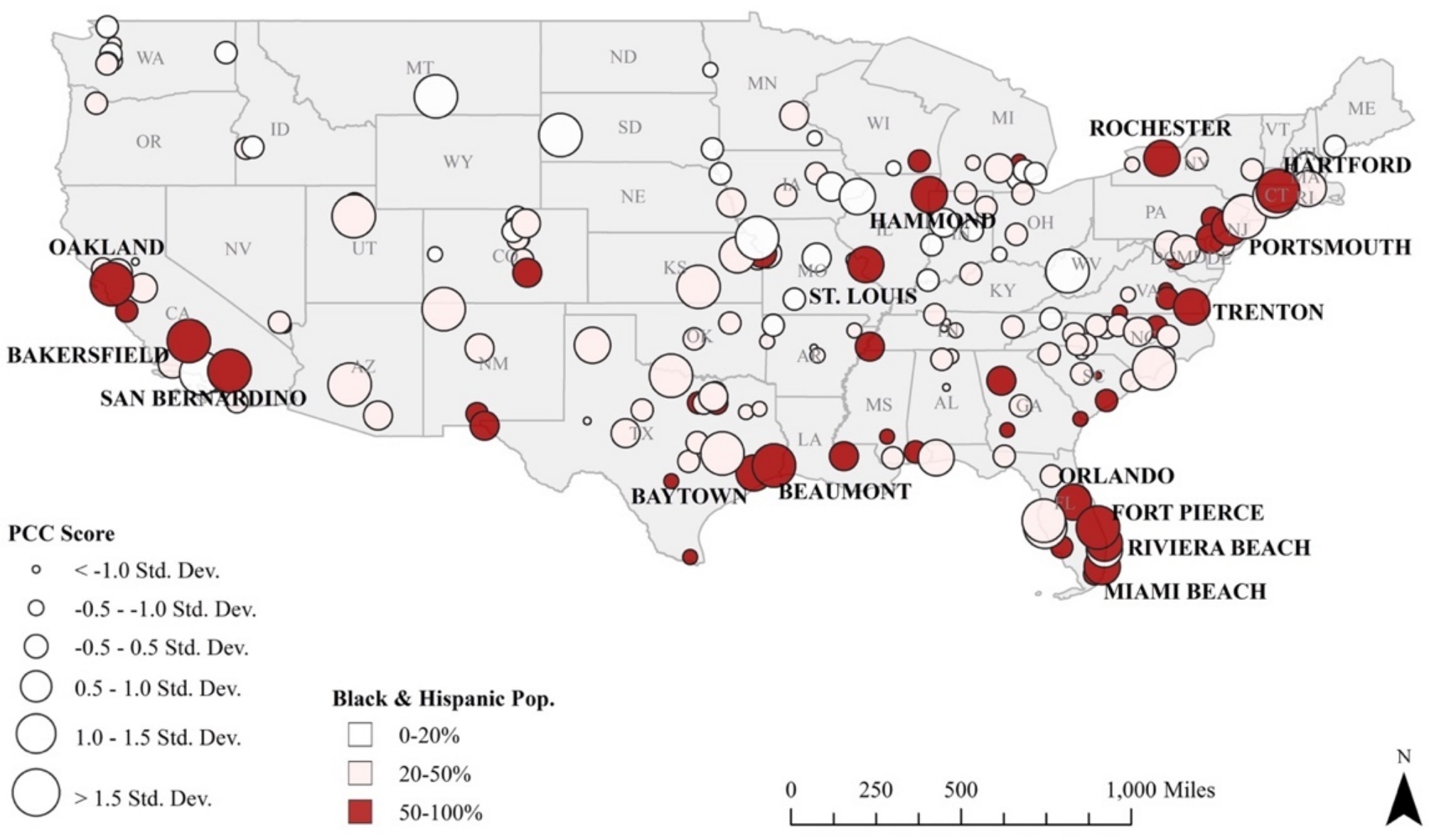

Figure 2. Police-citizen conflict and minoritized populations across the contiguous United States 
Of the 278 police departments included in the sample, $43.88 \%$ served populations of under 100,000 inhabitants, whereas $33.09 \%$ served populations between 100,000 and 200,000 inhabitants. Almost half of the police departments included in the sample were located in the South $(n=132)$, as defined by the U.S. Census Bureau's regional divisions. The majority of police departments in each of the four regions (Northeast, Midwest, South, and West) had average police-citizen conflict levels, and thus the score fell within a 0.5 standard deviation above and/or below the mean police-citizen conflict level of 11.392 (ranging from an index score of 8.636 to 14.149 ).

Cities with police-citizen conflict scores greater than 1.5 standard deviations above the mean were labeled as having the most conflict (with a police-citizen conflict score above 19.662). Out of the cities included in the sample, there were 22 locations that fell into the category of having the most police-citizen conflict. These cities' mean poverty level was $19.99 \%$, mean unemployment rate was $10.5 \%$, and average violent crime rate was 724.64 per 100,000 inhabitants. Cities labeled with the least police-citizen conflict had a score of more than 1.0 standard deviation below the mean (i.e., with a police-citizen conflict score below 5.879), a mean poverty level of $12.25 \%$, a mean unemployment rate of $8.55 \%$, and average violent crime rate of 336.29 per 100,000 inhabitants. There were 34 cities that fell into the category of having the least policecitizen conflict.

When comparing the five cities with the highest conflict to the five cities with the least conflict (see Table 3, geometric aggregation column), those cities with greater levels of police-citizen conflict also had greater levels of poverty, unemployment, violent crime, female-headed households, and Black and Hispanic populations. Police departments that 
fell within the highest category of police-citizen conflict also had lower levels of median income, median age, and owner-occupied housing (see Table 4 for a more in-depth comparison of all cities in the top and bottom categories). While these correlations may not necessarily have come as a surprise - as areas that are more underserved or disadvantaged may be expected to have higher police-citizen conflict scores-this result served as an informal validation of the index and added confidence to the index creation method for measuring police-citizen conflict.

Lastly, while each of the individual indicators used to comprise the composite index can be ranked and sorted in their respective categories and then displayed in a chart for corresponding departments, doing so does not provide a comprehensive sense of police-citizen conflict. In fact, using single measures as indicators of police-citizen conflict overall may provide a distorted view of reality. For instance, Table 5 displays the five highest ranking police departments across each of the individual indicators, where a higher rank is equivalent to a higher rate for the associated measure. When comparing the five highest scores for each indicator and ranking them accordingly, different police departments emerged with extreme high levels, and thus could be designated as "problematic." The ability to make these individual comparisons can be beneficial for assessing strengths and weaknesses of individual police departments and also for identifying key areas for improvements. However, this information is not sufficient for evaluating and discussing problematic police-community relations and/or police-citizen conflict as a whole. 
Table 4

Comparing Police Departments with High and Low Police-Citizen Conflict Scores

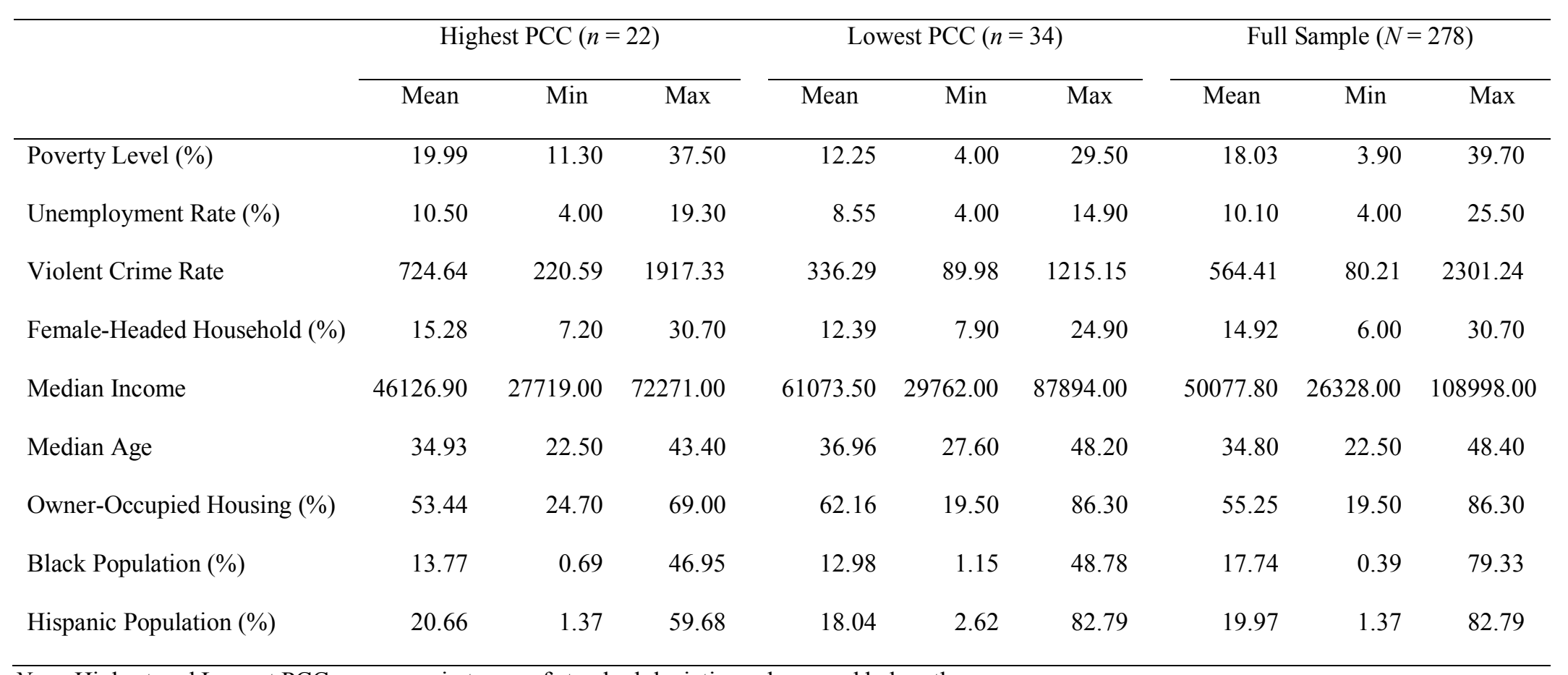

Note. Highest and Lowest PCC scores are in terms of standard deviations above and below the means. 


\section{Table 5}

Police Departments' Rank Across Individual Police-Citizen Conflict Indicators

\begin{tabular}{|c|c|c|c|c|}
\hline $\begin{array}{l}\text { Ranking } \\
\text { (highest } \\
\text { scoring) }\end{array}$ & Use of Force Rate & $\begin{array}{c}\text { Citizen Complaint } \\
\text { Rate }\end{array}$ & $\begin{array}{c}\text { Deaths by Police } \\
\text { Rate }\end{array}$ & $\begin{array}{l}\text { Assaults Against } \\
\text { Officer Rate }\end{array}$ \\
\hline 1 & $\begin{array}{l}\text { Hammond Police } \\
\text { Department (IN) }\end{array}$ & $\begin{array}{l}\text { Oakland Police } \\
\text { Department (CA) }\end{array}$ & $\begin{array}{l}\text { Lakewood Police } \\
\text { Department (WA) }\end{array}$ & $\begin{array}{l}\text { Farmington Police } \\
\text { Department (NM) }\end{array}$ \\
\hline 2 & $\begin{array}{l}\text { San Angelo Police } \\
\text { Department (TX) }\end{array}$ & $\begin{array}{l}\text { El Paso Police } \\
\text { Department (TX) }\end{array}$ & $\begin{array}{l}\text { Meriden Police } \\
\text { Department (CT) }\end{array}$ & $\begin{array}{l}\text { Homestead Police } \\
\text { Department (FL) }\end{array}$ \\
\hline 3 & $\begin{array}{l}\text { Tallahassee Police } \\
\text { Department (FL) }\end{array}$ & $\begin{array}{l}\text { Wilmington Police } \\
\text { Department (NC) }\end{array}$ & $\begin{array}{l}\text { Nampa Police } \\
\text { Department (ID) }\end{array}$ & $\begin{array}{l}\text { Amarillo Police } \\
\text { Department (TX) }\end{array}$ \\
\hline 4 & $\begin{array}{l}\text { Arlington Police } \\
\text { Department (TX) }\end{array}$ & $\begin{array}{l}\text { Wichita Falls Police } \\
\text { Department (TX) }\end{array}$ & $\begin{array}{l}\text { Pueblo Police } \\
\text { Department (CO) }\end{array}$ & $\begin{array}{l}\text { Santa Monica Police } \\
\text { Department (CA) }\end{array}$ \\
\hline 5 & $\begin{array}{l}\text { Rapid City Police } \\
\text { Department (SD) }\end{array}$ & $\begin{array}{l}\text { Plano Police } \\
\text { Department (TX) }\end{array}$ & $\begin{array}{l}\text { Temple Police } \\
\text { Department (TX) }\end{array}$ & $\begin{array}{l}\text { Rapid City Police } \\
\text { Department (SD) }\end{array}$ \\
\hline
\end{tabular}

\section{Conclusion}

One of the consistent trends in both research and in practice is to discuss problematic police-community relations as a whole while referring to specific indicators as all-encompassing. Relying solely on one or two individual measures of conflict does not capture police-citizen conflict as a multidimensional term. Numerous efforts have been made to ameliorate problematic police-community relations, yet scholars and practitioners have not consistently operationalized the term. This chapter serves as a first attempt to provide a CI of police-citizen conflict by compiling all of the various measures of police-citizen conflict used in the past into one comprehensive measure. Further, relying solely on an individual measure to assess police performance (e.g., use of force or citizen complaints) creates complications for making conclusive determinations of how a police department is performing. For instance, if a police department has high levels of citizen complaints and police killings of civilians, yet has low levels of assaults against 
officers and use of force, this pattern poses challenges for providing an overall assessment of the department's police-citizen conflict. Therefore, utilizing a comprehensive police-citizen conflict index can alleviate this challenge by providing an inclusive measure that also allows police departments and their respective cities to be compared to their counterparts across the country. It is evident that police-citizen conflict as a whole, and the individual parts that make up the sum, are important factors for police departments and cities. Thus, this research demonstrates how to create a composite indicator of police-citizen conflict using data that is readily available across various cities in the United States.

Limitations and future research. It is important to note that despite the usefulness of composite indicators, they have generated pushback due to the subjectivity associated with the construction of such indices. Subjective judgements must be made during

the selection of individual indicators, the treatment of missing values, the choice of aggregation model, and the weights of the indicators. All of these subjective choices are the bones of the composite indicator and, together with the information provided by the numbers themselves, shape the message communicated by the composite indicator. (Joint Research Centre-European Commission, 2008, p. 116)

Thus, this research is not without limitations. First, all composite indicators remove information about the individual sub-indicator variables that might be useful at the individual level. Those interested in the individual indicators can refer to Appendix C. Second, future research can create a more robust index as more data become available for 
all cities in the United States and by including additional indicators of police-citizen conflict. However, as alluded to previously, measuring police-citizen conflict is only one aspect of overall police-community relations. Other positive measures may exist that can be included in an index to create an even more inclusive appraisal of police-community relations. Similarly, the index herein did not necessarily capture the quality of the many other services provided to the public by police departments. Understanding the range of services and the quality thereof may have been more aptly captured by citizen surveys. Future research may consider incorporating both the behavioral as well as perceptual components of police-community relations into one index.

Furthermore, pertaining to the inclusion of indicator data, a question that must be given serious attention is whether the same indicators included in this analysis to measure police-citizen conflict are applicable to all cities and police departments, irrespective of size and/or developed environment (i.e., urban, suburban, rural, or exurban). For instance, citizen complaints may not be an appropriate indicator of police-citizen conflict in small, rural cities with smaller police departments. In these locations, few complaints may not necessarily indicate less police-citizen conflict; rather, conflict may be manifested differently, and such differences may not be accounted for using the measurement herein. When contrasting rural and urban areas, there are differences in terms of the types of crime that occur (e.g., theft of livestock in rural areas), the correlates of crime (e.g., poverty matters for urban areas, whereas family dwelling structures matter for rural areas; see Sampson, 1986), the social structure (e.g., more informality in rural areas), and the geographic spread (Muhammad, 2002; Weisheit, Wells, \& Falcone, 1995). However, the process of filing citizen complaints is often governed by formalized mechanisms and 
policies, which often requires community members to file complaints in person. Thus, though any of the aforementioned factors that differentiate urban from rural areas may reduce the complaint levels in rural areas, these factors may not be accurate indicators of citizen dissatisfaction or police-citizen conflict levels in those areas.

Additionally, it is important to acknowledge some limitations with the actual measurement of the individual indicators included in this analysis. For instance, police departments operationalize use of force differently; for example, one department may count the use of handcuffs as a use of force incident while another department may not. Unfortunately, differences in these measurements cannot be accounted for herein. Future research can improve upon these potential differences in accounting for use of force by surveying police departments and inquiring about the amounts or levels of specific use of force types. Alternatively, scholars can research each police department's use of force manual (for the departments that reported use of force statistics) to identify how use of force is defined. Doing so can allow for a categorization of departments by use of force definitions in order for departments to be more accurately compared to those with similar reporting guidelines. However, this method may limit the sample size drastically, as police departments' use of force manuals are often not publicly or readily available.

Once comprehensive data is more accessible, scholars can conduct further uncertainty and sensitivity analyses to improve the index. Conducting such analyses will allow for an assessment of how various changes_-including specific variables, missing data imputation, different normalizing procedures, and different weighting and aggregation methods - affect the overall structure of the index, the index score, and the 
ranking outcome. ${ }^{14}$ The result of these analyses will help to determine the robustness of creating a police-citizen conflict composite index (see Joint Research Centre-European Commission, 2008 for a more in-depth discussion on such analysis procedures). Future research should also seek to untangle why those cities with the highest police-citizen conflict category (with 1.5 or more standard deviations above the mean) also had more poverty, unemployment, violent crime, female-headed households, and Black and/or Hispanic populations when compared to those cities in the lower police-citizen conflict category.

Implications. Despite the limitations, the creation of this index is valuable and holds numerous implications for policy, practice, and research. This index provides scholars and practitioners the ability to assess the overall state of police-citizen conflict for a given police department and city and then compare it to others. To date, no index has been developed for ranking police-citizen conflict or overall police-community relations. Rather, "anecdata" has been used to identify and/or compare the worst of the worst, whether perceived or real. For instance, the police departments in Chicago, Illinois; Oakland, California; Baltimore, Maryland; and Newark, New Jersey often receive scrutiny due to narrative accounts perpetuated in the news and social media. Utilizing a police-citizen conflict index can also help policymakers determine where to direct resources in terms of geographic location. A comprehensive index can

\footnotetext{
${ }^{14}$ One way to assess both uncertainty and sensitivity is to assess that ranks assigned from the various methods of creating a composite indicator for a given city. To conduct the analysis, the average shift in city rankings is used, specifically by looking at the "relative shift in position of the entire system of [cities] in a single number. The shift can be calculated as the average of the absolute differences in [cities'] ranks with respect to a reference ranking over all of the [cities]" (Joint Research Centre-European Commission, 2008, p.118).
} 
help to justify attention, resources, and reform efforts being devoted to certain police departments and cities based on science rather than on other motives. Specifically, a composite index of police-citizen conflict can be used "to guide operational practices with respect to specified targets and to provide evidence of the success or failure of schemes, policies, units and personnel" (Kitchin et al., 2015, p. 14). It also allows police departments to compare themselves to locations with similar characteristics as a selfcheck measure. Furthermore, this study provides an opportunity for future researchers to identify the organizational, community, and situational correlates that explain interdepartmental variations in conflict levels and/or rankings.

Overall, this chapter depicts the first composite indicator of police-citizen conflict in the literature, which helps to recognize the multidimensional nature of policecommunity relations. This chapter provides a step-by-step example of how a policecitizen conflict composite indicator can be developed. As referenced above, future research can build upon this index and enhance it by integrating additional measures of police-community relations, and work to build a more comprehensive and robust composite indicator. Further, an examination of how overall conflict varies over time and space is needed, which requires longitudinal data. Having data over time would allow cities to compare current performance to past performance and possibly also predict future trends. Lastly, aggregating data collected on every police department in the United States would provide an even greater understanding of conflict across the country. 


\section{CHAPTER 3}

\section{Can Organizational and Managerial Strategies Solve Negative Police-Community Relations? An Analysis of United States City Police Departments}

Police-community relations has been a topic of debate for decades, particularly surrounding the question of how to improve relationships that are characterized by animosity and distrust (Brunson, 2007; Brunson \& Gau, 2015; Greene, 2004; Lee, Steinberg, \& Piquero, 2010; Willis, 2014). Historically, the relationship between the police and marginalized communities in particular has been negative, abusive, hostile, and even deadly (Rahtz, 2016; Williams \& Murphy, 1990). Moreover, the events occurring in recent years with police shootings and community unrest have illustrated the tension between police and these communities. Improving police-community relations is not only important for communities, but is also vital for police departments because of the strain that poor relations create for officers attempting to do their job effectively (Hunter \& Barker, 2010). Similarly, maintaining positive relations "can contribute to the reduction in incidents of excessive police force" (U.S. Department of Justice, 1999: Police-Community Relations section, para. 1). Such positive relations also reduce crime rates and increase clearance rates.

The Justice Department has long noted the deficiencies in many police departments' organizational dynamics and structures, which often cause poor policecommunity relations. For example, during an investigation of the City of Miami Police Department in 2013, the Department of Justice issued a letter stating that the problems faced by the Miami Police (concerning use of force and corruption) were deeply 
ingrained within their organizational culture (U.S. Department of Justice, 2013).

Additionally, in a Cleveland Police Department investigation, the Justice Department found problems related to policies, training, and accountability mechanisms (U.S. Department of Justice, 2014). Scholars, too, have argued that "the inadequate implementation or the lack of organizational mechanisms designed to ameliorate policeminority tensions within communities are said to be the primary cause of unnecessary violence against minority populations" (Smith \& Holmes, 2014, p. 84). The policing literature has, to a limited extent, examined the impact of the organizational characteristics of police departments (Maguire, 2009). However, organizational inquiries have only recently begun to gain prominent attention (Mazeika et al., 2010; Shjarback \& White, 2015). Thus far, the literature that does exist has failed to demonstrate consistent impacts of organizational factors on the outcomes of police-community relations. Furthermore, when examining the organizational level studies, the various outcomes measured pertaining to police-community relations have not received equal attention. For instance, four organizational studies of police use of force have been published (Alpert \& MacDonald, 2001; Nowacki, 2015; Smith, 2004; Willits \& Nowacki, 2014); six studies on assaults against officers (Barrick et al., 2014; Fridell et al., 2009; Ozkan et al., 2016; Shjarback \& White, 2015; Willits, 2014; Wilson \& Zhao, 2008); and six studies on citizen complaints (Cao et al., 2000; Hickman \& Piquero, 2009; Schuck \& Rabe-Hemp, 2014; Shjarback \& White, 2015; Smith \& Holmes, 2003, 2014).

The importance of studying the organizational impacts on police-community outcomes is ineffable. The lack of scholarly attention given to this topic has allowed for a policy atmosphere that has not relied on evidence to inform decision-making. 
Consequently, numerous policy suggestions have been made to reform the management and administration of policing and to improve police-community relations, yet the effectiveness of such strategies is unknown or limited at best. For example, the Justice in Policing toolkit — created in joint collaboration by the Center for Popular Democracy and PolicyLink (2015) as a direct response to police brutality incidents - put forth 15 policy reform proposals. Included in these proposals were accountability mechanisms, independent community oversight of the police, improved police training, and anti-bias policing - all of which can be traced back to recommendations made in the late 1960s under the Kerner Commission's reform proposals. Since the 1960s, little progress has been made in practice or in research. Having more research on the effectiveness of organizational and managerial strategies can better guide policy and practice at local levels. Such research can also provide a platform for best practices to be discussed and disseminated at the national level. Thus, the purpose of this chapter is to understand whether and to what extent the organizational characteristics and managerial strategies of police departments impact police-community relations (as measured by police-citizen conflict) while controlling for environmental and contextual community factors that fall outside the departments' control. It is imperative to understand whether and to what extent management (e.g., strategies, resources, personnel, and/or training) matters in the presence of influential environmental factors (e.g., poverty, crime rates, and/or demographics).

Three separate models were estimated for each dependent variable using ordinary least squares regression. The results portrayed the limited influence that organizational and managerial characteristics had on police-citizen conflict. In the use of force model, 
two of the four community policing indicator variables (community partnerships and beat officers) in addition to minority representation were statistically significant correlates. In the assault model, no correlates were statistically significant. Lastly, in the complaint model, only two variables - a community policing indicator (problem-solving officers) and the level of formalization — were statistically significant. These results demonstrate that not only do organizational and managerial characteristics have neither consistent nor equal impacts across the three models, but rather they carry little weight overall. The few variables that were found to be statistically significant have conditional impacts depending on the outcome being measured. Thus, in order to substantially reduce tensions between the police and the community, further inquiry to understand other correlates of police-citizen conflict is imperative.

This chapter proceeds with a review of the literature on police-community relations and police-citizen conflict. Subsequently, the theoretical framework guiding this analysis is presented with a focus on organizational behavior and theory. The research design, methodology, and findings are explained in detail, followed by a discussion of how the findings situate back in the literature. Lastly, in the final section of this chapter, the importance of this work for future research is discussed.

\section{Literature Review: Police-Community Relations and Police-Citizen Conflict}

"Police-community relations refer to the ongoing and changing relationship between the police and the communities they serve. This includes issues of cooperation, race relations, fear of police, violence, and corruption” (Hunter \& Barker, 2010, p. 117). By and large, researchers have assessed mistrust of police, public perceptions of police, or citizen satisfaction with police in order to understand police-community relations (e.g., 
Brunson \& Gau, 2015; Gau \& Brunson, 2010; Skogan, 2005; Weitzer, 2014; Weitzer \& Tuch, 2004, 2005; Weitzer et al., 2008). However, studying only public sentiment, trust, and/or satisfaction provides a one-sided view (i.e., the community perspective).

Moreover, to date, there is not comparable data across the country that accurately allows for measuring the relationships between police and their communities on a national level. As it stands, only a handful of police departments implement surveys of community perceptions, and the instruments being used for those surveys vary. Clearly, an inclusive, standardized alternative is needed. However, negative interactions between the police and the public, police behavior, and policing patterns have been some of the identified factors that impact public perceptions (see Weitzer et al., 2008 for in-depth discussion). So, in the absence of national and comparable perceptual data, it may prove fruitful to examine these behavioral factors that can influence public perceptions.

Negative interactions with the police can encompass a wide variety of behaviors; however, police-citizen conflict (also referred to as "police-citizen violence" or "policecommunity conflict") is one way to capture these types of interactions. Given the aforementioned definition of police-community relations, it is apparent that police-citizen conflict is only one aspect of police-community relations. However, due to the many issues pertaining to race relations and policing during the 1960s and onwards, "one of the specific goals [of police-community relations was] to reduce tension through communication between the police and minority groups within the community" (Trojanowicz, 1972, p. 401). Thus, based on Trojanowicz's (1972) description, measuring tension between the police and the community can serve as an effective indicator of the quality of current police-community relations. 
Police-citizen conflict has been conceptualized in prior literature as a way to understand the tensions that exist between police and the community. Scholars have operationalized police-citizen conflict in a variety of fashions and have included one or more of the following variables: citizen complaints, police use of force, and assaults against law enforcement (see Gustafson, 2010; Johnson, 2013; Long, 2012; Shjarback \& White, 2015; Trochmann \& Gover, 2016). From these various measurements, it is evident that police-citizen conflict encompasses understanding both sides: the police towards the community and the community towards the police. To date, no studies have comprehensively investigated how organizational factors of police departments impact all three of the aforementioned measures of police-citizen conflict. Most of the organizational studies have focused solely on isolated and specific characteristics of police departments such as community-oriented policing strategies (see Wilson \& Zhao, 2008) or minority representation (see Barrick et al., 2014). When scholars target specific individual organizational strategies employed within a police department, they fail to account for the complex organizational environment where managerial strategies and practices may coincide and even conflict. Therefore, this chapter not only includes multiple measures of police-citizen conflict in comparative models, but also tests multiple organizational characteristics and managerial strategies operating in police departments.

\section{Theoretical Framework}

Organizational theories were applied in order to appropriately hypothesize about the relationships between characteristics of police departments and various outcomes. Specifically, this chapter adopted the view that "police-community relationships are entwined with macro-level context [and this] can be viewed as a 'top-down' notion 
wherein it is the characteristics of a police department and its surrounding community that primarily affect the relationships between police and citizens" (Brunson \& Gau, 2015, p. 219). There is some research that suggests that it is the organizational characteristics of police departments (i.e., "rotten orchards"), rather than the individual officers (i.e., "rotten apple"), that tend to impact police misconduct and behavior, and thus more attention should be devoted to the organizational level (Armacost, 2003; O’Connor, 2005; Punch, 2003). For instance, Punch (2003) stated that "deviance [can be] systemic - in some way encouraged, and perhaps even protected, by certain elements in the system" (p. 172, emphasis in original). Likewise, scholars have argued that certain police behaviors are "group behavior that is rooted within established practices in the police force into which officers have to be initiated" (Gottschalk, Dean, \& Glomseth, 2011, p. 7). Perry (2001) noted that in order to control police corruption specifically, one must "examine the barrel, not just the apples, the organization, not just the individual in it" (p. 1). While police corruption is not the specific measure under analysis here, the concerns raised by these scholars lend support for the argument that an assessment of organizational impacts on various policing outcomes is needed. This analysis aids in determining whether police-citizen conflict is a system failure and if so, assesses what specific parts of the system have led to this failure.

Gustafson (2010) noted "it is well recognized in the field of general organizational theory that organizational structures can influence organizational performance" (p. 95). Thus, this research was informed by organizational behavior and public management theory, but specifically used two theoretical linkages (community 
policing and administrative responsibility and accountability) to explain the relationship between organizational characteristics and police-citizen conflict (see Figure 3).

Community-oriented policing. Community-oriented Policing (CP) is a guiding philosophy for police departments to embrace organizational policies that refocus attention towards citizens and it is promoted as a means to improve relationships between the police and the community (Cordner, 2014; Reisig, 2010; Skogan, 2006; Trojanowicz, 1972). This view gained prominence in the 1970s and 1980s, and was engendered by ineffective policing practices, rising crime rates, urban riots, public distrust, and hostility by youth against the police. The CP philosophy aligns with many central public administration values, emphasized through paradigm shifts such as the New Public Service (Denhardt \& Denhardt, 2000, 2011). These values include serving the public interest, receiving input and/or feedback from the public, and collaborating and working in partnership with the public. Examples of community policing efforts include engaging with citizens through social media, conducting citizen surveys, and establishing formal partnerships between police departments and local non-profit organizations.

The overall idea behind CP is that if the police work in close partnership with the community by including them in problem solving and policing activities as well as in drawing upon community resources, then a higher quality of services will result (Reed, 1999; Skolnick \& Bayley, 1986). Improved services that respond to community needs will enhance community trust and positive perceptions of the police, which can in turn lead to fewer citizen complaints and less violence against police. Additionally, $\mathrm{CP}$ is theorized to impact police behavior directly by increasing police officers understanding of and empathy for the people and communities they serve. This knowledge and empathy 
can help to prevent police biases and judgments on the basis of race, demeanor, socioeconomic status, or cultural behaviors alone. When officers work in close relations with communities this increases accountability, which can also improve police behavior (Reed, 1999).

Despite these clear theoretical linkages, the research on CP has shown mixed findings in terms of police-citizen conflict outcomes. For instance, some scholars have found no impact of CP variables on assaults against officers (see Barrick et al., 2014), whereas others found a significant negative relationship (see Wilson \& Zhao, 2008). In looking at complaints, Shjarback and White (2015) found that CP was not a statistically significant correlate, whereas Smith and Holmes (2014) demonstrated that CP was associated with increased sustained complaints. Despite the mixed findings, which suggest further exploration between these variables is needed, the assumptions that undergird community policing practices and policing outcomes has been continuously and strongly advocated in practice, and thus the hypothesis is as follows: ${ }^{15}$

Hypothesis 1: The greater the emphasis on community policing ideals and practices in the police department, the less likely police-citizen conflict-a proxy for negative PCR-will occur.

Administrative responsibility and accountability. The terms "responsibility" and “accountability" are often used interchangeably because a responsible bureaucrat is someone who can account or answer for his or her actions to his or her superior (Bunn,

\footnotetext{
${ }^{15}$ For each of the four hypothesized relationships, the evidence has been mixed, and thus the hypotheses rely primarily on the original theoretical underpinnings between the theoretical concepts, their operationalizations, and the outcome measures.
} 
1961, p. 407). Ensuring such responsibility is crucial to the bureaucracy to prevent abuse of authority or irresponsible actions, particularly when high levels of discretion are given to front-line bureaucrats. It has been well noted that the "ultimate aim of accountability is to ensure that governments are responsive to citizens" (Bourgon, 2007, p. 12). However, the ways to ensure bureaucratic accountability have often been debated, thus leaving diverse prevailing views on how to influence bureaucrats (Bunn, 1961).

At the heart of administrative responsibility and accountability lies the role of identifying the ways in which a workforce can be inspired to fulfill its charge (particularly as it pertains to serving the public good). Scholars have argued for several means by which this goal can be achieved. On one hand is subjective responsibility, which is investing in human capital with the underlying assumption that such investments will yield promising employee behavior. On the other hand, scholars have put forth the notion of objective responsibility, which is providing consequences and/or rules to ensure that problematic behavior is deterred.

Subjective responsibility. First, regarding subjective responsibility, Friedrich $(1935,1940)$ believed that bureaucrats need discretion and creative freedom to problemsolve effectively based on the needs of the situation as well as the bureaucrat's own personal sense of responsibility. The underlying argument is that well-trained professionals (i.e., experts) within the government that embody democratic responsibility will be able to effectively respond to the needs of the public. Echoing Friedrich's sentiments, Mosher (1968) added that higher education and training were both necessary to promote a professional bureaucracy and ensure the future of a democratic government. 


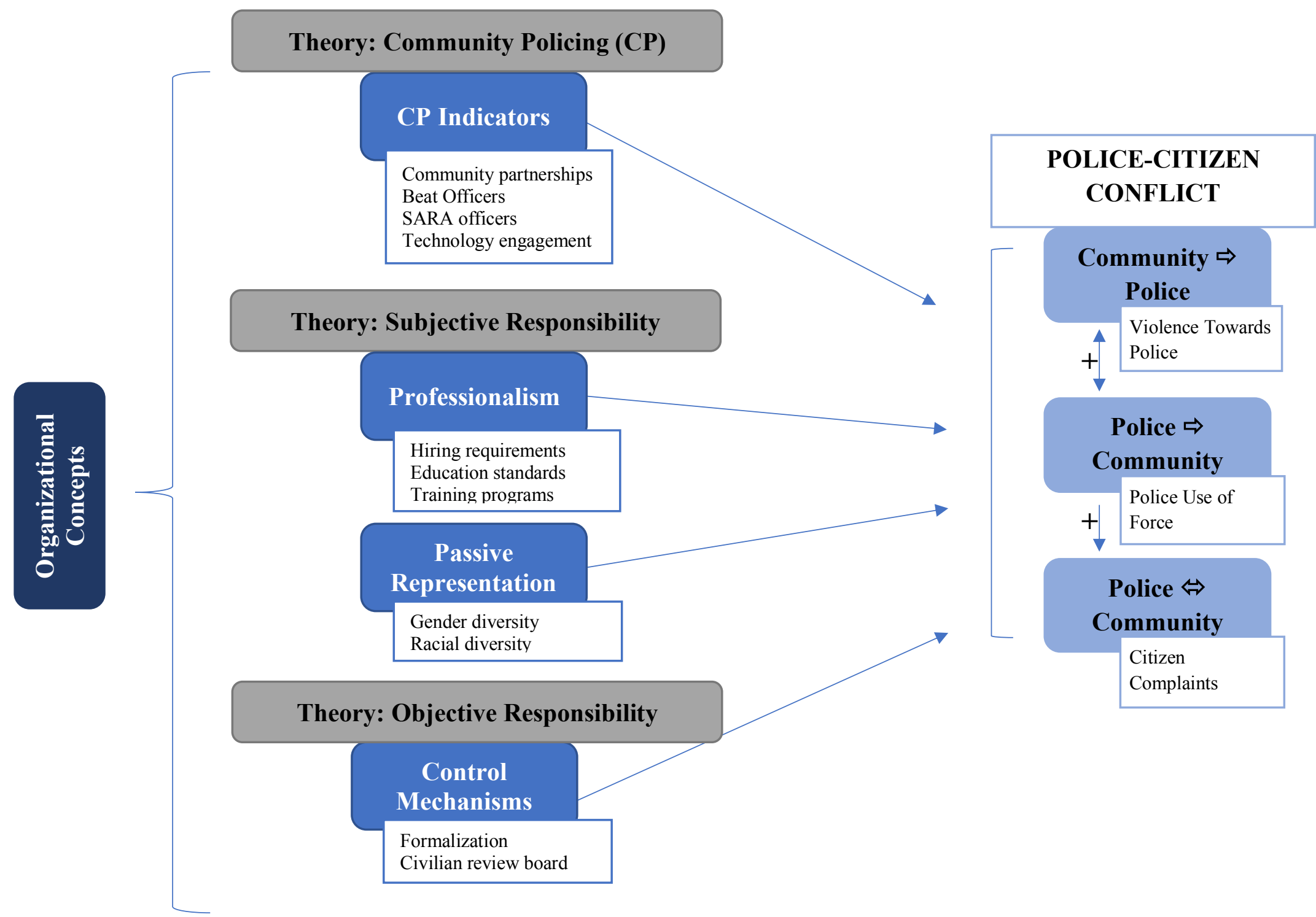

Figure 3. Conceptual framework 
The movement towards a professional police force in the United States came about during the 1920 s as a result of police corruption and ineffectiveness. Professionalism argues that a police department can improve officer behavior by implementing techniques to ensure the quality of character in the individual police officer through the use of stringent hiring practices, recruitment initiatives, educational standards, and training (Shjarback \& White, 2015; Smith, 2004). It is believed that a more professional police force will be more competent and therefore act more appropriately when on duty. According to this perspective, police officers who have greater training and higher education will better navigate police-citizen encounters, make better decisions, and be less likely to use unnecessary or excessive force. Likewise, a professional police force will be more understanding of their responsibilities and the communities they serve, and thus will be better able to relate to diverse populations. Some scholars have also argued that professionalism leads to decreased levels of officer alienation on the job while enhancing commitment and morale, which can then impact police behavior on the streets (Poole, Regoli, \& Lotz, 1978). Investing in a quality (i.e., more professional) workforce - via stringent hiring standards, educational requirements, and providing quality training — would result in satisfactory bureaucratic outputs and workforce performance. Improved employee behavior would then result in greater levels of community satisfaction (seeing as community members often complain or express dissatisfaction due to officer behavior).

The empirical research on the impact of professionalism in policing has produced mixed findings thus far. Some scholars have found professionalism to lead to worse outcomes such as officer disconnectedness from the community (Falcone et al., 2002) 
and more killings by police (Smith, 2004). Yet, other scholars have found that more professional police departments have fewer deadly force incidents (Willits \& Nowacki, 2014), are more compassionate (Crank, 1990a), and are more effective (Davis \& Lawler, 1985). ${ }^{16}$ Despite the mixed findings, the original tenets of professionalism would suggest the following hypothesis:

Hypothesis 2: The greater the commitment to subjective responsibility, via professionalism (i.e., hiring requirements, education standards, and training) in the police department, the less likely police-citizen conflict will occur.

It has been argued that representative bureaucracy is a formal institutional method of administrative responsibility (Kingsley, 1944; Larson, 1973; Meier, 1975). However, the idea behind representative bureaucracy can also be seen as an approach to promote subjective responsibility. "Representative bureaucracy" generally refers to the extent to which a bureaucracy is representative of the population it is serving (Kingsley, 1944). Notions of representation can fall under subjective responsibility because representation and the mechanisms by which it operates are at the level of the individual bureaucrat, and thus, theoretically, deal with the individual bureaucrat's personal sense of responsibility according to his or her demographic representation.

The literature initially distinguished between two forms of representation: passive and active (Mosher, 1968). Passive representation is when bureaucrats have similar demographic characteristics to the citizenry (also referred to as "descriptive representation,” see Kennedy, 2013). Active representation entails bureaucrats sharing

\footnotetext{
${ }^{16}$ It is important to note that these studies have measured various aspects of professionalism rather than the extent to which a police department is professionalized.
} 
beliefs and values similar to certain demographic groups, which leads them to act on behalf of the interests of those groups. For decades, it has been argued that it is critical to have a police force that mirrors the community it serves (in terms of ethnic and racial diversity) in order to promote better treatment of racially minoritized and marginalized populations. Many scholars have suggested that passive representation would lead to active representation (Meier \& Stewart, 1992; Selden \& Selden, 2001). Yet, the policing literature has shown that the link between passive and active representation is not always present (Bradbury \& Kellough, 2011; Wilkins \& Williams, 2008). Despite the discrepancies between linking passive and active representation specifically, scholars have expanded the theory of representative bureaucracy to include symbolic representation, which has yielded more promising results.

Unlike active representation, where the representative acts on the behalf of represented groups, symbolic representation works cognitively on the audience of those who belong to a group that is to be represented. With symbolic representation, then, attitudes and outcomes can change without any purposeful actions taken by the representatives other than holding a government office or position. (Theobald \& Haider-Markel, 2009, p.410)

Some research that has investigated the impact of representation in policing has demonstrated that hiring more racially diverse and/or female officers does in fact impact outcomes, perceptions, and feelings about the police. When there are positive impacts this can then lead to more cooperation between the public and the police in the coproduction of public safety as well as a reduction in the "social distance between police and [such] communities" (Gustafson, 2010, p.45). Gustafson (2010) found that racial 
diversity within police departments indeed minimizes police-citizen conflict to a certain extent. Specifically, increased demographic representation can lead to fewer citizen complaints as well as less violence between the community and the police. Whereas some research has shown that the presence of female officers has been associated with fewer complaints (Cao et al., 2000; Spillar et al., 2000), in other instances, Black officers were associated with more complaints (Cao et al., 2000). In looking at racial representation on the police force, research has shown negative correlations with complaints (Hong, 2017; Smith \& Holmes, 2014). Lastly, Smith (2004) found that for smaller cities, higher proportions of female officers were correlated with more police-caused homicides, whereas variations in racial representation were not significant. In terms of symbolic representation, some research has found that gender and racial representation are positively correlated with citizen perceptions (Riccucci, Van Ryzin, \& Lavena, 2014; Theobald \& Haider-Markel, 2009). Overall, the research investigating the impacts of gender and racial diversity on policing outcomes is mixed; however, this research tests the fundamental theoretical proponents of representative bureaucracy.

Hypothesis 3: The greater the commitment to subjective responsibility via passive representation (e.g., gender and racial diversity) in the police department, the less likely police-citizen conflict will occur. ${ }^{17}$

Objective responsibility. The second mechanism advocated to ensure administrative responsibility is through objective responsibility (more formally regarded

\footnotetext{
17 The mechanisms by which passive representation ("diversity") leads to outcomes is not explicitly assessed herein; however, based on the theory, it can occur through both active and symbolic representation.
} 
as accountability; see Jackson, 2009). Finer (1941) believed that bureaucrats may be more likely to act based on self-interest rather than on behalf of the public interest. Therefore, he thought it was critical to ensure accountability by monitoring bureaucrat behavior and by implementing policy restrictions. He argued that there was a need for supervising and controlling the bureaucracy to a certain extent in order to prevent problematic employee behavior. Aligned with this argument are mechanisms of controlling the police department, whether via the bureaucracy, the polity, or the community. Such mechanisms are often put in place to control, direct, or influence employee behavior and thus impact organizational outcomes — namely by preventing problematic outcomes. These control mechanisms are also considered forms of accountability that act as a check on employee behavior.

Bureaucratic (i.e., administrative) control refers to the idea that the bureaucracy needs formalized procedures and tight legalistic controls on bureaucrat behavior as well as external, imposed boundaries on discretion to promote accountability (Styhre, 2008; Walton, 2005). Within the police context, bureaucratic control can be seen as the extent by which police management controls street-level officer behavior. Such control can be achieved through the use of explicit rules and sanctions in attempt to decrease negative behavior and promote positive behavior. These rules provide guidance to officers and set the boundaries on police use of discretion.... More formalized agencies with considerable regulation may project an atmosphere of oversight and control, which may encourage caution and rule observance on the part of officers. (Smith, 2004, pp. 541-542) 
Some research has suggested that the impact of administrative policies on police use of deadly force is substantial, with more restrictive rules (e.g., the use of force continuum) leading to either less police use of deadly force (Fyfe, 1979; Nowacki, 2015; Smith, 2004; Tennenbaum, 1994; White, 2001) or decreased racial disparities (Walker, 1993). Whereas, other studies have demonstrated the exact opposite, suggesting that policy may impact feelings and attitudes but not necessarily behavior (Dugan, 2003). In order for administrative policy to truly be effective, rules must be enforced (White, 2001). Enforcement requires a close supervision of the police and potentially also micromanagement due to the extensive amount of discretion given to officers.

Control via the polity and/or the community is a form of organizational control exercised outside of the immediate bureaucracy. These control mechanisms can be referred to as accountability mechanisms in that police departments have to answer directly to external bodies concerning officer behavior, organizational performance, or misconduct. Thus, when administrative rules are coupled with other appropriate control and monitoring mechanisms (e.g., external review boards), both unwanted police behavior and overall police-citizen conflict can be minimized, particularly when mechanisms for consequences are in place and enforced (Willits \& Nowacki, 2014).

Hypothesis 4: The greater the commitment to objective responsibility via control mechanisms (formalization and civilian review board), the less likely police-citizen conflict will occur. 


\section{Research Design and Methodology}

Sample and data. The units of analysis were at the city and police department levels. The sample included only city police departments ${ }^{18}$ with 100 or more full-time sworn police officers (following suit of Barrick et al., 2014; Hickman \& Piquero, 2009; MacDonald, 2002; Shjarback \& White, 2015; Wilson \& Zhao, 2008). Analyzing at the city level allowed for a contextual approach to be taken (see Walker, Spohn, \& DeLone, 2000), where the examination of each city and police department comprised a unique system of interdependent sources of influence (i.e., “open systems approach”), which was why both organizational and community characteristics were included in this analysis. The sample was restricted to only police departments with 100 or more full-time sworn officers because these departments had the bureaucratic structures that were appropriate for the variables of interest. Similarly, the larger departments had more organizational variation (Cao et al., 2000; Chappell, Macdonald, \& Manz, 2006). The smaller police departments in the LEMAS sample had a great deal of missing data for the independent variables of interest. The magnitude of missing data for those departments resulted in a sample similar in size to that of the police departments with at least 100 sworn officers.

The sample of city police departments with 100 or more full-time sworn officers was taken from the Bureau of Justice Statistics' Law Enforcement Management and

\footnotetext{
${ }^{18}$ Local tribal, town/township, village, county, boroughs or other types of police departments are not included in the sample. Further, county and borough police departments fell outside the scope of this analysis since the focus herein was to assess police departments that have direct responsibility for servicing a particular city. Often, county and borough police departments are responsible for serving unincorporated areas of a county or cities that do not have a police force. Cities with their own police force located in a county jurisdiction do not receive the county police services. That being said, it is hard to get accurate characteristics about the specific population being served by those police department when there are cities or areas within the county that are not under sole jurisdiction of the county police department. Additionally, the town/townships and villages can often be nested within cities, thus similar problems may result.
} 
Administrative Statistics (LEMAS) survey's 2013 and 2007 sampling frame of 463 and 481 departments, respectively. According to the 2008 Bureau of Justice Statistics Census of State and Local Law Enforcement Agencies, there were approximately 582 city police departments throughout the United States with at least 100 full-time sworn officers. Thus, the 2007 and 2013 LEMAS samples consisted of approximately $82.6 \%$ and $79.6 \%$, respectively, of all city police departments with 100 or more full-time sworn employees in the United States. ${ }^{19}$

The data for the analysis was taken from five sources. First, the Bureau of Justice Statistics LEMAS surveys from 2007 and 2013 were used to capture variations in organizational characteristics of local municipal police departments. An external dataset from the National Association of Civilian Oversight of Law Enforcement (NACOLE) was used to update one of the variables in the LEMAS survey (i.e., the presence of a civilian review board). ${ }^{20}$ The FBI's statistics on Law Enforcement Officers Killed and Assaulted (LEOKA) from 2011 to 2013 was used to capture the level of assaults against officers that a police department faces. The FBI's Uniform Crime Report (UCR) Offenses Known database for the year 2012 was used to capture crime rate variations across police departments and their respective cities. Lastly, the United States' Census'

\footnotetext{
${ }^{19}$ LEMAS surveys all police departments in the United States with 100 or more full-time sworn employees, thus these departments are self-reporting in the LEMAS sample. LEMAS does not survey the entire population of police departments with fewer than 100 sworn officers due to the magnitude of departments. Rather, LEMAS draws on a sample of these smaller police departments (with less than 100 sworn officers) to survey and weights them accordingly

${ }^{20}$ Each civilian review board's creation date was identified in order to update the list accordingly to match the year that the LEMAS survey was sent out. Thus, if a civilian review board was on NACOLE's comprehensive list of review boards but it started after 2013 (which is after the LEMAS survey was conducted), then it was not included in the dataset.
} 
American Community Survey (ACS) 2012 five-year estimates were used to capture socio-economic factors for each city represented in the sample. Data from each of the sources were combined using either unique police department originating agency identifier (ORI) codes, which are official assigned numbers used to identify specific police departments, or by using the police department's name and corresponding city.

A methodological consideration was the loss of sample size as a result of combining data from numerous sources. Availability of key data across each of the aforementioned sources restricted the final samples used in each of the models (Model 1 $n=289$; Model $2 n=331 ;$ Model $3 n=269$ ). Nonetheless, Model 3, representing the smallest sample size, still accounted for approximately $46.2 \%$ of all city police departments with 100 or more sworn full-time employees in the United States. While the reduction in the sample size may seem substantial, incorporating key data from multiple sources allowed for a more theoretically informed and robust analysis of competing research hypotheses, which would otherwise have been impossible.

To better understand if the sample is representative of all police departments, a comparative analysis was conducted using a one-sample $t$ test to investigate differences on several key variables between the samples used in each model and the overall LEMAS sampling frame. ${ }^{21}$ Tables 6 through 8 compare the means of the following variables: size of the organization (i.e., number of full-time employees), the total budget, the percentage

\footnotetext{
${ }^{21}$ In the force and assault models, one police department with over 15,000 police officers (New York Police Department, NYPD) was removed from the comparison population when conducting the $t$ test because the sample did not include any police departments that large and thus it was skewing the population mean statistics. The NYPD is the largest police department in the United States and from an organizational perspective it is not representative of the average sized police department.
} 
of Black and Hispanic full-time officers, percentage of full-time female officers, the city size, the city poverty level, and geographic spread.

For Models 1 and 2, there were no statistically significant differences found on any characteristics between the subset of police departments used in each of the respective regression analyses and the police departments in LEMAS' overall sampling frame. However, for Model 3, there were three variables that were significantly different when comparing the regression sample $(n=269)$ to the overall sampling frame $(N=$ 481). For the subset of police departments that were used in Model 3-the complaint model - the mean population size was slightly larger (at 261,559) compared to the mean of 197,420 for the overall sampling frame $(p<0.10)$. Additionally, out of the police departments used in the complaint model, the mean percentage of female officers on the police force (11.7\%) was slightly larger than the mean percentage in the overall sampling frame $(11.2 \% ; p<0.10)$. Lastly, the mean percentage of police departments located in the Western United States was larger in the complaint model sample (30.94\%) when compared to the mean percentage in the overall sampling frame (22.87\%). This difference was the only one that was statistically significant at the $5 \%$ level. Despite these minor differences, most of the variables did not have any statistically significant differences when comparing the individual samples used for the respective regression analyses to the overall sampling frame of data.

Variable operationalizations. Three main dependent variables were used to operationalize police-citizen conflict, which served as a proxy for negative policecommunity relations. Police-citizen conflict (i.e., police-citizen violence or policecommunity conflict) has been conceptualized in prior literature to reflect the tensions 
Table 6

Results of One-sample T-test and Descriptive Statistics for Force Model

\begin{tabular}{|c|c|c|c|c|c|c|c|c|}
\hline Outcome & $M$ & $S D$ & $n$ & $\begin{array}{c}\text { Comparison } \\
\text { Value }\end{array}$ & {$[95 \%$ CI for Mean } & Difference] & $t$ & $\mathrm{df}$ \\
\hline Population Size & 181926.50 & 290789.30 & 289 & 191630.60 & 148259.40 & 215593.70 & -0.57 & 288 \\
\hline Organization Size & 501.53 & 967.56 & 289 & 532.40 & 389.51 & 613.56 & -0.54 & 288 \\
\hline Full Time Sworn Officers & 388.03 & 750.91 & 289 & 420.20 & 301.10 & 474.97 & -0.73 & 288 \\
\hline Total Budget & $5.70 \mathrm{e}+07$ & $1.04 \mathrm{e}+08$ & 286 & $6.04 \mathrm{e}+07$ & $4.49 \mathrm{e}+07$ & $6.92 \mathrm{e}+07$ & -0.54 & 285 \\
\hline Black Officer (\%) & 10.15 & 11.69 & 289 & 10.33 & 8.79 & 11.50 & -0.28 & 288 \\
\hline Female Officer $(\%)$ & 11.60 & 4.96 & 289 & 11.36 & 11.03 & 12.18 & 0.82 & 288 \\
\hline Black Population (\%) & 18.07 & 17.24 & 289 & 18.48 & 16.08 & 20.07 & -0.40 & 288 \\
\hline Hispanic Population (\%) & 19.59 & 16.69 & 289 & 20.13 & 17.66 & 21.52 & -0.54 & 288 \\
\hline Poverty Level (\%) & 13.73 & 6.20 & 289 & 14.06 & 13.01 & 14.44 & -0.92 & 288 \\
\hline Northeast (\%) & 14.53 & 35.30 & 289 & 15.80 & 10.44 & 18.62 & -0.61 & 288 \\
\hline Midwest (\%) & 18.34 & 38.77 & 289 & 17.75 & 13.85 & 22.83 & 0.26 & 288 \\
\hline West $(\%)$ & 24.22 & 42.92 & 289 & 24.46 & 19.25 & 29.19 & -0.09 & 288 \\
\hline
\end{tabular}

Note. Comparison value refers to the mean from the LEMAS 2013 sample of police departments (over 450 police departments)

$* * p<0.05 \quad * p<0.10$ 


\section{Table 7}

Results of One-sample T-test and Descriptive Statistics for Assault Model

\begin{tabular}{|c|c|c|c|c|c|c|c|c|}
\hline Outcome & $M$ & $S D$ & $n$ & $\begin{array}{c}\text { Comparison } \\
\text { Value } \\
\end{array}$ & {$[95 \%$ CI for Mean } & Difference] & $t$ & df \\
\hline Population Size & 188303.60 & 302582.50 & 331 & 191630.60 & 155586.50 & 221020.60 & -0.20 & 330 \\
\hline Organization Size & 507.57 & 984.10 & 331 & 532.40 & 401.16 & 613.97 & -0.46 & 330 \\
\hline Full Time Sworn Officers & 392.70 & 769.33 & 331 & 420.20 & 309.52 & 475.89 & -0.65 & 330 \\
\hline Total Budget & $5.84 \mathrm{e}+07$ & $1.06 \mathrm{e}+08$ & 327 & $6.04 \mathrm{e}+07$ & $4.69 \mathrm{e}+07$ & $7.00 \mathrm{e}+07$ & -0.33 & 326 \\
\hline Black Officer (\%) & 10.34 & 13.08 & 331 & 10.33 & 8.93 & 11.76 & 0.00 & 330 \\
\hline Female Officer $(\%)$ & 11.60 & 4.94 & 331 & 11.36 & 11.07 & 12.14 & 0.89 & 330 \\
\hline Black Population (\%) & 18.61 & 18.44 & 331 & 18.48 & 16.62 & 20.61 & 0.13 & 330 \\
\hline Hispanic Population (\%) & 20.00 & 17.58 & 331 & 20.13 & 18.10 & 21.90 & -0.13 & 330 \\
\hline Poverty Level (\%) & 13.69 & 6.04 & 331 & 14.06 & 13.04 & 14.34 & -1.13 & 330 \\
\hline Northeast (\%) & 13.29 & 34.00 & 331 & 15.80 & 9.62 & 16.97 & -1.34 & 330 \\
\hline Midwest (\%) & 16.01 & 36.73 & 331 & 17.75 & 12.04 & 19.98 & -0.86 & 330 \\
\hline West (\%) & 26.59 & 44.25 & 331 & 24.46 & 21.80 & 31.37 & 0.87 & 330 \\
\hline
\end{tabular}

Note. Comparison value refers to the mean from the LEMAS 2013 sample of police departments (over 450 police departments)

$* * p<0.05 \quad * p<0.10$ 
Table 8

Results of One-sample T-test and Descriptive Statistics for Complaint Model

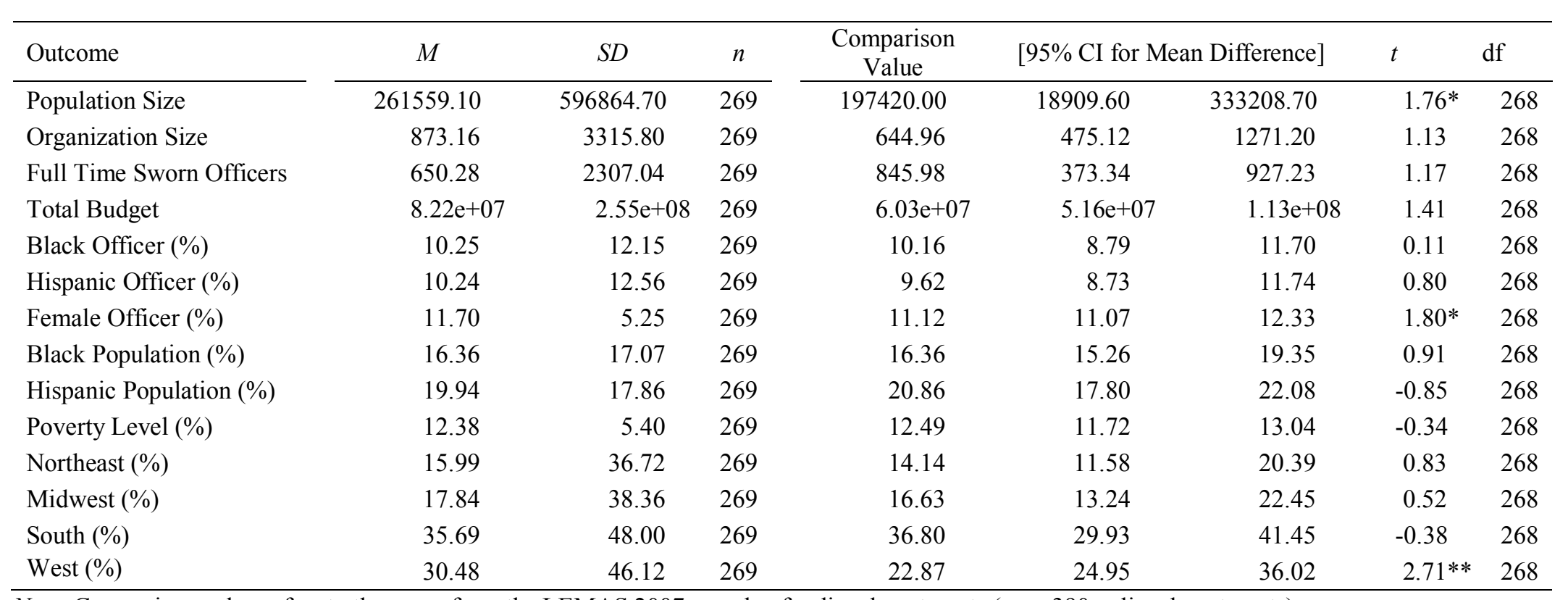

Note. Comparison value refers to the mean from the LEMAS 2007 sample of police departments (over 390 police departments)

$* * p<0.05 \quad * p<0.10$ 
that exist between the police and the community; however, the operationalization in research has varied (see Gustafson, 2010; Johnson, 2012; Long, 2012; Shjarback \& White, 2015). In order to provide a comprehensive understanding of police-citizen conflict, it was operationalized herein by examining officer use of force, citizen complaints, and assaults against officers. The officer use of force rate was measured as the total number of force incident that occurred for the year per 100,000 population. ${ }^{22}$ The citizen complaint rate was measured as the total number of citizen complaints about officer use of force for the year per 100 officers. The rate of assaults against officers was calculated as a weighted three-year average of total assaults per 100 officers. $^{23}$

The independent variables that were used in the model were grouped by conceptual relevance. The main conceptual categories that were explored included: community policing, representative bureaucracy, professionalism, and control

\footnotetext{
${ }^{22}$ The data provided on police use of force is taken from the LEMAS database. Police departments report use of force in terms of the number of incidents of force reported as well as the number of separate reports filed per officer in each incident. The number of incidents of use of force is used here in order to avoiding counting duplicate incidents when using the reported number of separate reports. Some police departments reported both types of force, whereas other police departments only reported the total number of unique incidents or the number of separate reports. After cleaning the data, the reported use of force incident number and separate report number were highly correlated $(\mathrm{r}=0.9744)$, thus for police departments that only reported separate report measures a regression analysis was used to estimate the number of reported force incidents for police departments. A total of 76 police departments were used in the force model that contained estimated force incident numbers. A dummy variable (i.e., "force estimate") was included in the final force model to account for any potential estimation problems.

${ }^{23}$ The data provided on assaults against officers was taken from LEOKA, which reports monthly officer assault numbers per department. Due to the number of police departments that do not consistently report each month, the rate of assaults against officers was weighted according to a method used by Wilson and Zhao (2008). First, the summed number of police assaults reported over a three year period was calculated, then it was multiplied by 36 (to account for all the months over the three year period). After, it was divided by the total number of months that the department reported assaults. For accuracy, only police departments that reported more than half of the data (18 months or more) were retained for analysis purposes. Then, to create the average rate of assaults per year per 100 officers, the summed and weighted numbers were divided by the number of years (3), and then divided by the number of officers on each police force and finally multiplied by 100 .
} 
mechanisms (all of which had various indicators included in the model). Community policing indicators included community partnerships, beat officers, SARA problemsolving officers, and the level of community-technology engagement. Community partnerships was a dichotomous variable to measure (yes/no) reflecting whether the police department had a problem-solving partnership or written agreement with any community organization. Beat officers represented the percentage of patrol officers that were assigned to continuously patrol a specific geographic locale or area (i.e., "beat"). SARA problem-solving officers referred to the percent of patrol officers that were engaged in active problem-solving with the community using the Scanning, Analysis, Response, and Assessment (SARA) Problem Solving Model. The community-technology engagement variable was an additive summated score of the level of engagement and/or interaction the police department had with the community via technology (see Tables D1 and D2 in Appendix D for items included in this additive measure).

Representative bureaucracy indicators were the level of gender and minority (racial) representation. Gender representation was measured as the percent of sworn officers that identified as female. Minority representation was measured as a ratio of the percent of sworn officers that identified as non-White in relation to the percent of minority (i.e., non-White) population in a given city. A value of 1 indicated parity in terms of minority representation between officers and the community, whereas values less than 1 indicated under-representation of officers, and greater than 1 indicated overrepresentation of officers.

Professionalism indicators included the hiring standards, educational standards, and community policing training requirements. The variable hiring standards was 
measured as an additive variety score to assess how many requirements the police department used to screen individuals that would be hired as sworn officers (see Table D3 in Appendix D for items included in this additive measure). Educational standards referred to a dichotomous variable that identified if the police department required a minimum of a two-year college degree for newly hired officers. Two separate dichotomous variables were used to measure whether a police department required at least eight hours of community policing training as part of (a) in-service training and (b) new recruit training.

Indicators of control mechanisms included the presence of civilian review boards and the level of formalization. A dichotomous variable was used to measure the presence of a civilian review board. Formalization was conceptualized as "the extent to which the organization is governed by codes, rule, and other written documents" (Eitle, 2005, p. 578). Thus, formalization was measured as an additive variety score for the number of formal policy directives or written rules and requirements a police department had that restricted officer discretion and/or aimed to standardize officer behavior (e.g., use of force or overtime hours; see Table D4 in Appendix D for items included in this additive measure). ${ }^{24}$

\footnotetext{
${ }^{24}$ Alkadry and Nyhan (2005) note, "the main goal of formalization is to ensure that actions of organizations are consistent regardless of who is taking these actions" and thus formal rules are put in place (p. 157). It is important to note there are other indicators of formalization that are not measured herein. Rather, this chapter relies on prior operationalizations of formalization as an indicator of bureaucratic, structural, or organizational control in police departments (see Eitle, 2005; Eitle, D'Alessio, \& Stolzenberg, 2014; Maguire, 2009, 1997; Matusiak, Campbell, \& King, 2014; Smith, 2004; Wilson, 2005). Further, while police departments are para-military organizations, and thus formal by definition, inclusion of this variable is to understand the level or extent of such formalization via policy directives.
} 
Several control variables that were correlated with police-citizen conflict were included in the analysis. Most of these control variables were city-level measures that prior research has found to be highly influential in impacting each dependent variable. The inclusion of such variables furthered the analysis beyond the organizational level. The control variables included the percent of the population that identified as Black, the percent of the population that identified as Hispanic, the percent of families living below the poverty level, the weighted average of violent crime per year per 100,000 population $^{25}$, the police density (i.e., number of full-time sworn officers per 1,000 population), and the region of the United States that a city falls in. ${ }^{26}$ Variable operationalizations can also be found in Table 9, whereas descriptive statistics for each of the variables can be found in Table $10 .^{27}$

Methodology. Bivariate relationships, analyzed using Pearson's $r$, as well as multivariate statistics were used to assess the relationship between the organizational

\footnotetext{
${ }^{25}$ The rate of violent crime was weighted according the same procedure by Wilson and Zhao (2008) that was used herein to sum and weight the average rate of assaults against officers (see footnote 24).

${ }^{26}$ In the use of force model, one additional control variable was included ("force estimate") to account for the police departments that were estimated based on the alternative use of force measure that was provided (see footnote 23). This was included to see if the regression imputations made a difference in the model results.

${ }^{27}$ There were three models used to estimate each dependent variable (use of force, citizen complaints, and assaults against officers). However, the complaint model relied on complaint data from the 2006-2007 LEMAS, and thus data for the independent variables were taken to correspond with those years accordingly, whereas the force and assault models used data to correspond with the 2012-2013 LEMAS. For comparative purposes, the operationalization of the key independent variables remained consistent across all models. However, it is important to note that in the two models (force and assaults) that relied on 2012-2013 data, there were two independent variables (the hiring requirements and the level of formalization) that only had data from 2006-2007 LEMAS. While, there is a significant year gap from 2006-2007 to 2012-2013, it is reasonable to believe that due to the relatively constant nature of police departments that these three variables remain consistent (with little to no change) over the years (see Maguire, 1997 for further discussion on the stable nature of department structure).
} 
measures and each of the three police-citizen conflict outcomes. The multivariate analysis performed was an ordinary least squares regression due to the ratio-level of the dependent variables. Additionally, STATA's cluster function (by state) was used to account for potential problems of nesting of police departments in similar locales (Shjarback \& White, 2015). Listwise deletion of cases with missing data reduced the measurable sample size of city police departments in each of the analyses. While it can be argued that there may have been a sample selection bias due to the decreased sample size, when conducting one-sample $t$ tests to compare means of the sample and population (i.e., budget, organization size, population served, gender and racial make-up of police force), the police departments used in each analysis were not significantly different from the larger population. Moreover, these departments represented a broad geography across the United States, covering between 46-47 clusters (depending on the model) at the state level.

Prior to running the multivariate regression, several standard diagnostic techniques were performed to check the data for various issues. First, multicollinearity was diagnosed using pairwise correlations and variance inflation factors. In examining the pairwise correlations, none of the measures exceeded or even approached the traditional threshold of 0.70 . Additionally, the variance inflation factors were less than or equal to 1.62 for the force model, 1.59 for the assault model, and 1.75 for the complaint model. Thus, no issues relating to multicollinearity were found herein. Non-normality of residuals was found using a variety of statistical and graphical tests. These statistical tests included the skewness-kurtosis test and the Shapiro-Wilk test, both of which failed to accept the null hypothesis of normality. The graphical displays assessed included 
standardized normal probability plots, normal quantile-quantile plots, and kernel density plots. To correct for non-normality, the dependent variables were transformed for the regression analysis. The use of these transformations corrected for the violations of the ordinary least squares assumption of normality of residuals. Next, to test for heteroscedasticity, the residuals versus fitted/predicted values plot and the Breusch-Pagan test were used for each model. These diagnostic assessments revealed that the error term held constant variance for all of the models. In the case that heteroscedasticity was a problem in any of the models, STATA's cluster function (used here at the state level) included robust standard errors, which would have accounted for heteroscedasticity. To preserve the actual data, outliers were retained in the analysis in order to limit the amount of data manipulations. Some research has found that slight violations of the ordinary least squares assumptions are acceptable (see Lumley, Diehr, Emerson, \& Chen, 2002). Further, the use of both transformations and robust regression helped with the presence of outliers in reducing potential bias. The final regression equation for each dependent variable was as follows:

$$
\begin{gathered}
\log (\text { Police }- \text { Citizen Conflict Indicators })_{i}=\beta_{0}+ \\
\beta_{1}(\text { Community Policing Indicators })_{i}+\beta_{2}(\text { Professionalism Indicators })_{i}+ \\
\beta_{3}(\text { Passive Representation Indicators })_{i}+ \\
\beta_{4}(\text { Control Mechanism Indicators })_{i}+\beta_{5}(\text { Control Variables })_{i}+\varepsilon_{I}
\end{gathered}
$$




\section{Results}

Bivariate relationships. Tables 11 and 12 present the results of the bivariate correlations for the force and assault rate (Table 11) and the complaint rate (Table 12). ${ }^{28}$ Focusing solely on the relationships between the dependent variable and the hypothesized predictor variables, it appeared that there was a positive correlation between the assault rate of citizens against officers and the use of force rate by police officers towards citizens $(r=0.15)$. Also, there was a negative relationship between minority representation and the force rate $(r=-0.21)$. This result was consistent with the predicted direction based on the passive representation hypothesis that greater representation would be correlated with less police-citizen conflict. The presence of a civilian review board was positively associated with the level of assaults $(r=0.10)$. This result was not in the hypothesized predicted direction. Lastly, based on the bivariate correlations, the percentage of problem-solving officers on the police force was negatively correlated with the complaint rate $(r=-0.12)$. This bivariate relationship was in the predicted direction, indicating that a greater emphasis on community policing was correlated with less policecitizen conflict. It is important to note that most of the community control variables included in the analysis were strongly correlated with at least one of the dependent variables.

Multivariate relationships. Multivariate analysis was used to provide a rigorous analysis of the theoretical relationships discussed herein. Table 13 shows the results of

\footnotetext{
${ }^{28}$ There are two separate tables because the first model was run with LEMAS data from the year 20122013, whereas the complaint model was run with data from 2006-2007 due to data availability issues. However, the independent variables are constant across models.
} 
Table 9

\section{Variable Operationalizations}

\begin{tabular}{|c|c|c|}
\hline Categories & Variable Name & Operationalization \\
\hline $\begin{array}{l}\text { Dependent } \\
\text { Variables }\end{array}$ & $\begin{array}{l}\text { Force Rate } \\
\text { Complaint Rate } \\
\text { Assault Rate }\end{array}$ & $\begin{array}{l}\text { Number of force incidents per } 100,000 \text { population (estimated) } \\
\text { Number of total citizen complaints about use of force per } 100 \text { officers } \\
\text { Average number total police assaults per year per } 100 \text { officers (weighted) }\end{array}$ \\
\hline Professionalism & $\begin{array}{l}\text { Educational Standards } \\
\text { Hiring Standards } \\
\text { Community Policing } \\
\text { Training: In-Service } \\
\text { Community Policing } \\
\text { Training: Recruits }\end{array}$ & $\begin{array}{l}\text { Dichotomous variable to measure 2- or 4-year educational requirement versus no college requirement } \\
\text { An additive variety score of the hiring standards (screening) that the police department uses } \\
\text { Dichotomous variable to measure if full-time officers receive at least } 8 \text { hours of in-service community } \\
\text { policing training } \\
\text { Dichotomous variable to measure if full-time officers receive at least } 8 \text { hours of recruit community } \\
\text { policing training }\end{array}$ \\
\hline $\begin{array}{l}\text { Passive } \\
\text { Representation }\end{array}$ & $\begin{array}{l}\text { Gender Representation } \\
\text { Minority Representation }\end{array}$ & $\begin{array}{l}\text { Percentage of sworn female police officers out of total sworn police officers } \\
\text { Ratio of minority officers in a police department to minority population of corresponding city }\end{array}$ \\
\hline $\begin{array}{l}\text { Control } \\
\text { Mechanisms }\end{array}$ & $\begin{array}{l}\text { Formalization } \\
\text { Civilian Review Board }\end{array}$ & $\begin{array}{l}\text { An additive variety score of the number of formal policy directives or written rules/requirements } \\
\text { Dichotomous variable to measure the presence of a civilian review board }\end{array}$ \\
\hline $\begin{array}{l}\text { Control } \\
\text { Variables }\end{array}$ & $\begin{array}{l}\text { Police Density }^{\mathrm{a}} \\
\text { Percent Black (city) } \\
\text { Percent Hispanic (city) } \\
\text { Population Size } \\
\text { Poverty Level (city) } \\
\text { Violent Crime Rate } \\
\text { United States Region }_{\text {Force Estimate }}\end{array}$ & $\begin{array}{l}\text { Number of full-time sworn officers per } 1,000 \text { population } \\
\text { Percentage of Blacks (not Hispanic) in the population } \\
\text { Percentage of Hispanics in the population } \\
\text { Count variable to measure the size of population } \\
\text { Percentage of families below the poverty level } \\
\text { Average violent crime rate per year per } 100,000 \text { (weighted) } \\
\text { Region of the United States where the police department (S, NW, NE, W) } \\
\text { Dummy variable to identify if the force rate was estimated or actually reported by the police department } \\
\text { (variable only included in Force Model) }\end{array}$ \\
\hline
\end{tabular}


Table 10

Descriptive Statistics

\begin{tabular}{|c|c|c|c|c|c|c|c|c|c|c|c|c|}
\hline \multirow{2}{*}{ Variables } & \multicolumn{4}{|c|}{ Force } & \multicolumn{4}{|c|}{ Assaults } & \multicolumn{4}{|c|}{ Complaints } \\
\hline & Min & Max & Mean & $\mathrm{SD}$ & Min & Max & Mean & $\mathrm{SD}$ & Min & Max & Mean & $\mathrm{SD}$ \\
\hline Use of Force Rate & 5.8 & 3719.4 & 159.9 & 260.9 & - & - & - & - & - & - & - & - \\
\hline Assault Rate & - & - & - & - & 1 & 71.5 & 16.1 & 12.3 & - & - & - & - \\
\hline Complaint Rate & - & - & - & - & - & - & - & - & 1.2 & 147.1 & 9.2 & 15.6 \\
\hline Gender Representation & 2.3 & 42.2 & 11.6 & 5 & 3.3 & 42.2 & 11.6 & 4.9 & 1.4 & 40.1 & 11.7 & 5.3 \\
\hline Minority Representation & 0 & 1.8 & 0.5 & 0.3 & 0 & 1.8 & 0.5 & 0.2 & 0 & 1.6 & 0.5 & 0.2 \\
\hline Education Standards & 0 & 1 & 0.2 & 0.4 & 0 & 1 & 0.2 & 0.4 & 0 & 1 & 0.3 & 0.4 \\
\hline Hiring Standards & 8 & 18 & 12.7 & 2.2 & 8 & 18 & 12.7 & 2.2 & 8 & 18 & 12.9 & 2.2 \\
\hline Community Pol. Train Recruits & 0 & 1 & 0.7 & 0.5 & 0 & 1 & 0.7 & 0.5 & 0 & 1 & 0.8 & 0.4 \\
\hline Community Pol. Train In-Service & 0 & 1 & 0.3 & 0.5 & 0 & 1 & 0.3 & 0.5 & 0 & 1 & 0.2 & 0.4 \\
\hline Formalization & 8 & 18 & 15 & 1.9 & 8 & 18 & 14.9 & 1.9 & 8 & 18 & 15.1 & 2 \\
\hline Civilian Review Board & 0 & 1 & 0.2 & 0.4 & 0 & 1 & 0.2 & 0.4 & 0 & 1 & 0.3 & 0.5 \\
\hline Community Partnerships & 0 & 1 & 0.7 & 0.5 & 0 & 1 & 0.6 & 0.5 & 0 & 1 & 0.9 & 0.3 \\
\hline Beat Officers & 0 & 100 & 36.5 & 23.2 & 0 & 99.4 & 35.9 & 22.9 & 0 & 100 & 45.1 & 25.9 \\
\hline Problem-Solving Officers & 0 & 100 & 22.8 & 27.8 & 0 & 100 & 23.4 & 27.7 & 0 & 100 & 31.3 & 32.3 \\
\hline Community-Tech. Engagement & 0 & 16 & 9.2 & 3.6 & 0 & 17 & 9.3 & 3.7 & 0 & 10 & 5.1 & 2.3 \\
\hline Poverty Level & 3.2 & 34.5 & 13.7 & 6.2 & 3.2 & 34.5 & 13.7 & 6 & 2.3 & 28.8 & 12.4 & 5.5 \\
\hline Violent Crime Rate & 80.2 & 2301.2 & 565.4 & 373.4 & 53.5 & 2478.0 & 563 & 384.2 & 108.7 & 2506.0 & 742.6 & 453.8 \\
\hline Police Density & 0.9 & 7.1 & 2.1 & 0.8 & 0.9 & 7.1 & 2 & 0.8 & 0.9 & 6.7 & 2.2 & 0.8 \\
\hline Northeast & 0 & 1 & 0.1 & 0.4 & 0 & 1 & 0.1 & 0.3 & 0 & 1 & 0.2 & 0.4 \\
\hline South & 0 & 1 & 0.4 & 0.5 & 0 & 1 & 0.4 & 0.5 & 0 & 1 & 0.4 & 0.5 \\
\hline Midwest & 0 & 1 & 0.2 & 0.4 & 0 & 1 & 0.2 & 0.4 & 0 & 1 & 0.2 & 0.4 \\
\hline West & 0 & 1 & 0.2 & 0.4 & 0 & 1 & 0.3 & 0.4 & 0 & 1 & 0.3 & 0.5 \\
\hline Force Estimate & 0 & 1 & 0.3 & 0.4 & - & - & - & - & - & - & - & - \\
\hline Sample Size & \multicolumn{4}{|c|}{289} & \multicolumn{4}{|c|}{331} & \multicolumn{4}{|c|}{269} \\
\hline
\end{tabular}

Note. These statistics are displayed using the original values, not the transformed variables (e.g. natural log). 
each of the ordinary least squares regression models with the dependent and independent variables of interest.

Use of force rate. In Model 1, the dependent variable of interest was the aggregated use of force rate per police department. The results of the regression indicated that the predictors explained about $23 \%$ of the variance $\left(R^{2}=0.23, F(21,46)=10.30, p<\right.$ 0.01). The $F$ test showed that the null-hypothesis could be rejected, thus this model provided a better fit than the constant-only model. Among the hypothesized relationships, there were three variables found to significantly impact a police department's use of force rate. Two of the six community policing measures included in the analysis were found to be associated with police departments' force rate. Police departments that had community partnerships $(\beta=-0.11 ; p<0.05)$ also had lower officer use of force rates, holding all other variables constant. Specifically, engaging in community partnerships was associated with an $18.9 \%$ lower force rate. ${ }^{29}$ Likewise, police departments with larger percentages of their police force assigned to patrol a specific area or geographic locale (i.e., "beat") had lower police use of force rates $(\beta=-0.12 ; p<0.10)$. However, due to the small coefficient size, it was more important to focus solely on directionality here. Both of these relationships were in alignment with Hypothesis 1, which stated that community policing would be negatively associated with police-citizen conflict. The two other community policing variables - the percentage of problem-solving officers, and the level of engagement with the community using technology—were not significant.

\footnotetext{
${ }^{29}$ This interpretations applies because the dependent variable is logged and the independent variable is a dummy variable, thus when the variable of interest switches from 0 to 1 , the percent impact of the independent variable, $\mathrm{X}$, on the dependent variable, $\mathrm{Y}$, is $100[\exp (b)-1]$.
} 
Table 11

Bivariate Correlations for Force and Assault Rate

\begin{tabular}{|c|c|c|c|c|c|c|c|c|c|c|}
\hline & FORCE AND ASSAULTS & Y1 & Y2 & $\mathrm{X} 1$ & $\mathrm{X} 2$ & $\mathrm{X} 3$ & $\mathrm{X} 4$ & $\mathrm{X} 5$ & X6 & $\mathrm{X} 7$ \\
\hline Y1 & Force Rate $(\log )$ & 1 & & & & & & & & \\
\hline $\mathrm{Y} 2$ & Assault Rate (log) & $0.15^{*}$ & 1 & & & & & & & \\
\hline $\mathrm{X} 1$ & Gender Representation & 0.03 & -0.02 & 1 & & & & & & \\
\hline $\mathrm{X} 2$ & Minority Representation & $-0.21 *$ & 0.02 & $0.35 *$ & 1 & & & & & \\
\hline $\mathrm{X} 3$ & Education Standards & -0.07 & 0.00 & $0.12^{*}$ & 0.05 & 1 & & & & \\
\hline $\mathrm{X} 4$ & Hiring Standards & -0.08 & -0.06 & -0.01 & 0.06 & 0.02 & 1 & & & \\
\hline $\mathrm{X} 5$ & Community Policing Training Recruits & -0.01 & 0.03 & 0.02 & 0.03 & -0.02 & -0.03 & 1 & & \\
\hline $\mathrm{X} 6$ & Community Policing Training In-Service & 0.09 & -0.07 & $0.10^{*}$ & $0.12 *$ & -0.01 & 0.02 & $0.29 *$ & 1 & \\
\hline $\mathrm{X} 7$ & Formalization & -0.06 & -0.02 & $0.17 *$ & $0.17^{*}$ & 0.06 & $0.10^{*}$ & $0.11 *$ & $0.13 *$ & 1 \\
\hline $\mathrm{X} 8$ & Civilian Review Board & 0.06 & $0.10^{*}$ & $0.27 *$ & $0.15^{*}$ & 0.07 & $0.16^{*}$ & 0.06 & 0.07 & $0.10^{*}$ \\
\hline X9 & Community Partnerships & -0.07 & -0.02 & 0.07 & 0.02 & 0.00 & 0.03 & $0.11 *$ & $0.11 *$ & $-0.16^{*}$ \\
\hline $\mathrm{X} 10$ & Beat Officers & -0.05 & -0.03 & 0.07 & $-0.10^{*}$ & -0.03 & $0.12 *$ & 0.04 & 0.02 & -0.01 \\
\hline $\mathrm{X} 11$ & SARA/Problem-Solving Officers (log) & -0.10 & 0.07 & 0.04 & 0.00 & 0.05 & $0.17^{*}$ & -0.01 & -0.08 & 0.02 \\
\hline $\mathrm{X} 12$ & Community-Technology Engagement & -0.02 & 0.07 & $0.16^{*}$ & 0.02 & $0.15^{*}$ & $0.22^{*}$ & $0.12^{*}$ & $0.11^{*}$ & $0.14^{*}$ \\
\hline $\mathrm{X} 13$ & Percent Black & $0.14^{*}$ & $-0.13^{*}$ & $0.39 *$ & $0.18^{*}$ & $-0.13^{*}$ & $-0.12^{*}$ & 0.05 & $0.10^{*}$ & $0.09 *$ \\
\hline $\mathrm{X} 14$ & Percent Hispanic & $-0.22 *$ & $0.15^{*}$ & $-0.15^{*}$ & $0.26^{*}$ & -0.07 & 0.06 & 0.04 & -0.05 & 0.03 \\
\hline $\mathrm{X} 15$ & Poverty Level & $0.17^{*}$ & 0.04 & 0.09 & $0.12^{*}$ & $-0.19^{*}$ & -0.06 & 0.00 & 0.04 & -0.01 \\
\hline $\mathrm{X} 16$ & Violent Crime Rate (log) & $0.31 *$ & $0.20 *$ & $0.26^{*}$ & $0.18 *$ & $-0.19^{*}$ & -0.08 & 0.07 & 0.06 & 0.06 \\
\hline $\mathrm{X} 17$ & Police Density (log) & $0.24 *$ & $-0.11^{*}$ & $0.26^{*}$ & $0.27 *$ & -0.06 & $-0.20 *$ & 0.10 & $0.15^{*}$ & $0.16^{*}$ \\
\hline $\mathrm{X} 18$ & Northeast & 0.05 & -0.05 & $-0.14^{*}$ & -0.05 & $-0.09 *$ & $-0.21 *$ & -0.01 & -0.04 & 0.02 \\
\hline X19 & Midwest & $0.16^{*}$ & 0.08 & 0.01 & $-0.17^{*}$ & 0.07 & 0.01 & -0.08 & -0.03 & $-0.13 *$ \\
\hline $\mathrm{X} 20$ & South & -0.05 & $-0.17 *$ & $0.14^{*}$ & $0.12 *$ & -0.01 & $-0.10^{*}$ & 0.07 & 0.08 & 0.07 \\
\hline $\mathrm{X} 21$ & West & $-0.12^{*}$ & $0.15^{*}$ & -0.06 & 0.05 & 0.03 & $0.28^{*}$ & 0.00 & -0.03 & 0.06 \\
\hline $\mathrm{X} 22$ & Force Estimate & 0.02 & -0.10 & -0.02 & -0.04 & $0.13 *$ & -0.11 & -0.04 & -0.04 & 0.03 \\
\hline
\end{tabular}


Table 11

Continued

\begin{tabular}{|c|c|c|c|c|c|c|c|c|c|c|}
\hline & FORCE AND ASSAULTS & $\mathrm{X} 8$ & $\mathrm{X} 9$ & $\mathrm{X} 10$ & $\mathrm{X} 11$ & $\mathrm{X} 12$ & $\mathrm{X} 13$ & $\mathrm{X} 14$ & $\mathrm{X} 15$ & $\mathrm{X} 16$ \\
\hline $\mathrm{X} 8$ & Civilian Review Board & 1 & & & & & & & & \\
\hline X9 & Community Partnerships & 0.07 & 1 & & & & & & & \\
\hline $\mathrm{X} 10$ & Beat Officers & 0.02 & 0.01 & 1 & & & & & & \\
\hline $\mathrm{X} 11$ & SARA/Problem-Solving Officers (log) & 0.05 & $0.06^{*}$ & $0.16^{*}$ & 1 & & & & & \\
\hline $\mathrm{X} 12$ & Community-Technology Engagement & $0.13^{*}$ & $0.16^{*}$ & $0.16^{*}$ & $0.15^{*}$ & 1 & & & & \\
\hline $\mathrm{X} 13$ & Percent Black & $0.09^{*}$ & 0.02 & -0.01 & $-0.17^{*}$ & $-0.15^{*}$ & 1 & & & \\
\hline $\mathrm{X} 14$ & Percent Hispanic & -0.06 & -0.06 & $-0.14^{*}$ & 0.01 & $-0.09 *$ & $-0.33^{*}$ & 1 & & \\
\hline $\mathrm{X} 15$ & Poverty Level & $0.16^{*}$ & 0.01 & -0.06 & $-0.15^{*}$ & $-0.20 *$ & $0.50 *$ & $0.18^{*}$ & 1 & \\
\hline X16 & Violent Crime Rate (log) & $0.28 *$ & 0.03 & 0.01 & -0.07 & -0.09 & $0.56^{*}$ & 0.01 & $0.68 *$ & 1 \\
\hline $\mathrm{X} 17$ & Police Density (log) & $0.18 *$ & 0.05 & $-0.11^{*}$ & $-0.15^{*}$ & $-0.13 *$ & $0.58 *$ & $-0.21^{*}$ & $0.51 *$ & $0.60 *$ \\
\hline X18 & Northeast & 0.03 & -0.00 & $-0.25^{*}$ & $-0.17^{*}$ & $-0.21 *$ & 0.00 & 0.09 & $0.12 *$ & 0.03 \\
\hline X19 & Midwest & $0.12 *$ & -0.01 & 0.04 & -0.03 & 0.03 & -0.01 & $-0.26^{*}$ & 0.04 & -0.04 \\
\hline $\mathrm{X} 20$ & South & $-0.17^{*}$ & -0.00 & $0.12^{*}$ & -0.04 & -0.04 & $0.38^{*}$ & $-0.11 *$ & 0.06 & $0.18 *$ \\
\hline $\mathrm{X} 21$ & West & $0.11^{*}$ & 0.02 & 0.04 & $0.21^{*}$ & $0.19^{*}$ & $-0.38 *$ & $0.25^{*}$ & $-0.24 *$ & $-0.19 *$ \\
\hline $\mathrm{X} 22$ & Force Estimate & -0.08 & 0.08 & $-0.11 *$ & -0.08 & -0.06 & 0.03 & -0.05 & -0.04 & -0.00 \\
\hline
\end{tabular}


Table 11

Continued

\begin{tabular}{l|lcccccc}
\hline \multicolumn{2}{c}{ FORCE AND ASSAULTS } & X17 & X18 & X19 & X20 & X21 & X22 \\
\hline X17 & Police Density (log) & $0.18^{*}$ & 0.05 & $-0.11^{*}$ & $-0.15^{*}$ & $-0.13^{*}$ & $0.58^{*}$ \\
X18 & Northeast & 0.03 & -0.00 & $-0.25^{*}$ & $-0.17^{*}$ & $-0.21^{*}$ & 0.00 \\
X19 & Midwest & $0.12^{*}$ & -0.01 & 0.04 & -0.03 & 0.03 & -0.01 \\
X20 & South & $-0.17^{*}$ & -0.00 & $0.12^{*}$ & -0.04 & -0.04 & $0.38^{*}$ \\
X21 & West & $0.11^{*}$ & 0.02 & 0.04 & $0.21^{*}$ & $0.19^{*}$ & $-0.38^{*}$ \\
X22 & Force Estimate & -0.08 & 0.08 & $-0.11^{*}$ & -0.08 & -0.06 & 0.03 \\
\hline
\end{tabular}




\section{Table 12}

Bivariate Correlations for Complaint Rate

\begin{tabular}{|c|c|c|c|c|c|c|c|c|c|c|}
\hline & COMPLAINTS & Y3 & $\mathrm{X} 1$ & $\mathrm{X} 2$ & $\mathrm{X} 3$ & $\mathrm{X} 4$ & $\mathrm{X} 5$ & X6 & $\mathrm{X} 7$ & $\mathrm{X} 8$ \\
\hline Y3 & Complaint Rate (log) & 1 & & & & & & & & \\
\hline $\mathrm{X} 1$ & Gender Representation & 0.03 & 1 & & & & & & & \\
\hline $\mathrm{X} 2$ & Minority Representation & 0.06 & $0.44^{*}$ & 1 & & & & & & \\
\hline $\mathrm{X} 3$ & Education Standards & 0.01 & $0.10^{*}$ & -0.05 & 1 & & & & & \\
\hline $\mathrm{X} 4$ & Hiring Standards & -0.03 & -0.00 & 0.03 & 0.06 & 1 & & & & \\
\hline $\mathrm{X} 5$ & Community Policing Training Recruits & 0.00 & $0.10 *$ & 0.02 & 0.04 & $0.13 *$ & 1 & & & \\
\hline X6 & Community Policing Training In-Service & -0.01 & 0.08 & 0.05 & 0.04 & $0.09 *$ & $0.23 *$ & 1 & & \\
\hline $\mathrm{X} 7$ & Formalization & 0.09 & $0.18 *$ & $0.19 *$ & -0.01 & $0.09 *$ & $0.18^{*}$ & 0.09 & 1 & \\
\hline $\mathrm{X} 8$ & Civilian Review Board & 0.09 & $0.25^{*}$ & $0.16^{*}$ & 0.03 & $0.16^{*}$ & 0.02 & -0.03 & $0.11 *$ & 1 \\
\hline X9 & Community Partnerships & 0.05 & 0.05 & 0.04 & 0.02 & $0.12 *$ & $0.10^{*}$ & $0.11 *$ & $0.10^{*}$ & 0.03 \\
\hline $\mathrm{X} 10$ & Beat Officers & 0.03 & $0.12 *$ & 0.03 & 0.03 & $0.14 *$ & $0.11 *$ & 0.07 & -0.01 & 0.00 \\
\hline $\mathrm{X} 11$ & SARA/Problem-Solving Officers (log) & $-0.12 *$ & 0.02 & -0.02 & 0.05 & $0.18 *$ & $0.26^{*}$ & $0.13 *$ & 0.01 & 0.04 \\
\hline $\mathrm{X} 12$ & Community-Technology Engagement & -0.01 & $0.25^{*}$ & $0.17 *$ & $0.22 *$ & $0.24 *$ & $0.16^{*}$ & $0.09 *$ & $0.24^{*}$ & $0.13^{*}$ \\
\hline $\mathrm{X} 13$ & Percent Black & $0.17^{*}$ & $0.39 *$ & $0.20^{*}$ & $-0.12^{*}$ & $-0.11 *$ & $0.14^{*}$ & -0.01 & $0.19 *$ & $0.14^{*}$ \\
\hline $\mathrm{X} 14$ & Percent Hispanic & 0.01 & $-0.22 *$ & $0.18^{*}$ & $-0.15^{*}$ & 0.06 & -0.08 & -0.05 & -0.03 & -0.10 \\
\hline $\mathrm{X} 15$ & Poverty Level & $0.23 *$ & 0.09 & $0.17^{*}$ & $-0.19^{*}$ & -0.07 & 0.03 & -0.01 & 0.02 & $0.16^{*}$ \\
\hline $\mathrm{X} 16$ & Violent Crime Rate (log) & $0.15^{*}$ & $0.22 *$ & $0.23 *$ & $-0.22 *$ & -0.07 & 0.09 & 0.03 & 0.07 & $0.28^{*}$ \\
\hline $\mathrm{X} 17$ & Police Density (log) & $0.15^{*}$ & $0.20 *$ & $0.20 *$ & $-0.13^{*}$ & $-0.18^{*}$ & $0.09 *$ & 0.02 & $0.18^{*}$ & $0.18^{*}$ \\
\hline $\mathrm{X} 18$ & Northeast & 0.10 & $-0.20 *$ & $-0.14^{*}$ & $-0.12^{*}$ & $-0.20 *$ & 0.02 & -0.07 & 0.03 & 0.03 \\
\hline $\mathrm{X} 19$ & Midwest & 0.04 & 0.02 & $-0.11^{*}$ & 0.09 & 0.00 & $-0.09 *$ & 0.03 & $-0.14^{*}$ & $0.11^{*}$ \\
\hline $\mathrm{X} 20$ & South & 0.03 & $0.21 *$ & $0.16^{*}$ & 0.04 & $-0.10^{*}$ & 0.06 & 0.04 & 0.08 & $-0.16^{*}$ \\
\hline $\mathrm{X} 21$ & West & $-0.15^{*}$ & -0.06 & 0.05 & -0.05 & $0.28 *$ & 0.00 & -0.03 & 0.05 & $0.10^{*}$ \\
\hline
\end{tabular}


Table 12

Continued

\begin{tabular}{|c|c|c|c|c|c|c|c|c|c|c|}
\hline & COMPLAINTS & X9 & $\mathrm{X} 10$ & $\mathrm{X} 11$ & $\mathrm{X} 12$ & $\mathrm{X} 13$ & $\mathrm{X} 14$ & $\mathrm{X} 15$ & $\mathrm{X} 16$ & $\mathrm{X} 17$ \\
\hline $\mathrm{X} 9$ & Community Partnerships & 1 & & & & & & & & \\
\hline $\mathrm{X} 10$ & Beat Officers & $0.20 *$ & 1 & & & & & & & \\
\hline $\mathrm{X} 11$ & SARA/Problem-Solving Officers (log) & $0.19 *$ & $0.30 *$ & 1 & & & & & & \\
\hline $\mathrm{X} 12$ & Community-Technology Engagement & $0.16^{*}$ & $0.22 *$ & $0.20^{*}$ & 1 & & & & & \\
\hline $\mathrm{X} 13$ & Percent Black & 0.02 & -0.02 & $-0.20^{*}$ & -0.01 & 1 & & & & \\
\hline $\mathrm{X} 14$ & Percent Hispanic & -0.02 & -0.04 & -0.01 & $-0.15^{*}$ & $-0.28 *$ & 1 & & & \\
\hline $\mathrm{X} 15$ & Poverty Level & 0.00 & 0.02 & $-0.15^{*}$ & $-0.15^{*}$ & $0.47 *$ & $0.26^{*}$ & 1 & & \\
\hline $\mathrm{X} 16$ & Violent Crime Rate (log) & 0.04 & 0.04 & -0.07 & -0.04 & $0.59 *$ & 0.02 & $0.66^{*}$ & 1 & \\
\hline $\mathrm{X} 17$ & Police Density (log) & $0.09 *$ & -0.04 & $-0.14^{*}$ & $-0.11 *$ & $0.63 *$ & $-0.19 *$ & $0.52 *$ & $0.58 *$ & 1 \\
\hline $\mathrm{X} 18$ & Northeast & 0.02 & $-0.21 *$ & $-0.16^{*}$ & $-0.29 *$ & 0.08 & 0.05 & $0.15^{*}$ & 0.03 & $0.30 *$ \\
\hline X19 & Midwest & -0.06 & -0.01 & -0.04 & $-0.10 *$ & 0.05 & $-0.26^{*}$ & 0.01 & -0.05 & -0.04 \\
\hline $\mathrm{X} 20$ & South & 0.00 & $0.10^{*}$ & -0.04 & $0.16^{*}$ & $0.35^{*}$ & -0.07 & $0.11^{*}$ & $0.19 *$ & $0.24 *$ \\
\hline $\mathrm{X} 21$ & West & -0.04 & 0.08 & $0.22 *$ & $0.13^{*}$ & $-0.40^{*}$ & $0.23 *$ & $-0.27^{*}$ & $-0.19 *$ & $-0.44 *$ \\
\hline
\end{tabular}

Table 12

Continued

\begin{tabular}{c|lcccc}
\hline \multicolumn{2}{c}{ COMPLAINTS } & X18 & X19 & X20 & X21 \\
\hline X18 & Northeast & 1 & & & \\
X19 & Midwest & $-0.18^{*}$ & 1 & & \\
X20 & South & $-0.32^{*}$ & $-0.34^{*}$ & 1 & \\
$\mathrm{X} 21$ & West & $-0.22^{*}$ & $-0.24^{*}$ & $-0.42 *$ & 1 \\
\hline Note. & p $<0.05$ & & & &
\end{tabular}


Table 13

Ordinary Least Squares Regression Results

\begin{tabular}{|c|c|c|c|c|c|c|}
\hline & \multicolumn{2}{|c|}{ (1) Force Rate (log) } & \multicolumn{2}{|c|}{ (2) Assault Rate (log) } & \multicolumn{2}{|c|}{ (3) Complaint Rate (log) } \\
\hline & $b(S E)$ & $\beta$ & $b(S E)$ & $\beta$ & $b(S E)$ & $\beta$ \\
\hline \multicolumn{7}{|l|}{ Community Policing } \\
\hline Community Partnerships & $-0.21(0.10)^{* *}$ & -0.11 & $-0.05(0.08)$ & -0.03 & $0.03(0.35)$ & 0.01 \\
\hline Problem-Solving Officers (log) & $0.04(0.03)$ & 0.07 & $0.04(0.03)$ & 0.08 & $-0.09(0.03)^{* * *}$ & -0.15 \\
\hline Community-Tech. Engagement & $0.00(0.01)$ & 0.01 & $0.01(0.01)$ & 0.03 & $-0.01(0.03)$ & -0.02 \\
\hline \multicolumn{7}{|l|}{ Professionalism } \\
\hline Education Standards & $0.03(0.10)$ & 0.02 & $-0.01(0.12)$ & -0.00 & $0.01(0.24)$ & 0.00 \\
\hline Hiring Standards & $-0.00(0.02)$ & -0.00 & $-0.04(0.03)$ & -0.10 & $-0.02(0.03)$ & -0.04 \\
\hline Comm. Pol. Training Recruits & $-0.04(0.10)$ & -0.02 & $0.19(0.12)$ & 0.10 & $0.11(0.22)$ & 0.04 \\
\hline Comm. Pol. Training In-Service & $0.12(0.09)$ & 0.06 & $-0.12(0.10)$ & -0.06 & $0.02(0.21)$ & 0.01 \\
\hline \multicolumn{7}{|l|}{ Passive Representation } \\
\hline Gender Representation & $-0.00(0.01)$ & -0.02 & $-0.02(0.01)$ & -0.08 & $-0.02(0.02)$ & -0.10 \\
\hline Minority Representation & $-0.71(0.18) * * *$ & -0.19 & $0.24(0.17)$ & 0.06 & $0.25(0.29)$ & 0.05 \\
\hline \multicolumn{7}{|l|}{ Control Mechanisms } \\
\hline Formalization & $-0.02(0.02)$ & -0.03 & $0.01(0.02)$ & 0.00 & $0.07(0.04)^{*}$ & 0.12 \\
\hline Civilian Review Board & $-0.20(0.16)$ & -0.09 & $-0.00(0.10)$ & -0.00 & $0.15(0.18)$ & 0.06 \\
\hline Percent Black (city) & $-0.00(0.01)$ & -0.09 & $-0.01(0.00)^{*}$ & -0.16 & $-0.00(0.01)$ & -0.02 \\
\hline Percent Hispanic (city) & $-0.01(0.00)^{*}$ & -0.11 & $0.00(0.00)$ & 0.05 & $0.00(0.00)$ & 0.00 \\
\hline Poverty (city) & $-0.00(0.01)$ & -0.01 & $-0.02(0.01)$ & -0.14 & $0.05(0.02)^{* * *}$ & 0.25 \\
\hline Violent Crime Rate (log) & $0.43(0.19)^{* *}$ & 0.32 & $0.67(0.11)^{* * *}$ & 0.52 & $-0.17(0.19)$ & -0.09 \\
\hline Police Density $(\log )$ & $0.65(0.23)^{* * *}$ & 0.25 & $-0.41(0.18)^{* *}$ & -0.16 & $0.23(0.39)$ & 0.07 \\
\hline Regional Fixed Effects & Yes & & Yes & & Yes & \\
\hline Force Estimate & $-0.00(0.09)$ & -0.00 & . & . & . & . \\
\hline Constant & $2.55(0.97)$ & . & $-0.52(0.61)$ & . & $0.97(1.26)$ & . \\
\hline F test & \multicolumn{2}{|c|}{$10.30^{* * *}$} & \multicolumn{2}{|c|}{$6.69 * * *$} & \multicolumn{2}{|c|}{$14.43 * * *$} \\
\hline R-squared & \multicolumn{2}{|c|}{0.23} & \multicolumn{2}{|c|}{0.22} & \multicolumn{2}{|c|}{0.13} \\
\hline Observations & \multicolumn{2}{|c|}{289} & \multicolumn{2}{|c|}{331} & \multicolumn{2}{|c|}{269} \\
\hline
\end{tabular}

Note. Entries are unstandardized coefficients $(b)$, standardized coefficients $(\beta)$, and robust standard errors in parentheses $(S E)$. $46-47$ state clusters across all models. $* * * p<0.01, * * p<0.05, * p<0.1$ 
Hypothesis 2, regarding the measures of professionalism in police departments, received no empirical support in the use of force model. In examining Hypothesis 3 , racial representation was negatively associated with a police departments' use of force rate. Thus, when the minority composition of the police department more accurately reflected the proportion of minorities in the community, police departments experienced lower use of force rates $(\beta=-0.19 ; p<0.01)$. Specifically, a one-unit increase in the minority representation ratio was associated with a $71 \%$ lower force rate compared to the average force rate of 159.9 use of force incidents per 100,000 population. ${ }^{30}$ Lastly, Hypothesis 4, regarding the control measures, was not empirically supported in the use of force model.

Several control variables were significantly associated with use of force rates as well. These included the percentage of the population served that was Hispanic $(\beta=-$ $0.11 ; p<0.10)$, the violent crime rate $(\beta=0.32 ; p<0.05)$, and the police density $(\beta=$ $0.25 ; p<0.01)$. Police departments serving cities with greater Hispanic populations had lower use of force rates; however, cities with higher violent crime rates and larger police densities had higher use of force rates, holding other variables constant.

Assault rate. In Model 2, the dependent variable of interest was the rate of assaults against officers aggregated for each police department. The results of the regression analysis indicated that the predictor variables explained about $22 \%$ of the variance $\left(R^{2}=0.22, F(20,46)=6.69, p<0.01\right)$. The $F$ test was statistically significant,

\footnotetext{
${ }^{30}$ This interpretation applies because the dependent variable is logged, and the independent variables is an interval variable, thus the log-level regression interpretation applies. Thus, if there is a change in the independent variable, $\mathrm{X}$, by 1 unit, then it is expected that the dependent variable, $\mathrm{Y}$, would change by $100 * b$ percent.
} 
showing adequate model fit. However, none of the variables measured under the four hypotheses concerning community policing, professionalism, passive representation, and control mechanisms found any support in the assault model.

Three control variables were correlated with the rate of assaulted officers. First, police departments that served cities with larger percentages of Blacks in the population were correlated with fewer officer assaults $(\beta=-0.16 ; p<0.10)$. Second, the violent crime rate of a city was positively correlated with assaults, indicating that cities with higher violent crime rates also had higher rates of assaults against officers $(\beta=0.52 ; p<$ $0.01)$. Lastly, the police density was negatively correlated with assaults assault rates $(\beta=$ $-0.16 ; p<0.05)$.

Citizen complaint rate. In Model 3 , the dependent variable was the police departments' rate of citizen complaints about officer use of force. The results of the regression indicated that the predictor variables explained about 13\% of the variance $\left(R^{2}\right.$ $=0.13, F(20,45)=14.43, p<0.01)$. Again, the $F$ test showed adequate model fit. In this model, only two of the main predictor variables appeared to be statistically significant. In testing Hypothesis 1, only one of the four indicator variables (the percent of problemsolving officers) demonstrated a statistically significant relationship with the complaint rate. Police departments that had a higher percent of problem-solving officers had fewer citizen complaints about officer use of force $(\beta=-0.15 ; p<0.01)$. Specifically, a $1 \%$ increase in the percentage of problem-solving officers was associated with a $0.09 \%$ lower average complaint rate (with the average being 9 complaints per 100 officers). Thus, while this variable was statistically significant, in regard to substantive significance a 
$100 \%$ increase in the percentage of problem-solving officers would be required to decrease the average complaint rate by $1 .{ }^{31}$

Neither Hypothesis 2 regarding professionalism nor Hypothesis 3 about passive representation received support in the complaint model. However, one of the indicator variables under Hypothesis 4 regarding control mechanisms was found to be a statistically significant correlate of citizen complaints. Police departments with more formalization (i.e., rules and policies limiting or directing police officer behavior) also had higher complaint rates $(\beta=0.07 ; p<0.10)$. Specifically, a one-unit change (an additional policy added) was associated with a $7 \%$ higher complaint rate. ${ }^{32}$ This relationship, although significant, was not in the hypothesized direction. Lastly, the level of poverty, a control variable, appeared to be significantly and positively associated with the complaint rate. Cities with greater percentages of families living below the poverty line had higher citizen complaint rates $(\beta=0.05 ; p<0.01)$.

In looking at all the models together, there were more statistically significant variables in Model 1 than in the other two models. However, the variance in Model 1 was only slightly higher than in Model 2, though none of the hypothesized variables were significant in Model $2 .{ }^{33}$ None of the hypothesized variables were consistently related to

\footnotetext{
${ }^{31}$ This interpretation applies because the dependent variable is logged and the independent variables is a logged interval variable, thus the log-log regression interpretation applies. Thus, if there is a change in the independent variable, $\mathrm{X}$, by one percent, then it is expected that the dependent variable, $\mathrm{Y}$, would change by $b$ percent.

${ }^{32}$ This interpretation applies because the dependent variable is logged and the independent variables is an interval variable, thus the log-level regression interpretation applies. Thus, if there is a change in the independent variable, $\mathrm{X}$, by 1 unit, then it is expected that the dependent variable, $\mathrm{Y}$, would change by $100 * b$ percent.

${ }^{33}$ In prior police organizational studies conducted on various police-citizen conflict outcomes, the variance explained ( $r$-squared levels) has ranged from a $0.15-0.21$. Thus, the $r$-squares reported here are around the
} 
more than one dependent variable (as shown when comparing across models). However, the "community policing" conceptual category had the most significant variables across all three models.

\section{Discussion}

With extensive focus placed on reforming police organizations, there is an underlying assumption that organizational elements impact policing outcomes. This chapter sought to understand the extent to which organizational characteristics and managerial strategies actually impact specific policing outcomes (i.e., police-citizen conflict). To do so, aggregate-level data was used for police departments with 100 or more full-time employees to test various hypotheses relating to the community policing paradigm and theories of administrative responsibility and accountability. Specifically, this chapter investigated whether community policing, professionalism, passive representation, and/or control mechanisms impacted the levels of tension between police departments and their respective cities. Negative correlations with the outcome measures were predicted for all of the hypothesized indicator variables. Three separate models were analyzed to understand these tensions between the police and the community. Tension between the police and the community was measured using three outcome variables: (a) violence towards the police, (b) police use of force, and (c) citizen complaints.

same range, if not slightly higher (see for instance Alpert \& MacDonald, 2001; Hickman \& Piquero, 2009; Shjarback \& White, 2016; Wilson \& Zhao, 2008). 
The Community Policing (CP) model puts citizens at the center of policing, with a keen focus on serving the public interest, gathering citizen input, and encouraging citizen participation and collaboration. $\mathrm{CP}$ argues that by refocusing on citizens, a more effective administration of police services and better police outcomes will result. $\mathrm{CP}$ is in alignment with many public administration paradigms, such as the New Public Service's focus on developing solutions with and from the grassroots level. Under CP, a negative correlation between community policing ideals and police-citizen conflict was predicted. The findings only partially supported this hypothesis. Across all of the models, four indicators of community policing were included - community partnerships, beat officers, problem-solving officer, and community-technology engagement. CP indicators better explained the use of force rate, in comparison to the assault rate and citizen complaint rate. Yet, even in the force model, only two of the four $\mathrm{CP}$ variables were significant and consistent with the hypothesis. There were no CP variables significant in the assault model and only one in the complaint model.

In the force model, police departments with formal community partnerships were negatively correlated with use of force rates. Partnerships with the community are a direct indication of collaboration efforts. Also, partnerships can serve as external accountability mechanisms for the police department seeing as this type of community policing effort has actually involved community members. The percentage of officers responsible for patrolling the same specific geographic area, locale, or beat was negatively correlated with the use of force rate. Neither the percentage of problem-solving officers on the police force nor the level of community engagement via technology were statistically significant predictors of force. The lack of significant findings for these two latter 
variables on the use of force rate across police departments demonstrated that either (a) not all community policing strategies are important or (b) the impact of such strategies is relative.

None of the community policing variables included in this analysis were significant predictors of the assault rate. This finding illustrates that the level of community policing (as operationalized here) at which a police department engages in does not necessarily lead to better outcomes in terms of officer safety. This is in alignment with the majority of research conducted prior (see Barrick et al., 2014; Ozkan et al., 2016; Shjarback \& White, 2015; Willits, 2014). In the complaint model, the percentage of officers dedicated to problem-solving activities was found to be negatively correlated with the citizen complaint rate. Police departments with a higher percent of officers dedicated to problem solving were correlated with fewer citizen complaints per 100 officers (a statistically significant impact); however, in terms of actual substantive significance, this impact was minimal. The remaining CP variables-community partnerships, beat officers, and community-technology engagement-had no impact on police departments' citizen complaint rates. These findings add to the two studies conducted on the aggregate impacts of community policing on complaints, one of which found no impacts (Shjarback \& White, 2015) and the other which found a positive effect of community policing on sustained complaints (Smith \& Holmes, 2014).

Overall, the lack of consistency across significant community policing variables may lend support to the narrative that community policing mechanisms need to be deeply embedded throughout an entire police department if they are to have the intended impacts (Radelet \& Carter, 1994; Skolnick \& Bayley, 1986; Smith \& Holmes, 2014). Further, 
seeing as only some of the community policing indicators were significant correlates, it is apparent that not all community policing strategies are effective in reducing policecitizen conflict. The findings on community policing were mixed and did not provide consistent support for the hypotheses across the three models. Including four different indicators of community policing in all three models demonstrated that certain strategies impacted only specific outcomes. This result begs the question: why do community partnerships, for instance, impact use of force but not assaults or complaints? While this question needs further exploration, one potential explanation could be that the people assaulting or complaining may not be the ones engaging in partnerships, or they may not have any knowledge of the partnerships for it to impact their behavior. However, community partnerships directly engage the police department and can affect officer behavior because of the accountability mechanisms at work.

Administrative responsibility, including both objective and subjective responsibility, was hypothesized as a way to impact bureaucratic discretion. Subjective responsibility focused on the bureaucrat's internal ability to effectively respond to and address the needs of the citizenry. It was argued that bureaucrats need discretion, and that if provided with the right tools such as education and training, they could remain responsible to the people they serve. Professionalism and passive representation both fell under subjective responsibility and were hypothesized to have negative relationships with police-citizen conflict. None of the four professionalism indicators were found to be significantly correlated with the levels of assaults, force, or complaint rates. Prior research has been mixed on the impacts of education requirements, hiring standards, and training on impacting outcomes (see Cao et al., 2000; Fridell et al., 2009; Ozkan et al., 
2016; Shjarback \& White, 2015; Smith, 2004; Willits, 2014; Willits \& Nowacki, 2014).

These findings add support to prior null findings, which show that these organizational factors do not impact police-citizen conflict outcomes.

One passive representation indicator was found to be correlated with only one of the three outcome measures. This negative correlation between minority representation and use of force partially supported the passive representation hypothesis. The directionality of this finding (i.e., negative association) is in alignment with prior research that has suggested that there are benefits to having minority representation on the police force. For instance, Willits and Nowacki (2014), found negative correlations between minority representation and deadly force. However, the majority of other scholars have also found similar benefits to minority representation on citizen complaint outcomes (see Hong, 2017; Smith \& Holmes, 2014; Trochmann \& Gover, 2016). Thus, the null findings in the complaint model are contrary to what other research has found. In regard to assaults, prior research has either found null effects (Ozkan et al., 2016; Wilson \& Zhao, 2008) or positive associations (Barrick et al., 2014). Therefore, the lack of findings in the assault model are consistent with the null findings from other studies.

Nevertheless, the causal mechanisms undergirding force and minority representation could be attributed to a variety of things. For instance, some scholars have suggested that increasing racial minorities on a police force improves the overall integrity of a police department (Hong, 2017). Other scholars have asserted that representation is important as it may impact the individual officer's behavior and allow them to better serve the public (Gilliard-Matthews, Kowalski, \& Lundman, 2008), which could translate into using less force. While not enough evidence is available to show the individual 
impacts of race during police-citizen interactions, these aggregate-level findings do hold important implications for human resources, hiring opportunities, and police use of force. However, the lack of support for racial representation impacting citizen behavior (as measured by assaults against officers and citizen complaints) may support the belief that representation only provides face value to the public; whereas, the actions and behaviors of police officers matter more for the public than does the racial makeup of the police department.

Gender representation on the police force had no impact across any of the three models. Some research has found that at the individual officer-level females receive fewer citizen complaints and engage less in use of force incidents (Brandl et al., 2001, Spillar et al., 2000). On the contrary, other research found that gender representation was associated with more complaints (Schuck \& Rabe-Hemp, 2014) or had no impact at all on complaints and assaults against officers (Ozkan et al., 2016; Shjarback \& White, 2015). Thus, the findings of this research add to the body of literature suggesting null impacts of officer gender at the aggregate level. The average proportion of women on the police force was between 11 and 12 percent. While the undergirding hypothesis alluded to women officer policing differently than men, the null findings may indicate that policing behaviors by officers does not vary by gender. Alternatively, it may be that a critical mass of women represented on the police force would be necessary to have a substantial impact (for further discussion on the notions of gender and critical mass see Keiser, Wilkins, Meier, \& Holland, 2002).

Objective responsibility focuses on how to control potential abuses of discretionary power through formal and/or external systems, with the impression that 
bureaucrats are self-interested and need to be constantly checked and managed. As a measure of objective responsibility, two indicators of control mechanism were included in each of the models (the level of formalization and the presence of a civilian review board). Formalization was found to be positively correlated with the citizen complaint rate. This finding is contrary to the hypothesized direction and suggests that increases in policies that guide and/or restrict bureaucrat behavior are associated with more, rather than fewer, complaints. However, it does confirm findings of prior studies that demonstrated a positive association between the number of policies and the level of citizen complaints (see Hickman \& Piquero, 2009; Schuck \& Rabe-Hemp, 2014). Perhaps more formalized police departments have better processes for receiving citizen complaints, thus making it easier for citizens to complain, which is why those departments have higher rates of complaints. Otherwise, it is hard to imagine that good practices on the part of police departments (i.e., more formalization) lead to worse outcomes (i.e., more complaints). However, another explanation for this phenomenon may be that poor performance (in terms of higher levels of citizen complaints) was what led to more formalized practices in the first place, as an effort to improve officer behavior and thus curb complaints. Formalization was not found to be a significant correlate for assaults against officers or police use of force.

There were null findings exhibited for the presence of civilian review boards in all three of the models. Only two prior studies have found aggregate level impacts of civilian review boards, both of which showed positive associations when assessing citizen complaints as the outcome measure (Cao et al., 2000; Smith \& Holmes, 2003). The majority of other studies found null effects for the impact of civilian review boards on 
use of force outcomes (Willits \& Nowacki, 2014), complaints (Hickman \& Piquero, 2009; Smith \& Holmes, 2014), and assaults (Willits, 2014). These null findings may suggest that formal and external mechanisms designed to check behavior only provide a way to handle police-citizen conflict situations as they arise, but do not prevent conflict from occurring.

The majority of null findings for the organizational indicators included in the model coupled with the low model fit statistics (as evidenced by the $r^{2}$ ) suggests that as a whole organizational and/or managerial elements of police departments neither significantly nor substantially matter in impacting police-citizen conflict. Rather it is very specific organizational characteristics and managerial strategies that have direct impacts on very specific outcomes. When assessed as a whole, none of the hypotheses could be sufficiently confirmed with the results herein. One of the potential complexities may be due to the translation of organizational imperatives and/or policies down to the front-line officers on the streets providing services to the public. In 1980, Lipsky's street-level bureaucracy sought to explain the actions of front-line public administrators charged with implementing policy directives. Lipsky discussed the bureaucrat's need for discretion to effectively respond to service demands, which provided a framework to understand why bureaucrats may or may not deviate from policy in order to respond to client demands. Lipsky's theory essentially argued that these front-line public servants become policymakers as they interpret and implement policy on the ground.

While this research was focused on the organizational and managerial aspects of police departments used to impact outcomes, the lack of sufficient substantive findings for organizational impacts herein may allude to the need to understand ground-level 
implementation as observed by the behavior of police officers on the front lines at the street-level. A department may have rigid policies in place to constrain problematic bureaucrat behavior or it may have policy incentives to promote positive behavior (e.g., community responsiveness); however, the way a policy is interpreted and/or implemented matters just as much as - if not more than — the presence of the policy itself. For instance, Erasmus (n.d.) noted that

street-level bureaucrats may be in conflict with, or have perspectives that differ from, other groups in the organization such as their managers. They may be able to resist organizational expectations.... Their actions and decisions may not always conform to policy directives and so their agencies could end up performing contrary to their stated policies, intentions or goals. (p. 1)

Thus, a policy that is in place to professionalize the police force, empower them to make the right decisions, and/or train them according to professional standards may not have the intended outcomes if the street-level bureaucrats are behaving in ways that contradict what the organization intended. This research was not designed to assess individual-level behaviors and thus could not parse out street-level implementation of policies. Nonetheless, these findings illustrate the importance of such implementation research while adding to the literature that explores organizational and managerial correlates of police-citizen conflict outcomes. The findings also reveal the complex nature of police departments and the competing organizational and managerial strategies that exist.

\section{Conclusion}

Taken together, these findings build upon the organizational research done in policing by demonstrating that the organization, as a whole, matters less than expected. 
This research points to the need to explore other factors that may better explain policecitizen conflict. The limited significant findings herein demonstrate that the impact of organizational factors on police-community relations is conditional on the outcome being measured. In practice, organizational reforms have typically been suggested as a way to alleviate "tensions" or "problems" overall, rather than being advocated for having impacts on specific individual outcomes in particular. This advocacy practice has posed problems in terms of assessment and evaluation, where organizational strategies or programs are deemed unsuccessful for not having impacted outcomes that they may never have been able to impact. Thus, it is necessary to reduce reliance on the organization alone as the solution to problematic police-community relations. Moreover, the lack of organizational correlates found to consistently impact all of the three indicators of police-citizen conflict illustrates the need for organizational strategies, when effective, to be tailored to and evaluated on specific intended outcomes rather than implemented as blanket solutions.

Limitations and future research. While this research has allowed for a greater understanding of the organizational factors that impact police-citizen conflict, it is not without limitations. First, this chapter has assessed police-community relations by using three indicators of police-citizen conflict. Police-citizen conflict is only one facet of police-community relations, and as such, it should be interpreted with caution. Future research must identify and operationalize positive measures of police-community relations, including but not limited to levels of police legitimacy, cooperation, collaboration, accountability, and mutual trust and confidence. As was once stated by Martin Luther King Jr., "true peace is not merely the absence of tension: it is the presence 
of justice." Thus, measuring conflict or tension alone does not suffice to truly understand the dynamic and complex relationship between police and communities.

Second, one of the major limitations of the analysis included the issue of reverse causality, which can lead to endogeneity problems. Endogeneity occurs when an independent variable, $\mathrm{X}$, correlates with the error term. Of the variables that were found to be statistically significant, formalization was positively correlated the complaint rate of police departments, which was in the opposite direction of what was initially hypothesized. While there are other possibilities (discussed above) that may be occurring within more formalized departments to explain higher rates of complaints, not enough information was available to rule out reverse causality as an alternative explanation. However, it is important to note that the effect of certain strategies can only be seen after a substantial amount of time has passed. Thus, longitudinal data would help to understand when effects are seen and at what point such effects occurred, rather than merely comparing across police departments without accounting for when the strategies were implemented.

Third, this chapter focused solely on city police departments with 100 or more full-time sworn employees. The findings of this chapter may not necessarily be generalizable to smaller police departments. Future studies should consider the differences between police departments with smaller or larger organizational sizes, as well as differences specific to county versus city police departments. Fourth, a host of secondary data was used to create a comprehensive dataset, which led to loss of sample size due to data availability issues across the various sources. Using secondary data reported directly from the police department had limitations as it pertained to potential 
reporting biases (whether it be under- or over-reporting) as well. Another limitation was the use of LEMAS data as it pertained to questions that survey respondents chose not to answer. In such cases, the LEMAS dataset imputed the averages of other responses. Thus, for this research, these averages were removed and replaced as missing data (which again limited the sample size). Further, due to the unit of analysis being at the city level, this chapter masked important neighborhood-level variations that occurred within cities.

Lastly, the dataset used did not provide enough in-depth information to fully understand how and when the organizational mechanisms were implemented. Identifying the process by which organizational strategies are implemented can provide a better understanding as to why a certain strategy does or does not work. Qualitative research is needed to delineate how and why organizational factors may or may not matter in terms of impacting police-citizen conflict. The qualitative case study (Chapter 4) conducted to supplement this chapter can provide more insights on causality (as well as the lack thereof).

Despite the limitations, the current chapter advances the understanding of the impact (and lack thereof) of organizational characteristics on police-citizen conflict specifically, and police-community relations generally. This chapter also provides a base for the qualitative component of this research to build upon and suggests numerous opportunities for future research. There are four primary areas for future research to explore. First, longitudinal studies conducted across multiple police departments can (a) provide more robust findings, (b) understand time-order effects, and (c) deal with issues of endogeneity. Second, future research should also reconcile larger organizational theories with implementation theories such as street-level bureaucracy in order to explore 
the ways in which these theories work together and/or conflict to impact organizational outcomes. Specifically, studying the individual level in addition to the organizational level may provide fruitful insights into the intricacies of police-citizen conflict.

Third, scholars may consider other organizational measures that capture a more nuanced understanding of the four conceptual categories included herein. However, attention may be better focused at understanding dynamics outside of the organization that can impact police-citizen conflict. Determining why officer assaults, police use of force, and citizen complaints are occurring in the first place can provide a better understanding as to how to prevent these actions in the future. Lastly, not only is in-depth qualitative research needed to understand the intricacies of organizational and managerial characteristics, but also it can help to uncover neighborhood variations of police-citizen conflict within cities.

Implications. The findings of this analysis have implications for both research and practice. In terms of research, the findings have implications for the operationalization of the key dependent variables. Scholars have often measured police use of force via citizen complaints about use of force, which has been acknowledged as an underreported measure (see Shjarback \& White, 2015; Smith \& Holmes, 2003; however, see Hickman \& Poore, 2016 for a discussion of the limitations of citizen complaint data). When comparing the use of force (self-reported) model and the citizen complaint (about use of force) model, the organizational factors that impact the two outcomes varied significantly. This disparity poses questions concerning the reliability of using citizen complaints about use of force as an appropriate measure or indicator of actual use of force. If citizen complaints about use of force served as a reliable proxy for 
use of force, it would be expected that the significant correlates would also be the same across the two models. However, the lack of consistent predictors across these models demonstrate that these dependent variables measure very different things and thus cannot be easily interchanged. Rather, the rate of citizen complaints about use of force may more accurately display citizen dissatisfaction or citizen engagement in the accountability process. If this is the case, there may have been other convoluting factors that have nothing to do with actual force levels, yet that impact citizen complaints — such as the length of the complaint process or accessibility in terms of the reporting mechanisms and locations to file complaints. Thus, a more accurate way to measure use of force is utilizing the actual officer reports of force provided by police departments. ${ }^{34}$

The practical implications of this research are limited since many of the organizational factors that were hypothesized to impact police-citizen conflict did not emerge as significant correlates. Nonetheless, from the organizational variables that did yield significant findings, police departments seeking to curb use of force levels should consider engaging in community partnerships, having officers assigned to patrolling specific geographic locations, and hiring and/or retaining more minority officers (particularly in consideration to the proportion of racial minorities in the city being served). It appears that these organizational and managerial characteristics are necessary for impacting the use of force rates of police departments. Lastly, police departments that are working to lower their number of citizen complaints should consider having police

\footnotetext{
${ }^{34}$ There are still problems using the overall use of force measure provided by LEMAS because it reports the total number of use of force incidents for the year per each police department. There is not additional information provided in regards to how the police department measures use of force in terms of what constitutes force by an officer.
} 
officers who are dedicated to problem-solving activities rather than merely patrolling and responding to calls for service. Problem-solving officers work collaboratively with the community to solve issues that are identified as important by the community such as quality of life issues (e.g., blight, littering, or noise complaints).

The final and arguably most important implication of this research pertains to policy platforms that have suggested that organizational reforms are the solution to police-citizen conflict and could improve police-community relations. This research has shown that, when taken as a whole, the organizational characteristics measured herein cannot suffice to measure all of the variation in the police-citizen conflict outcomes of use of force, citizen complaints, and assaults against law enforcement. Thus, merely proposing policy to fix the operations and/or practice of police departments (for instance, the recent suggestion of body-worn cameras) may not be fruitful in the long run without also paying attention to implementation and enforcement. 


\section{CHAPTER 4}

\section{Why and How: Untangling the Causal Mechanisms Undergirding Organizational and Managerial Factors and Police-Community Relations}

The current state of police-community relations in the United States has been debated and often questioned. There have been various instances brought to light about the reciprocal violence between police and the communities they serve- - with attention devoted to communities of color. On one hand, there have been key incidents of excessive use of force by police officer against various communities. On the other hand, there have been assaults against police officers by the public. Despite the frequency of these type of events, their mere occurrence has posed an even greater strain on the relationships between the police and the community. These events have sparked movements, demonstrations, and protests (e.g., Black Lives Matter and Blue Lives Matter), which have echoed for policy proposals and/or reforms that would impact the relationships between the police and the community.

The literature has attempted to identify the types of police reforms that can improve various police-community outcomes by applying organizational and institutional perspectives to policing. Researchers have investigated which organizational factors are important influences on outcomes such as police use of force, citizen complaints, assaults against police, arrests, and others (e.g., Chappell et al., 2006; Hickman \& Piquero, 2009; Shjarback \& White, 2015; Willits \& Nowacki, 2014). For instance, numerous calls have been made for increased minority representation on police forces as a potential solution to strained relations. Empirical investigations have shown that police departments that 
exhibit aggregate increases in minority representation also see decreases in citizen complaints (Hong, 2017; Smith \& Holmes, 2004) as well as reductions in crime (Hong, 2016). However, other research has not displayed such positive impacts, and instead have suggested that a critical mass of racial minorities on the police force may be necessary to result in these benefits (Nicholson-Crotty, Nicholson-Crotty, \& Fernandez, 2017). Similarly, support is mixed for the impact of civilian review boards on various policing outcomes (Cao et al., 2000; Hickman \& Piquero, 2009; Smith \& Holmes, 2014; Willits \& Nowacki, 2014; Willits, 2014). Although much work remains in order to concretely identify which organizational factors matter for which policing outcomes, scholars continue to make attempts towards advancing this quantitative body of literature.

Alternatively, the literature has not advanced much in detailing why and how certain organizational and managerial factors impact police-community relations. Rather, much of the literature that assesses the impact of organizational practices of police departments on policing outcomes has been quantitative in nature (e.g., Crank, 1990b; Eitle et al., 2014; Nicholson-Crotty \& O'Toole, 2004). Scholars have consistently relied on hypothesized relationships rather than actually advancing theoretical frameworks and/or adding to the understanding of causal mechanisms. In order to fully explain the patterns exhibited between organizational practices and managerial strategies, on one end, and police-community relations, on the other end, qualitative research methods are needed. The limited qualitative literature that does exist has not explored the key question of interest herein (e.g., Carr, Napolitano, \& Keating, 2007; Willis, Mastrofski, \& Weisburd, 2007; and Nordberg, Crawford, Praetorius, \& Hatcher, 2016). This lack of qualitative exploration hampers the ability to make effective policies that promote 
positive police-community relations and limit police-citizen conflict. Finally, qualitative research can help to shed light on the preexisting quantitative research by providing a context for understanding why certain patterns may or may not be exhibited in analyses of secondary data.

This chapter contributes to the literature by providing a comprehensive examination and nuanced understanding of police-community relations in a disadvantaged, underserved, inner-city area in the northeastern United States. Specifically, it investigates first-hand perspectives from police and community representatives regarding why and how police organizational factors impact relationships with the community. Given the limited knowledge on how and why organizational factors impact relations, this research design—which included in-depth interviews, participant observations, and a review of secondary sources - was necessary to identify undergirding theoretical relationships. The findings revealed that the relationship between police and the community is impacted by soft skills, human resources, and intentional engagement. There were two primary means by which these factors impacted policecommunity relations. First, these factors either impacted officers directly (e.g., officer attitudes, behavior, and/or treatment) or impacted the level and/or quality of service that officers provided to the community. Both of these mechanisms impacted community attitudes and perceptions. The implications of this research for organizational behavior, public management, and the field and practice of policing are discussed.

The remaining sections of this chapter proceed with a literature review of policing from an organizational perspective, and then expound on the importance of qualitative research in understanding police-community relations. Qualitative research methods were 
utilized in order to address the gap in the literature on understanding how and why organizational factors impact police-community relations. Specifically, a case study of police-community relations in the city of Hartford, Connecticut was conducted. The case study encompassed semi-structured interviews, participant observations, and a review of secondary sources. The findings from the content analysis were broken down into subcategories. First, attention was devoted to understanding police-community relations in Hartford. Then, the three main categories of factors that impact police-community relations were discussed: soft skills, human resources, and intentional engagement. The chapter closes with a discussion of the importance of understanding the causal mechanisms operating between organizational and managerial characteristics and policecommunity relations.

\section{Literature Review}

The organization and policing. Scholars have studied the impact of organizational characteristics on specific policing outcomes such as arrest rates, clearance rates, use of force, and citizen complaints. However, this literature has not made much progress in providing an in-depth explanation of the impact of the organization on the performance of police (Maguire, 2009). The majority of the literature that has used an organizational approach to study police departments has relied on traditional quantitative analyses in order to merely identify the factors and/or strategies employed by police departments that impact their outcomes (see Alpert \& MacDonald, 2001; Chappell et al., 2006; Eitle et al., 2014; Eitle et al., 2005; Hickman \& Piquero, 2009; Maguire, 2009; Mastrofski, 2004). Thus, research conducted to date has demonstrated which factors are correlated with various police-community outcomes, such as police use of force (e.g., 
Nowacki, 2015), assaults against law enforcement (e.g., Ozkan et al., 2016), citizen complaints (e.g., Smith \& Holmes, 2014), crime rates (e.g., Hur, 2013), arrests (e.g., Eitle \& Monahan, 2009), and police misconduct (e.g., Eitle et al., 2014). However, this body of knowledge has adequately revealed neither the underlying reasons why organizational reforms and/or managerial strategies have the impact they do (as demonstrated by the quantitative analyses), nor explanations for how such impacts happen. Rather, theories have only been offered as potential explanations for understanding the relationships being exhibited. In order to adequately address the why and how questions and to arrive at theoretical explanations, other types of research apart from quantitative research is needed, such as in-depth qualitative research or mixed methods experimental research.

Qualitative research and police-community relations. Qualitative studies in policing provide a rich understanding of the complexities and nature of police work. However, given that police systems are often recognized as closed systems, there are barriers to access that can complicate the research at multiple levels. Nonetheless, research dating back to the late 1960s and early 1970s included ethnographic monographs that took an organizational focus on police departments (e.g., Lambert, 1970; Reiss, 1971; Toch et al., 1975; Wilson, 1968). The importance of qualitative methods cannot be overstated as police scholars have continued to suggest the necessity of such methods to advance policing research. For instance, in examining assaults on police officers, Willits (2014) noted the need for qualitative research and case studies in order to provide insight on linking organizational structure to practices. In assessing citizen perspectives, Brunson and Weitzer (2009) stated that qualitative research allows us "to document complex and 
nuanced citizen understandings of police practices" (p. 861). However, the need and demand for such research has not yet been met.

A majority of the qualitative research that does exist that examines policecommunity relations has focused either (a) on specific types of qualitative data retrieval, such as interviews (Brunson et al., 2013; Oliva \& Compton, 2010; Weitzer, 2000) and observations (Conti \& Doreian, 2014; Wood, Sorg, Groff, Ratcliffe, \& Taylor, 2011), or (b) on administrative data ${ }^{35}$ such as internal use of force reports (e.g., Atherley \& Hickman, 2014). There has been less empirical research that has combined multiple methods into a single analysis (with the exceptions of Bordua \& Tift, 1971; Brunson \& Weitzer, 2009; Chappell, 2009; Engel \& Worden, 2003; Gundhus, 2012; Haarr, 1997; Katz, 2001; Porter, 2016). Using multiple qualitative methods is essential to triangulate data and improve credibility and confirmability. However, only three of the aforementioned studies employed more than two types of qualitative methods (Gundhus, 2012; Katz, 2001; Porter, 2016). Thus, this research includes multiple forms of qualitative methods, including in-depth interviews, participant observations, and an analysis of secondary data sources.

Due to the abstract conceptualization of the term "police-community relations," scholars have typically focused on a specific and diverse set of outcomes and/or behaviors in order to understand the concept. For instance, a large portion of research examining police-community relations has focused on the perceptions and/or attitudes of officers (e.g., Wooden \& Rogers, 2014), community members (e.g., Weitzer, 2000),

\footnotetext{
${ }^{35}$ It is important to note that administrative data is often limited when trying to get at underlying causal mechanisms and build theory.
} 
and/or youth (e.g., Brunson \& Weitzer, 2009). Also, qualitative research has typically assessed specific topics and/or issues pertinent to police-community relations rather than investigating the myriad of organizational influences. For instance, some specific topics explored in the literature to date include community policing (e.g., Chappell, 2009), use of force (e.g., Paoline \& Terrill, 2011), citizen demeanor (e.g., Dunham \& Alpert, 2009), race and/or ethnicity (e.g., Conti \& Doreian, 2014), crisis intervention teams (e.g., Hanafi et al., 2008), collaboration and partnerships (e.g., Brunson et al., 2013), and procedural justice (e.g., Elliott, Thomas, \& Ogloff, 2011). Concentrating on specific aspects of police-community relations, such as community policing or partnerships, does provide a thorough understanding of the topic under investigation. However, any results may also neglect the fact that police strategies are not implemented in a vacuum. There are often multiple strategies being deployed and organizational factors at play that are operating simultaneously, impacting each other as well as police-community outcomes.

Further, a substantial portion of the qualitative research exploring policecommunity relations has taken an international perspective, focusing on contexts outside of the United States (see Belur, 2010; Cashmore, 2001; Gundhus, 2012; Kiely \& Peek, 2002; Meredyth, McKernan, \& Evans, 2010; Porter, 2016; Rhodes et al., 2006; Wooden \& Rogers, 2014). ${ }^{36}$ Qualitative research, in and of itself, already poses difficulties for generalizability because it is often localized and context-specific research. While international research is critical for theory building and comparative analyses, these

\footnotetext{
${ }^{36}$ Belur (2010): Mumbai, India; Cashmore (2001): Britain; Gundhus (2012): Norway; Kiely \& Peek (2002): British Police; Meredyth, McKernan \& Evans (2010): Australia; Porter (2016): New South Wales, Australia; Rhodes et al. (2006): Russia; Wooden \& Rogers (2014): Sydney, Australia.
} 
studies have often not been comparative and thus trying to account for differences between countries only increases the complexities associated with generalizability. The United States has a unique history of police and community relations that is fraught with strife and conflict, dating back to slavery and the inception of the nation. Thus, the diverse cross-country contexts in the aforementioned studies may pose challenges for interpretation as well as for implications for practice and policy.

Filling the gap. Understanding why and how organizational factors generally impact police-community relations has not yet been explored. While some of the aforementioned studies have touched on key organizational elements of policecommunity relations (e.g., community policing, collaboration, and organizational change), these studies have not explicitly addressed why and/or how such elements impact various police-community outcomes. One exception is Katz's (2001) examination of the establishment of a police gang unit and the factors that shaped the gang unit's response to community problems. Katz (2001) addressed the "why" question. However, his analysis was focused on special gang units and their activities, which is only one aspect of police-community relations.

The present research adds to the literature in numerous ways. First, this research examined multiple managerial strategies and organizational factors employed in police departments such as communication, character, manpower, training, collaboration, engagement, and accountability. Including all of these factors provided a more in-depth understanding of the broader police organizational context and allow for an assessment of their relative importance. Second, both law enforcement and community perspectives were included in one study, whereas the majority of prior research (with very few 
exceptions) has focused primarily on the perspectives of only one group. Including perceptions of both the police and community allowed for direct comparisons and a holistic understanding of similarities and differences between the various perspectives. Third, it assessed police-community relations more generally by providing the respondents with the opportunity to define police-community relations rather than limiting the scope to certain factors or specific outcomes like use of force or community policing. Lastly, and most critically, it attempted to get at the "why" and the "how" questions to understand the causalities undergirding the relationships between organizational and managerial strategies and police-community relations. Taken as a whole, this research adds to the emerging body of knowledge to more accurately understand the dynamics of police-community relations. This study can also add to theory building for future research.

\section{Research Methodology}

The drive for methodological choices was predicated on the research questions being asked. Qualitative methods are essential for exploring questions about processes, experiences, history, and context as well as thoroughly explaining underlying causal mechanisms (Mack, Woodsong, MacQueen, Guest, \& Namey, 2005; Morgan \& Smircich, 1980). Qualitative inquiry allows scholars to examine real-world settings and produce rich, vivid, detailed descriptions (Marshall \& Rossman, 2014; Patton, 2005). Thus, qualitative exploration digs deep into complexities and nuances in order to provide explanations that better explicate behavioral phenomena. Given the nature of the research question under examination in this chapter, which sought to identify the reasons and 
processes by which organizational and managerial factors impact police-community relations, qualitative research methodologies were deemed appropriate (Creswell, 2013).

This chapter elaborates on an explanatory case study of police-community relations in a given city. Case studies are conducive to "collect descriptive data through intensive examination... and can be used to fill in the gaps in existing theories" as well as understand "rare or complex phenomena" (Boodhoo \& Purmessur, 2009, p. 5). Specifically, in organizational research, case studies may provide insight into the ways and manners in which events or behaviors occur in practice, and as such are more relevant to administrators (Silverman, 2007). Explanatory case studies aim to specifically address "how" and/or "why" questions, thereby providing the reasons associated with the occurrences of phenomena (Yin, 2009). Thus, the case study approach is the most beneficial qualitative research method to address the research question under investigation and achieve three goals. First, to identify the underlying causal mechanisms between organizational factors and police-community relations. Second, to better capture the relationship between police departments and the communities they serve. Lastly, to contribute to theoretical understandings of police organizations and community relations.

Case study selection. A unique case study site was identified using several criteria. First, the initial sample of police departments included all departments listed in the 2013 Law Enforcement Management and Administrative Statistics (LEMAS) survey and those that had data available on the following outcomes: police use of force, citizen 
complaints, citizen assaults against law enforcement, and police killings of citizens. ${ }^{37}$ Based on the data available, a police-citizen conflict index was created to identify police departments categorized as extreme cases (the highest—i.e., worst—ranked departments on the index). Second, it was important that police departments served diverse cities in order to identify potential group-level differences within a city. Thus, the sample was restricted to only those police departments that served a city with $30 \%$ or more of its population identifying as Black and/or Hispanic. The 30\% threshold served as a more conservative measure to that of a majority-minority city. The ethnic composition of the city was an important criteria because of the historical relationships between police and marginalized communities, which date back to the inception of policing and include issues of oppression, discrimination, and brutality. In understanding these issues within marginalized communities, most scholars have given significant attention to Black communities. However, more recently, issues within Hispanic communities have begun to surface as well (Weitzer, 2014). While the premise of this study did not solely rest on the relationships between police and racially minoritized communities, this study did explore the impacts of ethnic and/or racial composition on police-community relations.

Third, only police departments that served a population of 100,000 or larger were included in the sample in order to increase the probability of adequate neighborhood variations within the city. ${ }^{38}$ Lastly, after identifying the three cities with the highest levels

\footnotetext{
${ }^{37}$ These outcomes were captured by combining data from the following sources: Law Enforcement Management and Administrative Statistics, Law Enforcement Officers Killed and Assaulted, and the Fatal Encounters databases.

${ }^{38}$ Data for the racially minoritized population and population size was gathered from the 2013 American Community Survey Population Estimates.
} 
of police-citizen conflict, a brief news search was conducted to identify historical as well as recent incidents that may have impacted police-community relations for each of the cities. This latter step was important for two reasons. First, identifying police departments with in-depth histories around police-community relations can provide a richer analysis and detail a story of transformation. Second, police departments with recent controversial incidents may be reluctant to provide access to their police department due to the scrutiny and attention already being received.

After restricting the sample to only those cities with a population of 100,000 or more, with at least 30\% identifying as Black and/or Hispanic, the three police departments that ranked the highest in terms of police-citizen conflict were Oakland (CA), Hartford (CT), and Wichita Falls (TX). The Oakland Police Department ranked the highest (worst) in terms of the police-citizen conflict index and, based on 2013 Census estimates, served a population of over 400,000 with approximately $52 \%$ of the population identifying as either Black or Hispanic. As of 2013, the Hartford Police Department (which ranked second in terms of the police-citizen conflict measure) served a population of over 124,000 with approximately $78 \%$ of the populous identifying as Black or Hispanic. The Wichita Falls Police Department (ranked third) served a population of over 104,000 with approximately $32 \%$ identifying as Black or Hispanic.

News searches revealed that both the Oakland and Hartford Police Departments have had deep and historically contentious relationships with the communities they served, whereas Wichita Falls had no such evident historical relationship. For instance, in 2003, the Oakland Police Department signed a negotiated settlement agreement to implement constitutional policing practices due to excessive use of force and falsified 
evidence and arrests (City of Oakland, n.d.; Wilson, Cox, Smith, Bos, \& Fain, 2007). During the time of the news search, the Hartford Police Department was still under a federal consent decree that dated back to the 1970 s, which pushed for more accountability in use of force situations as well as diversity on the police force (see Cintron v. Vaughn, 1973). While both of these cities provided unique contexts for study, the Hartford Police Department appeared to be implementing strategies towards positively impacting and improving their relationships with the local community. Thus, current and more recent tensions between police and the community in Hartford were less evident in the news search. Further, at the time of the news search, the Oakland Police Department was undergoing an investigation for an alleged sex scandal involving multiple officers as well as for alleged racist communication (Debolt, 2016; Queally, 2016). Hence, it was decided that the Hartford Police Department provided a more suitable and unique case with a larger minoritized population as well as documentation of current efforts to improve historical relations characterized by distrust.

To gain access to the Hartford Police Department and secure a cooperation agreement, legitimacy was afforded through (a) having a federally-funded grant to explore and improve police-community relations, (b) obtaining letters of support received from law enforcement associations (e.g., the National Association of Chiefs of Police and the National Association of Police Organizations), and (c) using personal networks (i.e., a mutual colleague made an e-mail introduction between the researcher and the chief of police). The Hartford Police Department was extremely open to pursuing a research partnership and willing to assist research endeavors aimed at solving problems regarding police-community relations across the country. 
Study setting. A total of nine weeks was spent on site in Hartford, spanning the months of June to August 2017 (see Appendix E for the case study timeline). Hartford is the capitol of the State of Connecticut and located in southern New England (in the northeastern part of the United States). The city of Hartford has 14 neighborhoods located within less than 18 square miles (including land and water). According to the 2016 American Community Survey Census Estimates, Hartford had a population of approximately 124,320 with a median age of 30.6 years; $31.9 \%$ of the population was living below the poverty level, the unemployment rate was $17.5 \%$, and the median household income was $\$ 32,095$. Of the population, $44 \%$ identified as Hispanic, $35 \%$ as Black only, $15.5 \%$ as White only, and $2.8 \%$ as Asian only. According to the Federal Bureau of Investigation's Uniform Crime Report's 2016 statistics, the rate of violent crime in Hartford for 2016 was 1,093.5 per 100,000 inhabitants, whereas the rate of property crime was $4,200.1$ per 100,000 inhabitants. This rate is quite high compared to the estimated United States national average of 386.3 violent crimes per 100,000 inhabitants and 2,450.7 property crimes per 100,000 inhabitants. Lastly, per the Hartford Police Department's Crime Report, in 2016 and 2017 there were 133 and 132 shootings respectively.

As of April 2017, the Hartford Police Department had a total of 412 sworn personnel on the police force (including new recruits): 48 females, 85 Hispanics, 49 Blacks, 5 Asians, 82 veterans, 28 residing in Hartford, and 124 sworn personnel with 4 or more years of higher education. There were two Deputy Chiefs, two Commanders, and two administrative sergeants that were each responsible for either the North or the South district (see an organizational chart in Figure 4). There were eight neighborhoods 
represented in the North district and nine neighborhoods in the South district (see Figure 5). Within the two districts, assigned community service officers were responsible for specific neighborhoods. As of the summer of 2017, Hartford had approximately 14 community service officers and 1 city-wide faith-based officer. The community service officers and the faith-based officer were responsible for problem solving and addressing community concerns, quality of life issues, and social disorder. They also worked to foster better relationships between the community and the police department.

Hartford Police historical context. Although an in-depth discussion of the history of policing in Hartford is beyond the scope of this chapter, a brief contextual overview of police-community relations is warranted. In July 1860 , six police commissioners were appointed and charged with forming the first organized Hartford police force. The police commission recommended candidates from the Republican and Democratic Parties, and finalized a choice of 1 police chief, 1 captain, 1 lieutenant, and 16 policemen. In the early years of the police force, policing consisted of foot patrols within assigned geographical beats. Police would travel in pairs and carry clubs as a weapon. In 1886, the beginning of the patrol wagon system (mounted by horses) allowed for significant enhancements to policing, particularly as it pertained to transporting arrested individuals to the police station. Apart from making arrests, policemen were tasked with building familiarity with the context of and people within their assigned beats, ensuring sidewalks were clear in order to prevent injuries to pedestrians and lawsuits against the city, patrolling the business section of the city, and responding as needed to accidents, injuries, and fires. There were also physiological requirements imposed on those serving on the police force (e.g., a height of 5'7", and the minimum age 


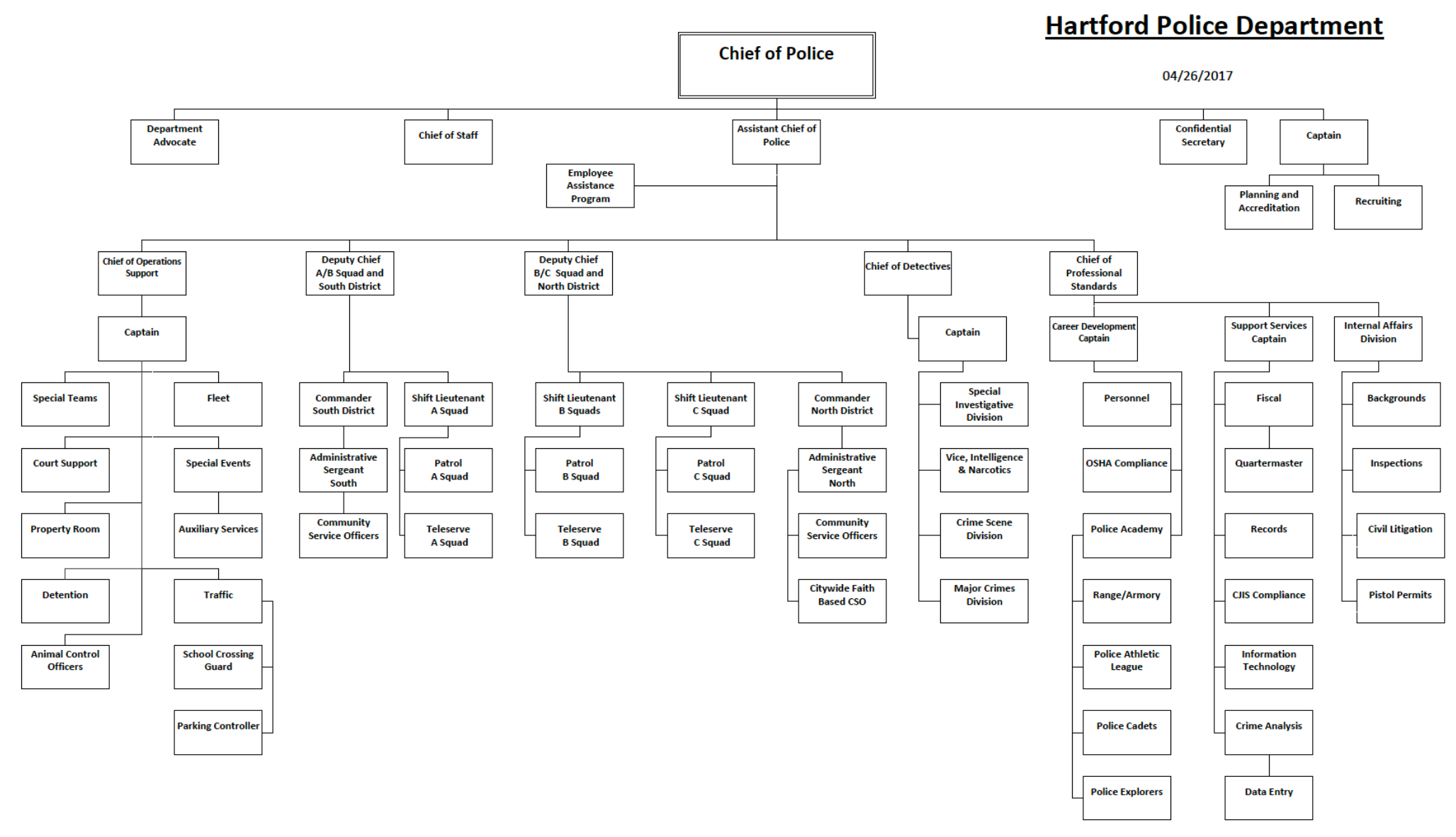

Figure 4. Hartford Police Department organizational chart. Retrieved from the Hartford Police Department. 


$$
\text { 本 }
$$

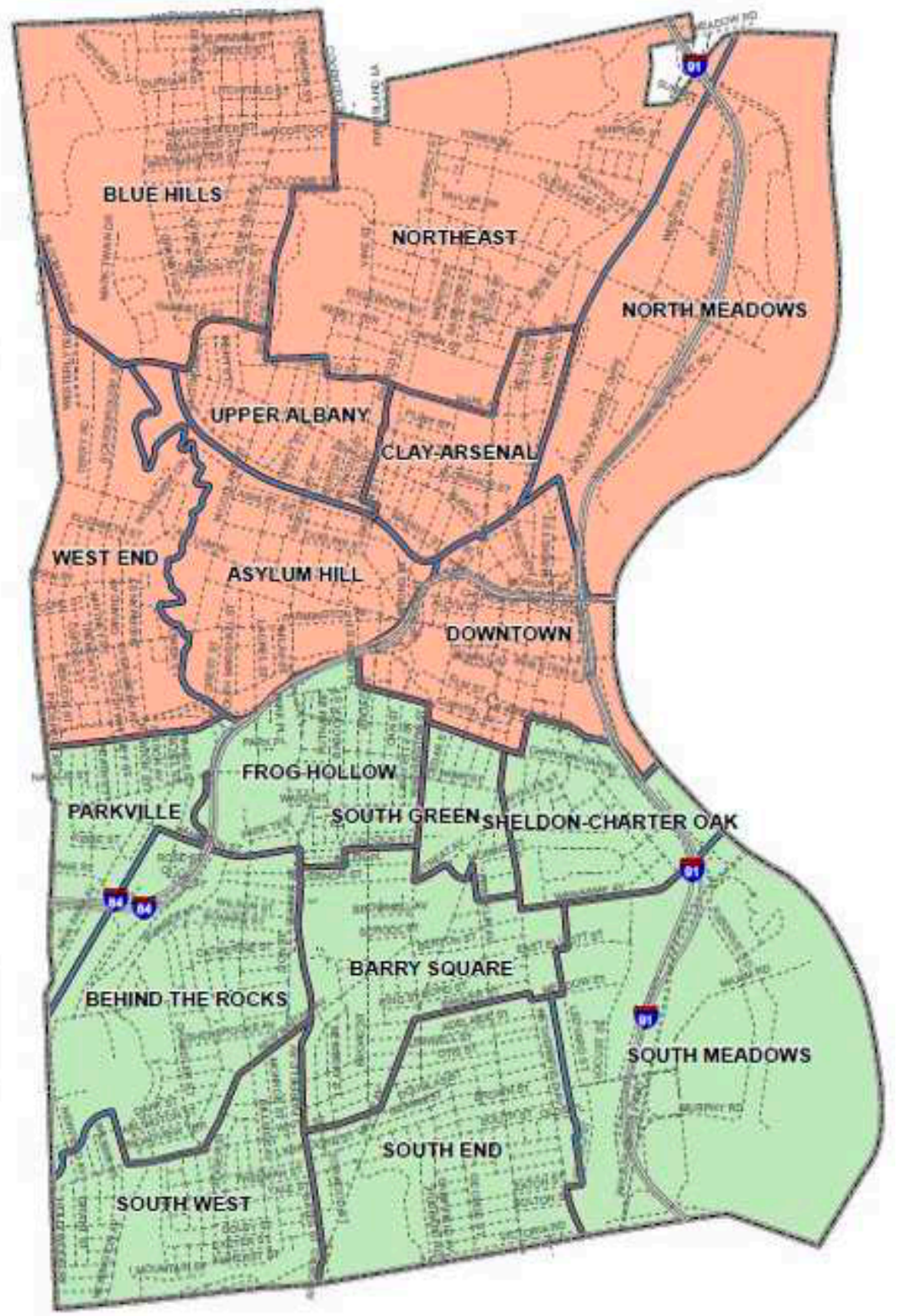

Figure 5. Hartford neighborhood maps. Retrieved from the Hartford Police Department. 
was reduced from 35 years old to 30 years old in the late 1800s; Weaver, 1901). In 1898, almost 40 years after the police force formed, the first police station was built.

Following its inception in the 1860 s, the police force continued to make arrests primarily for drunkenness and other petty offenses, such as breaches of peace (Bernstein, 1996). However, the sex trade and prostitution plagued Hartford's communities. Yet, it was not until the early 1900 s that legal pressure was put on the police and city officials to address these issues. In 1911, a court trial revealed monetary incentives from the owners of brothels to various Hartford police officers. Following this case and through activism by civic leaders, many of the brothels closed and street prostitution was formally addressed (Thornton, n.d.).

Despite the deplorable conditions of communities of color in Hartford from the early- to mid-1900s, the police and the communities of color managed to maintain civil working relationships. For instance, during the summer of 1919 (also referred to as the Red Summer), riots, violence, and deaths of Blacks by Whites occurred in many cities across the United States due to racial tensions. However, during that time, the Hartford police chief reassured Hartford's religious leaders in the communities of color that the racial riots being witnessed across the country would not occur in Hartford (Thornton, 2015). It was after the riots of the Red Summer that the all-male and all-White police force began integrating; however, integration occurred almost 70 years after the founding of the force. The police force hired its first female officer in 1927 and its first Black officer in 1939 (Bernstein, 1996).

The dilapidated conditions that plagued the Black and Hispanic communities of Hartford continued and encompassed problems pertaining to poverty, housing, education, 
police brutality, and accessibility to quality public service provisions. During the mid- to late-1960s, Hartford experienced numerous protests and riots by the Black and Hispanic communities. However, it was often the case that during attempts at organizing and/or demonstrating that negative police-citizen interactions occurred. In 1965, a group known as the North End Community Action Project marched to city hall with a black coffin to symbolically portray the sentiments and realities of what was being experienced in their communities. Thirty police officers met them at city hall and refused to allow them to proceed with their demonstration, arresting many of them. This incident fueled subsequent demonstrations by the Black community and led to even more police arrests (Thornton, 2015).

In the summer of 1967, a Black teenager was arrested because he used profane language towards a waitress. As a response to the perceived police brutality in this incident, the Black community engaged in violent demonstrations that entailed damage to multiple businesses, community members being arrested, and officers being injured (Lerner, 2002). A few months later, 40 Black protesters raised demands at the Hartford Police Department to have their complaints about injustices heard by the mayor. This act led to a city hall meeting that gave ear to the complaints of police brutality by Black community members, which were often supported by White community members as well (Tateosian, 1998). Nevertheless, police brutality persisted.

In April 1968, after hearing about the assassination of Martin Luther King Jr., multiple demonstrations occurred throughout the city as well as across the nation. Hundreds of students who attended the local public high schools held walkouts and marches (Thornton, 2015). However, the most damaging demonstration occurred when 
over 150 people took to the streets of Hartford, looting and burning White-owned stores and businesses. A total of 21 stores were damaged (Lerner, 2002). As an immediate response during this riot, the police used tear gas in attempts to disband the crowd. It was not until the community leaders (including both civic and religious leaders) assisted in easing tensions on the street that the violence and rioting calmed down (Cohen, 2008).

In the summer of 1969, the Hispanic community (which consisted of mainly Puerto Ricans) took the spotlight (Tateosian, 1998). The Hispanic community was exasperated with problematic police practices (including unconstitutional searches and arrests, the lack of police protection, and lack of bilingual police officers), housing and education conditions, and demeaning racialized language used and publicized by public administrators. As a result, violent riots broke out, which became known as the Labor Day riots (Heidenis, 2003; Maria Sánchez, n.d.; Thornton, 2015). Hartford police responded with aggressive tactics to these demonstrations, resulting in numerous deaths of Hispanic community members by the police (Thornton, 2015).

Amid these contentious police-community issues, a well-known researcher was asked to conduct a police-community relations analysis of Hartford. In the report, the Hartford Police Department was criticized for not paying attention to major crimes being committed by Whites, but rather focusing on the trivial crimes committed by Blacks and Hispanics, which often entailed harassment (Thornton, 2017). While these findings were later denied by the police department, they served to confirm what these communities had been expressing through their protests.

After the race riots of the 1960s, one crucial and defining moment in Hartford's police-community relations occurred as part of the Cintron v. Vaughn court case filed in 
1969. This federal discrimination lawsuit was filed by Maria Cintron on behalf of herself and others against Hartford Police Chief Thomas J. Vaughn and the police department for discriminatory behavior (including acts of intimidation and humiliation) towards Hartford's communities of color. This case resulted in a consent decree settlement being imposed in 1973 (Vella, 2016). The consent decree mandated formalized complaint processes, use of force guidelines, firearms training, the use police nametags, the establishment of an Internal Affairs division, restrictions to the use of specific crowd control mechanisms, and encouraged increased recruitment and retention of officers of color, to name a few (Hamilton, 2018; Radelat, 2016).

The decree was poorly enforced up until the early 2000s when the court case was revisited as a result of a White officer fatally shooting Aquan Salmon, an unarmed 14year-old Black boy (Allen, 1999b). This incident occurred in the midst of an investigation of corruption in the Hartford Police Department and just days after four current and former Hartford officers were arrested due to involvement in sexual misconduct with prostitutes (Allen, 1999a). This event eventually led to the appointment of an independent monitor to oversee compliance with the decree (Brown, 2007a). However, over the years, the Hartford Police Department had failed to achieve total compliance with the original mandates. In 2004, the court added provisions to the consent decree stating that the city was responsible for properly receiving, tracking, and investigating citizen complaints. Three years later, in 2007, a federal judge found that the City of Hartford was in contempt of court for noncompliance of the consent decree due to the inappropriate handling of citizen complaints (Brown, 2007b). Though the consent decree was set to expire in October 2016, a federal magistrate extended it for an additional three years due 
to the police department's lack of minority representation to mirror the community residing in Hartford (Vella, 2016). After over 40 years from its original conception, the decree is widely acknowledged as the longest-standing police consent decree in the United States.

Understanding the historical context of police-community relations in Hartford, Connecticut was relevant to providing context for the current state of police-community relations in the city. History provides a lens for understanding the long-standing issues that the marginalized communities of Hartford has faced throughout the years. It also presents a context for the organizational reform strategies implemented in the police department. Thus, a historical framework allowed for a more accurate assessment of the reasons why and process by which organizational reforms have impacted policecommunity relations.

Qualitative data collection. The primary data collection methods for the case study included semi-structured interviews, participant observations, and secondary data analysis. Utilizing multiple methods was one way to triangulate data and confirm research findings, thereby enhancing the overall quality of the research (Marshall \& Rossman, 2014). The data was collected (when permitted) through recordings and note taking.

Semi-structured interviews. Interviews were used to understand the perspectives of those actively involved in the police department or those with in-depth knowledge of the police department and their organizational practices. Such familiarity was important in order to identify how such practices have impacted police-community relations, if at all. The focused nature of the interviews allowed for interviewees to respond directly to 
the case study topic (Yin, 2009). A total of 88 in-depth semi-structured interviews were conducted. Of the 88 interviewees, 4 interviews were conducted with 2 people in each interview, creating a sample of 92 interviewees in total. ${ }^{39}$ There were an additional 25 potential interviewees that were contacted who either did not respond at all or were unable to schedule a convenient time to interview.

Interviewees primarily fell into one of two groups: police representatives or community representatives (the latter including local government representatives). The police respondents were further classified into either front-line police or police managers. "Front-line police" refers to patrol officers as well as officers in a specialized role or unit that have primary responsibilities for interacting with the community. "Police manager" refers to those sworn officers who hold mid- to upper-level management and administrative positions (such as Sergeants, Lieutenants, Captains, Deputy Chiefs, and the Chief of Police). All interview participants were assured confidentiality. Thus, names of individuals, organizations, locations, and any other uniquely identifiable information were changed and/or masked to ensure confidentiality and safeguard identity. At times physical descriptions and personal characteristics were also changed, however a diligent attempt was made to strike a balance between confidentiality and authenticity.

A semi-structured interview guide, with open-ended questions and probes, was used to allow for greater flexibility within the interview and to guide the discussion when necessary (Remler \& Van Ryzin, 2010). While the interview guide contained key

\footnotetext{
${ }^{39}$ In five of the interviews, there were people who stepped into the interview but who were not central characters in the interview. These people did not stay around long enough to fill out their identifying information. They were neither included in the official count of interviewees nor were the comments they stated coded as part of the formal interview data.
} 
questions of interest, the semi-structured nature of the interview allowed for "adapt[ing] the interview to capitalize on the special knowledge, experience, or insights of respondents” (Singleton, Straits, \& Miller Straits, 1993, p. 249). The interview guide instrument was piloted (via phone) with two male individuals, both of whom had law enforcement backgrounds in other cities in the United States. This step was taken in order to ensure clarity of questions, gain feedback, and improve the questionnaire prior to conducting the actual interviews. Apart from detailing the demographic information about each of the interviewees, the topics explored in the interview guide included community policing and engagement, diversity, police training, financial issues, neighborhood variations, and others (see Appendix F for further details on the interview guide). All interviews were audio recorded (unless the respondent declined) and then transcribed verbatim by a professional transcription company. This company was also given a detailed transcription protocol to follow (see Appendix G). Following the professional transcription service, each audio recording was listened to while reading the corresponding transcription to check for accuracy. In 12 of the interviews, recording was not permissible, and thus handwritten notes were taken during the interview. All interviewing concluded after theoretical saturation was sufficiently achieved, meaning there was no new information being discovered from conducting further interviews.

A combination of sampling strategies were utilized depending upon the group (community or law enforcement) being interviewed. The initial group of interviewees from both groups started with judgment sampling; thereafter, snowball sampling was the primary method used. However, volunteer sampling was also used to reach interviewees that represented the police department. Interviews were voluntary, conducted both face- 
to-face $(n=85)$ and via the phone $(n=3)$. The majority of interviews were conducted in private settings (e.g., homes, office spaces, interview rooms, cars); however, a few were conducted in public settings (e.g., coffee shops, local restaurants, parks). Interviews ranged from approximately 25 to 135 minutes, solely based upon the extent to which respondents were willing to share detailed information.

Police department group. There was a total of 58 police respondents: 56 of whom were currently working at the police department, representing approximately $14 \%$ of the police department ${ }^{40}$, and 2 who had retired after serving 20 or more years at the police department. ${ }^{41}$ The first few interviewees were identified through referral by the point of contact at the Hartford Police Department. However, this referral was still based on the objectives of the study and the key topics under investigation. Thus, initially individuals who had a fair understanding of the police-community relations in the city and the internal organizational efforts towards impacting such relations were recommended and subsequently interviewed. Shortly thereafter, chain referral and snowball sampling became the primary means for identifying potential interviewees. While very few interviews were the result of volunteer sampling, during some of the police roll calls the Sergeant or Lieutenant on duty would ask who was willing to be interviewed that shift.

\footnotetext{
40 As of April 2017, there were approximately 396 sworn personnel employed at the Hartford Police Department, not including new recruits.

41 The two retirees from the police department both had additional careers within the city of Hartford. However, the overwhelming majority of their responses to interview questions were based on their internal knowledge of working at the police department. Thus, it made more sense to classify them as police representatives. However, this was a hard decision because they also provided community insights.
} 


\section{Table 14}

Interviewee Sample Characteristics

\begin{tabular}{|c|c|c|c|}
\hline & $\begin{array}{c}\text { Full Sample } \\
(N=92)\end{array}$ & $\begin{array}{c}\text { Community Sample } \\
(n=34)\end{array}$ & $\begin{array}{c}\text { Police Sample } \\
(n=58)\end{array}$ \\
\hline \multicolumn{4}{|l|}{ Race } \\
\hline Hispanic & 23 & 9 & 14 \\
\hline Non-Hispanic $^{1}$ & 69 & 25 & 44 \\
\hline White & 38 & 11 & 27 \\
\hline Black & 27 & 13 & 14 \\
\hline Asian & 1 & 0 & 1 \\
\hline Multi-Racial & 2 & 0 & 2 \\
\hline Other & 1 & 1 & 0 \\
\hline \multicolumn{4}{|l|}{ Gender } \\
\hline Female & 25 & 13 & 12 \\
\hline Male & 67 & 21 & 46 \\
\hline \multicolumn{4}{|l|}{ Education/Degree } \\
\hline High School or less & 7 & 2 & 5 \\
\hline Some College & 22 & 5 & 17 \\
\hline Associates & 11 & 2 & 9 \\
\hline Bachelors & 25 & 8 & 17 \\
\hline Graduate & 18 & 10 & 8 \\
\hline Professional & 9 & 7 & 2 \\
\hline Hartford Origin & 36 & 15 & 21 \\
\hline Hartford Residency & 32 & 26 & 6 \\
\hline \multicolumn{4}{|l|}{ Age in years } \\
\hline $21-25$ & 3 & 0 & 3 \\
\hline $26-30$ & 5 & 1 & 4 \\
\hline $31-35$ & 13 & 5 & 8 \\
\hline $36-40$ & 14 & 3 & 11 \\
\hline $41-45$ & 15 & 3 & 12 \\
\hline $46-50$ & 19 & 5 & 14 \\
\hline $51-55$ & 5 & 3 & 2 \\
\hline $56-60$ & 9 & 5 & 4 \\
\hline $61-65$ & 4 & 4 & 0 \\
\hline $65+$ & 5 & 5 & 0 \\
\hline
\end{tabular}

Note. ${ }^{1}$ this category includes 6 respondents those who did not specify any ethnic category, but who identified as a particular race.

There was a wide range of diversity sought and achieved with regard to demographics, experience, assignment, education, residency, and origin (see Table 14). There was a total of 12 female and 46 male police interviewees. There were 14 Hispanic, 27 White, 14 Black, 1 Asian, and 2 multi-racial police interviewees. A total of 21 police interviewees were originally from Hartford while 36 were not. Six of the police 
interviewees were currently living in Hartford and an additional four stated that they had lived in Hartford at some point during their career. A total of 36 interviewees (approximately $62 \%$ of the police sample) held an Associate degree or higher.

Lastly, among the police respondents, there were 16 interviewees who were officers in the patrol division, 24 in mid- to upper-level management positions, 16 who were in specialized units (units that were not directly responsible for responding to calls for service such as detectives and community service officers), and 2 who were retired from the police department (see Figure 6). In regards to tenure at the Hartford Police Department, of all the police respondents, 4 interviewees had less than 3 years of service , 3 had between 3-6 years, 5 had between 6-9 years, 15 had between 9-12 years, 12 had between 12-15 years, 10 had between 15-18 years, 2 had between $18-20$ years, and 7 had 20 or more years of service on the police force. Figure 7 illustrates the percentages of Hartford police interviewees who fell into the respective years of service categories. The age of police respondents ranged from 21 to 60 years.

Community representatives group. To ensure that diverse perspectives were included, a total of 34 community representatives were interviewed. These community representatives included community leaders, representatives from both community-based non-governmental organizations as well as governmental organizations, and local public officials. It was important that these individuals had a fair understanding of the police department and the organizational dimensions in place in order to effectively answer interview questions. 


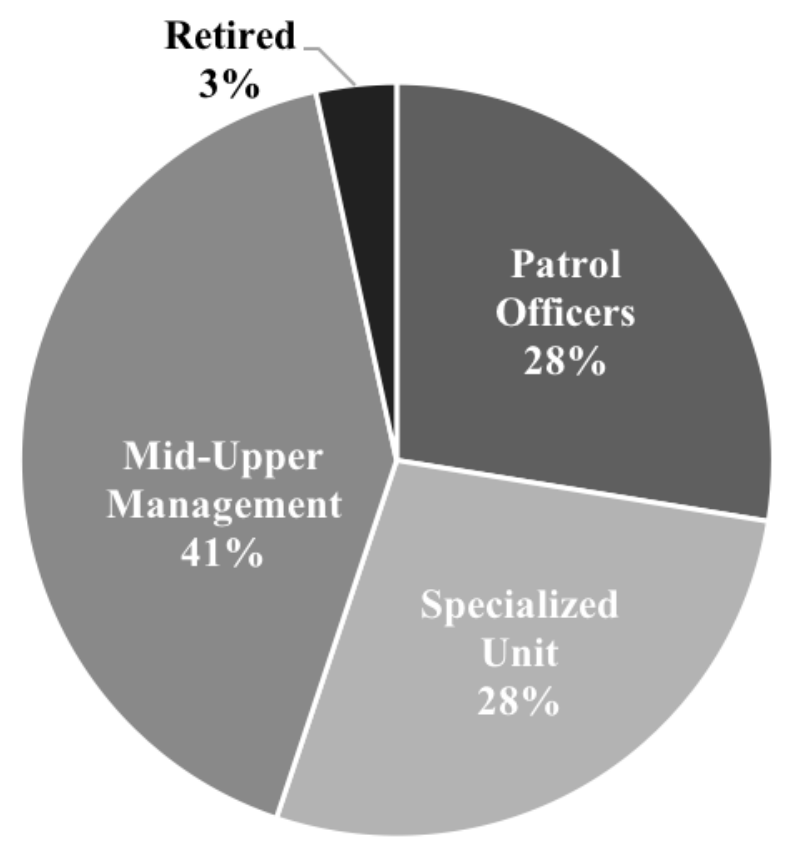

Figure 6. Police representatives: Division of labor.

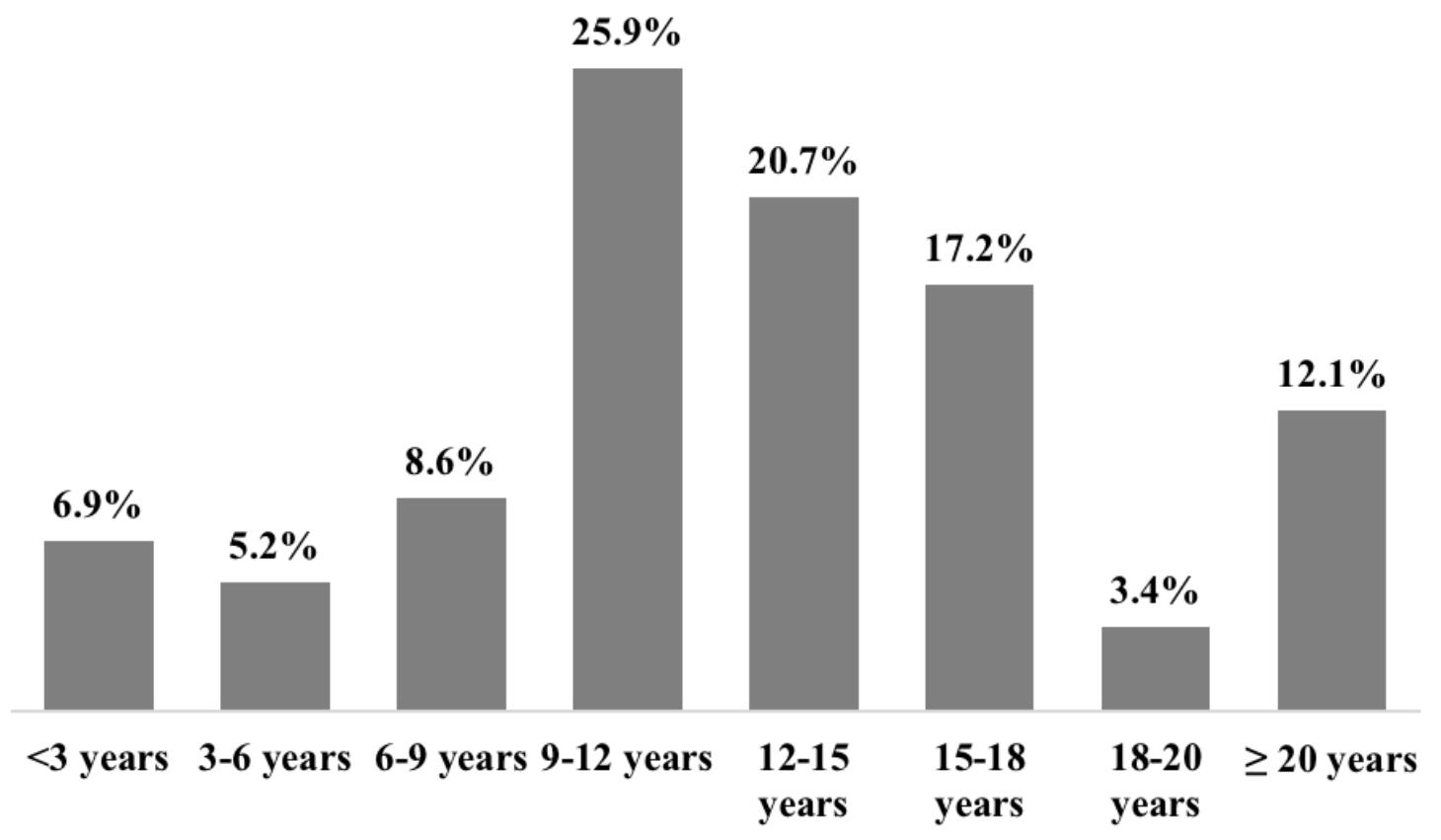

Figure 7. Police respondent's tenure (in years of service) at the police department. 
Initial recruitment began with community members who were ideal for participation, such as community organizations or advocacy group leaders. The initial list was gathered from a brief analysis of secondary data sources, including local news sites and social media. Any articles or social media posts that discussed key players in policecommunity relations were assessed (e.g., an article highlighting a community activist that either spoke for or against police use of force). Additionally, leaders were identified from local Hartford branches of national organizations, such as the National Association for the Advancement of Colored People, the Urban League, and the American Civil Liberties Union. The remaining participants were identified based upon recommendations (i.e., chain referral) from the initial set of interviewees. Recruitment took the form of emails, phone calls, and direct messaging on social media platforms.

The criteria for selection for community representatives was based on their familiarity with the policing context in the city of Hartford, irrespective of their current residence or place of origin. In all, 13 female and 21 male community representatives were interviewed. Of these 34 individuals, 15 were originally from Hartford and 19 were not; however, 26 were currently living in Hartford. Further, a total of 27 respondents had an Associate degree or higher. Lastly, 9 of the interviewees identified as Hispanic, 13 as Black, 11 as White, and 1 as "other." The age range of community respondents was from 26 to over 65 years old.

Observational studies. Observations were utilized as a way to build rapport with the police department and with the community, to accurately understand the real-time context of the policing environment in Hartford, and to compare observations with interview response content. Direct observations also allowed for the development of 
experiential perspectives pertaining to the real-world setting of the case study (Yin, 2009). The role assumed during the observations was observer as participant, meaning that the researcher was not naturally a part of the setting, but there was some involvement in the setting being observed (Gold, 1958). Participant observations imply that the researcher is immersed in a natural setting and taking on the role of both participant and observer, albeit each to varying degrees (Marshall \& Rossman, 2014). It has been noted that this is a "peripheral membership role," which allows the researcher to "observe and interact closely enough with members to establish an insider's identity without participating in those activities constituting the core of group membership" (Adler \& Adler, 1994, p. 380; as cited in Kawulich, 2005). Further, often during this type of observation role, the participants being observed are aware of the researcher's goals (Kawulich, 2005). ${ }^{42}$

Approximately 67.7 hours of direct participant observations took place. ${ }^{43}$ The majority of observation time was spent during police ride-alongs with officers (see Appendix $\mathrm{H}$ for a list of observation sites and types). "Police ride-alongs" refer to police officers having a civilian assigned to ride with them in their patrol car during their regular assigned work shift in order for the civilian to observe policing activities. Nine ridealongs were conducted, totaling over 40 hours of participant observations. During these

\footnotetext{
${ }^{42}$ In most of the observations, with only one exception, there was at least one person who was aware of the research goals and objectives (and typically there were multiple participants who were aware). However, there were some observations conducted during police ride-along and police-community events outside of the police department where the community was not aware of the role of the researcher.

${ }^{43}$ Apart from the organized participant observations, the researcher also lived in the city of Hartford, within a 10-minute drive of the police department and on the same street as, and in walking distance from, the Hartford City Hall.
} 
ride-alongs, the majority of the time was spent observing (a) police-citizen interactions as police responded to calls for service and (b) police interacting among themselves. There was a total of four police roll calls observed (totaling one hour), with the primary activity observed being the police command staff's overview of their subordinate patrol officers' tasks and responsibilities for that shift. There was a total of four police-community events attended and observed (totaling eight and a half hours of observations). During these formalized events, positive interactions between police and the community were observed. Examples of these events included an athletic picnic for youth hosted by the police activities league in partnership with local businesses, a shoe drive by the police activities league, and midnight basketball where police officers played basketball with the youth and fed them during the evening. Three internal police meetings were observed (totaling nine hours) where interactions between police command staff, police officers, and other personnel were observed. Lastly, five community meetings were attended (totaling six hours of observations) that included observations of public officials interacting with the community, community leaders holding meetings, as well as more informal interactions among these groups. Examples of these community meetings included a civilian police review board meeting, a city commission meeting, and a town hall held by the mayor.

The observations were conducted across a variety of settings, days, and times in order to ensure adequate context variability. During observations, informal conversations also helped to supplement the formal interviews. Field notes were taken at the time, 
where permissible, as well as mental notes that were written up at the end of each day. ${ }^{44}$ Permission was granted to take pictures at some of the community events.

Review of secondary sources. Secondary sources were reviewed primarily to provide historical insight, background information, and context to the setting (Yin, 2009). In some instances, these sources were also reviewed to enhance and verify the information gathered from the interviews and observations. These sources provided a stable way to collect evidence and understand phenomena in a way that was not necessarily impacted or altered by the researcher's presence (Bowen, 2009). Thus, such documentation provided unobtrusive means to gain more insight and background on items briefly mentioned by interviewees. Combining secondary sources with the data collected from the aforementioned methods served as a way to triangulate data (Bowen, 2009; Patton, 2002). Triangulation is a process of utilizing multiple sources of information and methodologies in order to corroborate findings and add credibility to the research (Berg \& Lune, 2012).

A total of 15 documents were given directly by police department representatives and 7 documents were gathered from the Hartford Police Department website. Examples of these types of collected documents included job advertisements, maps of the city, academy training documents, organizational charts, and personnel demographics. An additional 19 documents were provided by community representatives, which included various reports on community health and crime, legal court cases, independent reviews of

\footnotetext{
${ }^{44}$ The difference between written notes and mental notes depended on the type of observation conducted. For instance, ride-alongs primarily entailed the use of mental notes, whereas public community meetings were documented via written notes.
} 
the police department, police leadership training information, community-police engagement events, notes from committee meetings on public safety, and relevant news articles. A plethora of other secondary sources was found via an online search, which provided further understanding of police-community relations. These online documents included community and neighborhood policing plans, a police staffing and deployment analysis, a collaboration plan between the police department and the board of education, program implementation and evaluations, historical reports on Hartford, and various news articles pertaining to police-community relations in Hartford (e.g., a use of force incident that may have engendered mobilization or led to organizational change).

While the goal of this case study was to develop a broad understanding of why and how organizational factors influenced police-community relations, such relations did not develop overnight; rather, they were built up over an extensive period of time (as delineated by the historical overview of Hartford above). That said, when reviewing secondary sources with the intention to answer the research question of interest, the sources assessed spanned a short historical period, covering the years 2010 through 2017. ${ }^{45}$ In reviewing the secondary sources, attention was devoted to specific information that addressed or included the following: organizational characteristics or structures that need to be changed (e.g., diversity recruitment initiatives), the proposed mechanisms by which to improve relations, and/or potential reasons for negative community relations.

Content analysis. All data was collected either through voice recordings, notetaking, documents received and/or pictures taken. The analytic techniques employed were

\footnotetext{
${ }^{45}$ When writing the historical overview of Hartford's police-community relations, secondary sources were used that extended beyond the scope of this timeframe.
} 
thematic analysis and explanation building. Thematic analysis is a qualitative method used to identify and analyze patterns across the data. These patterns then become recognized as themes in the data to provide an organized and detailed description of the data (Braun \& Clarke, 2006). Explanation building is a qualitative analytic technique that is used to identify causal links or inferences and to explain what is happening in a given case (Yin, 2009). Attention was devoted specifically to a respondent's reasons for and process by which organizational characteristics and managerial strategies impacted police-community relations. Codes and themes were identified at a semantic (or explicit) level, where the "surface meanings of the data" were most important and "the analyst is not looking for anything beyond what a participant has said or what has been written" (Braun \& Clarke, 2006, p. 84). This analysis was focused on the descriptions given in the document and the interpretations thereof, rather than on examining latent and underlying ideas or assumptions (Braun \& Clarke, 2006).

After the interviews were professionally transcribed, the transcriptions were then reviewed, proofread, and edited against the audio files and revised for accuracy. Subsequently, transcripts were manually coded based on a set of pre-identified codes (i.e., words and/or concepts). These a priori themes were identified based on the categories of the questions in the interview guide and the existing literature on specific organizational elements of police departments and police-community relations more generally. The predetermined themes included the following: collaboration, engagement, financial state, manpower, communication, respect, humanizing, understanding, transparency, responsiveness, accountability, being present, hiring residents, media, training, personal interaction, diverse representation, and gender differences. 
The content analysis was conducted utilizing NVivo 10. NVivo is a qualitative data analysis software that allows for data storage and organization, in-depth data analyses (of transcriptions, videos, voice, notes, or pictures), and data visualizations. NVivo was used to code, identify themes, and run queries to assess the prevalence of and relationships between words, concepts, and themes. Utilizing qualitative data analysis software was particularly important to understand how codes and themes pertaining to organizational characteristics and managerial strategies were related to each other in complex ways. The use of this software also provided accessibility and assessment of all the data in a more systematic and comprehensive way.

In the findings section, quotes that illustrate themes consistently found throughout the data are presented. The quotes used are not uncommon unless it is explicitly stated that a small number of respondents shared these views. Attention was carefully devoted to ensuring that the themes were grounded in the qualitative data.

\section{Findings}

This present study extends prior research on police-community relations by providing insights from the viewpoint of police and community representatives, participant-observations and secondary data sources. This provides a more complete understanding of why and how organizational factors and managerial strategies impact police-community relations. Figure 8 provides a word cloud based on the 88 interviews conducted. Word clouds are graphical representations of the content in a given set of documents (Ramsden \& Bate, 2008). Word clouds provide visualizations of the words that appear most frequently throughout text data. The larger the text in the word cloud, the more frequently the word appeared (which is sometimes used as an indication of 
relative importance) ${ }^{46}$ The top 20 most frequent words that appeared in the word cloud included: policing, people, community, officers, departments, works, timing, differs, talks, calls, city, years, kindness, segment, needs, relations, personally, trainings, chief, and impact. These words give a bird's eye view of some of the content from the interviews.

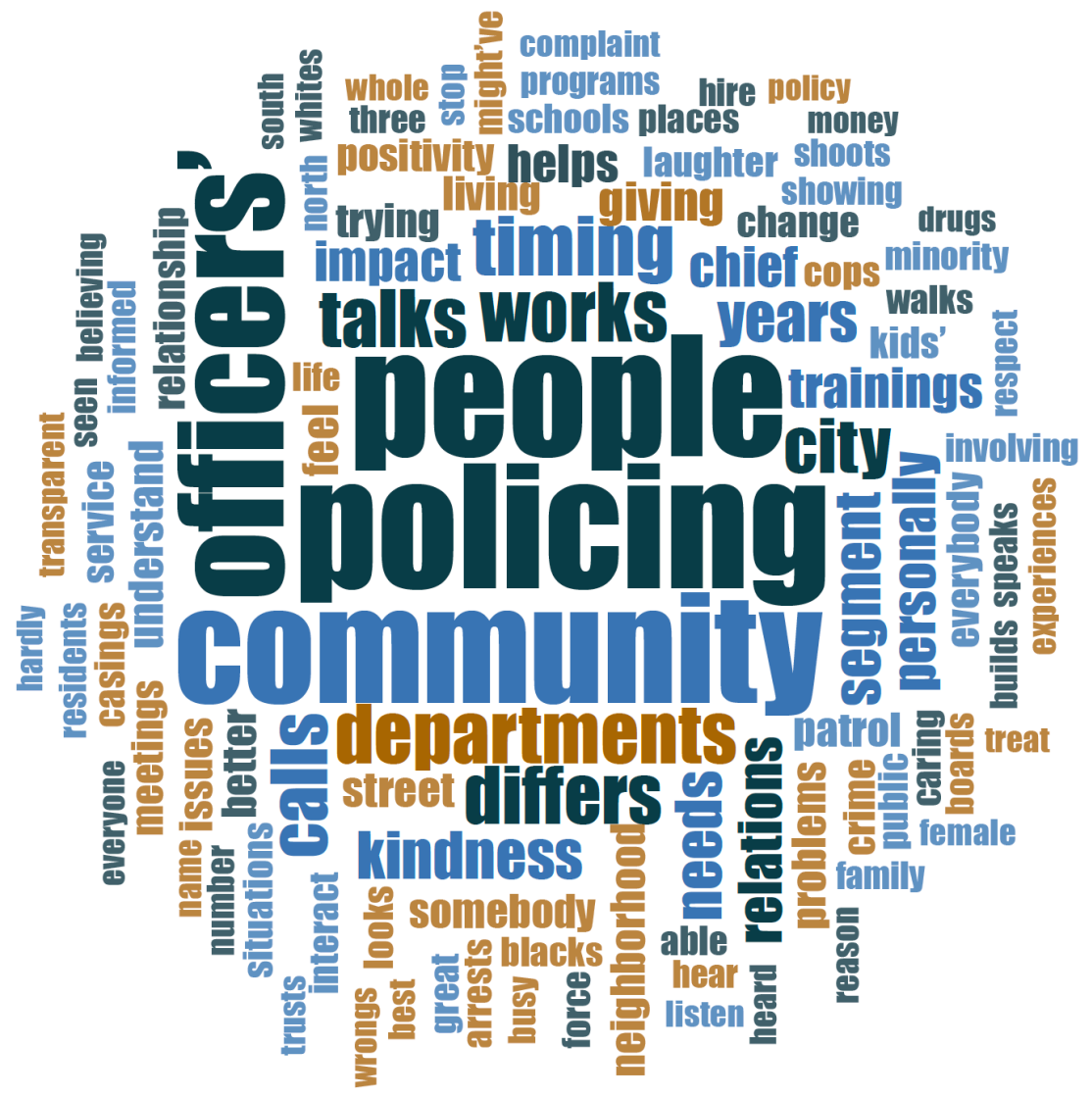

Figure 8. Word frequency cloud of qualitative interviews.

\footnotetext{
${ }^{46}$ Commonly used words in everyday language as well as words without much meaning were excluded from the word cloud analysis (e.g., the, and, every, him, her, she, well, whether).
} 
To address the main research question of interest, first an examination of the current state of police-community relations was provided. Interviewees often defined police-community relations by acknowledging the mutual roles that both the police and the community play. However, interviewees also suggested that police-community relations are determined by community judgments or perceptions of police demeanor and overall effectiveness. In terms of deciphering what the current state of police-community relations was in the city of Hartford, interviewees suggested that there were differences in perceptions based upon sub-groups and neighborhoods within the city. Nevertheless, while there were differences in pinpointing the current state, most interviewees suggested that relations have improved over time and are relatively better when compared to other locations.

After ascertaining how participants defined police-community relations and understanding the current state of relations in the city of Hartford, important organizational factors and managerial strategies were identified. Specific attention was devoted to considering how and/or why the emergent organizational and managerial factors impacted police-community relations. Three main categories emerged as impacting factors of police-community relations in the city of Hartford: soft skills, human resources, and intentional engagement.

"Soft skills" refers to communication with the community as well as officer character. Effective communication de-escalates tense situations, engages the community, and humanizes the police - all of which allow for community trust to develop. Officer character traits (such as respect and compassion) impact police behavior, which subsequently impacts community perceptions and attitudes. 
The human resource factors that emerged as important included hands-on training and ample manpower. Hands-on training had practical applications in that it provides officers with understandings of the diverse populations in the community and provides alternative courses of action to take during police-citizen interactions. On the other hand, the lack of sufficient staffing on the police force leads to increases in the response time and the workload per officer, which in turn impacts officer well-being. Inadequate staffing levels also lead to fewer officers positively engaging the community. This lack of human resources negatively impacts police-community relations.

"Intentional engagement" refers to activities where the community and police department were actively engaged with each other, which includes collaborative relationships and external accountability. Collaborative relationships foster positive relationships by allowing for familiarity, portrays the police department cares, and builds trust. They also provide alternative responses to address community issues. Contrarily, the lack of effective implementation of external accountability mechanisms leads to negative perceptions in the community.

\section{Police-community relations.}

\section{Defining police-community relations: It takes two to tango, but one to lead.}

Despite the frequent use of the term "police-community relations" in the literature, there is not one consistent definition that conceptualizes police-community relations. Thus, it was important to provide respondents with the opportunity to first define what policecommunity relations meant to them prior to discussing the current state of relations. However, specific and concrete definitions of police-community relations were usually 
not provided by the interviewees, but rather interviewees spoke of the concept more generally.

Often, police respondents connected the term "police-community relations" directly to "community policing" and used these phrases interchangeably. However, community policing is just one way to impact police-community relations and should not be confused with larger notions of police-community relations. As Hunter and Barker (2010) noted, "police-community relations refer to the ongoing and changing relationship between the police and the communities they serve. This includes issues of cooperation, race relations, fear of police, violence, and corruption" (p. 117).

Despite Hunter and Barker's (2010) acknowledgement that police-community relations encompass both positive and negative attributes, community and police respondents alike referred to the term with positive connotations. Respondents focused primarily on how to build police-community relations and rarely touched directly on negative aspects of police-community relations. Only one front-line police respondent explicitly addressed the fact that police-community relations is on a spectrum by stating that it is a "neutral $[\ldots]$ term, it can be negative or it can be positive [.... And you have varying levels of it."

There was congruence among both community and police responses in identifying key characteristics of police-community relations. First, reciprocity was an underlying theme of police-community relations. Respondents from each group emphasized that it is not solely the police or the community's responsibility, but rather that it takes both parties building rapport, caring, understanding, appreciating, respecting and getting to know each other. A police manager stated, “it's a partnership. It's give and take. It's 
understanding and appreciating each other. Appreciating each other's needs and what we can and cannot do." Likewise, respondents often emphasized the importance of working together in collaborative and cooperative relationships. It is about "everyone teaming up together to help the community. It is not all community or all police but a combination of everyone coming together" (front-line police respondent) because "the police cannot do their job without the community, they need the cooperation of the community to do it effectively" (police manager).

Second, though emphasis was placed on this idea of mutuality, interviewees suggested the onus was on the police. Specifically, respondents stated that policecommunity relations was about police behavior and actions towards the community as well as subsequent community perceptions and feelings about the police. In regards to police behavior, respondents often emphasized that police should be seen as part of the community, which entails interacting, engaging, and being involved in the community. Both groups of respondents highlighted the role that police play in terms of helping the community, attending to community concerns, and serving community needs. As one front-line police respondent illustrated,

Being a police officer, it is being involved in the community, being a part of the community, making them feel you are a part of the community, not just when things are wrong you are involved. Let them know you are here to serve them and be a part of the community, not just a robot in a uniform.

When respondents discussed the community's role, there was greater emphasis on community feelings such as acceptance, satisfaction, and trust of the police. Thus, it appeared that the quality of police-community relations depended on the police 
department's performance and the community's judgement thereof. This finding suggested that police actions can and do directly impact community perceptions.

Lastly, respondents drew attention to the importance of communication and everyday interactions, both of which lay at the core of police-community relations. As

one community leader stated, when he thinks of police-community relations it means "the police and the community $[\ldots]$ meeting, they're talking they're interacting, they're developing relationships." Front-line police representatives echoed similar sentiments in stating that it is through communication that information is provided to the police, which enables police to effectively resolve crime and address community concerns.

\section{Where you stand depends on where you sit: Differing perspectives on the}

current state of police-community relations. There were four sub-themes relevant to the current state of police-community relations. First, the police and the community members disagreed about the current state of relations. Second, it was apparent that the state of police-community relations is conditional based on the interviewee's reference or vantage point. Third, both comparative and futuristic perspectives came into play when discussing the state of relations. Lastly, there were differences across police and community interviewees concerning who should be credited for positively impacting policecommunity relations.

Most of the police respondents acknowledged the current state of relations in a positive light, stating not only that police-community relations were good in the city, but that it had significantly improved overtime. Police respondents would refer to specific examples of improved relations by asserting that the community trusts the police now, that there is mutual appreciation, that the community has confidence in police abilities, 
that what the public says about the police has improved, and that certain communities want police in their neighborhoods. One police manager exclaimed, there is "just a feeling of trust and what people say about us publicly has improved." A front-line police respondent also stated that

the community members are pro-police. They want change in their neighborhoods [...] positive change. They want to have a relationship with the police. And the perception is the neighborhoods don't like the police. That's not the case. The neighborhoods do want the police. They love the police.

While the police respondents were more in one accord about the current state of relations, there was more disagreement as to the current state of relations when speaking with community respondents. There were some community members who shared the view that there have been historical improvements in Hartford pertaining to police-community relations. For instance, one community leader stated, the community relations have improved tremendously quite frankly. I think that there are many more residents who actually know who their police officers are and respect what the police officers do [...] I would say recently over the last three to four years they've improved.

However, other community respondents often acknowledged the lack of a real relationship between the police department and the community. Another community representative exclaimed,

What comes to mind is that there is no real relationship, people don't talk to the police. [...] At the same time while the police may have some efforts in terms of trying to reach the community, the reality is they drive through in cars or they 
come when there's trouble. There, again, is a separation between the residents and the police.

Community and police respondents alike emphasized that the current state of relations was conditional based on (a) who was asked, (b) which group of individuals or police officers were being referred to, and (c) geographical locations. This finding added to our understanding of police-community relations in that such relations do not only exist on a spectrum ranging from positive to negative across cities, but that within-city differences also exist. In some cases, community respondents often suggested that certain officers had better relations with the community than others. For instance, one community respondent stated, "You can't like generalize. I know some police officers that are decent police officers. I know others that are completely-don't even talk to me because your views and what you think are just way off." In speaking specifically about community service officers (CSO), another community respondent exclaimed "My CSOs, I make sure I know them [....] I have my CSO over here and they are like family to me." Throughout the interviewing process, it was quickly realized that some officers were more consistently engaged at events and meetings than others because there were specific officers' names that were regularly mentioned by community respondents. These were the very officers who were observed interacting with the community during participant-observations at community events. Thus, it may be that only select officers are proactively engaged in building police-community relations.

Another community respondent pointed to the fact that certain community leaders were also more involved with the police and that their views may not always represent the larger community. In addressing the current state of relations, he elaborated: 
So, I guess it depends on who you ask [....] Many of the people that they [the police department] has good relationships with are probably "grasstops" individuals, not necessarily grassroots. And so, having relationships with pseudo political figures many a times is not having a good relationship with $[\ldots]$ the residents or the family members or the community members [....] Totally different. Having a good relationship with Pastor so and so, Reverend so and so, is very different than having a relationship in the community itself.

Based on my observations, it was very clear that there were certain community leaders who were consistently more active in police department affairs, which could be one of the reasons why they had more positive views of the department.

Both groups of respondents acknowledged that community interaction or involvement differs based on the different neighborhoods or geographical areas within Hartford. For instance, a front-line police respondent, acknowledged that in the South it was a larger Hispanic community [...] I feel they tend to call and rely on police more. Everybody wants $[\ldots]$ police mediation, they wanted things documented. As in the North end, people are more hesitant to call the police. And I don't know if it's previous interactions. They're more likely to keep it to themselves or try to handle it themselves.

Likewise, a community respondent described two types of models for how community groups in various parts of the cities deal with the police. It was noted that the South has a more collegial model in that they work collaboratively with the police department to try and get issues resolved. However, in the North the model may be perceived as more adversarial. The primary difference noted between the collegial and adversarial models 
was the ways in which the groups try to achieve things, though both models have the same end goals.

In regards to the geographical distribution of police-community relations, both groups of respondents acknowledged that the level of crime in an area may dictate the community perceptions of the police and/or police-community relations generally. It was perceived that community members in areas with more crime had more negative views of the police, whereas in areas with less crime or violence there were more positive relations. One community respondent stated, In a lot of those areas where their crime seems to not be as frequent or not seem to be as violent $[\ldots]$ you'll find that the relationship with those officers are different and I think where the crime seemed to be a bit more violent you'll find it's less of a relationship with the police department.

Another community respondent stated that when looking at people who are caught for criminal activity, they are the ones who have negative things to say, particularly the youth that are involved in the juvenile justice system already. This respondent further added that officers may feel it is difficult to have positive relations in communities where they are trying to actively establish order. Likewise, a front-line police respondent stated, "the people that interact with us voluntarily, they already believe in the institution of policing and they already trust us." Sharing similar remarks, one front-line police respondent notes,

It's easier to get along with everyone in the single-family areas because there is more one-to-one police interaction, whereas it becomes more difficult having that overarching community relations [...] If you're not educated and you don't have 
money, crime ensues $[\ldots$ and...] that same resident that is living a lifestyle tied to a criminal activity doesn't want the police around.

It is important to note that the difference of relations based upon which communities or groups are being referenced was not a finding unique to this study, and thus confirms prior research. Moreto, Brunson, and Braga (2017) found similar patterns when studying community-ranger relations in Uganda. They noted that "respondents were careful not to generalize and oversimplify community-ranger relations and recognized the variability among and between different communities and residents" ( $\mathrm{p}$. 931). This variability in relations in Hartford was also evident during participant observations via ride-alongs. For instance, there were some areas within the various neighborhoods that were historically characterized by high crime. During one ride-along the officer drove through various parts of the city and he gave instructions to pay attention to differences in community body language and interaction. It was apparent that in the areas with high crime, residents would often be hanging outside of and congregating in front of certain stores, houses, or buildings. Here, these residents often offered either blank stares or more serious facial expressions. While residents in these areas would greet or communicate with officers, it appeared that this interaction often occurred with officers who had established and pre-existing relationships within these communities or if the officer initiated the greeting or conversation. In other parts of the city, particularly the more affluent areas, the outside activities were more likely to be walking animals, exercising, or individuals outside with their children. In these settings, more interaction from the community was observed and often included waves to the 
police officer or verbal greetings. Further, in these areas, community members often initiated the greeting.

Despite disagreements as to the current state of relations between the police and the community, both community and police respondents emphasized that efforts were being made but there was still progress to be made in bridging the gap. For instance, one community respondent noted, "I think we're headed towards a way [...] of [police] having a better understanding with the community and hearing their concerns. I mean we are headed positively to a better future. But is there a gap? Absolutely." Community members acknowledged that the current relations are a "work in progress." Likewise, a police manager noted that improving police-community relations requires "an ongoing philosophical change." Echoing this, a front-line police respondent also stated that policecommunity relations is

something that you don't just get, you have to constantly work toward, you have to constantly evolve. We have to constantly learn [...] and no matter how long you're willing to learn and willing to work hard and willing to do things, you got to keep it going because once you stop it just kind of stops.

There was also an acknowledgement that Hartford is doing better compared to other places across the country. This view underscored the importance of comparative performance and/or assessments and the ways in which they factor into self-assessments. For instance, one community member who was new to the city of Hartford reflected on her previous city and stated, "I've only been in Hartford for a year and what I've seen happened here in Hartford, I've not seen that level of collaboration [between the police and community] happening in [my former city]." A police manager also stated, "the 
police-community relations is not terrible, but it is not Ferguson.” These sentiments portrayed that knowing what and how others are doing in other locations can put things into perspective when assessing successes, failures, and goals.

Furthermore, positive community perceptions of the police department were often personalized to specific individuals within the police department rather than in reference to the police department as a whole. More often than not, community respondents would refer to the chief of police and his leadership specifically for positively impacting policecommunity relations in the city. One respondent recounted the time he went to the city council meeting and stated, "You know we haven't had a Ferguson here, we haven’t had a whatever, there's a long list of them now, right? And one of the reasons we haven't is because we have [this] chief." However, when speaking to police respondents, they more often acknowledged the work of the front-line police, as opposed to giving the chief of police all of the credit. For instance, one front-line police respondent noted, "I think as a department we do very well as a whole to act in a professional manner and to always get out there and do the best job we can." Likewise, a police manager noted that the frontline officers "try to address the community problems" and that "the walk beat [officers], community service officers, and patrol officers are constantly getting thank you notes." Thus, there were differences among the community and police interviewees as to who was truly responsible for making a positive difference in police-community relations. Nonetheless, these diverse perspectives may allude to the fact that a team effort is needed from the entire police department and that there are individuals responsible for impacting different areas. 
Cultivating soft skills. Respondents often emphasized soft skills and their impacts on behavior as important determinants of police-community relations. These were noted to affect relations because they were directly evident in individual policecitizen interactions and could have immediate impacts on citizens within a situation. The specific factors that were raised included communication skills and character traits.

Police and community respondents alike emphasized communication as a way for the police to build positive relations with the community. Communication was discussed at two different levels: individual-level (or incident-level) communication between officers and community members and organizational-level communication targeted primarily at community leaders. The community respondents and police managers both listed individual-level and organizational-level communication as important factors, whereas the front-line officers focused solely on individual-level communication during police-citizen interactions. Figure 9 outlines a graphical display of the mechanism and processes by which communication impacts police-community relations.

Community and police respondents both emphasized the importance of officers' character traits. Character traits were emphasized as important because of the implications they have for officer treatment towards and behavior in the community. Since police officers have a wide range of discretion coupled with minimum supervision while performing their daily duties, it is important that their behavior in the community is in line with the quality of service that is expected of them. The interview responses clearly portrayed that officers who have certain character traits (e.g., being compassionate, caring, and respectful) are able to perform appropriately during their 
everyday interactions with citizens. Figure 10 outlines a graphical display of the mechanisms and processes by which character traits impacts police-community relations.

Winning the community one person at a time: Individual-level communication.

During individual police-citizen interactions, communication was emphasized as a way to build relations. As one community respondent stated, "It is all relationship building starting with conversations. The 'hello, how are you?' Those conversations.” Likewise, a front-line police respondent simply and blatantly stated that "community relations is communication," which is a way to "win the community one person at a time."

Communication offers a way to engage the community and provides officers and community members alike the ability to get to know each other. Effective communication can impact relations by portraying to the community the human side of police and by showing they are caring and want to help. This type of communication fosters trust, understanding, and comfort in the community, all of which break down barriers between the police and community. One front-line police respondent declared the importance of engaging in communication with the community, in that it offers a

back and forth conversation, now we're having a conversation now we're talking now we're getting things going and they get comfortable and we get comfortable. You find out, "oh I have this in common, I don't have this in common" and "this is my view, and this is your view" and it's very back and forth.

In discussing initial racial barriers that may exist between police and the community, a community respondent noted that, without having a conversation with them [the community], first impression, they see you they go "oh, he's one of them" or "she's one of them" [...] But you can 
always break that down by just conversation, like "listen, I'm here to try to help," you know, "I come to be the helper, but I understand I'm the authoritarian." Likewise, a front-line police respondent noted that just talking with the community "break[s] barriers, and that resistance kind of just melts away when they realize that you're just a human being just like them."

Thus, effective communication offered a means by which to build trust in the community. One front-line police respondent emphasized the importance of maintaining open lines of communication with the police in order to strengthen trust. Similarly, a community respondent noted:

Trust is always difficult to build, very easily you can lose it. So, right now, I believe they have a good percentage of trust. And that's only coming through communication. That's key right there. It's not programs, it's not who you know, it's communication. And it's not with other officials, it's with the folks that pay the taxes here, that lives in the neighborhood, the mom and pops, the small businesses. So, communication is key.

Another way in which communication impacted relations was by serving as a deescalation tactic during police-citizen encounters (often referred to as "verbal judo"). During these incidents, communication can be a means of preventing conflict from occurring that would harm relations. Further demonstrating the importance of communication as a tool for de-escalation, another front-line police respondent recounted:

I talked to an officer one time, when I first came on [the] job, I think at 22 years on job. He said, “I never use my baton. Never had to. Because I've always had the 
respect for the community, and they gave me the respect. And I might have yelled, I might have grabbed, I might have sworn, but, in the end, I never had to use physical violence for the most part because of the relationship we have." [...] Use your mouth. Why use your fist, your gun, your hand? You know, use your mouth.

Likewise, a community member mentioned that officers' attitudes can actually agitate and exacerbate a situation, and

if they would've come in like "listen I'm here to try to assess the situation, you sit over there, you sit over here, who wants to talk first?" Now you begin to mediate, then negotiate, try to figure out what's going on before you have to arrest somebody. But they come in [causing] more problems sometimes and you could actually resolve them.

During one participant observation (a police ride-along), a patrol officer responded to an upset juvenile—who was known to be a "runner" (i.e., someone who often ran in the presence of police officers) - by emphasizing how much she cared about him and wanted to really help him. She explained her actions to him as she performed them, such as letting him that the reason why she had to check his backpack was to make sure there were no weapons in there that he could use to harm someone. He began cooperating with her until another officer came on the scene and started using profane language and commands directed towards the juvenile. This aggravated the juvenile and he began stating how he did not do anything and questioned why she was talking to him like that. These two very diverse responses to the same situation demonstrated how communication can impact police-citizen interactions, both positively and negatively. 
Two key characteristics that were emphasized along with communication were respect and empathy. The idea of needing to incorporate both respect and empathy during police interactions with community members in order to improve relations is aligned with the procedural justice literature. Procedural justice is focused more on the process of interactions rather than their outcomes. At a surface level, procedural justice argues that people are more satisfied with police services when they feel they were treated fairly and with respect (Worden \& McLean, 2016). Communication is also a key component of procedural justice in that service recipients should be given an opportunity to voice their concerns and explain themselves while also being provided with an explanation from service providers pertaining to the service or treatment. For example, if a community member is pulled over for speeding, the police officer can explain the reason for the traffic stop rather than just directly issuing a ticket.

Police respondents often stated that a demonstration of mutual respect was key during police-citizen interactions. They acknowledged their own desire to be respected by the community, but also noted the importance of them giving respect to community. For instance, one police respondent stated, "the biggest thing that saves the city is there is mutual respect." Likewise, communicating empathy was often mentioned as it pertains to demonstrating to the community that police understand their current situations. For instance, in a casual conversation, a police respondent recounted a time when he was making an arrest at someone's home. He asked the person to step outside prior to placing the handcuffs on him, after gaining compliance the officer explained that he did not want to make an arrest in front of the children that were in the home. The officer further shared that the person he arrested thanked him in the end. 
Communication has impacted police-community relations in Hartford because it serves as a way to humanize the police and portray "the heart behind the badge," which allows officers to truly connect with the community and build relationships with them. For instance, one police manager shared,

I'm an advocate of shaking people's hands and talking about nothing $[\ldots]$

Because our lives are intertwined. Although perceived separately, we're intertwined. We have the same problems our kids have, or your kids have. We have the same problems marriage-wise or weather-wise or driving-wise [...] So, if I get police officers to share those stories, “Oh, when I was a kid—this kid's not bad out there because when I was a kid, this is what I did." So, if you share their human side, that's what folks thirst for out there. They thirst for that, just the [positive] interaction [with] police officers [...] Did they know those are real people? That there's a heart behind the badge? That's huge.

Front-line police respondents often acknowledged that some officers are better at communicating than others, however they would specifically recount their own effective communication skills used during individual interactions with the public. The communication that happens in these individual-level interactions may seem like exercising an innate ability or trait, but they have organizational implications for both hiring and training. For instance, one police manager stated that hiring was at the heart of the issue, emphasizing "you need to hire super good communicators, because officers need to take the time at demystifying things and explaining themselves. The biggest community relations you have is at the street level." Likewise, other front-line police respondents highlighted the fact that officers can be trained to de-escalate situations 
through communication rather than relying solely on the training that teaches them to make arrests.

\section{Organizational communication as a means to keep the community informed.}

Police managers and community respondents also acknowledged the importance of organizational communication. In this context, "organizational communication” referred to the leadership in the police department keeping the community informed by disseminating information to the public about critical incidents, which helps to manage misinformation, keeps the peace, and prevents negative community responses. Thus, communication as a whole was something that the police department prioritized as an organization. One community respondent noted how critical this type of communication is by stating that,

we have not fallen into the chaos of destruction, right, of burning buildings and store front windows being broken, I think it's the fact that we have a good amount of leadership, one. Two, communications [from the police department] has improved dramatically.

Likewise, a police manager noted, We've had shootings, police-involved shootings. We've had excessive force on video. We've had very sensitive incidents, protests. And we manage them and communicate, and we partner with so many people that we've been able to have almost zero issues through these times in an impoverished, diverse city where in other cities this would have been absolute chaos. 


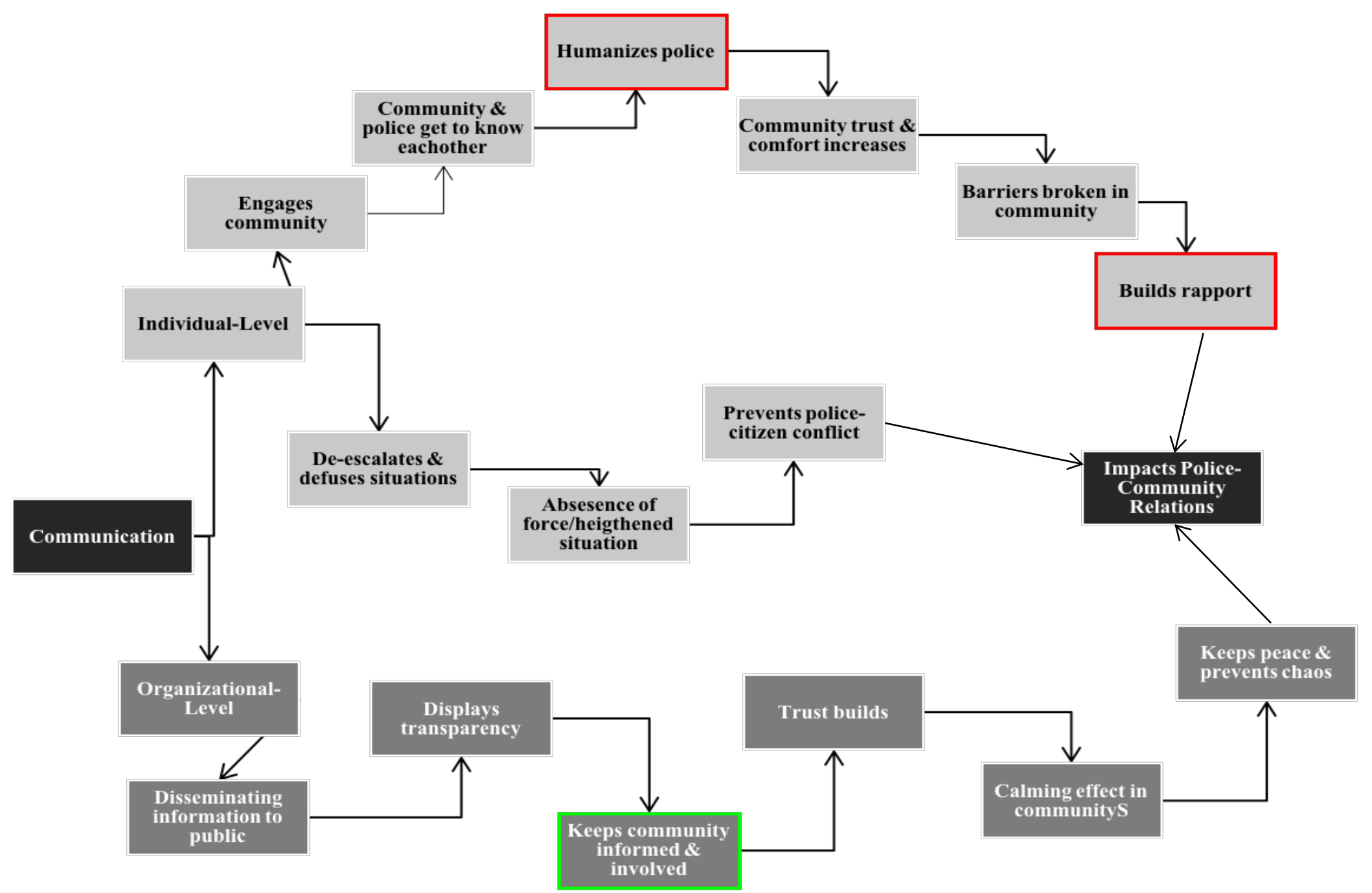

Figure 9. The impact of communication on police-community relations.

Note. Red outline means this was mentioned by police interviewees only and green outline is for community respondents only. 
Effective organizational communication can only occur with transparency. Transparency is essential because it begets trust. A police manager stated that the police department is

very transparent right now which is good. [The chief] has always tried to- since he's been the chief that was one of his biggest things, is transparency. [...] With a lot of the community leaders when they wanna know about things, he's very open with it. He'll tell them, "Yep, this is what's happening, this is what we're trying to do," and everything like that. That helps build trust.

The police department also maintained a listserv of community leaders and stakeholders to regularly send pertinent information to them directly. A community respondent noted that the email lists are the police department's "attempt to really try to be as communicative as possible." This respondent further expounded "they add a lot of people to a list, even when it comes down to series of violent crime [...] And that's another key piece, $[\ldots]$ no chief prior to that has taken on that strategy."

Respondents also shared that there were times where police use of force incidents occurred and the police department called in various stakeholders for an in-house debriefing meeting to inform them of the incident, show video or evidence, and provide explanations and/or take responsibility for their actions. These meetings occurred prior to information being provided to local news sources or other media. Disseminating this information directly to community stakeholders was seen as a form of providing community awareness but also as a way to empower the community. Specifically, one community respondent stated that this emphasis on communication keeps the community involved and informed. Being proactive and direct about informing the community 
demonstrated "respect for [the community], but it's also showing them that they know that they can rely on [the police] to be truthful and up front about everything" as noted by a community respondent. Another community respondent noted that the police chief directly communicating with the community "has a calming impact in that people don't jump off, fly off the handle and fight the police like we used to. [...] it makes a big difference in terms of how people deal with the police in general."

Not by the color of your skin, but by the content of your character: The link between officer character traits and behavior. Both community and police respondents emphasized the importance of being compassionate, caring, and respectful. Officers who are compassionate and caring convey that they are concerned about the community in their actions, which impacts the way that they perform their duties. For instance, one front-line police respondent stated, "follow ups make residents feel like they really care, and that is the part of being involved in the community, they are not just a robot in uniform." Officers that care and are compassionate will want to help the community. A community respondent shared,

A lot of these people are driven 'cause they have great compassion for people [...] And when you interact with people that care about people, you make a big difference. That don't mean 'cause you're a police officer that if you come to a crime scene and if you just there for a paycheck you'd setback and holdback. But when you're concerned about somebody and you're concerned about to save them, you go in and you do your job thoroughly.

As one community respondent noted, the "community needs to know that its law enforcement cares about them." Community members can easily detect when an officer 
has little or no concern for their livelihood. For instance, a front-line police respondent noted, "if you don't give a darn about the community [...] people will know. People know you don't give a shit about 'em." Likewise, the community can see when the police do care about them. Another front-line police respondent stated, "we care about protecting this city, residents. And you got to have a belief and love the city, believe in what you're doing. And if you do that then people see it." When residents see that officers do care about them and their community, this impacts residents' perceptions of officers as well as their willingness to work with them. For instance, one community respondent noted,

I just think that you can't come in here with a mindset of "I'm just going to go 9:00 to 5:00 and get a paycheck and be out." I think you actually got to care about your neighborhood, where you're working, care enough to have passion to build relationships within, you know, with community residents. [...] So, when community residents see you as an officer, a person in uniform that truly cares about them I think they're more willing to open up and have relationships. Respect was often emphasized as a key trait that officers must possess to be effective. When officers respect the community, this has a positive impact on how they treat the community. Treatment can be manifested in a variety of ways, such as officers being honest with the community and treating the community fairly. Honest interactions are critical for building community trust. As one front-line police respondent explained, "I think cops here are really good for the most part [at] just being honest and up front with folks, and I think that's why to a certain extent they trust us, they don't get too crazy." 


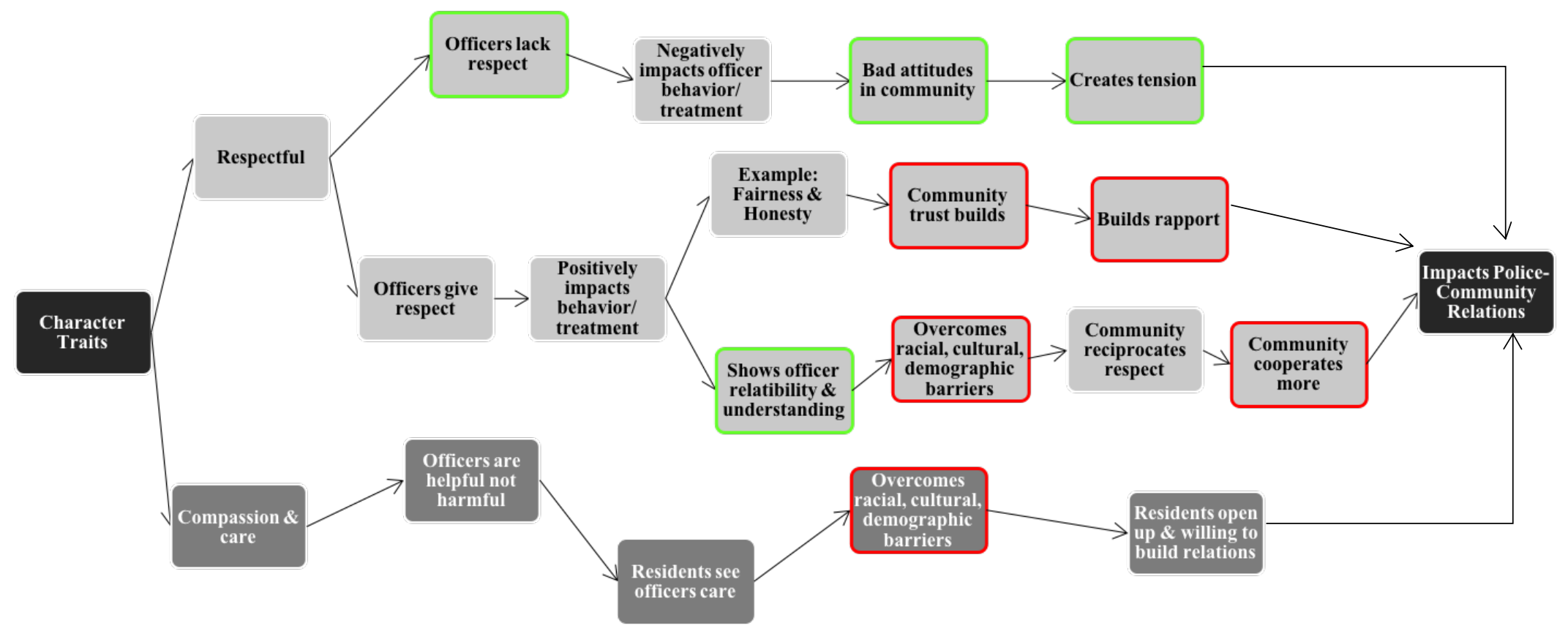

Figure 10. The impact of character traits on police-community relations.

Note. Red outline means this was mentioned by police interviewees only and green outline is for community respondents only. 
Likewise, a community respondent gave an example to demonstrate how respect impacts officers' actions, by stating that it is about

the person who's wearing [the uniform] being able to relate to you. You know, “you broke the law I got to arrest you [...] but I'm not going to slam you down on the ground and treat you like you're a piece of crap or something." You know treat them with respect.

When officers' treatment towards the community improved, this demonstrated to the community that the police can relate to the community and understand the community. Police respondents often noted that respect and its impact on officer treatment has the ability to overcome racial, cultural, and residential barriers as well as other demographic differences. While this sentiment was not explicitly shared by the community, one frontline police respondent noted, "you overcome the race thing immediately [if you] treat people with respect." Echoing these sentiments, another police respondent expounded by saying,

I think it's just building rapport and just looking at a person and saying, "you matter, what you're saying matters to me." And I think that makes a big difference. I don't think it's so much "I grew up in the city, you grew up in the city." I think it's "I care about what you have to say, and I'm here, and I'm gonna try to help you as best as I can.”

The community also reciprocates the respect that is given to them, which leads to more cooperation between the police and the community, as well as builds positive relations. A community respondent noted, "you give people respect, respect will come back to you and you can't do your job unless you have your community because your 
community is [the] one that's going to give you the information." Alternatively, when there is a lack of respect by officers to the community, this negatively impacts officers' behavior and treatment. Such treatment leads to negative community perceptions and feelings towards the police, which hinders police-community relations. For instance, a community respondent shared that when "people are not treated with respect, as a result you have the folks in a community have a bad attitude towards the police."

The police respondents often emphasized that they do possess these character traits and already behave with compassion, care, and respect. It was apparent that this behavior was something that was reinforced by the police department as a whole. For instance, one police manager stated, "I instill that, and I'm sure sergeants do too, which is 'do your job, be professional, be fair,' and I think for the most part our guys are." Another police manager spoke about the importance of looking for these traits in hiring as well, as he stated it is "how you vet your police officer and hopefully through the hiring process we hire the person [...] that will be a fair and a respectful police officer." Also, in the police academy where new officers undergo training, there are seminars on morals and ethics, where they instill respect and fair treatment. Likewise, community members sometimes go to the academy trainings to discuss community expectations. A community respondent with prior experience doing this shared,

I go to the academy to talk to the recruits and I told them what we are expecting as [a] resident. Respect, we need to be respected, and respect goes both way because it doesn't matter if I respect you and you don't respect me. So, respect comes out of understanding me and how I treat you. If you go out and you speak 
bad about me or you know, think you are all that up there and I'm just down here, no, we got to be on the same level.

Investing in human resources. Another impacting factor of police-community relations pertained to the importance of human resources. Investing in the personnel of an organization is crucial in order to sustain the organization and its success. In the policecommunity relations context, two themes within the human resources domain were found to be particularly salient. First, interactive and specific trainings were essential. Trainings that engaged police, provided them with new understanding, and broadened their interpersonal skills seemed to be the most effective (see Figure 11). The second theme that highlighted the importance of human resources was sufficient personnel staffing. Respondents detailed the various ways in which inadequate staffing of the police department impacted police-community relations (see Figure 12), from affecting officers' workloads to causing officer stress to removing community resources (such as officers dedicated to community engagement responsibilities). Building community relations is a labor-intensive task, and thus having adequate training and staffing are essential.

Tell me and I forget, teach me and I may remember, involve me and I learn: Training officers to deal with diverse populations. Training at-large was not often cited by police officers as impacting police-community relations, but rather as more of a requirement of the job. However, the two specific trainings that were consistently mentioned by police respondents in particular were cultural awareness training and crisis intervention training. These trainings proved to be impactful for two key reasons. First, they assisted officers in understanding or dealing with different types of populations. 
Second, they were both interactive (either hands-on or experiential) trainings as opposed to the traditional format viewed by many officers as "dry, off-the-textbook training."

Police respondents often referred to one specific type of cultural training that was implemented by the police department. The police administration invited different cultural and religious groups from the community to speak to the officers during one of their mandatory trainings, which provided cultural awareness and sensitivity. For instance, there were Sikhs who spoke about the differences from the Muslim religion and how carrying a sword/knife (a "kirpan") is for religious purposes. Officers noted that learning about these cultural differences broadened their understanding and allowed them to effectively respond to calls for service. This seemed to be particularly important in Hartford due to the magnitude of diversity present. One police manager narrated, We did [a training] a few months ago, we had people come in, I don't know where they came from and I don't even know who they were but there was a Sikh, a Hindu, a Jew. [...] it was exposure to different religions and the kind of real tenets of the religions and, I thought it was really interesting $[\ldots]$ They did a great job talking to a bunch of cops who were probably half asleep. This is who we are, and this is what it means, and this is why we're not this and this is what this is. Police interviewees also acknowledged that hearing firsthand from actual community members rather than police administration or managerial staff provided them with more personal interactions, which they felt were more meaningful and would have more enduring effects. Some police respondents even suggested the need for more cultural sensitivity and/or awareness training because of their positive benefits. Another police manager noted the importance of cultural training by stating, 
That's a major thing that we should have, cultural training, more and more. [...] If you get it more, get that diversity, the cultural training, I think you'd be more of understanding for the officers as well as the community. [...] We've had one a few years back with the Muslim community and they explained to us, "Sometimes we shy away from going to cops because they come in, they don't know our culture. They don't understand where we're coming from. We are peaceful. We have certain rules that not even their higher people will break because these are the rules." Stuff like that that we need. I mean, yes, I won't take off my boots to go into a mosque because that's gonna take a lot of time. So, I'll wait for them outside and ask them, "Do you like to speak up here or somewhere else privately where I won't disrespect the mosque?” Stuff like that I didn't know until I had that training.

Likewise, a front-line police respondent explained how hearing a Muslim individual speak about the things he goes through bred relatability. This front-line police respondent further explained that the way this Muslim individual spoke left the officers in amazement. Specifically, this police interviewee recounted his realization that 'I'm Puerto Rican, and I can relate to some of the [stuff] that he's saying" and he further added that "it kind of gave me a different point of view."

Crisis intervention training, aimed at improving police interactions with people who have mental illnesses, was also emphasized as an effective way to enhance policecommunity relations due to what interview respondents perceived as a large population of mentally ill people in the city. Not all officers in the police department received this training due to the expenses (both in money and time) associated with it. As of July 2017, 
a total of 73 sworn employees in the Hartford Police Department had received crisis intervention training. However, the police interviewees who did receive this training often reported reaping the benefits. This training provided officers with the tools needed to recognize signs of mental illness and to diffuse problems. Police respondents noted that this training taught patience and empathy, bestowing an interpersonal skillset that some may not have already possessed. When asked specifically about a training that was impactful, one front-line police respondent claimed,

The last one I went to was crisis intervention, which I really, really thought was good, and I would suggest for any and every officer to go to it, because it's a great program. [...] It teaches you how to deal with people with...mental health issues. And just understanding where their thoughts are, and stuff like that, whereas a person who doesn't have the training may, but just doesn't really know what they're experiencing, so [...] I'd go in with a better mindset. I'll go in and say, well, okay, I'll talk to somebody but he's not understanding me because maybe he is hearing voices. 'Cause they had us listening to this recording of somebody that could be hearing voices and all the crazy stuff that kind of goes on, whether it be somebody, another voice talking or just some bus noise going by. So, before, I never thought about it that way. I would just kind of go and [say] "Are you not listening to me? Why aren't you listening?" whereas now, I would get it differently. Maybe he's not hearing me. Maybe he's hearing the different voice. Maybe he's hearing something that's not making him pay attention. 


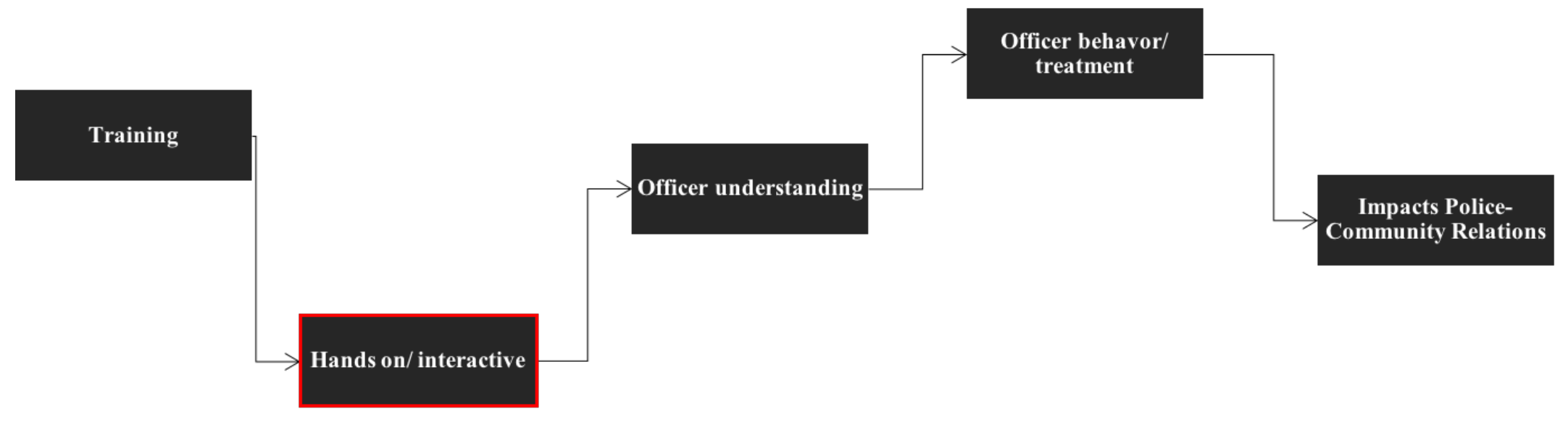

Figure 11. The impact of training on police-community relations

Note. Red outline means this was mentioned by police interviewees only and green outline is for community respondents only. 
Respondents were also aware of the limitations of these types of training. They acknowledged that change takes time. For instance, one front-line police respondent stated,

So, I think that took a while to get drilled into officers' heads that the police department is moving away from aggressive policing, aggressive quality-of-life enforcement policing, things like that. And I think that with fair and impartial policing and cultural sensitivity trainings, I think people are getting it, officers are getting it slowly.

Also, it was noted that participants get as much out of the trainings as they put into it. For instance, one respondent referred to hearing jokes made by other officers behind her during the cultural awareness training. Thus, as the adage goes, you can take a horse to the water, but you cannot make him drink. Unfortunately, community respondents knew less about the types of trainings provided in the police department, and therefore often emphasized a desire for additional as well as improved training. Some community respondents explicitly stated that there was a need for more cultural training for police officers in particular. For instance, one community respondent stated, The time allotted for that community engagement of cultures [...] I don't remember the exact amount of time for it, but I remember feeling like, "Wow" like, “That's not enough." So [...] one thing they could do better, I feel like, is having more cultural training especially in a city like Hartford [...] I think the officers need to have a better understanding [...] of how to engage with these communities. 
Seeing as these were the two trainings most frequently mentioned, overall police sentiments regarding the lack of importance of training as a whole may be attributed to the nature of learning on-the-job and overtime with more experience (e.g., see Bayley \& Bittner, 1997; Paoline \& Terrill, 2007). For instance, one police manager noted that, in regards to training, officers "learn by experience. You can read a book all you want, but if you don't know how to implement that and use it, it's pointless." He went on to state that the department "can make more time [for] training but [...] exposure is the best way to learn." The importance of learning by doing was also confirmed by the fact that the police department had implemented experiential training into both the academy and inservice trainings (as portrayed above with crisis intervention and cultural training).

Likewise, it was observed that several interactive activities were integrated within lessons for police academy trainings of new recruits. Specifically, during the fair and impartial police training, the trainers incorporated role playing, group work, and real-life scenarios of police encounters for the new hires to work through and problem-solve.

Time spent on hiring is time well spent: Inadequate staffing levels diminish police-community relations. Community and police respondents alike emphasized the impact that staffing levels have on police-community relations. Issues revolving inadequate staffing levels were discussed as something that harmed police-community relations. During the time of the case study (the summer of 2017), the police department was understaffed by approximately 100 officers. This staffing issue was the result of financial constraints due to the economic state of the city as well as large retirement classes phasing out of the police department. An independent staffing and deployment analysis of the police department noted that as of 2014, Hartford's police department was 
understaffed by a minimum of 60 positions (Daigle Law Group, 2015). This finding demonstrated that the lack of adequate staffing of the police force has been an ongoing trend.

The lack of personnel in the department hampered police-community relations through a variety of mechanisms. First, both police and community respondents agreed that understaffing increases officers' individual workloads. A shortage of staffing leads to officers becoming overworked, the resulting stress of which can cause harm to the officer. There were slight differences in the language used by interview respondents when describing the harm that understaffing could have on police officers, however the semantics undergirding these differences remained the same. For instance, community respondents often mentioned notions of "officer fatigue," whereas police respondents would discuss "officer stress." One community respondent noted, "the more officers you have, the more you can dispatch. So that would help $[\ldots]$ in some of the behavior, maybe they are not so tired, so drained, so short tempered that maybe they would behave better." Whereas, a front-line police respondent described the impacts on officer stress, by stating So, you're getting these officers that are overworked, hustling calls. [...] A lot of times, you don't even get that time to take a quick break. [...] So, you're stressing, you're not happy, [compared to] if we had the amount of officers that we needed. Officers having increased workloads also leads to longer response times, which in turn creates dissatisfaction in the community. There were constant narratives told that some calls for service were on hold for two to three hours or more due to inadequate staffing and the demand for police services in the city. A police manager clearly articulated these sentiments by stating, 


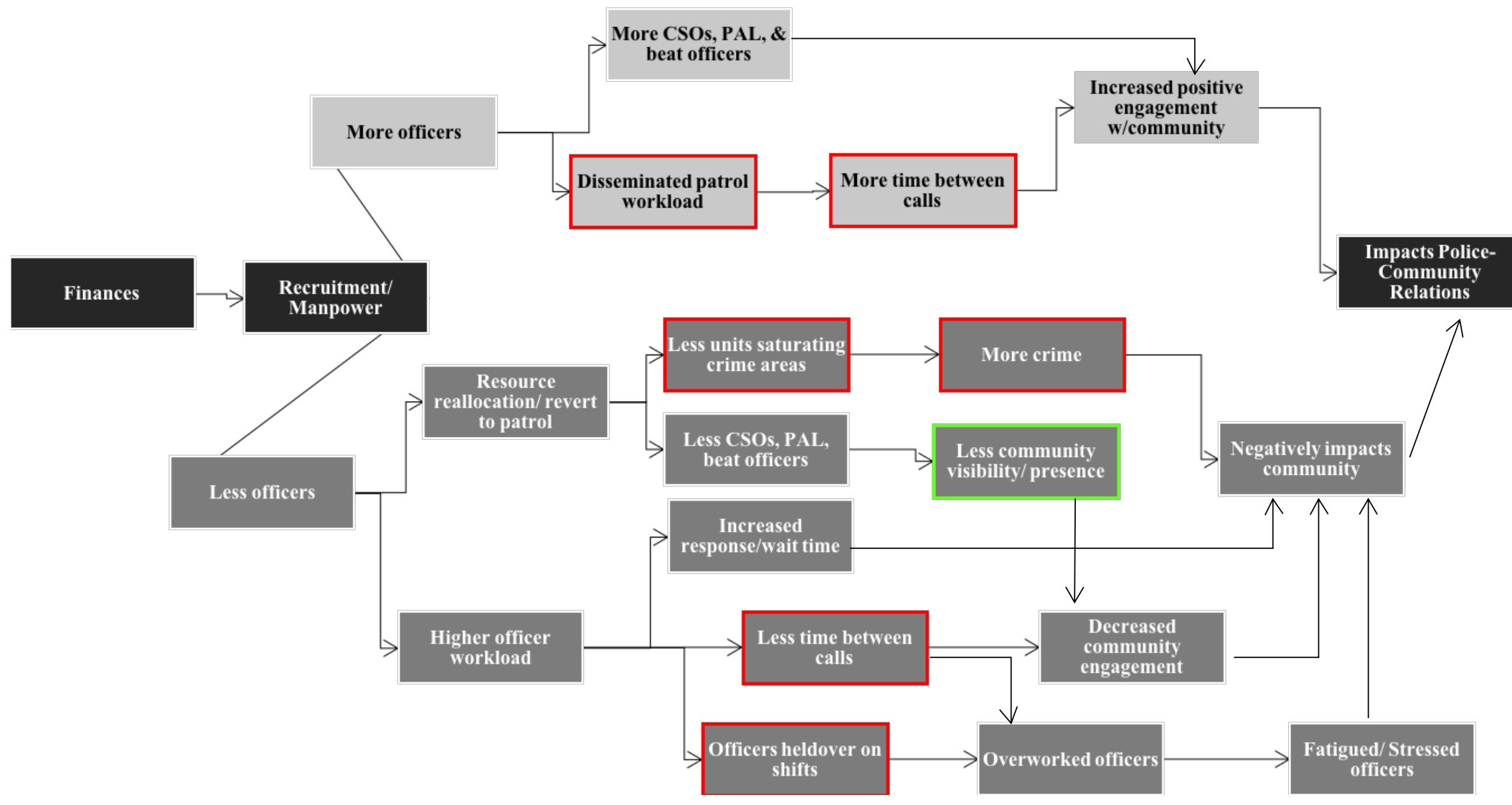

Figure 12. The impact of manpower on police-community relations

Note. Red outline means this was mentioned by police interviewees only and green outline is for community respondents only. 
But meanwhile now we have full officers tied up that—and that's why people that have accidents in Hartford, they're waiting three to four hours. 'Cause that's not an emergency call unless there's an injury. So, we can't effectively deal with the few people that actually get in a car accident while commuting here or going home. They [the community] have to wait four or five hours. They're ticked. [And it is] because [police officers are] humping from call to call to call.

The community may not understand why it takes so long for an officer to show up and so attribute the delay to police officers merely being non-responsive. Such misunderstandings further complicate the police-community relationship. For instance, a community respondent explained,

Sometimes $[\ldots]$ there's not a positive view of police. Because A, they're understaffed. So, people are like, "Well, how come there's not an officer here taking care of this?" There's a turtle walking across the street and maybe one neighborhood's going, “That's important to them" where another neighborhood you have drug deals going down and another neighborhood you have domestic abuse. It's a lot. And if you're understaffed I think that you can't respond to everything. And as a result, certain people think that police are not responsive enough $[\ldots$ or $]$ they're not responding in a manner that they see appropriate. Second, respondents noted how understaffing pulls resources away from community policing specifically and community engagement activities more broadly. The police department has various subdivisions and specialized units inside of it, including but not limited to the patrol division, community-oriented officers, proactive units, as well as detective and investigative units. The patrol division of the police 
department was referred to as "the backbone" of the department as it is fundamental to operations, whereas other units may be considered "nice-to-haves" meaning that they are beneficial but not essential. Patrol is responsible for answering calls for service that are dispatched from the community. When there is understaffing, officers who are assigned to specialized units get pulled and the patrol division gets backfilled in order to assist with the high call volume. In prior years, the department had dedicated staff serving as School Resource Officers and Business Service Officers, but due to the staffing issues, these positions have since been eliminated. Thus, this lack of personnel translates directly to fewer officers being devoted to non-patrol related activities; and having fewer Community Service Officers, School Resource Officers, Business Service Officers, and Faith-Based Officers means less visibility in the community.

Community respondents often mentioned the lack of beat cops patrolling in the communities. "Beat cops" are officers who are responsible for patrolling a specific geographic area regularly, typically via walking or biking. These types of activities allow for non-enforcement related interactions that have positive impacts on the community. Thus, taking beat cops away can degrade the relationships between the police and the community because it removes opportunities for positive interactions. Expounding on this, a front-line police respondent eloquently elaborated,

I think it has a huge impact, because, if you don't have the finances, then you can't hire as many police officers as you would need to service the city. We had a lot of people retire, and we haven't had a big budget for recruiting [...] So it cuts the resources that the community members get, because now you don't have enough people on a patrol, right? And so, you cut down the resources as far as the walk- 
beat units. We used to have several walk-beat units that kind of just walked the streets, which makes it kind of more personal with the community. You cut down the number of Community Service Officers because [...] patrol is the backbone of the department, so that needs to be filled versus other departments.

Not having officers in these key roles diminishes the potential to build strong positive community relations. Likewise, patrol officers may not even have the time to try and leave positive impressions or have positive interactions throughout their shift due to the constant calls for service. Another front-line police respondent stated that being understaffed

hurts our ability to forge strong relationships with the community because we also don't have as much undedicated time because $[\ldots]$ patrol officers specifically are going from call to call to call so they don't have time to grab a coffee with somebody, or talk to somebody. They're just there hustling and they're writing reports and the few minutes they get they just want to like park in a lot and just breathe.

Likewise, another front-line police respondent suggested that more employees would be better for police-community relations because

the workload would be less for people $[\ldots]$ they wouldn't necessarily be going call to call to call; you could take that extra 10 minutes and talk to the guy at the bodega, ask him how things are going. You could stop in when there's an event and they're serving food and eat with other people. [...] So, I think having more people and allowing officers to spend more time out in the community. 
Lastly, police respondents added that not having sufficient staffing led to reductions in the units that were dedicated to crime prevention. In the past, the Hartford Police Department had a "conditions unit" that was dedicated to proactively preventing and reducing crime by "saturating high crime areas" and "going after bad criminals." This unit was separate from patrol because patrol is responsible for responding to calls for service, which is viewed as a reactive approach to addressing crime rather than being proactive. Some police respondents have attributed the understaffing as a direct cause for reductions in the proactive crime-fighting units, which results in more crime being left unaddressed and consequently harms the community.

Despite the current personnel issues related to understaffing, there have been new efforts to improve recruitment and hiring within the police department. Throughout the duration of the case study period, two cohorts of recruits were in progress (one was ending and a new one was beginning) as well as oral board examinations for an upcoming recruit class. Nonetheless, the external funding environment in the city heavily dictates the level of hiring that can occur within the police department, which subsequently influences the quality of police-community relations.

Intentionally engaging. The last impacting factor of police-community relations is intentional engagement. "Intentional engagement" refers to the combined efforts by the police department and the community to actively work together towards impacting police-community relations in a targeted and directed way. Such engagement efforts allow the community to see the police outside of their official uniformed capacity, as well as provide the officers with opportunities to see the community in a different light (outside of responding to the criminal element). Intentional engagement increases the 
likelihood that community members will be willing to share crime-related information with the police in the future (Crawford, Lister, Blackburn, \& Burnett, 2005). Two themes related to intentional engagement surfaced as important: collaborative relationships and external accountability.

"Collaborative relationships" refer to the police and the community working together towards a common goal (see Figure 13). The various ways the police and the community work together can be categorized into three classifications: (a) police engaging the community in internal police department activities (i.e., the community coming in); (b) police actively engaging within the community (i.e., the police going out), and (c) partnerships in which the community and the police cooperatively achieve goals (i.e., the police and community joining together). Engaging with the public in these non-enforcement capacities was often mentioned as positively impacting policecommunity relations. On the other hand, perceived ineffective implementation pertaining to external accountability mechanisms was often cited as a factor that did not improve police-community relations, but rather left a negative impression on the community (see Figure 14). Three formal external accountability mechanisms were discussed during the course of interviewing: (a) a consent decree, (b) a civilian complaint review board, and (c) a firearms discharge committee. Having these mechanisms in place were positive in and of itself, but they were perceived as not being enforced appropriately, and thus did not have the intended impacts on police-community relations.

Bringing the community in: Broadening community understanding of police activities and internal challenges. There were various instances where the police 


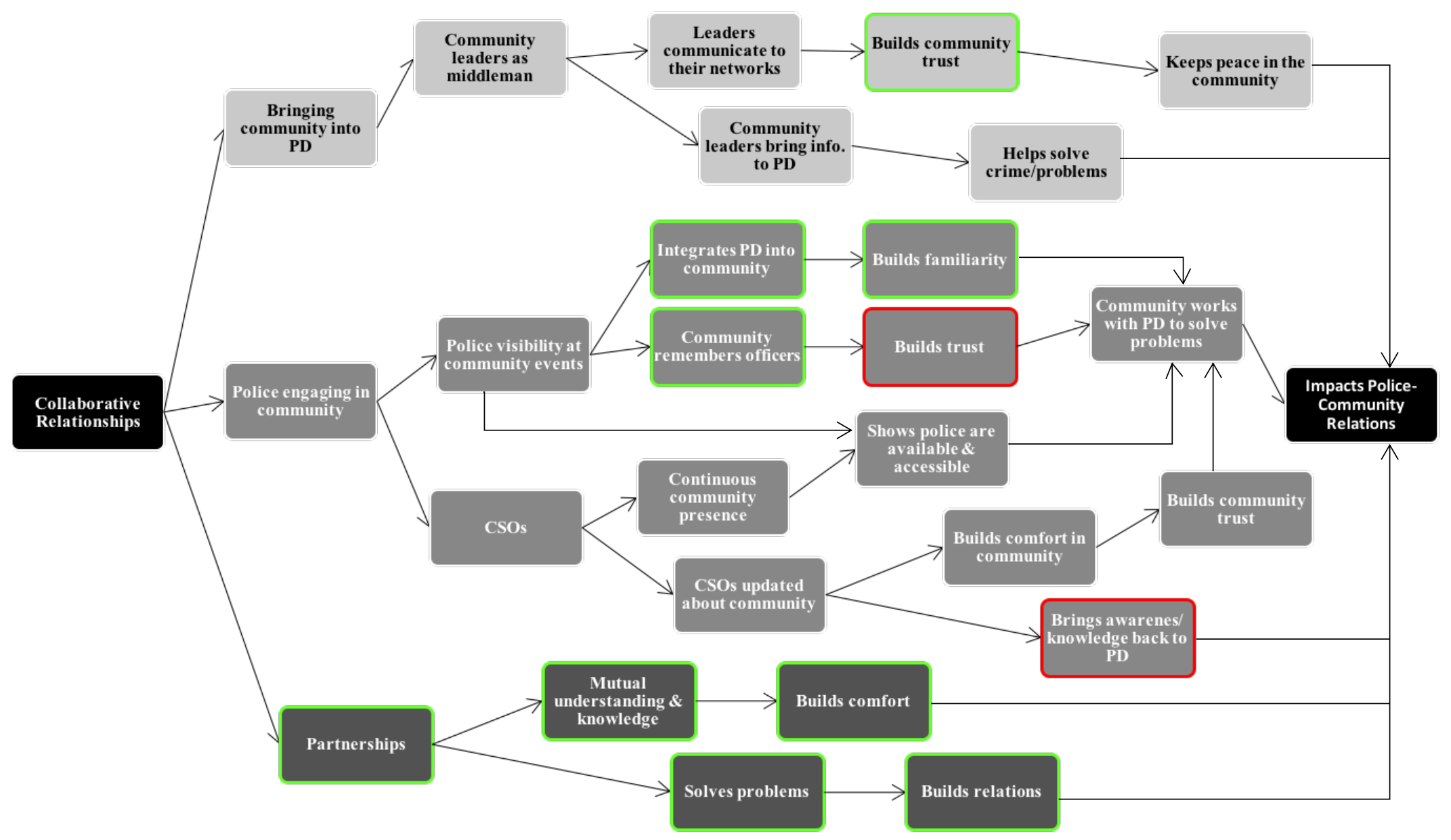

Figure 13. The impact of collaborative relationships on police-community relations

Note. Red outline means this was mentioned by police interviewees only and green outline is for community respondents only. 
department opened up its doors for the community at large or for specific community leaders. These events invited community members into direct involvement in police operations and activities, broadened community understanding, and provided community members with "insider" knowledge that they could then disseminate to the rest of the community (through their respective networks). In this role, the community leaders have often served as liaisons between the police department and the larger community. After gaining a more in-depth understanding of policing activities and internal challenges, the community leaders were able to help facilitate trust and support of the police department. Similarly, the community leaders helped the police department to understand challenges within the community and identify areas that need to be addressed. The role that these community leaders play can be referred to as "cultural brokering." Cultural brokering is a process by which individuals act as intermediaries between two or more diverse groups. Jezewski (1995) refers to this process as "the act of bridging, linking, or mediating between groups or persons of different cultural backgrounds for the purpose of reducing conflict or producing change" (p. 20).

In thinking about the roles that certain community leaders have played in bridging the gap between the police and the community, one community respondent shared,

But it took somebody like him to say, "No. You know what? I trust these guys [the police]. And they're doing something different" [...] I think that one of the biggest things that made a difference is folks in the community just saying, "I'm gonna tell you [the police] what we need" or "Listen. I'm gonna spend the time with you [the police]. So, you can hear what we need or what we're looking for." But also, "I'm gonna be a voice in the community, to start to change the hearts 
and minds of [the people or bring other leaders along" [...] That made a huge difference.

The police respondents also acknowledged the vital role that community leaders serve. For instance, one front-line police respondent stated that community leaders do address [issues] and they listen [to police concerns], and I think that's one of the reasons why the city probably hasn't blown up, because now those same people go back to the community and it kind of trickles out there, "hey, listen the police are working with us. Just let's use some common sense out here. Don't get crazy don't burn your whole community down."

Likewise, a police manager shared the importance of being "in good" with community and religious leaders because they have the power to either stir up or quell conflict. These types of engagement activities, combined with organizational communication (as discussed previously), were often viewed as being helpful for preventing major situations from erupting.

Various examples of the police department bringing in the community were discussed and observed. First, the police department worked with the public as well as various organizations to host regular open public CompStat meetings, where information pertaining to crime statistics were openly shared and discussed with the community. Apart from crime trends in the city, information was also discussed regarding predictive and preventive efforts. The police department described this effort as something that encouraged dialogue, questions, and recommendations from the public. A police manager elaborated on the impact by stating, 
Well [Public CompStat] shows our transparency, you know, it's open for the public to come and speak and ask any questions they have and there's people that can give them a straightforward answer. And if they aren't able to give them a straightforward answer they can give them the information they need, or they can get a contact info and get back to them later. Because they feel as though the information is going back and forth and it's a two-way street, it makes the community a lot more comfortable with what we're doing and what we're trying to do.

While some community respondents also emphasized the benefits of CompStat, they often referred to it as a way to receive information from the police department rather than framing it as a dialogue or a give-and-take between the community and the police. For instance, one community member noted,

Every month they have a meeting that they invite the community to at the police department $[\ldots]$ to give them an update as to what happened in [areas of the] city. All of the different commanders of the different communities give a report and you have a number of community folks there to be brought up to date as to what's going on in the particular areas as far as the police. [...] It's very good I mean we do it at least once a month.

Second, the police department also involved certain community members in hiring and recruitment. While the community leaders and police managers were aware of these initiatives to involve the community in hiring and recruitment, the front-line police respondents did not mention such engagement activities, and thus they may not have been aware of such initiatives. The police department formally established a hiring review 
committee that included a couple of community members. When there were potential discrepancies in police applicants (yet, that were not necessarily direct qualifiers), the committee was responsible for reviewing the file and deciding if they wanted this applicant to be a part of the police force. One police manager shared,

I think a lot of it [citizen's being on the oral board] just comes to understanding of how we do the process and we want to be fair, and ultimately these police officers that we hire are going to serve the community. So, we want the community input $—$ and there are minimum requirements that we have to abide by $[\ldots]$ through the police officer standards and training council. Those requirements are kind of center stone. But when it comes to answering questions, what type of person you're looking for, we want the community to be involved in that $[\ldots]$ [To] help formulate questions for new incoming police officers and then see what their responses are and then have input into whether they think those responses are good or bad.

Hiring residents and people of color were actions often raised due to Hartford being a majority-minority city and the Cintron vs. Vaughn consent decree that mandated certain levels of representation. However, the police department had not yet achieved the levels mandated by the consent decree to attain sufficient representation of the community. Despite such challenges, the chief of police appeared to be adamant about widening the pool of applicants to include more Hartford residents and racial minorities. One of the strategies utilized to aid in such efforts was to involve community leaders in the recruitment process. Community respondents were the only group of interviewees to 
discuss this process; nonetheless, they often shared examples from their own recruitment efforts. For instance, one community respondent noted, I'm involved in recruiting myself. The chief asked me [to] help as far as approaching individually young men and women as well who I think would make a good officer and see if I can encourage them to get involved. And, I've been doing that now for well over a year and I've had some success as far as references from individuals. I think one has become an officer that I referred. [...] Some didn't make it through the oral [...] Some dropped, didn't make it through the physical.

Likewise, echoing these sentiments, another community respondent shared some of the challenges faced in recruiting. He expounded, it's like you just don't get enough applicants from Hartford that want to be on the police force. So, while people could say what they want to say, being on the inside, I've seen it, I've been out there, I've been helping recruit. And it's unfortunate that people would say, "Yes, we need more Hartford residents," but then not enough people are stepping up.

Thus, inviting the community to be directly involved in these activities broadened the community's understanding of some of the issues faced in recruitment and hiring.

Lastly, it was noted that the police department also brought community leaders in to experience what the job of a police officer entails. This activity included bringing community leaders for a citizens' academy training as well as for ride-alongs with police officers. The citizens academy was a formalized initiative that the police department put 
on for community members; however, it was discontinued for reasons that were not made explicit. Nevertheless, one community member shared its impact by stating that after doing that Citizen Academy from the police department, I had a different view in general of the police. [... It] was really an eye opener for me to see what a cop actually goes through on a daily basis. And so, to me, it was just the thing to do to get to understand them and when you understand somebody, you can work with them much better.

Community members going on ride-alongs was more arbitrary in comparison to the Citizens Academy; nevertheless, their stated effects were similar. One of the police managers shared that after community leaders participated in ride-alongs, it opened their eyes to see what police go through in responding to calls for service, and it impacted their attitudes and perspectives. He then brought that newfound perspective to his network, and subsequently even supported officers during various incidents on several occasions. Another community leader noted that after doing a ride-along, it caused feelings of anger due to the "lack of respect for the law and the officers that there is throughout the city." However, it was noted that it was not necessarily the Hartford residents who were behaving disrespectfully, but seeing as the city is the capital and has a highly transient population, there was some disrespect exhibited from visitors.

Overall, it was found that engaging the community in the internal affairs of the police department was beneficial in terms of positively impacting police-community relations. Specifically, such engagement efforts humanized the police force and gave the community more of a voice, thereby facilitating positive community perceptions of the police department. 
Getting the police out: Police engaging in community-oriented activities. The

police department made a consistent effort to engage within the community in order to conduct problem-solving activities, address community concerns, provide resources, perform community service, and be present.

Both community and police respondents discussed the importance of the police department having officers who are dedicated to participating in community-oriented activities (such as the Community Service Officers and the Faith-Based Officers). These officers were often referred to as liaisons, points of contact, and/or lifelines from the community to the police department. These officers were typically assigned to a neighborhood within the city for longer periods of time, thereby providing the community with stability and consistency. They were not directly responsible for answering calls for service (as patrol officers do), but rather for attending to the needs of a community. This setup allowed the community and the police to develop familiarity with each other as well as enabled accessibility for the community. For instance, a police manager noted that the community officers were involved in

all kinds of stuff, schools, after-school programs, church programs, they're in everything. [The community will] see a lot of their officers and they're on a first name basis with their officers. They're "their officers". "I want my officer," that's what they say. And they're used to that. So, I think the community likes that relationship and a long-term relationship or someone's there for years. Some of the responsibilities of these officers included attending monthly neighborhood meetings and community events. When the officers attended these meetings it enhanced their understanding of the issues faced in the community and 
brought to light the concerns of the community residents. Officer presence during these meetings allowed the community to feel heard, that their concerns mattered, and that the police department cared —all of which built trust. For instance, one community respondent stated,

Our community service officer goes to meetings like the NRZ meetings, community group meetings, different organizations. And that is part of that program that we are enforcing. You have to go. You have to learn what's going on in that neighborhood, [...] It's working. And the trust is building, little by little, but it's building.

Specifically, with officers attending community meetings "the neighborhood really felt like there were police watching what was going on. And so, [officers] gave them a sense of comfort," a community responded elaborated. Another community respondent added that these officers really did listen to the community and inquired of the community as well. The assigned neighborhood officer is supposed to report back the following month to update the community on how the issues raised in prior meetings were being addressed. Thus, officers were tasked with finding solutions to problems in order to improve neighborhood conditions. A community respondent explained the fine line that community service officers must navigate in addressing community concerns by stating that when community concerns are raised but do not get addressed it's a double-edge sword. The [community] felt really good that they could go and talk to [the officer]. They felt really good about it but when nothing was done then it turned it to be negative. So, I think that stuff is really good as long as $[\ldots]$ there is a response to what is brought up. 
While the overall sentiments concerning community-oriented officers were positive, there were a few community respondents who acknowledged the limitations with such officers. For instance, one community respondent noted

I think [they] tried to create a community policing sense by having community service officers that go into the community and work with the NRZs, the Neighborhood Revitalization Zones. But, the problem is that a lot of the people who are in the community don't get to the zone meetings.

Likewise, another community respondent shared similar sentiments by stating that the CSOs are good because they show face and they're around and they build relationships. [...] But there's also a relational culture to the police that needs to be broadened, that needs to be more focused on, which I think they're trying with the CSOs.

Since patrol officers do not typically have time to proactively engage with the community in non-enforcement activities (given the staffing restraints previously discussed), the community-oriented officers are formally tasked with attending events. Having officers with dedicated responsibilities show up to meetings and community events allowed for more personalized interaction with the community. A police manager acknowledged the benefits of having dedicated personnel to be present in and participate with the community by stating,

When we have the community service officer, $[\ldots]$ the community members have their email, they have their phone number. They know who to talk to, they're familiar with that person. If they have any issues, they can call that person right 
away. [...] That's always been a big, a big asset for us [in] maintaining the strong ties.

Another police manager explained that the role these officers have played in reporting back to the police department allowed for the department to remain aware of the events happening in the surrounding neighborhoods and communities (e.g., faith-based or business communities). So, keeping current with community events also enabled the police department to be engaged and involved with the community. However, this is not to say that patrol officers do not attend events at all, but when they do it is typically on their own time, as part of organized outreach events or as part of various fraternal organizations in the police department. Overall, the more the police participate in community events, the more they become part of the fabric of the community.

There were slight differences in regard to how engagement activities were referenced by interviewees. For instance, police respondents, as a whole, often reported on engagement activities relevant to instances of the police providing resources to the community and/or engaging in acts of community service. On the contrary, the community respondents often referred to officers just being present at community events. For instance, police respondents noted that officers are often members of police fraternal organizations (e.g., Hartford Guardians, Hartford Police Hispanic Officers Association, the Emerald Society), and, as part of these organizations, have donated bikes and Christmas trees, hosted toy drives and back-to-school events, provided resources for the homeless, fed the hungry for Thanksgiving, hosted midnight basketball for the youth, and held clean-ups - all examples of community outreach. Community respondents recounted numerous examples of the presence of police representatives at events. These included, 
but were not limited to, the following: during community vigils held after gun violence and fatalities occurred in the community, at an event where a community member was giving away free gas, at Urban League events, at National Night Out (which is a national community-police awareness events), at YMCA events, at a community forum held on gun violence, and at a back to school meet-and-greet hosted by a community member. The police union also strived to have a presence in the community by attending events and making financial donations to the community. Specifically, a police manager shared that the union's presence in the community helps to build trust as well as gain community support and backing when critical incidents do occur.

Despite the importance of police attending community events, some community respondents noted the importance of moving beyond mere police presence towards having officers actually engage in community events. One community respondent shared that "participating in community events rather than policing them. Just $[\ldots]$ being there and wanting or seemingly being engaged" would be beneficial for building relations and help to dispel "always seeming like a them against us." Similarly, another community respondent shared that while officers being present "shows the community that they're out there," there are a few officers that do not do a good job at engaging the community. Specifically, this respondent elaborated, I've personally called out certain officers like, "Hey, great, awesome that you're here. Thank you. But you can't just stand by your cruiser. You gotta interact with the people." [...] But, for the most part I think it's good because the officers for the most part interact with the community. So, I think it's a sense of, "Yeah, I'm 
here 'cause it's my job." But then also, at least I'm having a conversation and we're able to build on something, whatever that is.

Likewise, there were other community respondents who also shared that they had to encourage officers to engage and participate in activities at various events. However, it was noted that once officers began participating, the benefits of police actively engaging in the community were evident. One community respondent shared that at one of the community vigils,

Hundreds of people came by. And when I tell you police chiefs, commanders, officers. Everybody was interacting. Everybody was talking. Everybody holding hands. Everybody praying. Everybody crying. And it was so touching to me because I've never seen that. I've never seen that where there was so much love. The leadership and administration in the police department were also often actively engaging the community. Several participant-observations occurred in the community during which the upper management and leadership of the police department were observed interacting and engaging within the community. During interviews, a key event that was consistently brought up was when the chief of police walked with demonstrators as they marched to the police department protesting a police use of force incident. Community respondents and police managers often discussed the importance of this action taken by the chief, whereas front-line police respondents had more negative feelings towards this action. One community respondent noted that the march was "a turning point for the community" and it was "symbolic." This respondent elaborated that For some of the leaders in the community that had been building a relationship with him or building a partnership, for them it was also a turning point. Because 
them trying to talk to their members of whatever organization or church they're from about working with the police, having him there, I think, it became more than just their words. [...Yet] the union grieved [...and was] really publicly against it. So, I thought that was just an interesting example 'cause it points to kind of the history of the work, a turning point, a very visible turning point, and then also just the resistance.

A police manager also shared that despite his personal feelings about the protest in and of itself, he was in support of the chief's decisions. He elaborated that

Some police officers may look at it as [the] chief is siding with them, but it's not a side. [...] It's about what can we do to help you. So, I was in support of it. Not in support of the protest but I'm in support of the chief going around and say[ing] "listen, what can we do" because [...] that's how you breakdown silos. That's how you build on the relationship that you have. That's how you get people to the table to want to speak.

However, front-line police respondents often did not share these feelings. For instance, one noted that actions like this taken by upper management and administration make front-line officers feel "that the community is more important than your police officer." He went on to say that

I'm not saying that we should be [more important]. But I think there should be [...] courtesy. We're all police officers. Okay? I understand that and when you do things like that it makes a lot of officers question your integrity towards us or, you know, it's things like that kill morale. 
Thus, while there has been engagement from the leadership in the police department, there have also been differing perceptions regarding such engagement. From the external community perspective, such acts of engagement were often viewed in a positive light (and were considered crucial for building community relations). However, this was not always the case from the perspective of internal police personnel (and were at times perceived as harmful in terms of building morale and solidarity within the police department).

\section{The whole is greater than the sum of its parts: Partnering to impact police-}

community relations. Formal partnerships were often discussed by community respondents as a way to work hand-in-hand with the community in order to build positive relations. Collaboration is important for a variety of reasons. Brunson et al. (2013) noted that certain policing efforts are only effective when a police department is able to "forge and maintain mutually beneficial relationships with organizations that can effectively broker trust between neighborhood residents and police...” (p. 1008).

Community respondents often emphasized that such collaborations were a product of the current chief's leadership efforts. For instance, one community respondent noted "I think it's really important for us to continue to build a relationship and I've seen a lot of difference in Hartford, especially with this chief to try to build that bridge and the gap between resident $[\mathrm{s}]$ and police." She further expounded that the chief "has tried to bring people together to work together to say $[\ldots]$ we can't do it by our self, we need your help and the only way we are going to do this [is] if we build a relationship." The key to these collaborative efforts being successful was the formal nature of the collaboration and the precise intention to impact relationships within the community. One community 
respondent noted that "for Hartford, this is the best that [police-community relations] ever been," attributing it to "a real planned, concerted effort to make that happen." Likewise, another community respondent shared that the chief approaches policing very "scientifically" with a plan, involving various groups, and organizing efforts to solve problems. Thus, it was "not happenstance or accidental" that there have been no significant issues, but rather because of his "very planned and methodological effort."

The types of partnerships ranged from formalized problem-solving agreements to providing financial assistance to community organizations. Most of the examples of such partnerships were raised by community respondents (with the exception of the Police Activities League, explained below, which police often referred to as well). In the examples provided, it became apparent that these partnerships were more than just boxchecking on paper, but rather quite substantive. For instance, the police department provided direct aid to support the continuation of activities by certain organizations to play key roles in post-critical incident response. Community representatives were essential for helping to keep the peace in the community following critical incidents such as those including gun violence and homicides in the city. Specifically, a community respondent shared that a group of individuals were notified by the police when a crisis incident occurred in the city, and these community leaders also partnered with the hospitals to act as

the liaisons between police and family, family and hospital, hospital and police, to try to bring down some of that tension that might exist at the front door. [...And] help with getting the family the resources that they might need and then also working on a preventative side in terms of any retaliation that might happen. 
Likewise, other organizations in the city of Hartford also provided funding to impact law enforcement generally and to help improve police-community relations specifically. For instance, in the Spring of 2017, three insurance companies (Aetna, The Hartford, and Travels Cos) made a multimillion dollar pledge to invest in Hartford. One of the targeted areas earmarked for funding was law enforcement.

Two other examples of formalized partnerships included the Know Thy Neighbor program and the Police Activities League. Know Thy Neighbor is an initiative that was created with the specific goal of reducing violence and strengthening the relationship between the community, houses of worship, and the police and fire departments in the City of Hartford. This initiative started in 2016 as a collaboration between a religious leader and the police department. As a part of this initiative, two neighborhoods in Hartford-Clay Arsenal and Frog Hollow—were targeted to have both informal and formal dialogues, meetings, and events. Regular meetings were held in both of the neighborhoods, in which community members and public safety representatives convened to engage in joint problem solving. Two of the community outreach events that have occurred thus far were a three-day community beautification project and a food drive, both of which included volunteers from the police department. One community respondent elaborated how police officers were involved in sanding and painting a 100foot-long fence as part of the Frog Hollow beautification project. He shared that this particular activity was "led by one of the officers, but [the officer] had a group of kids, which is the important thing." Further expounding on the impact, the community respondent stated 
He had probably ten kids with him. So, now you have a police officer along with these teenage kids who are working on a project together from different walks of life. So, when you kind of think about even the small talks that they've had and just that relationship bonding within those hours. I think [it] goes a long way for them to see a different side of a police officer, giving back to the community. Another community respondent shared that Know Thy Neighbor hosted events "with a purpose [of] intentionally bringing together residents and firefighters and police officers and having them interact."

The next of these formalized partnerships was the Police Activities League (PAL). PAL is a non-profit branch of the police department that aims to improve the livelihood of youth through both recreational and educational programming and to prevent future criminal involvement ("Hartford Police Activities League," n.d.). A key function of the program is to promote the positive development of relationships between city youth and the police. Several respondents discussed the importance of community engagement through PAL. One police respondent in particular explained that not only are the youth directly impacted but also the parents. She affirmed,

I find that that $[\mathrm{PAL}]$ was a really good example because it was a good interaction between, I think, kids and then their families. And there was a lot of events where the officers would personally interact with them [...] And I found that that was a really good way because if they're having those good interactions there as kids they're going to grow up remembering that. They're going to share with their friends [and] their families are going to share with their friends. And it's just word 
of mouth that $[\ldots]$ there are good officers still out there because unfortunately we don't always have that rep right now.

Similarly, a community respondent stated:

I would say, [PALs] incredible and the community, I believe, views it as important. And it's incredibly connected. [...] There's kids that came out of PAL who are officers now. In fact, there was just a story in our media last week [or] maybe the week before of an officer who bought—at PAL—a kid a bike.

Further describing PAL, another police respondent described the impact it had by stating that the kids engaged in PAL are

with police officers. Police officers are running the PAL. So, these kids see police officers interacting. We're cool, we're funny and we're-you know, we're not these, you know, Robocop [...] type people that their parents or that their brothers or older brothers or uncles may portray us to be. We're not these, you know, these devils_-if you will—or these, you know, whatever.

Involving youth in positive ways at an early age helps to counteract the negative stereotypes or images of police that may emerge later in life (Subhas \& Chandra, 2004). While the benefits of this program are clear, the resources behind the program have not always met the expectations. Due to issues with staffing in the police department, the number of police officers involved with the program had decreased over the years (while civilian involvement had increased), thus reducing the exposure that kids have with actual law enforcement. Nevertheless, funding from businesses such as Aetna helps to continue PAL's positive work with the youth. 
Throughout the duration of the case study, two events that were included in the participant-observations provided direct observations of the benefits of PAL. The first event was a sneakers giveaway for youth involved in PAL. At this event, there were two officers as well as community representatives from donor organizations assisting with the sneaker distribution. The children also got to take pictures with the officers. The second event was a community day sponsored by Aetna where the youth involved in PAL were brought to a local park to engage with the police department. There were many officers present from all ranks, some who were in uniforms and some who were not. The youth and police engaged in various activities together, which included officers providing face painting for the kids, games where the youth got to dunk-an-officer, police taking the youth out on the police boats, police cooking and serving the youth, and police dancing with the youth. Thus, from these participant observations, it was clear that the youth recognized that the police department was responsible for and involved in PAL, and the youth greatly enjoyed engaging in these activities.

Another example of partnerships included the police department partnering with a local organization to raise awareness of unsolved homicides by creating a calendar with homicide victims represented each month. This effort was made with the specific goal of resolving the homicide cases by promoting community cooperation in providing information to the police pertaining to gun violence. Respondents often reported that the community had a "no snitching" culture that discourages cooperation from the community in helping the police to solve crime. This uncooperative culture was often fueled by fears of retaliation from certain community members as well as a lack of trust in the police to conceal informants' identities. However, the various partnerships allowed 
for an environment of trust to be built. One community respondent noted that as a result of these partnerships

people now are beginning to cry "we need the police." Before you have where people were reluctant. Now people know, "Look. We got to do something, and we need the police to do something to help us to solve these crimes." But so often, as we said before, people wasn't talking.

Apart from building trust, these partnerships allowed for the community to feel a sense of ownership and that they have a stake in the police department. These partnerships provided opportunities to specifically address community problems, allowed the police and the community to work together, and built relationships.

Overall, there were some minor discrepancies (from both community and police respondents) about how to intentionally engage the community and build relations, whether through bringing the community into the police department, investing in allocating officers to community-oriented roles, or providing community services directly to the community. However, it was clear that building relations and allowing for more personalized interactions established a foundation for fostering good police-community relations.

\section{A dream deferred: External accountability mechanisms in place but}

enforcement lacking. Accountability is often discussed as a way to hold individuals responsible for their conduct and to encourage compliance with organizational procedures and guidelines. Accountability mechanisms can be internal and/or external to the organization. In the policing context specifically, accountability is closely connected to issues of officer discretion (Walker, 2012). "Internal accountability" refers to police 
administrators and/or management holding their officers accountable for wrongdoings or misconduct. Most, if not all, large police departments have policies in place that govern officer behavior, a hierarchical chain of command, performance evaluations, as well as internal affairs staff or departments that are responsible for investigating complaints of officer misconduct (Walker, 2012; Walker \& Archbold, 2013). Some police departments also have early intervention or early warning systems, which are computer-based systems designed to use performance data to allow for proactive monitoring of problematic patterns in officer behavior (Walker et al., 2001). ${ }^{47}$ "External accountability" refers to political or civilian accountability systems that operate to provide an external check on police department affairs and officer behavior (Walker \& Archbold, 2013). Examples of external accountability include civilian complaint review boards, independent investigation boards, and court oversight. These latter external accountability mechanisms were included here as intentional engagement efforts because they are formalized arrangements that involve individuals outside of the police department to help facilitate accountability to the community.

External accountability mechanisms from the police department to the public were more often mentioned by community respondents, yet the presence of real accountability was questioned. For instance, one community respondent stated, "There's no accountability, not [in] my opinion alone." He also noted that "[One external] study [of the police department] talked about transparency [and] the lack of supervisors in the disciplinary process." Although, there were mechanisms in place that could function as

\footnotetext{
${ }^{47}$ The Hartford Police Department noted that they did have an early intervention system but rarely, if ever, used it.
} 
accountability checks, there was little confidence in the extent to which they served as an effective checks-and-balance system. Three of the external accountability mechanisms that exist in Hartford include a court-ordered consent decree, a civilian complaint review board, and a firearms discharge committee.

As noted above, the police department had been under a relatively long consent decree from the 1973 Cintron vs. Vaughn court case. Since this litigation over 50 years ago, the Hartford Police Department had been required to meet certain standards and/or requirements relating to minority representation, the civilian review board, and complaint intake procedures, among other things. The Cintron Negotiating Committee was in place to ensure compliance with the consent decree. During one of the interviews, the consent decree had been offered as one explanation for why police-community relations were not as bad as they could have been. A community respondent noted that the decree's impact on police-community relations has "been tremendous." He further added,

I think it's probably one of the best kept secrets in America to be quite honest with you. [...] I think what happens because it's been around for so long, the city $[\ldots]$ and so does most of those who've been a part of law enforcement, recognize its advantages and its ability to enhance policing within the Greater Hartford area. I think that a lot of them have really decided to embrace it because they can actually statistically and in their daily operations of policing see that when citizens play an integral part within the police department then issues can be averted and even issues that come up can be dealt with in a much more effective manner.

A police manager echoed similar sentiments by stating that, 
I think that's part of what saves our rear. Because we're still under that mandate from $1974[\ldots]$ The one that we have is federal. And most of the signers are dead that it's gonna be impossible to lift that. [...] And that's basically what keeps our standard here in terms of the few demographics that you have - gender and race and these positions, keeps us there. And in terms of, like, our name tags, all that came from that consent decree. [...] we've been lucky enough that we have that in place. And so, that keeps our checks and balances. Our Internal Affairs has to be staffed by a certain amount of supervisors. Some of them have to be minorities because of that. So, that language is there. So, is it that we're doing something or is this something that's already there.

Remarkably, the majority of police respondents were not familiar with the consent decree, and those that were suggested that it was neither relevant nor impactful in terms of police officers' everyday duties. There have also been pushes from the City of Hartford to end the consent decree, arguing that it has "outlived its usefulness" (Radelat, 2016). Some community respondents pointed out that the majority of community residents may not be aware of the consent decree either, rather usually it is the older individuals who were involved with the process that are aware. Specifically, one community respondent noted,

I would have to say, from a grassroots perspective, most folks don't know what The Cintron is. Grasstops do, but the grassroots don't. So, it's a grasstops speak. They speak about things, and they roll it out from a historical perspective, but there's no real context. Down here in the grassroots, folks don't know what that is. "What is that? And how does that pertain to me? Is that something I should 
know? Or who's reporting that, you know, who's keeping that alive in the minds of residents?" I don't know.

The civilian complaint review board is tasked with reviewing all investigations of citizen complaints of police officers and provides the chief of police with recommendations for actions to be taken. The civilian complaint review board has its own investigator who conducts interviews and retrieves documents and evidence pertaining to the facts of the case. There are nine allotted seats on the board for community members who are appointed by the mayor. The potential for promise was evident with this establishment of this external review board. In referring to the board, a community respondent noted that "largely everyone would agree we need that." Another community respondent reiterated

I think it makes a big difference because you have a right for civilians to review what took place and to investigate and find out what's going on. So, if you find something that you question, then you can be able to present [it]. And I think that's a good thing.

While the presence of the complaint review board demonstrated accountability mechanisms, the operations of the board have often been scrutinized. The complaint review board had suffered in recent years from not having the appropriate level of staffing, thus leading to a lack of quorum for a large portion of board meetings. For instance, in 2016 there were only five of the nine board seats filled, and six out of twelve meetings had to be cancelled due to lack of attendance, which contributed to a backlog of cases (Vella, 2017b). In 2017, the mayor instituted a new complaint board, retaining only two members from the previous board. This change took place in the midst of the 
complaint review board's investigation of a controversial use of force incident during which an officer was caught on camera kicking an arrested suspect in the head (Vella, 2017a). The challenges faced by the review board have impacted the effectiveness and efficiency of its operations. Some community respondents noted a lack of awareness in the community overall pertaining to the complaint review board. Further elaborating on the challenges of the board, another community respondent stated, the Review Board has not been at full strength for a long time. And a lot of things have fallen [through] the cracks. A lot of things have taken a long time. And recently, the mayor's office has been working to get that up and some new people were appointed to the board, but I don't think it's been functioning $100 \%$ like it should've been for years. [...] It hasn't been a positive effect—hasn't yet. I think it's just a work in progress."

Confirming this viewpoint, a community representative affirmed I just want to see if it's if it's really going to be meaningful [...] I don't know if the civilian police review board is going to have any kind of teeth or just window dressing to say we have it on paper. And [people] go through and it doesn't mean anything. So, this is what I'm waiting to see myself 'cause if it is just window dressing [people] don't have time to waste to be sitting in a meeting for a couple hours and just to go through the motions and so that they can say "well we have a civilian police review board."

Another community respondent suggested that the experiences with the civilian review board can serve to help others as it has "illustrated problems in the Civilian Review Board model for other activists to consider." 
In one of the participant observations during the first public meeting of the renewed complaint review board, it was evident that historical challenges had been faced by the board. At the end of the meeting, time was allotted for community dialogue. There were two community members who stood up to express their dissatisfaction concerning the operations of the complaint board. One of them discussed how his own case went through a lengthy, time-consuming process and failed to receive a proper investigation or proper notice regarding the resolution of the case. Another community member added that the complaint board needed to institute procedures to notify complainants when their complaint was scheduled to be discussed. She further elaborated that cases have often taken months to years to be heard (due to the backlog), and that community residents who made the complaint must call the city each month to inquire if their case was being heard. She noted that the inefficient operations of the board ran counter to the intentions of the board from the perspective of the original Cintron consent decree.

A third external accountability mechanisms, the firearm discharge review committee, was established to review every incident in which a police officer fired his or her gun (i.e., used deadly force) to determine whether the incident and the police officer's behavior were in alignment with policy and procedure, and ultimately if the use of deadly force was justified. This is a nine-member board, made up of six police representatives and three community representatives. Community representatives serve on the board to be the "voice of the citizenry, be the eyes and ears and [...] consciousness of the community to make those who are part [of] policing aware of the perspective that [the] citizenry has with respects to the use of deadly force," as one community respondent noted. 


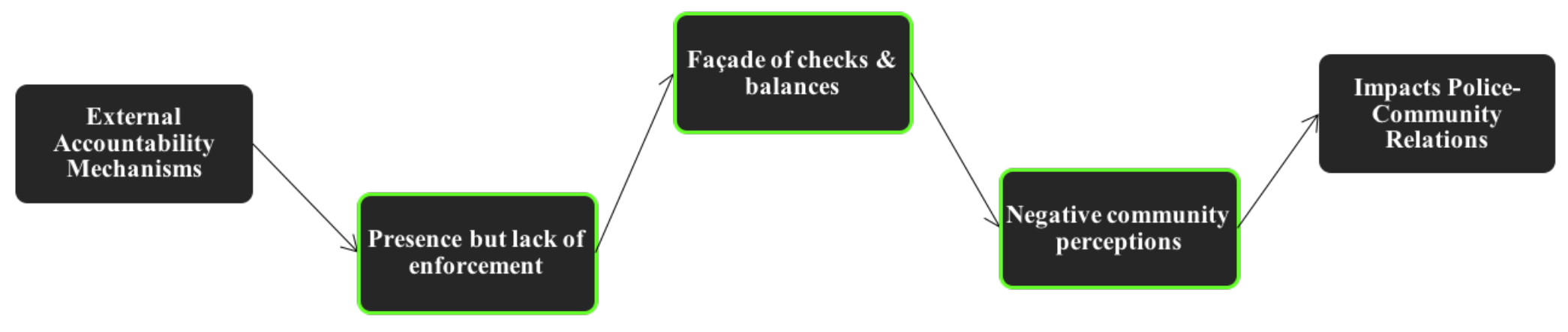

Figure 14. The impact of external accountability on police-community relations.

Note. Red outline means this was mentioned by police interviewees only and green outline is for community respondents only. 
After the investigation of the case is completed by the firearm discharge review committee, a report is compiled and given to the police chief concerning the findings of the case and any recommended courses of actions (e.g., more training for the officer). Despite the greater number of police representatives on the board relative to the number of civilians, there is an opportunity to write a minority report when there are disagreements on the board. Nevertheless, the ultimate decision of recourse is up to the chief of police. The board can only provide recommendations, while the chief of police is tasked with implementing actions. A police manager described the potential impact of involving citizens in the firearm review committee as an opportunity to broaden the community's understanding of police initiatives. He stated that involving members of the community, even if it's a couple, like on the firearms [committee] board there is only three. But those people talk to three other people who talk to three other people and the message of what we really do internally gets out that way.

This comment was less about actually utilizing the citizens to serve as external checks on officer conduct and more about providing awareness to the community. Even then, when the interviewees were asked about this board, community members had little awareness or knowledge of the actual activities and outcomes of the board.

Despite the various external accountability mechanisms in place, community respondents still suggested the need for more accountability. Some community respondents argued that such accountability should be completely separate from the police department as well as the political offices of the city overall, stating that "you need 
different checks-and-balances system that's not linked internally to the actual department." Another respondent expounded

It needs to be taken out of that political setting and put somewhere else. It doesn't need to be in the police department for sure, but it also doesn't need to be under the mayor and council. It needs to be in a totally separate place...then it would be better $[\ldots]$ Because if I'm appointing you to the Civilian Police Review Board and I also hire the police chief and then the police chief is the one who releases the information. [...] That kind doesn't work.

Overall, it appears that the problems associated with the operations of the external accountability mechanisms outweigh the benefits that the presence of such mechanisms actually generate. Having mechanisms in place without actual enforcement may do little to improve (and could even harm) police-community relations in the long run. Therefore, when accounting for the impact that accountability systems have on police performance and outcomes, it is important to bear in mind these issues related to implementation.

\section{Discussion}

Through in-depth interviewing, participant observations, and document analysis, two primary processes by which salient organizational and managerial strategies impact police-community relations were identified. Thus, in order to impact police-community relations it is imperative to either influence individual officer attitudes and behavior or to impact the overall level and quality of service provided from the police department to the community. The findings also underscore the importance of larger theoretical constructs relating to open-system approaches and the variety of factors that operate at various levels within as well as outside the police department to impact police-community 
relations. This research was inspired by the need to understand organizational factors internal to police departments that affect their relationships with the community; however, the findings illustrated that there are (a) environmental factors that influence organizational factors and (b) factors at the individual officer level that impact policecommunity relations. Traditionally, police departments have been viewed as closedsystems separate from the community. There is limited (and often dated) literature that details the open-systems nature of policing with external environmental factors shaping the organization as well (see Langworthy, 1986; Maguire, 1997, 2003; Mastrofski, 1998; Wilson, 2005). The aforementioned studies were purely quantitative in nature and did not utilize qualitative methods to gain insight on the mechanisms by which policing operates as an open-system.

In assessing the key question of interest here-why and/or how organizational factors impact police-community relations - the findings portrayed three main categories (and six subcategories) of factors that have affected police-community relations in Hartford. The first theme was focused on cultivating officers' soft skills. Within this theme, officer communication during individual police-citizen interaction was emphasized as a way to engage the community, relate to the community, and de-escalate situations, whereas organizational communication served as a way to inform the public and spread awareness. Officer character traits (such as respect and compassion) were responsible for impacting officer behavior and treatment in the community. These soft skills were not only essential for improving police-community relations by building community trust and rapport, but also for overcoming barriers in the community. 
The second theme centered around investing in human resources, particularly as it relates to training and staffing. Two types of training were emphasized (cultural sensitivity training and crisis intervention training), both of which are hands-on and impact the ways in which an officer responds to specific situations. A lack of adequate investment in police staffing translates to longer response times for community members, higher demand placed on patrol officers, as well as the loss of special divisions aimed at building relations and/or preventing and solving crime —all of which have detrimental impacts. Economic conditions were often cited as the primary reason for the lack of adequate staffing levels. Both training and staffing are indicators of the quality of the workforce, thus such investments in personnel improve workforce quality and lead to better outcomes in terms of police-community relations.

The final theme was intentional engagement efforts between the police department and the community, ranging from collaboration to accountability. Formal and intentional collaboration and engagement with community leaders helped to quell negative police-community relations. Having productive relationships with a few key stakeholders allowed these leaders to act as a bridge between the police department and the larger community. External accountability mechanisms that involve the community often fall short of their promise to positively impact relations due to problems in implementation, which result in a lack of effectiveness and provide a false sense of hope to the community. Both collaborative relationships and external accountability offer ways for the community and police to work together; however, efforts must be made to go beyond the mere appearance of engagement and extend deeper into building meaningful forms of engagement. 


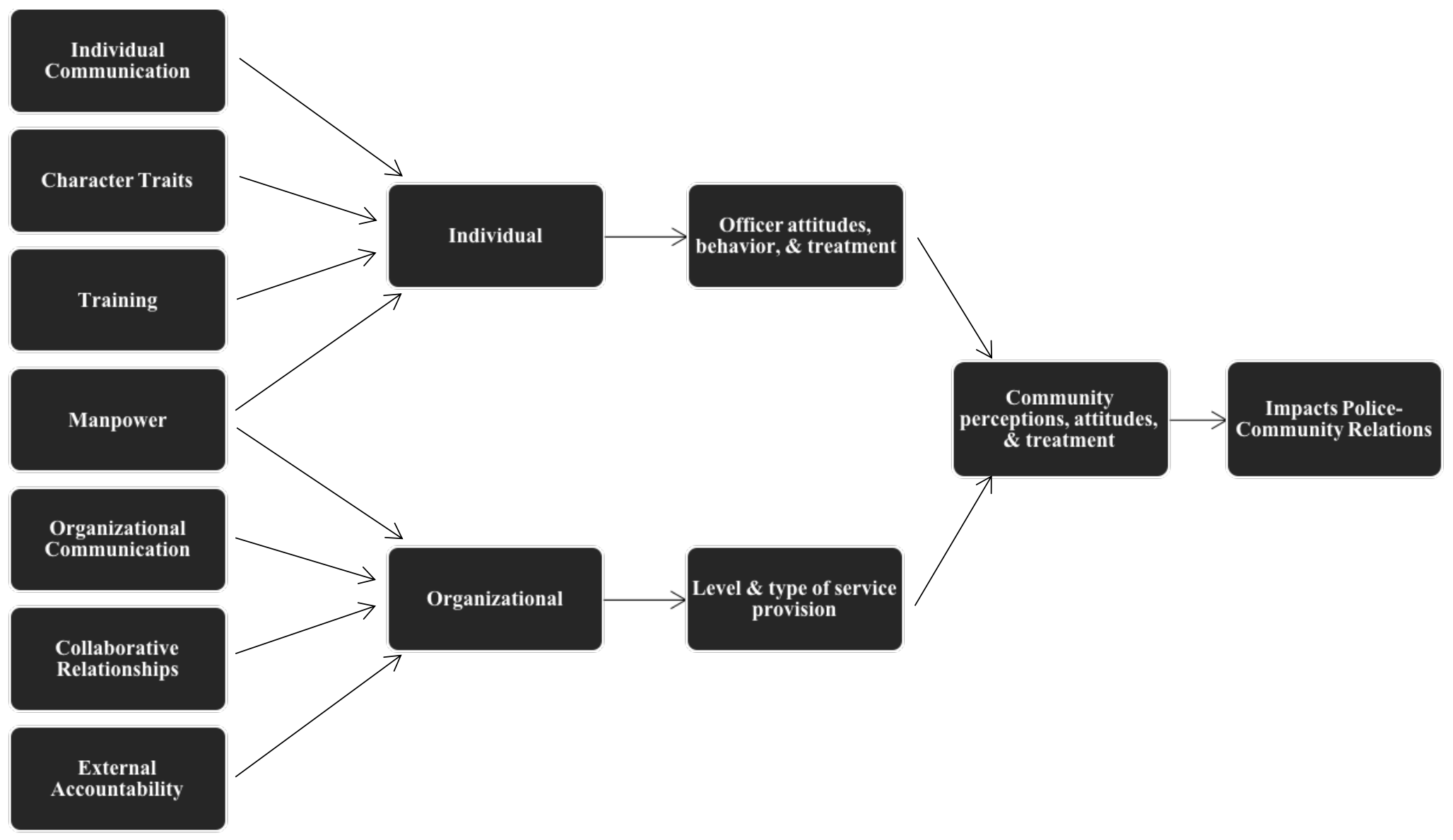

Figure 15. The processes by which organizational and managerial factors impact police-community relations. 
Taken as a whole, the mechanisms by which these factors impacted policecommunity relations, whether positively or negatively, can be summed up in two ways. First, such organizational mechanisms and/or managerial strategies can directly impact officer attitudes, behavior and/or treatment. Second, the organizational mechanisms and/or managerial strategies can directly impact the level, type, and/or quality of overall service provision provided from the police department to the community. Both of these mechanisms impact community attitudes, perceptions, and/or treatment towards the police. Character traits, individual communication, and training all have direct effects on officer demeanor and behavior; whereas organizational communication, staffing, collaborative relations, and external accountability more directly impact the quality of service provision. However, these mechanisms are interrelated and should not be assessed independent of each other. These findings display the importance of focusing on the police and the community in tandem, not in isolation as prior research has done, but rather incorporating both when working to improve police-community relations. See Figure 15 for a graphical display of the processes by which the individual organizational characteristics impact police-community relations.

\section{Conclusion}

Overall, these findings have demonstrated the intricacies and complexities that exist when discussing police-community relations. The current state of police-community relations in Hartford is conditional on the demographic groups or sub-populations in the community (e.g., youth vs. adults; residents in more affluent areas vs. crime-ridden communities). Respondents suggested that adults and residents in affluent areas viewed police-community relations in more of a positive light, whereas youth and residents of 
communities plagued with higher levels of crime had more problematic relations with the police. Furthermore, six primary factors were found to impact police-community relations, either through influencing officers individually or affecting the level and/or quality of overall service provision.

Limitations and future research. While this research is not without limitations, specific mechanisms were used during data collection and content analysis to ensure the overall quality of the research design. Specifically, questions related to credibility, transferability, and confirmability were addressed (Lincoln \& Guba, 1985; Whittemore, Chase, \& Mandle, 2001). First, to establish that the findings were credible from the perspective of the study participants, the study incorporated triangulation, prolonged engagement, member-checking, and negative case analysis methodologies. The data was triangulated across the in-depth interviews, participant observations, and secondary data analyses in order to provide a comprehensive overview of police-community relations in the city. Although the short time period used to gather and analyze secondary sources from 2010 to 2017 is a limitation in and of itself, this time period was deemed appropriate in order to better understand the current state of relations.

The participant observations allowed for prolonged engagements with the police department and community, which also allowed for member checks. "Member checks" refer to providing the informants and/or participants in a study with the findings in order to elicit feedback from participants as well as limit errors of interpretation (Lincoln \& Guba, 1985). This process was followed throughout the study with an arbitrary selection of participants during observations, over casual conversation, and during interviews. The prolonged and persistent engagements limited potential reactivity or interaction effects 
from the mere presence of an outside researcher (Moreto et al., 2017). In order to conduct negative case analysis, the disconfirming evidence — data that did not support the causal patterns believed to be true - was sought. When identified, disagreements among participants were explicitly reported in the findings above. This step permitted competing interpretations and explanations to be investigated in order to thoroughly and accurately identify patterns and relationships.

Another potential limitation is transferability, which refers to the degree to which the findings of the study are applicable to other contexts. The findings discussed herein were based on only one case study conducted of Hartford, Connecticut. Thus, given the variability across contexts and settings, the specific findings detailing the organizational characteristics that impact police-community relations for this city may not be broadly generalizable to other cities and police departments across the United States. However, there are cities that bear resemblance in terms of demographic and socio-economic characteristics of the city, where the findings may be applicable. For instance, Baltimore, Maryland; Birmingham, Alabama; Cleveland, Ohio; Detroit, Michigan; Newark, New Jersey; Oakland, California; and St. Louis, Missouri, are all cities that serve communities characterized by high poverty levels, limited employment opportunities, high crime rates, and large minority populations. The findings also provided insight and applicability to the underlying theoretical constructs and relationships explored herein (Yin, 2009), thus providing a foundation and a guide for future scholarship. Specifically, this study provides insight into the open-systems approach for local public sector organizations through the identification of various factors that impact police-community relations. 
Finally, confirmability is the extent to which findings can be corroborated by others in the future. Techniques to ensure that others can, if need be, validate the findings were employed. Such techniques included triangulation, reflexivity, providing verbatim transcriptions, and utilizing computer-aided qualitative data analysis software. Reflexive journaling entails acknowledging and identifying the observer's personal perspectives, interpretations, and assumptions apart from the straightforward descriptive observations. This type of journaling was done on an ongoing basis - often at the end of interviewsthrough acknowledging and often documenting thoughts, feelings, perceptions, and/or interpretations (see Appendix I for a reflexivity statement). The verbatim transcriptions for the audio interview recordings allow others to derive their own codes and themes based on the actual words spoken by these participants. Lastly, utilizing NVivo 10 software helps to limit the amount of interpretation relied on by one person, which assists in limiting potential biases.

The limitations aside, the findings herein provide a platform for subsequent research to build upon. Future research should further disentangle the theoretical relationships examined herein that undergird police-community relations by exploring their implementations in different settings and contexts across the country. In order to truly advance theory, it is imperative for diverse contexts to be taken into account to determine how findings are corroborated or nullified. Specifically, there are three areas of improvement that other scholars can consider. First, with regard to the context of the study, researchers should consider comparing police departments serving rural, suburban, and urban communities. Also, the size of different police departments and communities must be evaluated to understand how organizational factors, or the lack thereof, may have 
differing implications in larger versus smaller departments and communities. In the list of cities named above that share similar demographics and socio-economic conditions with Hartford, the cities range in terms of their population size. For instance, Baltimore and Detroit both have populations over 600,000; Cleveland, Oakland, and St. Louis have populations between 300,000 and 450,000; and Birmingham and Newark have populations between 200,000 and 300,000 . Thus, assessing the extent to which the findings here are generalizable irrespective of city or organizational size can yield further insights.

Second, in regards to the methods, future research should consider conducting more observations with prolonged engagements. The observations conducted here provide a baseline for understanding a variety of interactions and relationships between the police department and the community. However, multiple observations should be conducted with different types of activities such as foot patrols or diverse types of police academy training sessions, which over an extensive period of time could potentially provide a more robust understanding of how such factors operate and interact. Further, exploring differences in community interviewees based on those who have experienced primarily more negative police-citizen interactions (e.g., citations/tickets, police searches, arrests, or use of force) may provide more ways to evaluate and understand the extent to which certain organizational practices are working or not for a particular community or police department. Although community respondents shared personal accounts of negative interactions with the police department in some interviews, these were not representative of the majority of interviews. 
Finally, future research should consider exploring some of the specific organizational examples mentioned that impact police-community relations more indepth to understand their inner workings and create best practices (e.g., program evaluations). This chapter was primarily concerned with understanding larger causal mechanisms and not necessarily the in-depth workings of specific programmatic elements. For instance, future research can delve into the types of cultural sensitivity trainings and the extent to which they occur, or conduct a comprehensive study of complaint review boards and the mechanisms by which they operate (including factors such as frequency of meetings, powers given, and effectiveness of meetings). Doing so can help make more informed recommendations for best practices on specific programmatic elements that police departments can adopt. Further research can also more thoroughly address issues of implementation, which would require much more time being devoted to a specific program or organizational element rather than a broad review of several organizational characteristics.

Implications. This study disentangled the causal mechanisms at play between organizational characteristics and police-community relations by providing a comprehensive representation of both police and community perspectives. The findings of this study have implications for policy recommendations to improve police-community relations. Such recommendations should be formulated around the two main mechanisms by which organizational factors were found to impact police-community relationships: through impacting (a) officer attitudes and behaviors, and (b) the level or quality of service provision. For instance, interpersonal skills and character traits were found to correspond with officer attitudes and behaviors, thus police departments can implement 
hiring evaluations to assess an individual's level of interpersonal or people skills such as effective communication abilities and character traits. Supplemental training can be provided for individuals who do not have such skills. However, it is imperative that the trainings incorporate interactive, hands-on learning and can be evaluated for effectiveness. Additionally, the findings herein underscored the importance of adequate staffing levels, which are impacted by funding and directly affect the level of service provided to the community. Thus, revisiting initiatives to sufficiently staff police departments are needed. For instance, reinstituting the grant programs provided to local law enforcement agencies by the U.S. Department of Justice Community Oriented Policing Services, which aimed to hire community-service officers. Finally, attention should be devoted to creating external accountability systems only if appropriate and adequate resources are also allocated towards their implementation and monitoring.

Further, this study shed light on which organizational practices are promising for impacting police-community relations and why. Those interested in police reform can gain insights from this research into the causal mechanisms needed for effective reform. For instance, one of the more current police reforms centers around officer body-worn cameras. These cameras serve as accountability mechanisms for officer discretion and behavior. Evidence has been mixed in terms of the impact of these cameras on outcomes. Some results have supported the continued use of the cameras (Ariel, Farrar, \& Sutherland, 2015; Headley, Guerette, \& Shariati, 2017). However, other research has not found support for the theoretical relationships undergirding the impact of body-worn cameras on various policing outcomes such as decreasing officer use of force or citizen complaints (Ariel et al., 2016; Sousa, Coldren, Rodriguez, \& Braga, 2016). The findings 
herein pertaining to accountability mechanisms would suggest that more attention should be devoted to the implementation of body-worn cameras to accurately determine whether the differences in implementation or enforcement are more likely to influence outcomes. 


\section{CHAPTER 5}

\section{Where, What, Why, and How? Reconciling the Quantitative and Qualitative Findings to Better Understand Police-Community Relations}

The interface between local government agencies and the community can often be tenuous due to the many challenges faced in public service delivery. This difficulty can be easily seen in the context of police departments, which often serve as the face of local government agencies to the broader community. The practice of policing has faced challenges since its inception in the United States decades ago. From the onset of policing as a formalized practice (and even prior), there have been issues relating to gender and racial representation, police misconduct and corruption, adequate training of police officers, and citizen sentiments towards police. Thus, in many cases, the challenges plaguing police departments since the 1800s still exist despite the attempts made to improve relationships. There have been numerous policy proposals and organizational reform measures taken to improve police-community relations, particularly in communities with marginalized populations. Yet, the empirical literature to evaluate such reforms has been scant.

\section{Summary of the Dissertation Chapters}

This dissertation sought to identify which organizational and managerial factors of police departments had the greatest impact on police-community relations, and to understand why and how these factors affect such relations. In order to adequately answer this question, a mixed methods approach combining quantitative and qualitative research 
methodologies was utilized. Such an approach provided a more robust perspective linking police-community relations to organizational characteristics and managerial strategies.

Chapter 1 of this dissertation uncovered the need to apply an organizational approach to evaluating and understanding police-community relations. This chapter began with an overview of recent events involving reciprocated violence between police and the community, which have shaped the current state of police-community relations in the United States. A historical overview of policing and police reforms in the United States was outlined, portraying the recurrent nature of organizational reform aimed at addressing strained relations between the police and various communities. This chapter also provided an in-depth review of the empirical literature to date that pertains to organizational studies of police departments.

Chapter 2 of this dissertation presented a comparative analysis of policecommunity relations across various cities in the United States. In doing so, this chapter provided an overview and distribution of the current state of police-community relations. A composite index of police-citizen conflict was created based on four main indicators of problematic relationships between police and communities (i.e., police use of force, citizen complaints, civilian killings by officers, and civilians assaults against officers). This chapter argued that police-citizen conflict measures should be incorporated into traditional measures of police performance.

The composite index of police-citizen conflict (Chapter 2) illustrated that the majority of cities represented across the 278 police departments in the sample had average levels of police-citizen conflict. A total of 116 police departments had policecitizen conflict scores that ranged within a 0.5 standard deviation of the mean police- 
citizen conflict score, representing approximately $42 \%$ of the sample. Nearly $8 \%$ of the sample had police-citizen conflict scores that were at least 1.5 standard deviation above the mean, representing the highest level of conflict. In contrast, approximately $12 \%$ of the sample had police-citizen conflict scores that were at least 1.0 standard deviations below the mean, the lowest level of police-citizen conflict in the sample. When comparing cities with the highest and lowest scores of police-citizen conflict, the former cities had higher levels of poverty, unemployment, and violent crime, as well as larger proportions of racially minoritized populations.

In Chapter 3, attention was devoted to identifying the organizational factors that impacted police-citizen conflict outcomes. Two theoretical frameworks were used to guide the analysis: community-oriented policing, and administrative responsibility and accountability. Ordinary least squares regression (OLS) models were used to assess the extent to which indicators of community policing, professionalism, passive representation, and control mechanisms impacted use of force, citizen complaints, and assaults against officers. As a whole, the findings demonstrated that assessing the structure, organization, and management of police departments did not necessarily provide substantive understandings of police-citizen conflict. Nevertheless, some specific factors were found to be significant correlates for use of force and citizen complaints, but none were identified for assaults against law enforcement.

The regression estimation findings (Chapter 3) demonstrated that organizational and managerial factors had minimal impacts on police-citizen conflict outcomes. Of the 12 hypothesized variables included in each of the models, 3 were significant in the force model, 0 in the assault model, and 2 in the complaint model. In the police use of force 
model, the presence of formal partnerships between the police and the community, the percentage of officers dedicated to patrolling specific geographic areas (i.e., "beat officers"), and the level of racially minoritized representation on the police force each resulted in statistically significant negative correlations. In the assault model, no organizational or managerial factors were found to be statistically significant. In the complaint model, the number of police officers dedicated to problem-solving activities had negative correlations with the complaint rate, while the level of formalization was positively correlated with complaints. Community contextual factors were also included in the models as control variables and had differing impacts on the outcomes being assessed. With regard to race and ethnicity, the percentage of a city that identified as Hispanic was negatively associated with use of force rates, while the percentage that identified as Black was negatively correlated with assault rates. The level of poverty across cities was positively correlated with complaint rates, and the level of violent crime was positively correlated with the force and assault rates. Finally, police density was positively correlated with the force rate and negatively associated with the assault rate of police departments. Thus, based on the small number of statistically significant correlates found, at best, there is only modest quantitative support for organizational theories explaining police-community relations.

In Chapter 4, a qualitative assessment was undertaken to shed light on the reasons why and the processes by which various organizational and managerial factors impact police-community relations. A qualitative case study was conducted in Hartford, Connecticut, which entailed 88 semi-structured interviews with police and community representatives, over 60 hours of participant observations, and a review of secondary 
sources. The findings pointed out specific organizational aspects of the police department as well as individual characteristics of police officers as factors that substantially influenced the quality of relationships between police departments and the communities they serve.

The qualitative findings (Chapter 4) outlined the processes by which both individual and organizational characteristics influence the quality of police-community relations. Based on the interview respondents (both police and community members), it was clear that police departments determine the course of police-community relations, but that, ultimately, they are evaluated by the community. Three main themes of impacting factors for police-community relations emerged, into which six sub-themes fell. The first main theme revolved around cultivating soft skills, the second on investing in human resources, and the third category on intentional engagement. Two primary mechanisms by which these factors impact police-community relations were identified. The first mechanism operates by directly impacting officer attitudes and subsequent behavior; the second is by affecting the level and quality of services provided by the police department as a whole. For instance, officer communication skills and character traits (both soft skills) and hands-on training (human resources) directly influenced officer behavior, whereas staffing (human resources), collaborative relationships and external accountability (both engagement) directly related to the levels and quality of overall service provision.

\section{Integrating the Quantitative and Qualitative Findings}

When juxtaposing the aforementioned findings, two important insights surfaced. First, the police-citizen conflict index (Chapter 2) was the primary instrument for 
determining a case study location (along with other secondary factors such as population size and the size of the Black and Hispanic population). Given the conflict index and demographic characteristics of the sample, Hartford, Connecticut, quickly emerged as one of the top cities with a high police-citizen conflict score (indicating problematic or negative police-community relations) as well as a large racially minoritized population. As part of the qualitative case study of police-community relations in Hartford, the current state of police-community relations was assessed. While the findings demonstrated that the current state of relations was contingent upon the "community" or "group" of individuals that was being referenced, there was general agreement that relations in Hartford had been improving recently. This finding can mean either of two things. Given that the most recent data used to create the composite police-citizen conflict index was from 2012 to 2013, this qualitative finding could underscore the point that relations had been improving since the time that the statistical data was collected that originally indicated high police-citizen conflict. Alternatively, it could be that policecitizen conflict (as measured by the behavioral indicators of violence between civilians and police) and police-community relations (as measured by the perceptual responses from interview respondents) can co-exist. Thus, negative statistics may not necessarily equate to poor interpersonal relationships.

Second, the lack of significant findings in the regression model (Chapter 3) on organizational and managerial correlates of police-citizen conflict indicators could be attributed to one of two reasons: (a) the organizational factors simply do not matter as much as theorized, or (b) the wrong organizational correlates and/or operationalizations of the correlates were included in the analysis. The qualitative findings from the case 
study (Chapter 4) supplemented the quantitative findings to provide context as well as further insight into the findings. For instance, the organizational-level factors that impair police-community relations (per the qualitative findings) included the lack of sufficient staffing levels and inadequate implementation of external accountability mechanisms. These findings may speak directly to the lack of significant findings for two variables included in the OLS model: (a) whether community policing training is incorporated during recruitment and/or in-service training and (b) the presence of civilian review boards. The lack of adequate staffing negatively impacts police-community relations in that resources dedicated to positively engaging the community are redirected and officer workload increases, leaving little to no time at all for patrol officers to engage in the community. Thus, even if departments were incorporating trainings for recruits and inservice personnel about the importance of community policing, the lack of resources and time devoted to actually engaging in community policing activities could inhibit the effectiveness of such training efforts. While the presence of external accountability mechanisms seemed promising, the lack of appropriate enforcement hampered the effectiveness of such mechanisms. Accordingly, measuring the mere presence of a civilian review board did not shed light on issues surrounding the effectiveness of implementation. For instance, the qualitative findings portrayed that there were issues pertaining to the implementation and organization of the Civilian Review Board in Hartford, which led people to question its effectiveness and impact on police-community relations.

One of the organizational-level factors that improved police-community relations (per the qualitative findings) was collaborative relationships between the police 
department and the community (which is a key component of community policing). Collaborative relationships promote the development of familiarity, shared knowledge, and understanding between the police and the community, which breed comfort and facilitated cooperation. When comparing this finding to the OLS models, three community policing variables were found to be statistically significant. Community partnerships and beat officers were each negatively associated with police use of force rates, and problem-solving officers was negatively related to citizen complaint rates. All three of these variables are factors that fell into the collaborative relationships theme in the qualitative portion of this study. Beat officers and problem-solving officers both permitted and encouraged non-enforcement related interactions to occur in the community, thus promoting the building of positive police-community relations. Maintaining community partnerships allowed for the community and the police to work together in addressing community problems and identifying potential solutions. It also provided the community with a sense of ownership of and investment in the police department.

The case study highlighted two individual-level factors that impacted policecommunity relations, which included officer communication skills and character traits. While communication and character may both be emphasized at the organizational level in training, hiring, supervising, and/or in the broader organizational culture, these measures were not included in the quantitative model. Instead, the quantitative model included measures of professionalism (such as education and hiring standards) that were theorized to impact bureaucrat (i.e., officer) behavior through notions of subjective responsibility; yet none of these indicators was significant. However, the qualitative 
findings pertaining to the importance of character traits may provide partial support for Friedrich's subjective responsibility theory. Friedrich (1935) argued that bureaucrats who have an internal personal sense of responsibility, maintain professional knowledge, and are committed to the values of the profession will be motivated to make good decisions. The two character traits that were emphasized in the qualitative findings were compassion and respect, both of which influence officer treatment towards the public (e.g., being more helpful than harmful to the community). Thus, the internal values that officers held were reflected in their external behaviors in the community, and these behaviors directly impacted citizens. Effective officer communication during policecitizen interactions was emphasized as a way to de-escalate tense situations, engage the community, and humanize as well as personalize the police force. This finding may have elucidated the reasons why, in the OLS model, the level of community-technology interaction and engagement was not significant. If communication during individual interactions was found to be important, then, in light of this finding, technology may serve as a barrier between the police and the community, and ultimately lead to depersonalization and disengagement.

Overall, the OLS models assessed organizational and managerial indicators of community policing, professionalism, passive (i.e., diverse) representation, and control (i.e., accountability) mechanisms. Whereas, the case study highlighted the importance (or lack thereof) of some of these specific organizational indicators (bureaucracy) while also adding the importance of individual (bureaucrat) factors. Not only is the bureaucracy as an organization important in terms of impacting community outcomes and relationships, but the bureaucrats who are responsible for directly interacting with the community also 
matter in terms of shaping overall relationships. These findings contribute to the knowledge base linking police-community relations and organizational and managerial characteristics. This research illustrated the complementary roles that the organization and the individual play in impacting the quality of police-community relations. The findings also highlighted the necessity of appropriately accounting for the enforcement or implementation of organizational characteristics and managerial strategies. Thus, the quantitative research that examines organizational aspects of policing would be wellserved by incorporating measures of individuals embedded within organizations as well as the implementation of organizational priorities.

\section{Strengths and Limitations}

The strengths of this research study are specific and substantial. First, this work represents the first attempt to create a composite police-citizen conflict index as an indicator of police-community relations and a measure of police performance. This composite index allowed for an assessment of relative performance across multiple cities in the United States. Second, this study compared the impact of multiple organizational characteristics and managerial strategies on three different police-citizen conflict outcomes. In contrast, other studies in this domain typically examined specific and isolated organizational factors to approximate their effectiveness and/or impact on specific policing outcomes. Third, the use of a mixed methods approach to understand how organizational aspects of policing impacted the relationship between police and communities has not yet been conducted. Thus, the qualitative component was a meaningful enhancement of scientific knowledge in that it revealed probable causal 
mechanisms between organizational characteristics and managerial strategies, which could aid in overall theoretical development.

While this research proposed a robust mixed methods approach, there were still limitations. First, there were limitations pertaining to data availability for the regression analysis. The use of secondary data and compiling data from several sources limited the number of cities eligible to be included in the analysis. Also, since the unit of analysis was at the city-level, this study could not necessarily provide insights for police departments serving smaller towns or entire counties. Nevertheless, while the quantitative component of the study may have masked important neighborhood-level variations that occurred within cities, the qualitative design allowed for an exploration of potential neighborhood variations. Finally, the qualitative component is an analysis of only one case. This case study yielded a wealth of robust, complex findings that were contextspecific and thus not necessarily generalizable to places with different demographic and/or socio-economic characteristics. However, the findings may be applicable to locations with similar profiles and can enhance the understanding of larger theoretical processes and conceptualizations of bureaucrat-citizen relations, generally, and policecommunity relations, specifically.

\section{Implications and Future Research}

The main contributions of this research are to the organizational behavior, public management, and policing literatures. First, this research illustrated that organizational and managerial changes matter to the extent that they are coupled with effective implementation. Further, this research also pointed to the importance of individuals embedded within organizations. Whereas prior research has often focused on either the 
organizational and managerial aspects of police departments or solely on the individual police officers, this research contributes to the literature by portraying the intersections of the organization and the individual. It highlights the need to study both organizations and individuals together in order to sufficiently understand the interface between local governments and the community. Second, the findings herein underscore the importance of community problem-oriented policing as an effective tool for alleviating police-citizen conflict and building police-community relations (Goldstein, 1990). This research has shown that fostering community partnerships, building collaborative relationships, and having officers dedicated to problem-solving roles and who are responsible for patrolling specific geographical locales all build positive police-community relations. More specifically, this research is the first aggregate-level study to investigate and find impacts for community policing on police departments' use of force levels. Thus far, there has not been extensive empirical evidence to suggest that community problem-oriented policing actually works in terms of impacting outcomes across numerous police departments. However, this strategy has been continuously promoted in the practitioner realm and labeled as a promising philosophy. Lastly, the findings add to the literature of the importance of minority representation in impacting use of force outcomes.

This research also has numerous recommendations for policy and practice. First, mandates at the state and federal level should require police departments to make consistent and thorough efforts to measure and report on police-civilian encounters and their associated outcomes. Second, administrative, organizational, structural and/or managerial changes in police departments need to be coupled with proper and consistent implementation and evaluation mechanisms. Third, police departments looking to change 
individual officer behavior should invest in hands-on and interactive training. Trainings such as cultural diversity and crisis intervention training expose officers to diverse individuals and unfamiliar situations in order to prepare officers to respond accordingly. In the hiring phase, police departments should test individual interpersonal characteristics, such as communication skills and character traits. It is imperative that police departments not only test potential hires but also use the information gathered from these tests accordingly. For instance, the information can be used to determine individuals who may need additional interpersonal training or to identify more appropriate senior officers to match with those individuals for in-service training. Fourth, support and resources for engaging in community problem-oriented policing practices should be made available for police departments serving communities with high service demands. For instance, police departments serving inner-cities are often resourceconstrained and have high volumes of calls for service, and thus may not be able to devote officers to problem-solving activities or assigned geographical beats. However, it is often the case that these cities would benefit from having community policing. Fifth, strategic investments should be made in recruiting, hiring, and promoting diverse and representative workforces to match the demographic and socio-economic makeup of the community. Lastly, external accountability mechanisms should not be mandated without proper support for implementation and evaluation of effectiveness.

Finally, this research has also provided a foundation for future research to build upon. First, scholars should incorporate additional measures of police-community relations to extend beyond measuring police-citizen conflict and into understanding the more frequent and daily encounters that occur between police officers and civilians. 
Second, future research should study both police-citizen conflict and police-community relations in a variety of contexts, including but not limited to rural and suburban cities, county police departments, and even highway patrol. It is imperative to ascertain if the findings hold true across contexts. Third, in order to adequately explain the variance in police-community relations, scholars should move the needle beyond merely measuring the presence or absence of certain organizational and managerial features in police departments. Specifically, future research should incorporate more nuanced details regarding the implementation of organizational imperatives and managerial priorities. Fourth, scholars should explore potential interactions or non-linear effects among key variables included in the quantitative analysis, which would also help to determine the presence of any conditional effects. Specifically, it would provide insight into some of the aforementioned nuances by detailing under what circumstances and contexts certain effects may or may not be present. However, this process would also require revisiting theoretical considerations pertaining to such effects.

Fifth, on one hand, a portion of this study was able to compare across several organizational contexts and, on the other hand, this study was able to explore individual perspectives within one specific organizational context. Thus, scholars can move this research forward by comparing individuals within organizations across multiple organizational contexts, which will allow for a more comprehensive understanding and integration of the intricacies within and between contexts as well as the ways in which diverse contexts impact individual officers. Lastly, this research has only begun to illuminate pertinent issues pertaining to procedural justice, consent decrees, minority representation, and notions of cultural brokering. Thus, there are many questions that 
must still be addressed, such as how can procedural justice most effectively be embedded within organizations? Are court-ordered consent decrees a sustainable solution to promoting police-community relations? What are the causal mechanisms undergirding minority representation and police-citizen conflict outcomes? How can cultural brokering be an effective strategy utilized by police departments across the nation? 


\section{REFERENCES}

Adler, P. A., \& Adler, P. (1994). Observation techniques. In N. K. Denzin \& Y. S. Lincoln (Eds.), Handbook of qualitative research (pp. 377-392). Thousand Oaks, CA: Sage.

Ajilore, O., \& Shirey, S. (2017). Do \#AllLivesMatter? An evaluation of race and excessive use of force by police. Atlantic Economic Journal, 45(2), 201-212.

Alam, M., Dupras, J., \& Messier, C. (2016). A framework towards a composite indicator for urban ecosystem services. Ecological Indicators, 60, 38-44.

Alkadry, M. G., \& Nyhan, R. C. (2005). The impact of rational organizations on public administrators: A structural equation model. International Journal of Organization Theory \& Behavior, 8(2), 155-173.

Allen, M. (1999a, April 8). 4 Hartford policemen charged in corruption inquiry. The New York Times. Retrieved from https://www.nytimes.com/1999/04/08/nyregion/4hartford-policemen-charged-in-corruption-inquiry.html

Allen, M. (1999b, April 4). Unarmed boy is fatally shot by the police in Hartford. The New York Times. Retrieved from https://www.nytimes.com/1999/04/14/nyregion/unarmed-boy-is-fatally-shot-bythe-police-in-hartford.html

Alpert, G. P., \& Dunham, R. G. (1997). Policing urban America. Prospect Heights, IL: Waveland Press.

Alpert, G. P., \& Dunham, R. G. (2004). Understanding police use of force: Officers, suspects, and reciprocity. New York: Cambridge University Press.

Alpert, G. P., \& MacDonald, J. M. (2001). Police use of force: An analysis of organizational characteristics. Justice Quarterly, 18(2), 393-409.

Alpert, G. P., \& Moore, M. H. (1993). Measuring police performance in the new paradigm of policing. In Performance measures for the criminal justice system: Discussion papers from the BJS-Princeton project (pp. 109-142). Washington DC: Bureau of Justice Statistics.

American Civil Liberties Union. (n.d.) Reforming police practices. Retrieved from https://www.aclu.org/issues/criminal-law-reform/reforming-police-practices

Sen, A., \& Anand, S. (1994). Human development index: methodology and measurement. Retrieved from http://hdr.undp.org/sites/default/files/oc12.pdf 
Ariel, B., Farrar, W. A., \& Sutherland, A. (2015). The effect of police body-worn cameras on use of force and citizens' complaints against the police: A randomized controlled trial. Journal of Quantitative Criminology, 31(3), 509-535.

Ariel, B., Sutherland, A., Henstock, D., Young, J., Drover, P., Sykes, J., Magicks, S., \& Henderson, R. (2016). Wearing body cameras increases assaults against officers and does not reduce police use of force: Results from a global multi-site experiment. European Journal of Criminology, 13(6), 744-755.

Aristovnik, A., Seljak, J., \& Mencinger, J. (2013). Relative efficiency of police directorates in Slovenia: A non-parametric analysis. Expert Systems with Applications, 40(2), 820-827.

Aristovnik, A., Seljak, J., \& Mencinger, J. (2014). Performance measurement of police forces at the local level: A non-parametric mathematical programming approach. Expert Systems with Applications, 41(4), 1647-1653.

Armacost, B. E. (2003). Organizational culture and police misconduct. George Washington Law Review, 72, 453-546.

Arribas-Bel, D., Kourtit, K., \& Nijkamp, P. (2013). Benchmarking of world cities through self-organizing maps. Cities, 31, 248-257.

Ashkenas, J., \& Park, H. (2015, April 8). The race gap in America's police departments. The New York Times. Retrieved from https://www.nytimes.com/interactive/2014/09/03/us/the-race-gap-in-americaspolice-departments.html

Atherley, L. T., \& Hickman, M. J. (2014). Controlling use of force: Identifying police use of excessive force through analysis of administrative records. Policing: A Journal of Policy and Practice, 8(2), 123-134.

Barrett, K., \& Greene, R. (2016, March). 5 urgent public management issues. Governing: The states and localities. Retrieved from http://www.governing.com/columns/smart-mgmt/gov-2016-managementissues.html

Barrick, K., Hickman, M. J., \& Strom, K. J. (2014). Representative policing and violence towards the police. Policing: A Journal of Policy and Practice, 8(2), 193-204.

Bartels, E. C., \& Silverman, E. B. (2005). An exploratory study of the New York City civilian complaint review board mediation program. Policing: An International Journal of Police Strategies \& Management, 28(4), 619-630. 
Bayley, D. H. (1992). Comparative organization of the police in English-speaking countries. Crime and Justice, 15(1), 509-545.

Bayley, D. H., \& Bittner, E. (1997). Learning the skills of policing. In R. G. Dunham and G. Alpert (Eds.), Critical issues in policing: Contemporary readings ( $3^{\text {rd }} \mathrm{ed}$., pp. 114-137). Prospect Heights, IL: Waveland Press.

Belur, J. (2010). Why do the police use deadly force? Explaining police encounters in Mumbai. British Journal of Criminology, 50(2), 320-341.

Berg, B. L., \& Lune, H. (2012). Qualitative research methods for the social sciences (8th ed.). Boston, MA: Pearson.

Bernstein, M. (1996, January 26). The history of the Hartford police: 135 years of service recorded in commemorative album. The Hartford Courant. Retrieved from http://articles.courant.com/1996-01-26/news/9601260731_1_police-stationofficers-135-year-history

Bierie, D. M., Detar, P. J., \& Craun, S. W. (2016). Firearm violence directed at police. Crime and Delinquency, 62(4), 501-524.

Blair, J. M., Fowler, K. A., Betz, C. J., \& Baumgardner, J. L. (2016). Occupational homicides of law enforcement officers, 2003-2013: Data from the national violent death reporting system. American Journal of Preventive Medicine, 51(5), S188S196.

Boivin, R., \& Lagacé, M. (2016). Police use-of-force situations in Canada: Analyzing the force or resistance ratio using a trichotomous dependent variable. Police Quarterly, 19(2), 180-198.

Bolger, P. C. (2015). Just following orders: A meta-analysis of the correlates of American police officer use of force decisions. American Journal of Criminal Justice, 40(3), 466-492.

Boodhoo, R., \& Purmessur, R. D. (2009). Justifications for qualitative research in organisations: A step forward. The WWW Journal of Online Education, 1-7.

Bordua, D. J., \& Tift, L. L. (1971). Citizen interviews, organizational feedback, and police-community relations decisions. Law and Society Review, 6(2), 155-182.

Bourgon, J. (2007). Responsive, responsible, and respected government: Towards a new public administration theory. International Review of Administrative Sciences, 73(1), 7-26. 
Bowen, G. A. (2009). Document analysis as a qualitative research method. Qualitative Research Journal, 9(2), 27-40.

Bradbury, M., \& Kellough, J. E. (2011). Representative bureaucracy: Assessing the evidence on active representation. The American Review of Public Administration. 41(2), 157-167.

Brandl, S. G., \& Stroshine, M. (2012). The role of officer attributes, job characteristics, and arrest activity in explaining police use of force. Criminal Justice Policy Review, 24(5), 551-572.

Brandl, S. G., Stroshine, M. S., \& Frank, J. (2001). Who are the complaint-prone officers?: An examination of the relationship between police officers' attributes, arrest activity, assignment, and citizens' complaints about excessive force. Journal of Criminal Justice, 29(6), 521-529.

Braun, V., \& Clarke, V. (2006). Using thematic analysis in psychology. Qualitative Research in Psychology, 3(2), 77-101.

Brooks, L. W. (2015). Police discretionary behavior: A study of style. In R. G. Dunham and G. P. Alpert (Eds.), Critical issues in policing: Contemporary readings $\left(7^{\text {th }}\right.$ ed., pp. 122-142). Long Grove, IL: Waveland Press, Inc.

Brown, T. A. (2007a, July 6). Police slow to comply '04 order targeted citizen complaints. The Hartford Courant. Retrieved from http://www.hartfordinfo.org/issues/documents/Crime/htfd_courant_070607.asp

Brown, T. A. (2007b, December 7). City held in contempt over court order. The Hartford Courant. Retrieved from http://articles.courant.com/2007-1207/news/0712070017_1_contempt-order-citizen-complaints-consent-decree

Brunson, R. K. (2007). Police don't like black people: African-American young men's accumulated police experiences. Criminology and Public Policy, 6(1), 71-102.

Brunson, R. K., Braga, A. A., Hureau, D. M., \& Pegram, K. (2013). We trust you, but not that much: Examining police-black clergy partnerships to reduce youth violence. Justice Quarterly, 32(6), 1006-1036.

Brunson, R. K., \& Gau, J. M. (2015). Officer race versus macro-level context: A test of competing hypotheses about black citizens' experiences with and perceptions of black police officers. Crime and Delinquency, 61(2), 213-242.

Brunson, R. K., \& Weitzer, R. (2009). Police relations with black and white youths in different urban neighborhoods. Urban Affairs Review, 44(6), 858-885. 
Buffone, S., Chenier, A., Schulenberg, J. L., \& Sycz, D. (2017). Improving the police complaints system: Stakeholder collaboration as a vehicle for systems change. American Journal of Criminal Justice, 42(2), 293-314.

Bukszpan, D. (2011, February 1). America's most destructive riots of all time. $C N B C$. Retrieved from http://www.cnbc.com/id/41372364 [http://perma.cc/ET8ELGZZ].

Bunn, R. F. (1961). Notes on the control and responsibility of the bureaucrat. The Southwestern Social Science Quarterly, 51(4), 407-414.

CALEA. (2012, December). The commission. Retrieved from http://www.calea.org/content/commission

Calhoun, J. A. (2016, November 20). Building trust between police and the communities they serve. National League of Cities. Retrieved from, http://www.nlc.org/article/building-trust-between-police-and-the-communitiesthey-serve

Cao, L., Deng, X., \& Barton, S. (2000). A test of Lundman's organizational product thesis with data on citizen complaints. Policing: An International Journal of Police Strategies and Management, 23(3), 356-373.

Cao, L., \& Huang, B. (2000). Determinants of citizen complaints against police abuse of power. Journal of Criminal Justice, 28(3), 203-213.

Caplan, J. M., Marotta, P., Piza, E. L., \& Kennedy, L. W. (2014). Spatial risk factors of felonious battery to police officers. Policing: An International Journal of Police Strategies \& Management, 37(4), 823-838.

Carr, P. J., Napolitano, L., \& Keating, J. (2007). We never call the cops and here is why: A qualitative examination of legal cynicism in three Philadelphia neighborhoods. Criminology, 45(2), 445-480.

Cashmore, E. (2001). The experiences of ethnic minority police officers in Britain: Under-recruitment and racial profiling in a performance culture. Ethnic and Racial Studies, 24(4), 642-659.

Center for Popular Democracy \& PolicyLink. (2015). Building momentum from the ground up: A toolkit for promoting justice in policing. Retrieved from http://www.justiceinpolicing.com/docs/JusticeInPolicing.pdf

Chappell, A. T. (2009). The philosophical versus actual adoption of community policing: A case study. Criminal Justice Review, 34(1), 5-28. 
Chappell, A. T., MacDonald, J. M., \& Manz, P. W. (2006). The organizational determinants of police arrest decisions. Crime \& Delinquency, 52(2), 287-306.

Chen, C. (2016). Effects of fiscal stress on state highway infrastructure finance: A composite index approach. Municipal Finance Journal, 37(2), 1-28.

Cintron v. Vaughn, No. 3:69-cv-13578, 2000 WL 620427, at *1 (D. Conn. Mar. 15, 2000)

City of Oakland. (n.d.). The Oakland police department and court-ordered reform: The Negotiated Settlement Agreement drives cultural and operational change. Retrieved from http://www.oaklandcityattorney.org/PDFS/Riders/Background\%20Fact\%20Sheet $\% 20$ on $\% 20$ NSA.pdf

Cohen, J. B. (2008, April 6). Anger after King's death left lasting mark on Hartford's North End. The Hartford Courant. Retrieved from http://www.hartfordinfo.org/issues/documents/history/htfd_courant_040608.asp

Conti, N., \& Doreian, P. (2014). From here on out, we're all blue: Interaction order, social infrastructure, and race in police socialization. Police Quarterly, 17(4), $414-447$.

Cordner, G. (2014). Community policing. In M. D. Reisig and R. J. Kane (Eds.), The Oxford handbook of police and policing (pp. 148-171). New York, NY: Oxford University Press.

Covington, M. W., Huff-Corzine, L., \& Corzine, J. (2014). Battered police: Risk factors for violence against law enforcement officers. Violence and Victims, 29(1), 34-52.

Crank, J. P. (1990a). Police: Professionals or craftsmen? An empirical assessment of professionalism and craftsmanship among eight municipal police agencies. Journal of Criminal Justice, 18(4), 333-349.

Crank, J. P. (1990b). The influence of environmental and organizational factors on police style in urban and rural environments. Journal of Research in Crime and Delinquency, 27(2), 166-189.

Crawford, A., Lister, S., Blackburn, S., \& Burnett, J. (2005). Plural policing: The mixed economy of visible patrols in England and Wales. Bristol: The Policy Press.

Creswell, J. W. (2013). Research design: Qualitative, quantitative, and mixed methods approaches. Thousand Oaks, CA: Sage Publications. 
Curry, A. (1999). Innovation in public service management. Managing Service Quality: An International Journal, 9(3), 180-190.

Cutter, S. L., Boruff, B. J., \& Shirley, W. L. (2003). Social vulnerability to environmental hazards. Social Science Quarterly, 84(2), 242-261.

Daigle Law Group. (2015). Staffing and deployment analysis for the Hartford police department. Retrieved from https://www.scribd.com/document/266696725/Hartford-Police-DepartmentStaffing-and-Deployment-Analysis-3-02-201-2

Danois, E. B. (2015, August 25). Check out America's worst police departments. The Root. Retrieved from https://www.theroot.com/check-out-america-s-worst-policedepartments-1790860913

Davis, J. A., \& Lawler, J. J. (1985). Police professionalism: Does it make a difference? Justice Professional, 1(1), 45-56.

De Angelis, J. (2009). Assessing the impact of oversight and procedural justice on the attitudes of individuals who file police complaints. Police Quarterly, 12(2), 214236.

De Guzman, M. C. (2004). One for all? Philippine police officers' perceptions of civilian review. Policing: An International Journal of Police Strategies \& Management, 27(3), 358-379.

de Sherbinin, A., Reuben, A., Levy, M. A., \& Johnson, L. (2013). Indicators in practice: How environmental indicators are being used in policy and management contexts. Palisades, NY and New Haven, CT: CIESIN, Columbia University and YCELP.

Debolt, D. (2016, August 10). Two Oakland cops facing suspension for exchanging racist, homophobic text messages. The Mercury News. Retrieved from https://www.mercurynews.com/2016/08/10/two-oakland-cops-facing-suspensionfor-exchanging-racist-homophobic-text-messages/

Denhardt, J. V., \& Denhardt, R. B. (2011). The new public service: Serving, not steering ( ${ }^{\text {rd }}$ Ed.). Armonk, NY: M. E. Sharpe.

Denhardt, R. B., \& Denhardt, J. V. (2000). The new public service: Serving rather than steering. Public Administration Review, 60(6), 549-559.

Drake, L. M., \& Simper, R. (2005). The measurement of police force efficiency: An assessment of UK Home Office policy. Contemporary Economic Policy, 23(4), 465-482. 
Dugan, L. (2003). Domestic violence legislation: Exploring its impact on the likelihood of domestic violence, police involvement, and arrest. Criminology \& Public Policy, 2(2), 283-312.

Dunham, R. G., \& Alpert, G. P. (2009). Officer and suspect demeanor: A qualitative analysis of change. Police Quarterly, 12(1), 6-21.

Dunn, R. A. (2010). Race and the relevance of citizen complaints against the police. Administrative Theory \& Praxis, 32(4), 557-577.

Edwards, A. (2000). Reported use of force by Queensland police: Findings from 1999 Queensland defendants survey. Brisbane: Queensland Criminal Justice Commission.

Eitle, D. (2005). The influence of mandatory arrest policies, police organizational characteristics, and situational variables on the probability of arrest in domestic violence cases. Crime and Delinquency, 51(4), 573-597.

Eitle, D., D'Alessio, S. J., \& Stolzenberg, L. (2014). The effect of organizational and environmental factors on police misconduct. Police Quarterly, 17(2), 103-126.

Eitle, D., \& Monahan, S. (2009). Revisiting the racial threat thesis: The role of police organizational characteristics in predicting race-specific drug arrest rates. Justice Quarterly, 26(3), 528-561.

Eitle, D., Stolzenberg, L., \& D'Alessio, S. J. (2005). Police organizational factors, the racial composition of the police, and the probability of arrest. Justice Quarterly, 22(1), 30-57.

Elliott, I., Thomas, S. D., \& Ogloff, J. R. (2011). Procedural justice in contacts with the police: The perspective of victims of crime. Police Practice and Research: An International Journal, 13(5), 437-449.

Engel, R. S., Sobol, J. J., \& Worden, R. E. (2000). Further exploration of the demeanor hypothesis: The interaction effects of suspects' characteristics and demeanor on police behavior. Justice Quarterly, 17(2), 235-258.

Engel, R. S., Tillyer, R., Klahm, C. F., \& Frank, J. (2012). From the officer's perspective: A multilevel examination of citizens' demeanor during traffic stops. Justice Quarterly, 29(5), 650-683.

Engel, R. S., \& Worden, R. E. (2003). Police officers' attitudes, behavior, and supervisory influences: An analysis of problem solving. Criminology, 41(1), 131166. 
Erasmus, E. (n.d.). Street-level bureaucracy. University of Cape Town. Retrieved from http://www.hpsa-africa.org/images/Street_level_bureaucracy_final_for_web.pdf

Falcone, D. N., Wells, L. E., \& Weisheit, R. A. (2002). The small-town police department. Policing: An International Journal of Police Strategies and Management, 25(2), 371-384.

Ferdik, F. V., Kaminski, R. J., Cooney, M. D., \& Sevigny, E. L. (2014). The influence of agency policies on conducted energy device use and police use of lethal force. Police Quarterly, 17(4), 328-358.

Fielding, N., \& Innes, M. (2006). Reassurance policing, community policing and measuring police performance. Policing and Society, 16(2), 127-145.

Finer, H. (1941). Administrative responsibility in democratic governance. Public Administration Review, 1(4), 335-350.

Fingerhut, H. (2017, September 15). Deep racial, partisan divisions in Americans' views of police officers. Pew Research Center. Retrieved from http://www.pewresearch.org/fact-tank/2017/09/15/deep-racial-partisan-divisionsin-americans-views-of-police-officers/

Fischer-Baum, R. (2014, August 19). Nobody knows how many Americans the police kill each year. FiveThirtyEight. Retrieved from http://fivethirtyeight.com/features/how-many-americans-the-police-kill-each-year/

Fridell, L., Faggiani, D., Taylor, B., Brito, C. S., \& Kubu, B. (2009). The impact of agency context, policies, and practices on violence against the police. Journal of Criminal Justice, 37(6), 542-552.

Friedrich, C. J. (1935). Problems of the American public service. New York, NY: McGraw-Hill.

Friedrich, C. J. (1940). Public policy and the nature of administrative responsibility. In C.J. Friedrich, and E. Mason (Eds.), Public policy: A yearbook of the graduate. Cambridge, MA: Harvard University Press.

Fryer, R. G. (2016). An empirical analysis of racial differences in police use of force. NBER Working Paper, Retrieved from http://www.nber.org/papers/w22399

Fyfe, J. (1979). Administrative interventions on police shooting discretion: An empirical examination. Journal of Criminal Justice, 7(4), 309-24. 
Garner, J. H., Maxwell, C. D., \& Heraux, C. (2002). Characteristics associated with the prevalence and severity of force used by the police. Justice Quarterly, 19(4), 70546.

Gau, J. M., \& Brunson, R. K. (2010). Procedural justice and order maintenance policing: A study of inner-city young men's perceptions of police legitimacy. Justice Quarterly, 27(2), 255-279.

Gau, J., Mosher, C., \& Pratt, T. C. (2009). An inquiry into the impact of suspect race on police use of tasers. Justice Quarterly, 13(1), 27-48.

Giambona, F., \& Vassallo, E. (2014). Composite indicator of social inclusion for European countries. Social Indicator Research, 116(1), 269-293.

Gibbs, J. C., Lee, J., Moloney, J., \& Olson, S. (2017). Exploring the neighborhood context of serious assaults on police. Policing and Society: An International Journal of Research and Policy, 1-17.

Gibbs, J. C., Ruiz, J., \& Klapper-Lehman, S. A. (2014). Police officers killed on duty: Replicating and extending a unique look at officer deaths. International Journal of Police Science \& Management, 16(4), 277-287.

Gill, C., Weisburd, D., Telep, C. W., Vitter, Z., \& Bennett, T. (2014). Communityoriented policing to reduce crime, disorder and fear and increase satisfaction and legitimacy among citizens: A systematic review. Journal of Experimental Criminology, 10(4), 399-428.

Gilliard-Matthews, S., Kowalski, B. R., \& Lundman, R. J. (2008). Office race and citizen-reported traffic ticket decisions by police in 1999 and 2002 . Police Quarterly, 11(2), 202-219.

Gold, R. (1958). Roles in sociological field observation. Social Forces, 36(3), 217-213.

Goldstein, H. (1990). Problem-oriented policing. New York, NY: McGraw-Hill.

Gorman, M. F., \& Ruggiero, J. (2008). Evaluating U.S. state police performance using data envelopment analysis. International Journal of Production Economics, 113(2), 1031-1037.

Gottschalk, P., Dean, G., \& Glomseth, R. (2011). Police misconduct and crime: Bad apples or systems failure? Journal of Money Laundering Control, 15(1), 6-24.

Greene, J. R. (2004). Community policing and organization change. In W. G. Skogan (Ed.), Community policing (Can it work?) (pp. 30-53). Belmont, CA: Wadsworth/Thomson. 
Gundhus, H. I. (2012). Experience or knowledge? Perspectives on new knowledge regimes and control of police professionalism. Policing, 7(2), 178-194.

Gustafson, J. L. (2010). Diversity in municipal police agencies: a national examination of its determinants and effects (Doctoral dissertation). Retrieved from the Northeastern University Digital Repository Service: https://repository.library.northeastern.edu/files/neu:1018/fulltext.pdf

Haarr, R. N. (1997). Patterns of interaction in a police patrol bureau: Race and gender barriers to integration. Justice Quarterly, 14(1), 53-85.

Halpern, B. S., Longo, C., Hardy, D., McLeod, K. L., Samhouri, J. F., Katona, S. K., \& Zeller, D. (2012). An index to assess the health and benefits of the global ocean. Nature, 488(7413), 615-620.

Hamilton, A. M. (2018, February 25). Extraordinary life: A passionate activist for Puerto Rican community. The Hartford Courant. Retrieved from http://www.courant.com/obituaries/hc-extraordinary-life-carmen-rodreguez-0225story.html

Hanafi, S., Bahora, M., Demir, B. N., \& Compton, M. T. (2008). Incorporating crisis intervention team (CIT) knowledge and skills into the daily work of police officers: A focus group study. Community Mental Health Journal, 44(6), 427-432.

Harris, C. J. (2010). Problem officers? Analyzing problem behavior patterns form a large cohort. Journal of Criminal Justice, 38(2), 216-225.

Hartford police activities league. (n.d.). Retrieved from http://www.hartford.gov/police/community-services/police-activities-league-pal

Hassell, K. D., \& Archbold, C. A. (2010). Widening the scope on complaints of police misconduct. Policing: An International Journal of Police Strategies and Management, 33(3), 473-489.

Headley, A. M., D’Alessio, S., \& Stolzenberg, L. (2017). The effect of a complainants race on dispositional outcome in police misconduct cases in Chicago. Race and Justice. https://doi.org/10.1177/2153368717726829

Headley, A. M., Guerette, R. T., \& Shariati, A. (2017). A field experiment of the impact of body-worn cameras (BWCs) on police officer behavior and perceptions. Journal of Criminal Justice, 53, 102-109. http://doi.org/10.1016/j.jcrimjus.2017.10.003

Heidenis, C. (2003). An analysis of the Hartford Time and the Hartford Courant's coverage of the 1969 riots in Hartford. Hartford Studies Collection: Papers by 
Students and Faculty. Retrieved from the Trinity College Digital Repository: http://digitalrepository.trincoll.edu/hartford_papers/19

Hickman, M., \& Piquero, A. (2009). Organizational, administrative, and environmental correlates of complaints about police use of force: Does minority representation matter? Crime \& Delinquency, 55(1), 3-27.

Hickman, M. J., \& Poore, J. E. (2016). National data on citizen complaints about police use of force: Data quality concerns and the potential (mis)use of statistical evidence to address police agency conduct. Criminal Justice Review, 27(5), 455479.

Holmes, M. D. (2000). Minority threat and police brutality: Determinants of civil rights criminal complaints in U.S. municipalities. Criminology, 38(2), 343-367.

Hong, S. (2016). Representative bureaucracy, organizational integrity, and citizen coproduction: Does an increase in police ethnic representativeness reduce crime? Journal of Policy Analysis and Management, 35(1), 11-33.

Hong, S. (2017) Does increasing ethnic representativeness reduce police misconduct? Evidence from police reform in England and Wales. Public Administration Review, 77(2), 195-205.

Hsu, A., Lloyd, A., \& Emerson, J. W. (2013). What progress have we made since Rio? Results from the 2012 environmental performance index (EPI) and pilot trend EPI. Environmental Science \& Policy, 33, 171-185.

Huggins, R. (2009). Regional competitive intelligence: Benchmarking and policymaking. Regional Studies, 44(5), 639-658.

Human Development Reports. (2016). Why is geometric mean used for the HDI rather than the arithmetic mean? Retrieved from the United Nations Development Programme. Retrieved: http://hdr.undp.org/en/content/why-geometric-mean-usedhdi-rather-arithmetic-mean

Hunter, R. D., \& Barker, T. (2010). Police-community relations and the administration of justice ( $8^{\text {th }}$ ed.). Englewood Cliffs, NJ: Prentice Hall.

Hur, Y. (2013). Turnover, voluntary turnover, and organizational performance: Evidence from municipal police departments. Public Administration Quarterly, 37(1), 3-35.

Innes, M., Fielding, N., \& Cope, N. (2005), The appliance of science: The theory and practice of crime intelligence analysis. British Journal of Criminology, 45(1), 3957. 
International Association of Chiefs of Police (IACP). (2015). IACP national policy summit on community-police relations: Advancing a culture of cohesion and community trust. Retrieved from:

http://www.theiacp.org/Portals/0/documents/pdfs/CommunityPoliceRelationsSum mitReport_web.pdf

Jackson, M. (2009). Responsibility versus accountability in the Friedrich-Finer debate. Journal of Management History, 15(1), 66-77.

Jezewski, M. A. (1995). Evolution of a grounded theory: Conflict resolution through culture brokering. Advances in Nursing Science, 17(3), 14-30.

Johnson, R. R. (2012). Police officer job satisfaction: A multidimensional analysis. Police Quarterly, 15(2), 157-176.

Johnson, R. R. (2013). An examination of police department uniform color and policecitizen aggression. Criminal Justice and Behavior, 40(2), 228-244.

Joint Research Centre-European Commission. (2008). Handbook on constructing composite indicators: Methodology and user guide. OECD publishing.

Jones, C., \& Supinski, S. B. (2010). Policing and community relations in the homeland security era. Journal of Homeland Security and Emergency Management, 7(1).

Jones, J. M. (2015, June 19). In U.S., confidence in police lowest in 22 years. Gallup. Retrieved from http://news.gallup.com/poll/183704/confidence-police-lowestyears.aspx

Kachurik, S., Ruiz, J., \& Staub, M. (2013). Police officers killed on duty: A different view. International Journal of Police Science \& Management, 15(2), 1-11.

Kaminski, R. J. (2008). Assessing the county-level structural covariates of police homicides. Homicide Studies, 12(4), 350-380.

Kaminski, R. J., \& Stucky, T. D. (2009). Reassessing political explanations for murders of police. Homicide Studies, 13(1), 3-20.

Kaminski, R. J., Jefferis, E., \& Gu, J. (2003). Community correlates of serious assaults on police. Police Quarterly, 6(2), 119-149.

Kane, R. J. (2002). The social ecology of police misconduct. Criminology, 40(4), 867896. 
Kappeler, V. E., Sapp, A. D., \& Carter, D. L. (1992). Police officer higher education, citizen complaints, and departmental rule violations. American Journal of Police, 11(2), 37-54.

Katz, C. M. (2001). The establishment of a police gang unit: An examination of organizational and environmental factors. Criminology, 39(1), 37-74.

Kawulich, B. B. (2005). Participant observation as a data collection method. Forum: Qualitative Social Research, 6(2).

Keiser, L. R., Wilkins, V. M., Meier, K. J., \& Holland, C. A. (2002). Lipstick and logarithms: Gender, institutional context, and representative bureaucracy. American Political Science Review, 96(3), 553-564.

Kelling, G. L., \& Moore, M. K. (1988). The evolving strategy of policing: Perspectives on policing (Report No. 4). Washington, DC: U.S. Department of Justice.

Kennedy, B. A. (2013). Sorting through: The role of representation in bureaucracy. Journal of Public Administration Research and Theory, 23(4), 791-816.

Kent, S. (2010). Killings of police in US cities since 1980: An examination of environmental and political explanation. Homicide Studies, 14(1), 3-23.

Kiely, J. A., \& Peek, G. S. (2002). The culture of the British police: Views of police officers. Service Industries Journal, 22(1), 167-183.

Kingsley, J. D. (1944). Representative bureaucracy: An interpretation of the British Civil Services. Yellow Springs, Ohio: Antioch Press.

Kitchin, R., Lauriault, T. P., \& McArdle, G. (2015). Knowing and governing cities through urban indicators, city benchmarking and real-time dashboards. Regional Studies, Regional Science, 2(1), 6-28.

Klahm, C. F., \& Tillyer, R. (2010). Understanding police use of force: A review of the evidence. Southwest Journal of Criminal Justice, 7(2), 214-239.

Kochel, T. R., Wilson, D. B., \& Mastrofski, S. D. (2011). Effect of suspect race on officers' arrest decisions. Criminology, 49(2), 473-512.

Lambert, J. (1970). Crime, police, and race relations: A study in Birmingham. London: Oxford University Press.

Langan, P., Greenfield, L., Smith, S., Durose, M., \& Levin, D. (2001). Contacts between police and the public: Findings from the 1999 national survey. Retrieved from the Bureau of Justice Statistics: https://www.bjs.gov/content/pub/pdf/cpp99.pdf 
Langworthy, R. H. (1986). The structure of police organizations. New York: Praeger.

Langworthy, R. H., \& Travis, L. F. (1999). Policing in America: A balance of forces. Upper Saddle River, NJ: Prentice Hall.

Larson, A. D. (1973). Representative bureaucracy and administrative responsibility: a reassessment. Midwest Review of Public Administration, 7(1), 79-89.

Laughland, O., Swaine, J., McCarthy, C., \& Lartey, J. (2015, October 05). Justice Department trials system to count killings by U.S. law enforcement. The Guardian. Retrieved from http://www.theguardian.com/usnews/2015/oct/05/justice-department-trials-system-count-killings-us-lawenforcement-the-counted

Lawton, B. A. (2007). Levels of nonlethal force: An examination of individual, situational, and contextual factors. Journal of Research in Crime and Delinquency, 44(2), 163-184.

Lee, H., Jang, H., Yun, I., Lim, H., \& Tushaus, D. W. (2010). An examination of police use of force utilizing police training and neighborhood contextual factors: A multilevel analysis. Policing: An International Journal of Police Strategies \& Management, 33(4), 681-702.

Lee, J. M., Steinberg, L., \& Piquero, A. R. (2010). Ethnic identity and attitudes toward policing among African American juvenile offenders. Journal of Criminal Justice, 38(4), 781-789.

Lerner, R. (2002). The role of ministers and church groups in the Hartford civil rights movement. Hartford Studies Collection: Papers by Students and Faculty. Retrieved from the Trinity College Digital Repository: http://digitalrepository.trincoll.edu/hartford_papers/3

Lersch, K. M. (2002). Are citizen complaints just another measure of officer productivity? An analysis of citizen complaints and officer activity measures. Police Practice and Research, 3(2), 135-147.

Lincoln, Y. S., \& Guba, E. G. (1985). Naturalistic inquiry. Newbury Park, CA: Sage Publications.

Lipsky, M. (1980). Street-level bureaucracy: Dilemmas of the individual in public services. New York: Russell Sage Foundation

Lipsky, M. (2010). Street-level bureaucracy, 30th anniversary edition: Dilemmas of the individual in public service. New York: Russell Sage Foundation. 
Long, D. (2012). Understanding police-citizen conflict: a neighborhood environmental perspective (Doctoral dissertation). Education Doctoral. Paper 120. Retrieved from the Fisher Digital Publications: Education Doctoral: https://fisherpub.sjfc.edu/cgi/viewcontent.cgi?article=1121\&context=education_et d

Lumley, T., Diehr, P., Emerson, S., \& Chen, L. (2002). The importance of the normality assumption in large public health data sets. Annual Review of Public Health, 23(1), 151-169.

Luque-Martinez, T., \& Munoz-Leiva, F. (2005). City benchmarking: A methodological proposal referring specifically to Granada. Cities, 22(6), 411-423.

MacDonald, J. M. (2002). The effectiveness of community policing in reducing urban violence. Crime \& Delinquency, 48(4), 592-618

Maciag, M. (2015). Diversity on the force: Where police don't mirror communities. Retrieved from http://media.navigatored.com/documents/policediversityreport.pdf

Mack, N., Woodsong, C., MacQueen, K. M., Guest, G., \& Namey, E. (2005). Qualitative research methods: A data collectors field guide. Hoboken, NJ: Wiley.

Maguire, E. R. (1997). Structural change in large municipal police organizations during the community policing era. Justice Quarterly, 14(3), 547-576.

Maguire, E. R. (2003). Organizational structure in American police agencies: Context, complexity, and control. Albany, NY: SUNY Press.

Maguire, E. R. (2009) Police organizational structure and child sexual abuse case attrition. Policing: An International Journal of Police Strategies \& Management, 32(1), 157-179.

Maguire, E. R., Nix, J., \& Campbell, B. A. (2017). A war on cops? The effects of Ferguson on the number of U.S. police officers murdered in the line of duty. Justice Quarterly, 34(5), 739-758.

Maria Sánchez, State Representative and Community Advocate. (n.d.). Connecticut History. Retrieved from https://connecticuthistory.org/maria-sanchez-staterepresentative-and-community-advocate/

Marshall, C., \& Rossman, G. B. (2014). Designing qualitative research. Thousand Oaks, CA: Sage Publications. 
Mastrofski, S. D. (1998). Community policing and police organization structure. In J. Brodeur (Ed.), How to recognize good policing: Problems and issues (pp. 161240). Thousand Oaks: Sage Publications.

Mastrofski, S. D. (2004). Controlling street-level police discretion. The Annals of the American Academy of Political and Social Science, 593(1), 100-118.

Matusiak, M. C., Campbell, B. A., \& King, W. R. (2014). The legacy of LEMAS: Effects on police scholarship of a federally administered, multi-wave establishment survey. Policing: An International Journal of Police Strategies \& Management, 37(3), 630-648.

Maynard-Moody, S. W., \& Musheno, M. C. (2003). Cops, teachers, counselors: Stories from the front lines of public service. Ann Arbor, MI: University of Michigan Press.

Mazeika, D., Bartholomew, B., Distler, M., Thomas, K., Greenman, S., \& Pratt, S. (2010). Trends in police research: a cross-sectional analysis of the 2000-2007 literature. Police Practice and Research: An International Journal, 11(6), 520547.

McCluskey, J. D., Terrill, W., \& Paoline, E. A. (2005). Peer group aggressiveness and the use of coercion in police-suspect encounters. Police Practice and Research, 6(1), 19-37.

McElvain, J. P., \& Kposowa, A. J. (2004). Police officer characteristics and internal affairs investigations for use of force allegations. Journal of Criminal Justice, 32(3), 265-279.

Meier, K. J. (1975). Representative bureaucracy: An empirical analysis. American Political Science Review, 69(2), 526-543.

Meier, K. J., \& Stewart, J., Jr. (1992). The impact of representative bureaucracies: Educational systems and public policies. American Review of Public Administration, 22(3), 157-171.

Meredyth, D., McKernan, H., \& Evans, R. (2010). Police and Vietnamese-Australian communities in multi-ethnic Melbourne. Policing: A Journal of Policy and Practice, 4(3), 233-240.

Messer, L. C., Laraia, B. A., Kaufman, J. S., Eyster, J., Holzman, C., Culhane, J., Elo, I., Burke, J. G., \& O’Campo, P. (2006). The development of a standardized neighborhood deprivation index. Journal of Urban Health, 83(6), 1041-1062. 
Min, H., \& Min, H. (2013). Cross-cultural competitive benchmarking of fast-food restaurant services. Benchmarking: An International Journal, 20(2), 212-232.

Mitchell, O., \& Caudy, M. S. (2013). Examining racial disparities in drug arrests. Justice Quarterly, 32(2), 288-313.

Monkhouse, E. (1995). The role of competitive benchmarking in small-to medium-sized enterprises. Benchmarking for Quality Management \& Technology, 2(4), 41-50.

Moore, M. H., \& Braga, A. A. (2003). Measuring and improving police performance: The lessons of CompStat and its progeny. Policing: An International Journal of Police Strategies \& Management, 26(3), 439-453.

Moreto, W. D., Brunson, R. K., \& Braga, A. A. (2017). 'Anything we do, we have to include the communities': Law enforcement rangers' attitudes towards and experiences of community-ranger relations in wildlife protected areas in Uganda. British Journal of Criminology, 57(4), 924-944.

Morgan, G., \& Smircich, L. (1980). The case for qualitative research. Academy of Management Review, 5(4), 491-500.

Mosher, F. C. (1968). Democracy and the public service. New York, NY: Oxford University Press.

Muhammad, B. R. (2002). Rural crime and rural policing practices (multi-cultural law enforcement). Submitted to the Department of Interdisciplinary Technology. Retrieved from http://citeseerx.ist.psu.edu/viewdoc/download?doi=10.1.1.594.4468\&rep=rep1\&t ype $=$ pdf

National Advisory Commission on Civil Disorders. (1968). Report of the National Advisory Commission on Civil Disorders, March 1, 1968. Retrieved from the National Criminal Justice Reference Service: https://www.ncjrs.gov/pdffiles1/Digitization/8073NCJRS.pdf

National Commission on Law Observance and Enforcement. (1931). Report on crime and the foreign born (Report No. 10). Retrieved from the National Criminal Justice Reference Service: https://www.ncjrs.gov/pdffiles1/Digitization/44540NCJRS.pdf

New York (NY) Knapp Commission. (1972). The Knapp Commission report on police corruption. New York: George Braziller. 
Nicholson-Crotty, S., \& O'Toole, L. J. (2004). Public management and organizational performance: The case of law enforcement agencies. Journal of Public Administration Research and Theory, 14(1), 1-18.

Nicholson-Crotty, S., Nicholson-Crotty, J., \& Fernandez, S. (2017). Will more black cops matter? Officer race and police-involved homicides of black citizens. Public Administration Review, 77(2), 206-216.

Nordberg, A., Crawford, M. R., Praetorius, R. T., \& Hatcher, S. S. (2016). Exploring minority youths' police encounters: A qualitative interpretive meta-synthesis. Child and Adolescent Social Work Journal, 33(2), 137-149.

Novak, K. J., \& Chamlin, M. B. (2008). Racial threat, suspicion and police behavior. Crime \& Delinquency, 58(2), 275-300.

Novak, K. J., Frank, J., Smith, B. W., \& Engel, R. S. (2002). Revisiting the decision to arrest: Comparing beat and community officers. Crime \& Delinquency, 48(1), 70-98.

Nowacki, J. S. (2011) Organizational-level police discretion: An application for use of force. Crime \& Delinquency, 20(10), 1-26.

Nowacki, J. S. (2015). Organizational-level police discretion: An application for police use of lethal force. Crime \& Delinquency, 61(5), 643-668.

Nyhan, R. C., \& Martin, L. L. (1999). Assessing the performance of municipal police services using data envelopment analysis: An exploratory study. State and Local Government Review, 31(1), 18-30.

O’Connor, T. R. (2005, November 11). Police deviance. Retrieved from http://policecrimes.com/police_deviance-html/

Office of Community Oriented Policing Services. (2016). Collaborative reform initiative for technical assistance. Retrieved from U.S. Department of Justice: https://cops.usdoj.gov/pdf/technical_assistance.pdf

Office of Community Oriented Policing Services. (2018). Fact sheet: Collaborative reform initiative for technical assistance (CRI-TA) program. Retrieved from U.S. Department of Justice: https://cops.usdoj.gov/pdf/2018AwardDocs/crita/Fact_Sheet.pdf

Oliva, J. R., \& Compton, M. T. (2010). What do police officers value in the classroom?: A qualitative study of the classroom social environment in law enforcement education. Policing: An International Journal of Police Strategies \& Management, 33(2), 321-338. 
Oliver, W. M. (2006). The fourth era of policing: Homeland security. International Review of Law Computers \& Technology, 20(1-2), 49-62.

Ozkan, T., Worrall, J. L., \& Piquero, A. R. (2016). Does minority representation in police agencies reduce assaults on the police? American Journal of Criminal Justice, 41(3), 402-423.

Paoline, E. A., III, \& Terrill, W. (2007). Police education, experience, and the use of force. Criminal Justice and Behavior, 34(2), 179-196.

Paoline, E. A., III, \& Terrill, W. (2011). Listen to me! Police officers' views of appropriate use of force. Journal of Crime and Justice, 34(3), 178-189.

Patton, M. Q. (2002). Qualitative research and evaluation methods ( $3^{\text {rd }}$ ed.). Thousand Oaks, CA: Sage Publications.

Patton, M. Q. (2005). Qualitative research. John Wiley \& Sons, Ltd.

Perry, F. (2001). Repairing broken windows: Preventing corruption within our ranks. FBI Law Enforcement Bulletin, 70(2), 23-27.

Phillips, T., \& Smith, P. (2000). Police violence occasioning citizen complaint: An empirical analysis of time-space dynamics. British Journal of Criminology, 40(3), 480-496.

Police Executive Research Forum (PERF). (2013). COMPSTAT: Its origins, evolution, and future in law enforcement agencies. Retrieved from Bureau of Justice Assistance: https://www.bja.gov/publications/perf-compstat.pdf

Poole, E. D., Regoli, R. M., \& Lotz, R. (1978). Linkages between professionalism, work alienation and cynicism in large and small police departments. Social Science Quarterly, 59(3), 525-534.

Porter, A. (2016). Decolonizing policing: Indigenous patrols, counter-policing and safety. Theoretical Criminology, 20(4), 548-565.

Potter, G. (2013). The history of policing in the United States. Retrieved from EKU Online: http://plsonline.eku.edu/sites/plsonline.eku.edu/files/the-history-ofpolicing-in-us.pdf

Prenzler, T., Allard, T., Curry, S., \& Macintyre, S. (2010). Complaints against police: The complainants' experience. The Journal of Criminal Justice Research, 1(1), 118. 
Prenzler, T., Mihinjac, M., \& Porter, L. E. (2013). Reconciling stakeholder interests in police complaints and discipline systems. Police Practice and Research: An International Journal, 14(2), 155-168.

Prescott-Allen, R. (2001). The wellbeing of nations: A country-by-county index of quality of life and the environment. Washington, DC: Island Press.

President's Commission on Law Enforcement and Administration of Justice. (1967). The challenge of crime in a free society. Washington, DC: U.S. Government Printing Office. Retrieved from https://www.ncjrs.gov/pdffiles1/nij/42.pdf

President's Task Force on 21st Century Policing. (2015). Final report of the president's task force on 21st century policing. Washington, DC: Office of Community Oriented Policing Services.

Punch, M. (2003). Rotten orchards: 'Pestilence', police misconduct and system failure. Policing and Society, 13(2), 171-196.

Queally, J. (2016, June 15). After a sex scandal rocked Oakland police, officials are trying to figure out how to restore public trust. The Los Angeles Times. Retrieved from http://www.latimes.com/local/lanow/la-me-ln-oakland-sex-scandal20160613-snap-story.html

Rabe-Hemp, C. E., \& Schuck, A. E. (2007). Violence against police officers: Are female officers at greater risk? Police Quarterly, 10(4), 411-428.

Radelat, A. (2016, January). Hartford police begin New Year with old civil rights problem. The Connecticut Mirror. Retrieved from https:/ctmirror.org/2016/01/06/hartford-police-begin-new-year-with-old-civilrights-problem/

Radelet, L. A., \& Carter, D. L. (1994). The police and the community. Englewood Cliffs, NJ: Prentice Hall.

Rahtz, H. (2016). Race, riots, and the police. Boulder, CO: Lynne Rienner Publishers, Inc.

Ramsden, A., \& Bate, A. (2008). Using word clouds in teaching and learning. Retrieved from the University of Bath, e-learning: http://opus.bath.ac.uk/474/1/using\%2520word\%2520clouds\%2520in\%2520teachi ng\%2520and\%2520learning.pdf

Reed, W. E. (1999).The politics of community policing: The case of Seattle. New York, NY: Garland. 
Reisig, M. D. (2010). Community and problem-oriented policing. Crime and Justice, $39(1), 1-53$.

Reiss, A. (1992). Police organization in the twentieth century. In M. Tonry and N. Morris (Eds.) Modern policing: Crime and justice: A review of research (vol. 15, pp. 5197). Chicago, IL: University of Chicago Press.

Reiss, A. J. (1971) The police and the public. New Haven, CT: Yale University Press.

Remler, D. K., \& Van Ryzin, G. G. (2010). Research methods in practice: Strategies for description and causation. Sage Publications.

Rhodes, T., Platt, L., Sarang, A., Vlasov, A., Mikhailova, L., \& Monaghan, G. (2006). Street policing, injecting drug use and harm reduction in a Russian city: A qualitative study of police perspectives. Journal of Urban Health, 83(5), 911-925.

Riccucci, N. M., Van Ryzin, G., \& Lavena, C. F. (2014). Representative bureaucracy in policing: Does it increase perceived legitimacy? Journal of Public Administration Research and Theory, 24(3), 537-551

Rittel, H. W., \& Webber, M. M. (1973). Dilemmas in a general theory of planning. Policy Sciences, 4(2), 155-169.

Rosenbaum, D. P., Lawrence, D. S., Hartnett, S. M., McDevitt, J., \& Posick, C. (2015). Measuring procedural justice and legitimacy at the local level: The policecommunity interaction survey. Journal of Experimental Criminology, 11(3), 335366.

Sampson, R. J. (1986). The effects of urbanization and neighborhood characteristics on criminal victimization. Metropolitan Crime Patterns, 3-25.

Schaible, L. M., De Angelis, J., Wolf, B., \& Rosenthal, R. (2013). Denver's citizen/police complaint mediation program: officer and complainant satisfaction. Criminal Justice Policy Review, 24(5), 626-650.

Schuck, A. M., \& Rabe-Hemp, C. (2014). Citizen complaints and gender diversity in police organizations. Policing and Society, 26(8), 859-874.

Schulenberg, J. L., Chenier, A., Buffone, S., \& Wojciechowski, C. (2017). An application of procedural justice to stakeholder perspectives: Examining police legitimacy and public trust in police complaint systems. Policing and Society: An International Journal of Research and Policy, 27(7), 779-797. 
Selden, S. C., \& Selden, F. (2001). Rethinking diversity in public organizations for the $21^{\text {st }}$ century: Moving toward a multicultural model. Administration and Society, 33(3), 303- 329.

Sessions, J. B. (2017). Memorandum for heads of department components and the United States Attorneys. Washington, D.C.: U.S. Department of Justice, Office of the Attorney General.

Sherman, L. W. (1980). Causes of police behavior: The current state of quantitative research. Journal of Research in Crime and Delinquency, 17(1), 69-100.

Shjarback, J. A. (2015). Emerging early intervention systems: An agency-specific prepost comparison of formal citizen complaints of use of force. Policing, 9(4), 314325.

Shjarback, J. A., \& White, M. D. (2015). Departmental professionalism and its impact on indicators of violence in police-citizen encounters. Police Quarterly, 19(1), 32-62.

Silber, J. (1989). Factor components, population subgroups, and the computation of the Gini index of inequality. The Review of Economics and Statistics, 71(1), 107-115.

Silverman, D. (2007). A very short, fairly interesting and reasonably cheap book about qualitative research. Thousand Oaks, CA: Sage Publications.

Simon, C. (2012, August 24). The arithmetic mean is not always appropriate [Blog post]. Retrieved from, http://mathemathinking.blogspot.com/2012/08/thearithmetic-mean-is-not-always.html

Singleton, R. A., Jr., Straits, B. C., \& Miller Straits, M. (1993). Approaches to social research (2nd ed.). New York, NY: Oxford University Press.

Skogan, W. (2005). Citizen satisfaction with police encounters. Police Quarterly, 8(3), 298-321.

Skogan, W. (2006). The promise of community policing. In D. Weisburd and A. Braga (Eds.), Police innovation: Contrasting perspectives (pp. 27-43). Cambridge, MA: Cambridge University Press.

Skolnick, J. (1966). Justice without trial: Law enforcement in democratic society. New York, NY: Wiley.

Skolnick, J. H., \& Bayley, D. H. (1986). The new blue line: Police innovation in six American cities. New York, NY: The Free Press. 
Skolnick, J. H., \& Fyfe, J. J. (1993). Above the law: Police and the excessive use of force. New York, NY: The Free Press.

Smith, B. W. (2004). Structural and organizational predictors of homicide by police. Policing: An International Journal of Police Strategies and Management, 27(4), 539-557.

Smith, B. W., \& Holmes, M. D. (2003). Community accountability, minority threat, and police brutality: An examination of civil rights criminal complaints. Criminology, 41(4), 1035-1064.

Smith, B. W., \& Holmes, M. D. (2014). Police use of excessive force in minority communities: A test of the minority threat, place and community accountability hypotheses. Social Problems, 61(1), 83-104.

Smith, D. A. (1986). The neighborhood context of police behavior. Crime and Justice, 8, 313-341.

Smith, G. (2009). Why don't more people complain against the police? European Journal of Criminology, 6(3), 249-266.

Sobol, J. J. (2010). The social ecology of police attitudes. Policing: An International Journal of Police Strategies and Management, 33(2), 253-269.

Sousa, W. H., Coldren, J. R., Rodriguez, D., \& Braga, A. A. (2016). Research on body worn cameras: Meeting the challenges of police operations, program implementation, and randomized controlled trial designs. Police Quarterly, 19(3), 363-384.

Spillar, K., Harrington, P., Wood, M., Aguirre, P., Aguilar, S., Yick, J., Abdo, M. \& Meza, L. (2000). Gender differences in the cost of police brutality and misconduct: A content analysis of LAPD civil liability cases: 1990-1999. Retrieved from the National Center for Women and Policing: http://www.womenandpolicing.org/ExcessiveForce.asp?id=4516

Stoughton, S. (2015). Law enforcement's "warrior" problem. Harvard Law Review Forum, 128, 225-234. Retrieved from http://harvardlawreview.org/wpcontent/uploads/2015/04/vol128_Stoughton.pdf

Styhre, A. (2008). Management control in bureaucratic and postbureaucratic organizations: A Lacanian perspective. Group and Organization Management, 33(6), 635-656. 
Subhas, N., \& Chandra, A. (2004). Baltimore City police athletic league assessment study. Retrieved from Johns Hopkins Bloomberg School of Public Health: https://www.jhsph.edu/research/centers-and-institutes/center-for-adolescenthealth/_includes/_pre-redesign/PAL_Report-long_version.pdf

Sun, I. Y., Payne, B. K., \& Wu, Y. (2008). The impact of situational factors, officer characteristics, and neighborhood context on police behavior: A multilevel analysis. Journal of Criminal Justice, 36(1), 22-32.

Sun, I., \& Payne, B. (2004). Racial differences in resolving conflicts: A comparison between black and white police officers. Crime \& Delinquency, 50(4), 516-541.

Swedler, D., Kercher, C., Simmons, M. M., \& Pollack, K. M. (2014). Occupational homicide of law enforcement officers in the U.S., 1996-2010. Injury Prevention, 20(1), 35-40.

Tateosian, N. (1998). Hartford, Connecticut: Discrimination, segregation, and urban riots. Hartford Studies Collection: Papers by Students and Faculty. Retrieved from the Trinity College Digital Repository:

https://digitalrepository.trincoll.edu/cgi/viewcontent.cgi?article $=1023 \&$ context $=\mathrm{h}$ artford_papers

Tennenbaum, A. N. (1994). The influence of the 'Garner' decision on police use of deadly force. The Journal of Criminal Law and Criminology, 85(1), 241-260.

Terrill, W., \& Ingram, J. R. (2016). Citizen complaints against the police. Police Quarterly, 19(2), 150-179.

Terrill, W., \& Mastrofski, S. D. (2002), Situational and officer based determinants of police coercion. Justice Quarterly, 19(2), 215-248.

Terrill, W., \& Paoline, E. (2015). Citizen complaints as threats to police legitimacy: The role of officer's occupational attitudes. Journal of Contemporary Criminal Justice, 31(2):192-211.

Terrill, W., \& Reisig, M. (2003). Neighborhood context and police use of force. Journal of Research in Crime and Delinquency, 40(3), 291-321.

Terrill, W., Leinfelt, F. H., \& Kwak, D. (2008). Examining police use of force: A smaller agency perspective. Policing: An International Journal of Police Strategies \& Management, 31(1), 57-76.

Theobald, N. A., \& Haider-Markel, D. P. (2009). Race, bureaucracy, and symbolic representation: Interactions between citizens and police. Journal of Public Administration Research and Theory, 19(2), 409-26. 
Thornton, S. R. (2015, March 3). The language of the unheard. The Shoeleather History Project. Retrieved from https://shoeleatherhistoryproject.com/2015/03/03/thelanguage-of-the-unheard/

Thornton, S. R. (2017). Wicked Hartford. Mount Pleasant, SC: Arcadia Publishing.

Thornton, S. R. (n.d.). Hartford's sex trade: Prostitutes and politics. Connecticut History. Retrieved from https://connecticuthistory.org/hartfords-sex-trade-prostitutes-andpolitics/

Toch, H., Grant, J .D., \& Galvin, R. T. (1975). Agents of change: A study in police reform. New York, NY: Schenkman.

Tofallis, C. (2014). Viewpoints: On constructing a composite indicator with multiplicative aggregation and the avoidance of zero weights in DEA. Journal of the Operational Research Society, 65(1), 791-793.

Trochmann, M. B., \& Gover, A. (2016). Measuring the impact of police representativeness on communities. Policing: An International Journal, 39(4), 773-790.

Trojanowicz, R. C. (1972). Police-community relations: Problems and process. Criminology, 9(4), 401-423.

U.S. Department of Justice. (1994, October 24). Violent Crime Control and Law Enforcement Act of 1994 Fact Sheet. Retrieved from https://www.ncjrs.gov/txtfiles/billfs.txt

U.S. Department of Justice. Civil Rights Division. (2013). Investigation of City of Miami police department. Retrieved from http://www.justice.gov/crt/about/spl/documents/miami_findings_7-9-13.pdf

U.S. Department of Justice. Civil Rights Division. (2014). Investigation of the Cleveland Division of Police. Retrieved from http://www.justice.gov/sites/default/files/opa/pressreleases/attachments/2014/12/0 4/cleveland_division_of_police_findings_letter.pdf

U.S. Department of Justice. Civil Rights Division. (2015). Investigation of the Ferguson Police Department. Retrieved from http://www.justice.gov/sites/default/files/opa/pressreleases/attachments/2015/03/04/ferguson_police_department_report.pdf

U.S. Department of Justice. Community Relations Service. (1999). Police use of excessive force: A conciliation handbook for the police and the community. Retrieved from http://www.justice.gov/archive/crs/pubs/pdexcess.htm\#12 
U.S. Department of Justice. Office of Public Affairs. (2017). Department of Justice announces changes to the collaborative reform initiative (Press Release No. 171010). Retrieved from https://www.justice.gov/opa/pr/department-justiceannounces-changes-collaborative-reform-initiative

Uchida, C. D., \& King, W. R. (2002). Police employee data: Elements and validity. Justice Research and Policy, 4(1-2), 1-9.

United Nations Development Programme (UNDP). (2014). Human development report 2014: Sustaining human progress: Reducing vulnerabilities and building resilience. Retrieved from http://hdr.undp.org/sites/default/files/hdr14-report-en1.pdf

Vella, V. (2016, November 10). Federal decree now in 5th decade as fully diverse force remains elusive goal for Hartford PD. The Hartford Courant. Retrieved from http://www.courant.com/community/hartford/hc-hartford-police-cintron-111020161110-story.html

Vella, V. (2017a, February 15). Hartford councilwoman's resolution to keep civilian police review board members. The Hartford Courant. Retrieved from http://www.courant.com/community/hartford/hc-hartford-civilian-police-reviewboard-0215-20170214-story.html

Vella, V. (2017b, December 2). Old issues return to plague Hartford civilian police review board. The Hartford Courant. Retrieved from http://www.courant.com/community/hartford/hc-news-hartford-cprbcancellations-20171201-story.html

Verma, A., \& Gavirneni, S. (2006). Measuring police efficiency in India: An application of data envelopment analysis. Policing: An International Journal of Police Strategies \& Management, 29(1), 125-145.

Verschelde, M., \& Rogge, N. (2012). An environment-adjusted evaluation of citizen satisfaction with local police effectiveness: Evidence from a conditional Data Envelopment Analysis approach. European Journal of Operational Research, 223(1), 214-225.

Walker, S. (1993). Taming the system: The control of discretion in criminal justice, 19501990. New York, NY: Oxford University Press.

Walker, S. (2005). The new world of police accountability. Thousand Oaks, CA: Sage Publications.

Walker, S. (2012). Police accountability: Current issues and research needs. BiblioGov. 
Walker, S. (2017). Twenty years of DOJ "pattern or practice” investigations of local police: Achievements, limitations, and questions. Retrieved from http://samuelwalker.net/wp-content/uploads/2017/02/DOJ-PP-Program-Feb24.pdf

Walker, S. E., \& Archbold, C. A. (2013). The new world of police accountability. Thousand Oaks, CA: Sage Publications.

Walker, S., Alpert, G. P., \& Kenney, D. J. (2001). Early warning systems: Responding to the problem police officer. Washington, DC: US Department of Justice, Office of Justice Programs, National Institute of Justice.

Walker, S., Spohn, C., \& DeLone, M. (2000). The color of justice: Race, ethnicity, and crime in America (2 ${ }^{\text {nd }}$ ed.). Belmont, CA: Wadsworth.

Walton, E. J. (2005). The persistence of bureaucracy: A meta-analysis of Weber's model of bureaucratic control. Organization Studies, 26(4), 569-600.

Weaver, T. S. (1901). Historical sketch of the police service of Hartford from 1636 to 1901. Hartford, CT: The Hartford Police Mutual Aid Association.

Weber, E. P., \& Khademian, A. M. (2008). Wicked problems, knowledge challenges, and collaborative capacity builders in network settings. Public Administration Review, 68(2), 334-349.

Weisheit, R. A., Wells, L. E., \& Falcone, D. N. (1995). Crime and policing in rural and small-town America. NIJ Research Report. Retrieved from National Criminal Justice Reference Service: https:/www.ncjrs.gov/txtfiles/crimepol.txt

Weitzer, R. (2000). White, black, or blue cops? Race and citizen assessments of police officers. Journal of Criminal Justice, 28(4), 313-324.

Weitzer, R. (2014). The puzzling neglect of Hispanic Americans in research on policecitizen relations. Ethnic and Racial Studies, 37(11), 1995-2013.

Weitzer, R., \& Tuch, S. A. (2004). Race and perceptions of police misconduct. Social Problems, 51(3), 305-325.

Weitzer, R., \& Tuch, S. A. (2005). Determinants of public satisfaction with the police. Police Quarterly, 8(3), 279-297.

Weitzer, R., Tuch, S. A., \& Skogan, W. G. (2008). Police-community relations in a majority-Black city. Journal of Research in Crime and Delinquency, 45(4), 398428. 
Wells, W., \& Schafer, J. A. (2007). Police skepticism of citizen oversight: Officers' attitudes toward specific functions, processes, and outcomes. Journal of Crime and Justice, 30(2), 1-25.

White, M. D. (2000). Assessing the impact of administrative policy on use of deadly force by on- and off-duty police. Evaluation Review, 24(3), 295-318.

White, M. D. (2001). Controlling police decisions to use deadly force: Reexamining the importance of administrative policy. Crime and Delinquency, 47(1), 131-151.

Whittemore, R., Chase, S. K., \& Mandle, C. L. (2001). Validity in qualitative research. Qualitative Health Research, 11(4), 522-537.

Wilkins, V. M., \& Williams, B. N. (2008). Black or blue: Racial profiling and representative bureaucracy. Public Administration Review, 68(4), 654-664.

Williams, H., \& Murphy, P. V. (1990). The evolving strategy of policing: A minority view (Report No. 13). Retrieved from the National Criminal Justice Reference Service: https://www.ncjrs.gov/pdffiles1/nij/121019.pdf

Willis, J. J. (2014). A recent history of the police. In M. D. Reisig and R. J. Kane (Eds.), The Oxford handbook of police and policing (pp. 3-33). New York, NY: Oxford University Press.

Willis, J. J., Mastrofski, S. D., \& Weisburd, D. (2007). Making sense of COMPSTAT: A theory-based analysis of organizational change in three police departments. Law \& Society Review, 41(1), 147-188.

Willits, D. W. (2014). The organizational structure of police departments and assaults on police officers. International Journal of Police Science \& Management, 16(2), $140-154$.

Willits, D. W., \& Nowacki, J. S. (2014). Police organisation and deadly force: An examination of variation across large and small cities. Policing and Society, 24(1), 63-80.

Wilson, J. M. (2005). Determinants of community policing: An open systems model of implementation. Report submitted to the U.S. Department of Justice. Retrieved from the National Criminal Justice Reference Service: https://www.ncjrs.gov/pdffiles1/nij/grants/211975.pdf

Wilson, J. M., Cox, A. G., Smith, T. L., Bos, H., \& Fain, T. (2007). Community policing and violence prevention in Oakland. Retrieved from RAND Corporation: https://www.rand.org/pubs/technical_reports/TR546.html 
Wilson, J. Q. (1968). Varieties of police behavior. Cambridge, MA: Harvard University Press.

Wilson, S., \& Zhao, J. (2008). Determining the correlates of police victimization: An analysis of organizational level factors on injurious assaults. Journal of Criminal Justice, 36(5), 461-468.

Wood, J., Sorg, E. T., Groff, E., Ratcliffe, J. H., \& Taylor, C. J. (2011). Cops as treatment providers: Realities and ironies of police work in a foot patrol experiment. Policing and Society: An International Journal of Research and Policy, 24(3), 362-379.

Wooden, K., \& Rogers, C. (2014). Restoring public confidence: Perceptions of community police officers. The Police Journal: Theory, Practice and Principles, 87(3), 186-194.

Worden, R. E. (1995). 'Causes' of police brutality: Theory and evidence on police use of force. In W. A. Geller and H. Toch (Eds.), And justice for all: Understanding and controlling police abuse of force (pp. 31-60). Washington, DC: Police Executive Research Forum.

Worden, R. E., \& McLean, S. J. (2016). Measuring, managing, and enhancing procedural justice in policing: Promise and pitfalls. Criminal Justice Policy Review, 29(2), $149-171$.

Wu, T. H., Chen, M. S., \& Yeh, J. Y. (2010). Measuring the performance of police forces in Taiwan using data envelopment analysis. Evaluation and Program Planning, 33(3), 246-254.

Yin, R. K. (2009). Case study research: Design and methods (4th ed.). Thousand Oaks, CA: Sage Publications 


\section{APPENDIX A}

\section{Literature on Organizational Correlates on Police-Citizen Conflict Outcomes ${ }^{48}$}

\begin{tabular}{|c|c|c|c|}
\hline CORRELATES & $\begin{array}{l}\text { FORCE } \\
\text { (4 studies) }\end{array}$ & $\begin{array}{l}\text { COMPLAINTS } \\
\text { (6 studies) }\end{array}$ & $\begin{array}{l}\text { ASSAULTS } \\
\text { (6 studies) }\end{array}$ \\
\hline $\begin{array}{l}\text { Racial } \\
\text { Representation }\end{array}$ & $\begin{array}{l}\text { Willits \& Nowacki } \\
(2014)^{*}\end{array}$ & $\begin{array}{l}\text { Hickman \& Piquero (2009); } \\
\text { Smith \& Holmes (2014)*; } \\
\text { Smith \& Holmes (2003)*; } \\
\text { Cao et al. (2000)* }\end{array}$ & $\begin{array}{l}\text { Barrick et al. (2014)*; } \\
\text { Wilson \& Zhao (2008); } \\
\text { Ozkan et al. (2016) }\end{array}$ \\
\hline $\begin{array}{l}\text { Community } \\
\text { Policing }\end{array}$ & & $\begin{array}{l}\text { Shjarback \& White (2015); } \\
\text { Smith \& Holmes (2014)* }\end{array}$ & $\begin{array}{l}\text { Barrick et al. (2014); } \\
\text { Ozkan et al. (2016); } \\
\text { Shjarback \& White } \\
\text { (2015); Willits (2014); } \\
\text { Wilson \& Zhao (2008)* }\end{array}$ \\
\hline Hiring Standards & $\begin{array}{l}\text { Smith (2004); Willits } \\
\text { \& Nowacki (2014)* }\end{array}$ & $\begin{array}{l}\text { Shjarback \& White (2015); } \\
\text { Cao et al. (2000) }\end{array}$ & $\begin{array}{l}\text { Ozkan et al. (2016); } \\
\text { Shjarback \& White } \\
\text { (2015) }\end{array}$ \\
\hline $\begin{array}{l}\text { Female } \\
\text { Representation }\end{array}$ & & $\begin{array}{l}\text { Shjarback \& White (2015); } \\
\text { Smith \& Holmes (2003); } \\
\text { Schuck \& Rabe-Hemp } \\
(2014)^{*} \text {; Cao, Deng \& } \\
\text { Barton (2000)* }\end{array}$ & $\begin{array}{l}\text { Ozkan et al. (2016); } \\
\text { Shjarback \& White } \\
(2015) \text {; Wilson \& Zhao } \\
(2008)\end{array}$ \\
\hline $\begin{array}{l}\text { Restrictive } \\
\text { Policy/ } \\
\text { Formalization }\end{array}$ & $\begin{array}{l}\text { Alpert \& MacDonald } \\
(2001)^{*} ; \text { Nowacki } \\
(2015)^{*} ; \text { Smith } \\
\text { (2004); Willits \& } \\
\text { Nowacki (2014) }\end{array}$ & $\begin{array}{l}\text { Hickman \& Piquero } \\
(2009)^{*} \text {; Schuck \& Rabe- } \\
\text { Hemp (2014)*; Cao et al. } \\
(2000)\end{array}$ & $\begin{array}{l}\text { Willits (2014); Fridell et } \\
\text { al. (2009)* }\end{array}$ \\
\hline $\begin{array}{l}\text { Civilian Review } \\
\text { Board }\end{array}$ & $\begin{array}{l}\text { Willits \& Nowacki } \\
\text { (2014) }\end{array}$ & $\begin{array}{l}\text { Cao et al. }(2000) * \text {; Hickman } \\
\text { \& Piquero (2009); Smith \& } \\
\text { Holmes (2014); Smith \& } \\
\text { Holmes }(2003)^{*}\end{array}$ & Willits (2014) \\
\hline $\begin{array}{l}\text { Education } \\
\text { Requirement }\end{array}$ & $\begin{array}{l}\text { Smith (2004); Willits } \\
\text { \& Nowacki (2014) }\end{array}$ & $\begin{array}{l}\text { Shjarback \& White (2015)*; } \\
\text { Cao et al. (2000) }\end{array}$ & $\begin{array}{l}\text { Ozkan et al. }(2016)^{*} ; \\
\text { Shjarback \& White } \\
(2015)^{*} ; \text { Willits }(2014)\end{array}$ \\
\hline Training & $\begin{array}{l}\text { Smith (2004); Willits } \\
\text { \& Nowacki (2014)* }\end{array}$ & Cao et al. (2000)* & Fridell et al. (2009) \\
\hline
\end{tabular}

Note. * indicates that authors found a significant relationship between correlate and outcome

\footnotetext{
48 The boxes with few or no citations show that some organizational correlates have either been tested very little or not at all on some of the outcomes. Thus, apart from the many mixed findings, some studies did not include important organizational correlates. What is not displayed in the table is after further exploration of the literature, independent variables of organizational correlates are conceptualized and/or measured in inconsistent ways (e.g., including training hours vs. training programs). Finally, directionality of significant correlates sometimes differs across studies as well.
} 


\section{APPENDIX B}

Comparing Index Creation Scores and Ranking (sorted by Geometric Index)

\begin{tabular}{|c|c|c|c|c|}
\hline Police Department (State) & $\begin{array}{c}\text { Geometric } \\
\text { Index }\end{array}$ & $\begin{array}{c}\text { Geometric } \\
\text { Rank }\end{array}$ & PCA Index & PCA Rank \\
\hline Oakland PD (CA) & 37.347 & 1 & 1.395 & 1 \\
\hline Wilmington PD (NC) & 30.865 & 2 & 1.119 & 2 \\
\hline Farmington PD (NM) & 29.105 & 3 & 0.665 & 21 \\
\hline Rapid City PD (SD) & 28.716 & 4 & 0.821 & 15 \\
\hline Hartford PD (CT) & 28.414 & 5 & 0.998 & 4 \\
\hline Wichita Falls PD (TX) & 26.514 & 6 & 1.000 & 3 \\
\hline Fort Pierce PD (FL) & 25.643 & 7 & 0.943 & 6 \\
\hline Meriden PD (CT) & 25.024 & 8 & 0.820 & 16 \\
\hline Glendale PD (AZ) & 24.984 & 9 & 0.901 & 8 \\
\hline Charleston PD (WV) & 23.280 & 10 & 0.866 & 10 \\
\hline St. Joseph PD (MO) & 23.046 & 11 & 0.859 & 11 \\
\hline College Station PD (TX) & 22.978 & 12 & 0.977 & 5 \\
\hline Beaumont PD (TX) & 22.885 & 13 & 0.772 & 17 \\
\hline Billings PD (MT) & 22.636 & 14 & 0.840 & 13 \\
\hline West Valley PD (UT) & 21.742 & 15 & 0.601 & 24 \\
\hline St. Petersburg PD (FL) & 21.548 & 16 & 0.392 & 48 \\
\hline Bayonne PD (NJ) & 21.093 & 17 & 0.709 & 19 \\
\hline San Bernardino PD (CA) & 20.829 & 18 & 0.396 & 46 \\
\hline Bradenton PD (FL) & 20.674 & 19 & 0.506 & 30 \\
\hline Bakersfield PD (CA) & 20.433 & 20 & 0.503 & 33 \\
\hline Santa Monica PD (CA) & 20.304 & 21 & 0.376 & 51 \\
\hline Wichita PD (KS) & 20.128 & 22 & 0.441 & 38 \\
\hline Hammond PD (IN) & 19.359 & 23 & 0.837 & 14 \\
\hline St. Louis PD (MO) & 19.272 & 24 & 0.405 & 44 \\
\hline Topeka PD (KS) & 19.237 & 25 & 0.403 & 45 \\
\hline Clifton PD (NJ) & 19.057 & 26 & 0.676 & 20 \\
\hline Rochester PD (NY) & 18.852 & 27 & 0.846 & 12 \\
\hline Orlando PD (FL) & 18.649 & 28 & 0.294 & 70 \\
\hline Davenport PD (IA) & 18.443 & 29 & 0.505 & 31 \\
\hline Amarillo PD (TX) & 18.158 & 30 & 0.225 & 84 \\
\hline Trenton PD (NJ) & 17.947 & 31 & 0.538 & 26 \\
\hline Riviera Beach PD (FL) & 17.918 & 32 & 0.339 & 60 \\
\hline Boynton Beach PD (FL) & 17.888 & 33 & 0.423 & 41 \\
\hline Miami Beach PD (FL) & 17.645 & 34 & 0.331 & 63 \\
\hline Pensacola PD (FL) & 17.458 & 35 & 0.349 & 57 \\
\hline Portsmouth PD (VA) & 17.259 & 36 & 0.608 & 23 \\
\hline Pawtucket PD (RI) & 17.022 & 37 & 0.363 & 54 \\
\hline Baytown PD (TX) & 16.997 & 38 & 0.469 & 37 \\
\hline El Paso PD (TX) & 16.886 & 39 & 0.521 & 27 \\
\hline Columbia PD (MO) & 16.850 & 40 & 0.436 & 40 \\
\hline Fairfield PD (CA) & 16.834 & 41 & 0.363 & 53 \\
\hline San Angelo PD (TX) & 16.625 & 42 & 0.513 & 29 \\
\hline Norfolk PD (VA) & 16.534 & 43 & 0.439 & 39 \\
\hline Kansas City PD (KS) & 16.393 & 44 & 0.301 & 68 \\
\hline Clearwater PD (FL) & 16.348 & 45 & 0.253 & 80 \\
\hline Baton Rouge PD (LA) & 16.327 & 46 & 0.305 & 65 \\
\hline Wilmington PD (DE) & 16.218 & 47 & 0.335 & 62 \\
\hline
\end{tabular}




\begin{tabular}{|c|c|c|c|c|}
\hline Police Department (State) & $\begin{array}{c}\text { Geometric } \\
\text { Index }\end{array}$ & $\begin{array}{c}\text { Geometric } \\
\text { Rank }\end{array}$ & PCA Index & PCA Rank \\
\hline Lansing PD (MI) & 16.181 & 48 & 0.377 & 50 \\
\hline Lafayette PD (IN) & 16.026 & 49 & 0.198 & 89 \\
\hline Plano PD (TX) & 15.970 & 50 & 0.592 & 25 \\
\hline Raleigh PD (NC) & 15.906 & 51 & 0.422 & 43 \\
\hline Annapolis PD (MD) & 15.801 & 52 & 0.191 & 92 \\
\hline Anaheim PD (CA) & 15.646 & 53 & 0.345 & 58 \\
\hline Minneapolis PD (MN) & 15.445 & 54 & 0.422 & 42 \\
\hline Nashua PD (NH) & 15.377 & 55 & 0.255 & 78 \\
\hline New Brunswick PD (NJ) & 14.955 & 56 & 0.928 & 7 \\
\hline Inglewood PD (CA) & 14.929 & 57 & 0.286 & 73 \\
\hline East Point PD (GA) & 14.929 & 58 & 0.879 & 9 \\
\hline Modesto PD (CA) & 14.735 & 59 & 0.237 & 81 \\
\hline Independence PD (MO) & 14.707 & 60 & 0.122 & 111 \\
\hline Lauderhill PD (FL) & 14.663 & 61 & 0.261 & 76 \\
\hline Omaha PD (NE) & 14.617 & 62 & 0.495 & 34 \\
\hline Hayward PD (CA) & 14.475 & 63 & 0.478 & 36 \\
\hline Pueblo PD (CO) & 14.469 & 64 & 0.206 & 88 \\
\hline Cedar Rapids PD (IA) & 14.468 & 65 & 0.171 & 94 \\
\hline Tucson PD (AZ) & 14.416 & 66 & 0.162 & 96 \\
\hline Albuquerque PD (NM) & 14.369 & 67 & 0.149 & 101 \\
\hline Greeley PD (CO) & 14.350 & 68 & 0.130 & 105 \\
\hline Memphis PD (TN) & 14.249 & 69 & 0.362 & 55 \\
\hline Santa Barbara PD (CA) & 14.163 & 70 & 0.169 & 95 \\
\hline Frederick PD (MD) & 14.149 & 71 & 0.197 & 90 \\
\hline Warren PD (MI) & 14.127 & 72 & 0.216 & 86 \\
\hline Vineland PD (NJ) & 13.818 & 73 & 0.297 & 69 \\
\hline Springfield PD (MO) & 13.714 & 74 & 0.104 & 121 \\
\hline Farmington Hills PD (MI) & 13.709 & 75 & 0.489 & 35 \\
\hline Surprise PD (AZ) & 13.390 & 76 & 0.213 & 87 \\
\hline Perth Amboy PD (NJ) & 13.379 & 77 & 0.739 & 18 \\
\hline Petersburg PD (VA) & 13.267 & 78 & 0.503 & 32 \\
\hline Toledo PD (OH) & 13.228 & 79 & 0.254 & 79 \\
\hline Delray Beach PD (FL) & 13.217 & 80 & 0.221 & 85 \\
\hline Greenville PD (SC) & 13.165 & 81 & 0.260 & 77 \\
\hline Allentown PD (PA) & 13.087 & 82 & 0.012 & 138 \\
\hline Yonkers PD (NY) & 12.961 & 83 & 0.188 & 93 \\
\hline Springfield PD $(\mathrm{OH})$ & 12.949 & 84 & 0.358 & 56 \\
\hline Syracuse PD (NY) & 12.933 & 85 & 0.665 & 22 \\
\hline Tallahassee PD (FL) & 12.924 & 86 & 0.304 & 66 \\
\hline Fort Myers PD (FL) & 12.918 & 87 & 0.126 & 107 \\
\hline Greenville PD (NC) & 12.907 & 88 & 0.079 & 127 \\
\hline Albany PD (NY) & 12.901 & 89 & 0.516 & 28 \\
\hline Las Vegas Metro PD (NV) & 12.715 & 90 & 0.338 & 61 \\
\hline Temple PD (TX) & 12.654 & 91 & -0.034 & 152 \\
\hline Boulder PD (CO) & 12.553 & 92 & 0.123 & 110 \\
\hline Knoxville PD (TN) & 12.544 & 93 & 0.128 & 106 \\
\hline Elkhart PD (IN) & 12.487 & 94 & 0.064 & 130 \\
\hline Lakewood PD (WA) & 12.468 & 95 & -0.029 & 149 \\
\hline Kissimmee PD (FL) & 12.461 & 96 & 0.192 & 91 \\
\hline Huntington Beach PD (CA) & 12.446 & 97 & -0.003 & 144 \\
\hline Tulsa PD (OK) & 12.440 & 98 & 0.112 & 118 \\
\hline Columbia PD (SC) & 12.437 & 99 & 0.151 & 100 \\
\hline
\end{tabular}




\begin{tabular}{|c|c|c|c|c|}
\hline Police Department (State) & $\begin{array}{c}\text { Geometric } \\
\text { Index }\end{array}$ & $\begin{array}{c}\text { Geometric } \\
\text { Rank }\end{array}$ & PCA Index & PCA Rank \\
\hline Las Cruces PD (NM) & 12.427 & 100 & -0.102 & 177 \\
\hline Bryan PD (TX) & 12.369 & 101 & 0.233 & 83 \\
\hline Tacoma PD (WA) & 12.323 & 102 & 0.107 & 120 \\
\hline Santa Ana PD (CA) & 12.268 & 103 & -0.031 & 151 \\
\hline Johnson City PD (TN) & 12.221 & 104 & 0.261 & 75 \\
\hline Waterbury PD (CT) & 12.081 & 105 & 0.088 & 123 \\
\hline Fayetteville PD (AR) & 12.052 & 106 & 0.122 & 112 \\
\hline Waterloo PD (IA) & 12.001 & 107 & 0.098 & 122 \\
\hline Atlanta PD (GA) & 11.972 & 108 & 0.080 & 126 \\
\hline Rocky Mount PD (NC) & 11.928 & 109 & 0.114 & 117 \\
\hline Plainfield PD (NJ) & 11.888 & 110 & 0.283 & 74 \\
\hline San Francisco PD (CA) & 11.791 & 111 & 0.057 & 131 \\
\hline Ventura PD (CA) & 11.772 & 112 & 0.007 & 142 \\
\hline Ann Arbor PD (MI) & 11.697 & 113 & 0.366 & 52 \\
\hline Gastonia PD (NC) & 11.550 & 114 & -0.057 & 159 \\
\hline Philadelphia PD (PA) & 11.526 & 115 & 0.042 & 132 \\
\hline Warner Robins PD (GA) & 11.459 & 116 & -0.065 & 162 \\
\hline Mesquite PD (TX) & 11.449 & 117 & 0.319 & 64 \\
\hline Arlington PD (TX) & 11.447 & 118 & 0.291 & 72 \\
\hline Myrtle Beach PD (SC) & 11.391 & 119 & 0.235 & 82 \\
\hline Des Moines PD (IA) & 11.342 & 120 & 0.066 & 129 \\
\hline Charlotte-Mecklenburg PD (NC) & 11.252 & 121 & -0.002 & 143 \\
\hline Spokane PD (WA) & 11.232 & 122 & -0.093 & 175 \\
\hline Largo PD (FL) & 11.049 & 123 & 0.008 & 141 \\
\hline Louisville Metro PD (KY) & 10.972 & 124 & 0.019 & 136 \\
\hline Gulfport PD (MS) & 10.873 & 125 & 0.383 & 49 \\
\hline Boise PD (ID) & 10.862 & 126 & 0.008 & 140 \\
\hline Clarksville PD (TN) & 10.849 & 127 & 0.112 & 119 \\
\hline Evansville PD (IN) & 10.829 & 128 & 0.020 & 135 \\
\hline Port Arthur PD (TX) & 10.819 & 129 & 0.120 & 114 \\
\hline Providence PD (RI) & 10.767 & 130 & -0.052 & 156 \\
\hline Long Beach PD (CA) & 10.672 & 131 & -0.031 & 150 \\
\hline Salinas PD (CA) & 10.668 & 132 & -0.189 & 192 \\
\hline Margate PD (FL) & 10.664 & 133 & 0.302 & 67 \\
\hline Austin PD (TX) & 10.629 & 134 & 0.136 & 104 \\
\hline Colorado Springs PD (CO) & 10.594 & 135 & 0.124 & 109 \\
\hline Sioux City PD (IA) & 10.568 & 136 & -0.005 & 145 \\
\hline Fort Wayne PD (IN) & 10.405 & 137 & 0.153 & 98 \\
\hline North Charleston PD (SC) & 10.379 & 138 & -0.044 & 153 \\
\hline Gainesville PD (FL) & 10.329 & 139 & -0.071 & 166 \\
\hline McKinney PD (TX) & 10.187 & 140 & 0.156 & 97 \\
\hline Mobile PD (AL) & 10.128 & 141 & 0.117 & 115 \\
\hline Anderson PD (IN) & 10.107 & 142 & 0.125 & 108 \\
\hline Costa Mesa PD (CA) & 10.097 & 143 & -0.129 & 183 \\
\hline Virginia Beach PD (VA) & 10.069 & 144 & 0.067 & 128 \\
\hline Hillsboro PD (OR) & 10.011 & 145 & 0.035 & 134 \\
\hline Denver PD (CO) & 10.011 & 146 & 0.115 & 116 \\
\hline Seattle PD (WA) & 10.000 & 147 & 0.014 & 137 \\
\hline Fullerton PD (CA) & 9.888 & 148 & -0.178 & 189 \\
\hline Santa Rosa PD (CA) & 9.832 & 149 & -0.086 & 172 \\
\hline Abilene PD (TX) & 9.825 & 150 & -0.047 & 154 \\
\hline Oklahoma City PD (OK) & 9.803 & 151 & -0.196 & 194 \\
\hline
\end{tabular}




\begin{tabular}{|c|c|c|c|c|}
\hline Police Department (State) & $\begin{array}{c}\text { Geometric } \\
\text { Index }\end{array}$ & $\begin{array}{c}\text { Geometric } \\
\text { Rank }\end{array}$ & PCA Index & PCA Rank \\
\hline Scottsdale PD (AZ) & 9.784 & 152 & -0.123 & 182 \\
\hline Federal Way PD (WA) & 9.762 & 153 & -0.150 & 186 \\
\hline Kansas City PD (MO) & 9.671 & 154 & -0.246 & 206 \\
\hline Richmond PD (CA) & 9.644 & 155 & 0.153 & 99 \\
\hline Terre Haute PD (IN) & 9.604 & 156 & -0.055 & 157 \\
\hline Decatur PD (AL) & 9.595 & 157 & 0.345 & 59 \\
\hline Winston-Salem PD (NC) & 9.564 & 158 & -0.138 & 184 \\
\hline Homestead PD (FL) & 9.549 & 159 & -0.351 & 221 \\
\hline Newport News PD (VA) & 9.530 & 160 & -0.068 & 164 \\
\hline Washington PD (DC) & 9.497 & 161 & -0.056 & 158 \\
\hline Glendale PD (CA) & 9.414 & 162 & -0.102 & 178 \\
\hline El Cajon PD (CA) & 9.399 & 163 & -0.220 & 201 \\
\hline Olathe PD (KS) & 9.334 & 164 & -0.205 & 195 \\
\hline Bellingham PD (WA) & 9.283 & 165 & -0.070 & 165 \\
\hline Burlington PD (NC) & 9.263 & 166 & 0.138 & 103 \\
\hline Fort Lauderdale PD (FL) & 9.184 & 167 & -0.111 & 179 \\
\hline Hickory PD (NC) & 9.172 & 168 & -0.062 & 160 \\
\hline Longmont PD (CO) & 9.130 & 169 & -0.086 & 171 \\
\hline Nampa PD (ID) & 9.116 & 170 & -0.143 & 185 \\
\hline Milford PD (CT) & 9.051 & 171 & -0.017 & 147 \\
\hline Los Angeles PD (CA) & 9.050 & 172 & -0.064 & 161 \\
\hline Manchester PD (NH) & 9.007 & 173 & 0.144 & 102 \\
\hline West Palm Beach PD (FL) & 8.972 & 174 & -0.232 & 202 \\
\hline Milwaukee PD (WI) & 8.905 & 175 & -0.081 & 168 \\
\hline Phoenix PD (AZ) & 8.901 & 176 & -0.459 & 236 \\
\hline Sioux Falls PD (SD) & 8.876 & 177 & -0.265 & 210 \\
\hline Fort Worth PD (TX) & 8.862 & 178 & -0.215 & 199 \\
\hline Fort Collins PD (CO) & 8.861 & 179 & -0.011 & 146 \\
\hline Ogden PD (UT) & 8.860 & 180 & -0.316 & 216 \\
\hline New Rochelle PD (NY) & 8.780 & 181 & -0.051 & 155 \\
\hline Portland PD (ME) & 8.778 & 182 & -0.017 & 148 \\
\hline Whittier PD (CA) & 8.751 & 183 & -0.288 & 214 \\
\hline Irving PD (TX) & 8.746 & 184 & -0.112 & 180 \\
\hline High Point PD (NC) & 8.691 & 185 & -0.234 & 203 \\
\hline Suffolk PD (VA) & 8.651 & 186 & 0.122 & 113 \\
\hline North Miami PD (FL) & 8.550 & 187 & -0.218 & 200 \\
\hline Janesville PD (WI) & 8.523 & 188 & 0.012 & 139 \\
\hline Sandy PD (UT) & 8.482 & 189 & -0.101 & 176 \\
\hline Harlingen PD (TX) & 8.478 & 190 & -0.266 & 211 \\
\hline Grand Rapids PD (MI) & 8.438 & 191 & 0.294 & 71 \\
\hline San Antonio PD (TX) & 8.390 & 192 & -0.260 & 209 \\
\hline Everett PD (WA) & 8.366 & 193 & -0.090 & 174 \\
\hline Longview PD (TX) & 8.313 & 194 & -0.253 & 207 \\
\hline O'Fallon PD (MO) & 8.211 & 195 & -0.259 & 208 \\
\hline North Little Rock PD (AR) & 8.211 & 196 & 0.393 & 47 \\
\hline Buffalo PD (NY) & 8.154 & 197 & 0.037 & 133 \\
\hline Lakewood PD (CO) & 8.153 & 198 & -0.213 & 197 \\
\hline Huntsville PD (AL) & 8.050 & 199 & -0.084 & 169 \\
\hline Aurora PD $(\mathrm{CO})$ & 8.009 & 200 & -0.307 & 215 \\
\hline Garden Grove PD (CA) & 7.948 & 201 & -0.591 & 255 \\
\hline Santa Clara PD (CA) & 7.785 & 202 & -0.205 & 196 \\
\hline Concord PD (CA) & 7.697 & 203 & -0.081 & 167 \\
\hline
\end{tabular}




\begin{tabular}{|c|c|c|c|c|}
\hline Police Department (State) & $\begin{array}{c}\text { Geometric } \\
\text { Index }\end{array}$ & $\begin{array}{c}\text { Geometric } \\
\text { Rank }\end{array}$ & PCA Index & PCA Rank \\
\hline Durham PD (NC) & 7.685 & 204 & -0.158 & 187 \\
\hline Hampton PD (VA) & 7.646 & 205 & -0.346 & 218 \\
\hline Berkeley PD (CA) & 7.628 & 206 & -0.090 & 173 \\
\hline Lee's Summit PD (MO) & 7.623 & 207 & -0.236 & 204 \\
\hline Lakeland PD (FL) & 7.512 & 208 & -0.160 & 188 \\
\hline Jacksonville PD (NC) & 7.296 & 209 & -0.086 & 170 \\
\hline Fort Smith PD (AR) & 7.253 & 210 & -0.187 & 191 \\
\hline Grand Junction PD (CO) & 7.195 & 211 & -0.369 & 225 \\
\hline Danville PD (VA) & 7.184 & 212 & -0.215 & 198 \\
\hline Beaverton PD (OR) & 7.068 & 213 & -0.238 & 205 \\
\hline Hattiesburg PD (MS) & 6.922 & 214 & -0.192 & 193 \\
\hline Daly City PD (CA) & 6.898 & 215 & -0.436 & 233 \\
\hline Hoboken PD (NJ) & 6.883 & 216 & -0.347 & 219 \\
\hline Rock Hill PD (SC) & 6.861 & 217 & -0.355 & 223 \\
\hline Downey PD (CA) & 6.761 & 218 & -0.564 & 252 \\
\hline Sunrise PD (FL) & 6.745 & 219 & -0.553 & 250 \\
\hline Port St. Lucie PD (FL) & 6.730 & 220 & -0.353 & 222 \\
\hline Rochester PD (MN) & 6.724 & 221 & -0.284 & 213 \\
\hline Flint PD (MI) & 6.702 & 222 & -0.497 & 240 \\
\hline Savannah-Chatham Metro PD (GA) & 6.685 & 223 & -0.068 & 163 \\
\hline Henderson PD (NV) & 6.659 & 224 & -0.443 & 234 \\
\hline Oceanside PD (CA) & 6.537 & 225 & -0.483 & 238 \\
\hline Covington PD (KY) & 6.499 & 226 & -0.488 & 239 \\
\hline Albany PD (GA) & 6.441 & 227 & 0.083 & 125 \\
\hline Pasadena PD (CA) & 6.431 & 228 & -0.543 & 247 \\
\hline Sanford PD (FL) & 6.413 & 229 & -0.328 & 217 \\
\hline Palm Bay PD (FL) & 6.392 & 230 & -0.595 & 256 \\
\hline Fargo PD (ND) & 6.303 & 231 & -0.518 & 244 \\
\hline Lynchburg PD (VA) & 6.259 & 232 & 0.084 & 124 \\
\hline Jonesboro PD (AR) & 6.198 & 233 & -0.424 & 231 \\
\hline Pearland PD (TX) & 6.181 & 234 & -0.401 & 229 \\
\hline Richmond PD (VA) & 6.144 & 235 & -0.182 & 190 \\
\hline Murfreesboro PD (TN) & 6.140 & 236 & -0.615 & 258 \\
\hline Beverly Hills PD (CA) & 6.091 & 237 & -0.358 & 224 \\
\hline Burbank PD (CA) & 6.088 & 238 & -0.540 & 246 \\
\hline Lewisville PD (TX) & 6.082 & 239 & -0.451 & 235 \\
\hline Cape Coral PD (FL) & 6.051 & 240 & -0.567 & 253 \\
\hline Grand Prairie PD (TX) & 5.966 & 241 & -0.549 & 249 \\
\hline Bethlehem PD (PA) & 5.938 & 242 & -0.465 & 237 \\
\hline Tyler PD (TX) & 5.923 & 243 & -0.568 & 254 \\
\hline Dallas PD (TX) & 5.921 & 244 & -0.543 & 248 \\
\hline Hollywood PD (FL) & 5.865 & 245 & -0.602 & 257 \\
\hline Nashville PD (TN) & 5.832 & 246 & -0.397 & 228 \\
\hline Concord PD (NC) & 5.824 & 247 & -0.278 & 212 \\
\hline Cranston PD (RI) & 5.658 & 248 & -0.561 & 251 \\
\hline Franklin PD (TN) & 5.647 & 249 & -0.534 & 245 \\
\hline Charleston PD (SC) & 5.624 & 250 & -0.118 & 181 \\
\hline Chandler PD (AZ) & 5.556 & 251 & -0.640 & 259 \\
\hline Boca Raton PD (FL) & 5.494 & 252 & -0.915 & 275 \\
\hline Pembroke Pines PD (FL) & 5.419 & 253 & -0.742 & 266 \\
\hline Carrollton PD (TX) & 5.376 & 254 & -0.389 & 227 \\
\hline Greensboro PD (NC) & 5.338 & 255 & -0.429 & 232 \\
\hline
\end{tabular}




\begin{tabular}{lcccc}
\hline Police Department (State) & $\begin{array}{c}\text { Geometric } \\
\text { Index }\end{array}$ & $\begin{array}{c}\text { Geometric } \\
\text { Rank }\end{array}$ & PCA Index & PCA Rank \\
\hline Roseville PD (CA) & 5.327 & 256 & -0.779 & 270 \\
Sumter PD (SC) & 5.272 & 257 & -0.349 & 220 \\
North Richland Hills PD (TX) & 5.176 & 258 & -0.646 & 260 \\
Miami PD (FL) & 5.150 & 259 & -0.748 & 267 \\
Simi Valley PD (CA) & 5.139 & 260 & -0.859 & 273 \\
Danbury PD (CT) & 5.093 & 261 & -0.507 & 242 \\
Bartlett PD (TN) & 4.905 & 262 & -0.517 & 243 \\
Midland PD (TX) & 4.825 & 263 & -0.380 & 226 \\
Plantation PD (FL) & 4.568 & 264 & -0.755 & 268 \\
Norman PD (OK) & 4.525 & 265 & -0.756 & 269 \\
Livonia PD (MI) & 4.504 & 266 & -0.649 & 261 \\
Roswell PD (GA) & 4.465 & 267 & -0.411 & 230 \\
Warwick PD (RI) & 4.400 & 268 & -0.816 & 271 \\
Alexandria PD (VA) & 4.312 & 269 & -0.655 & 262 \\
Palm Beach Gardens PD (FL) & 4.241 & 270 & -0.721 & 264 \\
Boston PD (MA) & 4.074 & 271 & -0.723 & 265 \\
Conway PD (AR) & 3.778 & 272 & -0.498 & 241 \\
Marietta PD (GA) & 3.645 & 273 & -0.685 & 263 \\
Richardson PD (TX) & 3.197 & 274 & -1.065 & 277 \\
Peoria PD (AZ) & 3.193 & 275 & -1.001 & 276 \\
Rio Rancho PD (NM) & 2.789 & 276 & -0.912 & 274 \\
Union City PD (NJ) & 2.766 & 277 & -0.854 & 272 \\
Hoover PD (AL) & 1.874 & 278 & -1.295 & 278 \\
\hline
\end{tabular}




\section{APPENDIX C}

Comparing Individual Police-Citizen Conflict Indicators (sorted by Geometric Index in

Appendix B)

\begin{tabular}{|c|c|c|c|c|}
\hline Police Department (State) & $\begin{array}{c}\text { Complaint } \\
\text { Rate }\end{array}$ & $\begin{array}{c}\text { Death by } \\
\text { Police Rate }\end{array}$ & Force Rate & $\begin{array}{c}\text { Officer } \\
\text { Assault Rate }\end{array}$ \\
\hline Oakland PD (CA) & 146.069 & 2.036 & 316.374 & 12.771 \\
\hline Wilmington PD (NC) & 89.200 & 1.867 & 187.647 & 17.700 \\
\hline Farmington PD (NM) & 7.200 & 4.400 & 226.583 & 70.523 \\
\hline Rapid City PD (SD) & 6.195 & 1.469 & 711.137 & 52.825 \\
\hline Hartford PD (CT) & 15.588 & 1.602 & 686.264 & 21.011 \\
\hline Wichita Falls PD (TX) & 70.984 & 1.920 & 163.223 & 13.404 \\
\hline Fort Pierce PD (FL) & 35.238 & 0.000 & 377.804 & 30.581 \\
\hline Meriden PD $(\mathrm{CT})$ & 15.000 & 4.944 & 276.890 & 13.889 \\
\hline Glendale PD (AZ) & 27.949 & 1.744 & 287.358 & 16.068 \\
\hline Charleston PD (WV) & 17.582 & 0.000 & 591.520 & 25.720 \\
\hline St. Joseph PD (MO) & 21.552 & 0.000 & 474.397 & 25.369 \\
\hline College Station PD (TX) & 46.296 & 1.068 & 303.215 & 8.401 \\
\hline Beaumont PD (TX) & 58.468 & 0.849 & 96.800 & 24.769 \\
\hline Billings PD (MT) & 47.015 & 2.874 & 130.301 & 9.832 \\
\hline West Valley PD (UT) & 2.732 & 2.323 & 642.798 & 27.027 \\
\hline St. Petersburg PD (FL) & 1.822 & 4.076 & 282.846 & 52.214 \\
\hline Bayonne PD (NJ) & 52.679 & 0.000 & 109.239 & 32.759 \\
\hline San Bernardino PD (CA) & 6.970 & 4.273 & 103.027 & 42.471 \\
\hline Bradenton PD (FL) & 4.098 & 3.989 & 279.213 & 24.722 \\
\hline Bakersfield PD (CA) & 4.533 & 2.881 & 279.466 & 28.049 \\
\hline Santa Monica PD (CA) & 3.738 & 2.222 & 194.427 & 56.260 \\
\hline Wichita PD (KS) & 2.786 & 1.574 & 361.775 & 45.548 \\
\hline Hammond PD (IN) & 2.370 & 0.000 & 3719.408 & 10.208 \\
\hline St. Louis PD (MO) & 2.596 & 2.512 & 306.096 & 34.683 \\
\hline Topeka PD (KS) & 9.253 & 1.571 & 116.250 & 43.691 \\
\hline Clifton PD (NJ) & 60.645 & 0.000 & 92.939 & 22.020 \\
\hline Rochester PD (NY) & 13.739 & 0.948 & 711.012 & 5.187 \\
\hline Orlando PD (FL) & 1.463 & 2.498 & 280.617 & 49.033 \\
\hline Davenport PD (IA) & 5.488 & 0.000 & 431.946 & 40.286 \\
\hline Amarillo PD (TX) & 4.714 & 2.616 & 88.427 & 58.505 \\
\hline Trenton PD (NJ) & 12.605 & 3.538 & 147.407 & 10.399 \\
\hline Riviera Beach PD (FL) & 1.770 & 3.064 & 306.373 & 28.889 \\
\hline Boynton Beach PD (FL) & 5.488 & 1.461 & 226.386 & 27.329 \\
\hline Miami Beach PD (FL) & 2.597 & 2.257 & 249.357 & 32.181 \\
\hline Pensacola PD (FL) & 7.692 & 3.828 & 97.615 & 21.677 \\
\hline Portsmouth PD (VA) & 30.041 & 2.088 & 105.443 & 7.778 \\
\hline Pawtucket PD (RI) & 4.054 & 1.404 & 237.206 & 28.132 \\
\hline Baytown PD (TX) & 13.178 & 1.393 & 136.509 & 17.021 \\
\hline El Paso PD (TX) & 90.959 & 0.768 & 28.889 & 16.307 \\
\hline Columbia PD (MO) & 4.698 & 0.000 & 401.805 & 34.211 \\
\hline Fairfield PD (CA) & 3.175 & 2.846 & 249.509 & 19.048 \\
\hline San Angelo PD (TX) & 0.714 & 2.140 & 1348.315 & 9.524 \\
\hline Norfolk PD (VA) & 7.835 & 1.646 & 192.548 & 15.603 \\
\hline Kansas City PD (KS) & 5.067 & 2.060 & 142.852 & 26.230 \\
\hline Clearwater PD (FL) & 2.290 & 1.849 & 219.164 & 33.766 \\
\hline
\end{tabular}




\begin{tabular}{|c|c|c|c|c|}
\hline Police Department (State) & $\begin{array}{c}\text { Complaint } \\
\text { Rate }\end{array}$ & $\begin{array}{c}\text { Death by } \\
\text { Police Rate }\end{array}$ & Force Rate & $\begin{array}{c}\text { Officer } \\
\text { Assault Rate }\end{array}$ \\
\hline Baton Rouge PD (LA) & 5.678 & 2.182 & 130.905 & 24.544 \\
\hline Wilmington PD (DE) & 3.401 & 1.406 & 254.503 & 24.671 \\
\hline Lansing PD (MI) & 4.545 & 1.746 & 234.859 & 18.166 \\
\hline Lafayette PD (IN) & 0.813 & 1.486 & 334.314 & 42.781 \\
\hline Plano PD (TX) & 69.298 & 0.000 & 68.789 & 12.451 \\
\hline Raleigh PD (NC) & 21.268 & 0.247 & 93.579 & 23.633 \\
\hline Annapolis PD (MD) & 3.704 & 2.610 & 109.635 & 32.479 \\
\hline Anaheim PD (CA) & 23.846 & 2.074 & 44.152 & 16.768 \\
\hline Minneapolis PD (MN) & 6.690 & 0.519 & 269.594 & 17.063 \\
\hline Nashua PD (NH) & 3.659 & 0.000 & 238.416 & 49.333 \\
\hline New Brunswick PD (NJ) & 59.155 & 1.813 & 295.552 & 0.000 \\
\hline Inglewood PD (CA) & 18.182 & 0.907 & 54.434 & 23.946 \\
\hline East Point PD (GA) & 44.355 & 2.897 & 281.037 & 0.000 \\
\hline Modesto PD (CA) & 5.776 & 1.980 & 109.414 & 20.332 \\
\hline Independence PD (MO) & 5.392 & 1.717 & 70.378 & 37.285 \\
\hline Lauderhill PD (FL) & 9.565 & 2.961 & 71.055 & 14.545 \\
\hline Omaha PD (NE) & 26.574 & 0.727 & 105.891 & 8.054 \\
\hline Hayward PD (CA) & 15.707 & 3.444 & 119.864 & 3.933 \\
\hline Pueblo PD (CO) & 3.665 & 4.675 & 114.078 & 13.514 \\
\hline Cedar Rapids PD (IA) & 1.596 & 0.788 & 260.004 & 35.314 \\
\hline Tucson PD (AZ) & 2.852 & 3.642 & 121.144 & 18.943 \\
\hline Albuquerque PD (NM) & 7.019 & 2.752 & 58.523 & 23.209 \\
\hline Greeley PD (CO) & 5.426 & 3.223 & 64.459 & 23.239 \\
\hline Memphis PD (TN) & 7.129 & 2.611 & 158.667 & 7.852 \\
\hline Santa Barbara PD (CA) & 0.752 & 3.387 & 292.417 & 16.905 \\
\hline Frederick PD (MD) & 6.015 & 0.000 & 133.495 & 41.791 \\
\hline Warren PD (MI) & 2.941 & 1.486 & 193.237 & 20.034 \\
\hline Vineland PD (NJ) & 13.816 & 0.000 & 102.293 & 23.057 \\
\hline Springfield PD (MO) & 3.492 & 1.248 & 107.959 & 31.441 \\
\hline Farmington Hills PD (MI) & 34.167 & 0.000 & 104.828 & 8.581 \\
\hline Surprise PD (AZ) & 8.654 & 1.739 & 79.126 & 14.363 \\
\hline Perth Amboy PD (NJ) & 14.634 & 1.962 & 547.263 & 0.265 \\
\hline Petersburg PD (VA) & 7.921 & 0.000 & 471.669 & 6.364 \\
\hline Toledo PD (OH) & 5.697 & 0.696 & 166.268 & 15.217 \\
\hline Delray Beach PD (FL) & 5.263 & 0.000 & 182.914 & 25.641 \\
\hline Greenville PD (SC) & 6.587 & 1.687 & 129.934 & 10.339 \\
\hline Allentown PD (PA) & 3.743 & 0.848 & 75.461 & 43.349 \\
\hline Yonkers PD (NY) & 5.410 & 0.000 & 157.285 & 26.989 \\
\hline Springfield PD (OH) & 12.195 & 0.000 & 166.315 & 11.811 \\
\hline Syracuse PD (NY) & 44.124 & 0.691 & 165.857 & 1.211 \\
\hline Tallahassee PD (FL) & 0.549 & 0.550 & 992.185 & 10.708 \\
\hline Fort Myers PD (FL) & 1.970 & 1.577 & 187.617 & 18.391 \\
\hline Greenville PD (NC) & 4.118 & 2.368 & 79.342 & 19.289 \\
\hline Albany PD (NY) & 8.408 & 1.022 & 388.183 & 2.752 \\
\hline Las Vegas Metro PD (NV) & 11.632 & 3.914 & 94.606 & 3.451 \\
\hline Temple PD (TX) & 3.077 & 4.516 & 51.178 & 21.282 \\
\hline Boulder PD (CO) & 0.585 & 1.008 & 396.261 & 18.690 \\
\hline Knoxville PD (TN) & 3.927 & 1.667 & 116.129 & 15.226 \\
\hline Elkhart PD (IN) & 0.000 & 3.899 & 358.723 & 12.834 \\
\hline Lakewood PD (WA) & 0.000 & 8.520 & 185.728 & 12.667 \\
\hline Kissimmee PD (FL) & 2.222 & 0.000 & 338.649 & 21.094 \\
\hline Huntington Beach PD (CA) & 2.232 & 2.612 & 88.295 & 22.278 \\
\hline
\end{tabular}




\begin{tabular}{|c|c|c|c|c|}
\hline Police Department (State) & $\begin{array}{c}\text { Complaint } \\
\text { Rate }\end{array}$ & $\begin{array}{c}\text { Death by } \\
\text { Police Rate }\end{array}$ & Force Rate & $\begin{array}{c}\text { Officer } \\
\text { Assault Rate }\end{array}$ \\
\hline Tulsa PD (OK) & 6.658 & 1.277 & 73.310 & 17.735 \\
\hline Columbia PD (SC) & 2.462 & 3.083 & 161.841 & 9.462 \\
\hline Las Cruces PD (NM) & 0.000 & 1.027 & 224.862 & 51.326 \\
\hline Bryan PD (TX) & 3.623 & 0.000 & 286.533 & 16.667 \\
\hline Tacoma PD (WA) & 1.872 & 2.500 & 169.989 & 12.500 \\
\hline Santa Ana PD (CA) & 4.582 & 2.449 & 45.927 & 24.615 \\
\hline Johnson City PD (TN) & 19.463 & 0.000 & 73.018 & 13.927 \\
\hline Waterbury PD (CT) & 3.667 & 0.908 & 119.919 & 18.945 \\
\hline Fayetteville PD (AR) & 3.306 & 0.000 & 190.050 & 24.779 \\
\hline Waterloo PD (IA) & 1.754 & 0.000 & 269.605 & 26.933 \\
\hline Atlanta PD (GA) & 4.292 & 2.348 & 84.990 & 12.646 \\
\hline Rocky Mount PD (NC) & 13.986 & 0.000 & 52.153 & 24.904 \\
\hline Plainfield PD (NJ) & 11.258 & 0.000 & 140.842 & 10.569 \\
\hline San Francisco PD (CA) & 14.546 & 0.990 & 30.950 & 19.184 \\
\hline Ventura PD (CA) & 2.344 & 1.882 & 103.507 & 18.254 \\
\hline Ann Arbor PD (MI) & 28.333 & 0.000 & 87.165 & 6.322 \\
\hline Gastonia PD (NC) & 3.030 & 1.391 & 69.575 & 25.536 \\
\hline Philadelphia PD (PA) & 3.585 & 2.032 & 89.526 & 13.180 \\
\hline Warner Robins PD (GA) & 4.630 & 1.486 & 47.539 & 24.919 \\
\hline Mesquite PD (TX) & 18.919 & 0.716 & 88.816 & 4.658 \\
\hline Arlington PD (TX) & 1.167 & 0.545 & 775.424 & 5.616 \\
\hline Myrtle Beach PD (SC) & 1.786 & 0.000 & 539.496 & 10.204 \\
\hline Des Moines PD (IA) & 5.249 & 0.979 & 86.122 & 14.537 \\
\hline Charlotte-Mecklenburg PD (NC) & 5.402 & 0.945 & 61.949 & 19.784 \\
\hline Spokane PD (WA) & 2.837 & 1.917 & 59.894 & 22.749 \\
\hline Largo PD (FL) & 0.714 & 0.000 & 318.701 & 26.277 \\
\hline Louisville Metro PD (KY) & 3.294 & 0.335 & 120.556 & 19.973 \\
\hline Gulfport PD (MS) & 6.806 & 1.467 & 293.436 & 1.473 \\
\hline Boise PD (ID) & 6.884 & 0.480 & 60.480 & 18.728 \\
\hline Clarksville PD (TN) & 3.196 & 0.000 & 212.602 & 14.530 \\
\hline Evansville PD (IN) & 1.799 & 0.000 & 210.525 & 22.340 \\
\hline Port Arthur PD (TX) & 4.167 & 1.851 & 125.875 & 6.389 \\
\hline Providence PD (RI) & 14.545 & 0.000 & 26.377 & 31.772 \\
\hline Long Beach PD (CA) & 1.543 & 2.157 & 125.974 & 11.827 \\
\hline Salinas PD (CA) & 1.183 & 1.328 & 78.336 & 31.532 \\
\hline Margate PD (FL) & 34.783 & 0.000 & 59.456 & 5.079 \\
\hline Austin PD (TX) & 2.191 & 0.875 & 261.020 & 7.173 \\
\hline Colorado Springs PD (CO) & 15.868 & 1.198 & 43.110 & 6.882 \\
\hline Sioux City PD (IA) & 13.386 & 0.000 & 36.351 & 22.849 \\
\hline Fort Wayne PD (IN) & 2.222 & 1.577 & 258.263 & 4.465 \\
\hline North Charleston PD (SC) & 1.342 & 1.019 & 155.884 & 14.744 \\
\hline Gainesville PD (FL) & 2.622 & 0.800 & 92.014 & 17.975 \\
\hline McKinney PD (TX) & 27.027 & 0.000 & 40.946 & 8.384 \\
\hline Mobile PD (AL) & 9.125 & 2.049 & 66.585 & 4.119 \\
\hline Anderson PD (IN) & 5.042 & 0.000 & 171.132 & 9.091 \\
\hline Costa Mesa PD (CA) & 3.704 & 0.906 & 54.386 & 20.313 \\
\hline Virginia Beach PD (VA) & 4.234 & 0.228 & 141.515 & 10.303 \\
\hline Hillsboro PD (OR) & 2.564 & 1.087 & 152.177 & 7.874 \\
\hline Denver PD (CO) & 4.924 & 1.820 & 118.473 & 4.073 \\
\hline Seattle PD (WA) & 5.403 & 1.305 & 73.256 & 8.249 \\
\hline Fullerton PD (CA) & 3.750 & 2.215 & 36.922 & 15.952 \\
\hline Santa Rosa PD (CA) & 2.286 & 0.000 & 123.201 & 22.083 \\
\hline
\end{tabular}




\begin{tabular}{|c|c|c|c|c|}
\hline Police Department (State) & $\begin{array}{c}\text { Complaint } \\
\text { Rate }\end{array}$ & $\begin{array}{c}\text { Death by } \\
\text { Police Rate }\end{array}$ & Force Rate & $\begin{array}{c}\text { Officer } \\
\text { Assault Rate }\end{array}$ \\
\hline Abilene PD (TX) & 2.381 & 2.532 & 93.684 & 7.330 \\
\hline Oklahoma City PD (OK) & 0.601 & 1.721 & 109.965 & 18.287 \\
\hline Scottsdale PD (AZ) & 0.233 & 1.364 & 212.401 & 13.801 \\
\hline Federal Way PD (WA) & 0.763 & 3.345 & 105.919 & 10.193 \\
\hline Kansas City PD (MO) & 3.661 & 3.045 & 26.100 & 16.777 \\
\hline Richmond PD (CA) & 5.590 & 0.000 & 189.014 & 5.946 \\
\hline Terre Haute PD (IN) & 0.000 & 0.000 & 493.016 & 16.253 \\
\hline Decatur PD (AL) & 3.077 & 3.593 & 452.716 & 0.000 \\
\hline Winston-Salem PD (NC) & 2.400 & 0.869 & 78.251 & 15.824 \\
\hline Homestead PD (FL) & 0.000 & 0.000 & 125.280 & 65.359 \\
\hline Newport News PD (VA) & 5.102 & 0.000 & 74.102 & 17.244 \\
\hline Washington PD (DC) & 3.016 & 2.311 & 80.395 & 6.611 \\
\hline Glendale PD (CA) & 5.512 & 1.039 & 47.264 & 11.518 \\
\hline El Cajon PD (CA) & 3.008 & 1.003 & 45.144 & 20.536 \\
\hline Olathe PD (KS) & 1.220 & 1.589 & 81.810 & 15.146 \\
\hline Bellingham PD (WA) & 0.926 & 0.000 & 245.892 & 14.679 \\
\hline Burlington PD (NC) & 3.810 & 0.000 & 256.181 & 4.975 \\
\hline Fort Lauderdale PD (FL) & 0.000 & 0.597 & 342.953 & 11.987 \\
\hline Hickory PD (NC) & 3.478 & 0.000 & 109.794 & 13.396 \\
\hline Longmont PD (CO) & 2.206 & 0.000 & 138.961 & 14.599 \\
\hline Nampa PD (ID) & 3.361 & 4.898 & 42.857 & 5.263 \\
\hline Milford PD (CT) & 6.796 & 0.000 & 78.255 & 10.000 \\
\hline Los Angeles PD (CA) & 6.124 & 1.814 & 48.548 & 5.894 \\
\hline Manchester PD (NH) & 5.607 & 0.000 & 197.657 & 4.040 \\
\hline West Palm Beach PD (FL) & 0.000 & 2.004 & 162.320 & 12.288 \\
\hline Milwaukee PD (WI) & 3.776 & 1.010 & 77.398 & 7.467 \\
\hline Phoenix PD (AZ) & 0.588 & 2.393 & 34.191 & 33.062 \\
\hline Sioux Falls PD (SD) & 1.794 & 1.294 & 54.360 & 16.810 \\
\hline Fort Worth PD (TX) & 1.133 & 1.748 & 84.962 & 11.387 \\
\hline Fort Collins PD (CO) & 3.704 & 0.000 & 138.572 & 8.460 \\
\hline Ogden PD (UT) & 1.538 & 0.000 & 62.841 & 37.626 \\
\hline New Rochelle PD (NY) & 4.918 & 2.595 & 59.683 & 3.680 \\
\hline Portland PD (ME) & 3.871 & 0.000 & 131.350 & 8.282 \\
\hline Whittier PD (CA) & 1.527 & 1.171 & 56.191 & 18.033 \\
\hline Irving PD (TX) & 3.086 & 0.922 & 81.559 & 8.135 \\
\hline High Point PD (NC) & 0.455 & 0.958 & 132.191 & 14.155 \\
\hline Suffolk PD (VA) & 2.959 & 0.000 & 315.854 & 3.480 \\
\hline North Miami PD (FL) & 3.175 & 0.000 & 62.329 & 19.540 \\
\hline Janesville PD (WI) & 6.731 & 0.000 & 97.506 & 6.000 \\
\hline Sandy PD (UT) & 2.632 & 0.000 & 125.068 & 10.398 \\
\hline Harlingen PD (TX) & 7.937 & 1.540 & 16.937 & 12.438 \\
\hline Grand Rapids PD (MI) & 11.838 & 0.000 & 219.182 & 0.802 \\
\hline San Antonio PD (TX) & 2.117 & 1.198 & 54.221 & 12.335 \\
\hline Everett PD (WA) & 3.468 & 0.000 & 108.596 & 9.096 \\
\hline Longview PD (TX) & 0.000 & 2.471 & 154.453 & 7.906 \\
\hline O'Fallon PD (MO) & 0.980 & 0.000 & 116.348 & 18.730 \\
\hline North Little Rock PD (AR) & 27.273 & 0.000 & 160.785 & 0.000 \\
\hline Buffalo PD (NY) & 7.334 & 0.763 & 88.565 & 2.397 \\
\hline Lakewood PD (CO) & 2.667 & 2.091 & 52.963 & 6.361 \\
\hline Huntsville PD (AL) & 9.091 & 1.668 & 36.696 & 3.250 \\
\hline Aurora PD (CO) & 2.070 & 2.759 & 39.234 & 8.088 \\
\hline Garden Grove PD (CA) & 3.145 & 4.085 & 7.002 & 26.042 \\
\hline
\end{tabular}




\begin{tabular}{|c|c|c|c|c|}
\hline Police Department (State) & $\begin{array}{c}\text { Complaint } \\
\text { Rate }\end{array}$ & $\begin{array}{c}\text { Death by } \\
\text { Police Rate }\end{array}$ & Force Rate & $\begin{array}{c}\text { Officer } \\
\text { Assault Rate }\end{array}$ \\
\hline Santa Clara PD (CA) & 2.920 & 0.860 & 64.488 & 6.813 \\
\hline Concord PD (CA) & 2.597 & 0.815 & 128.787 & 3.175 \\
\hline Durham PD (NC) & 5.118 & 1.305 & 48.269 & 4.126 \\
\hline Hampton PD (VA) & 1.866 & 1.455 & 42.918 & 10.320 \\
\hline Berkeley PD (CA) & 12.707 & 0.000 & 39.055 & 5.325 \\
\hline Lee's Summit PD (MO) & 2.459 & 0.000 & 80.624 & 11.111 \\
\hline Lakeland PD (FL) & 0.427 & 1.017 & 226.817 & 3.876 \\
\hline Jacksonville PD (NC) & 5.556 & 0.000 & 89.346 & 3.839 \\
\hline Fort Smith PD (AR) & 0.621 & 0.000 & 233.845 & 6.301 \\
\hline Grand Junction PD (CO) & 0.926 & 0.000 & 84.937 & 15.385 \\
\hline Danville PD (VA) & 1.575 & 0.000 & 129.675 & 6.977 \\
\hline Beaverton PD (OR) & 2.344 & 0.000 & 90.855 & 7.214 \\
\hline Hattiesburg PD (MS) & 3.053 & 0.000 & 95.065 & 4.959 \\
\hline Daly City PD (CA) & 0.917 & 0.985 & 52.197 & 10.398 \\
\hline Hoboken PD (NJ) & 2.632 & 0.000 & 52.106 & 10.859 \\
\hline Rock Hill PD (SC) & 1.653 & 0.000 & 69.419 & 11.029 \\
\hline Downey PD (CA) & 0.000 & 0.894 & 58.136 & 17.974 \\
\hline Sunrise PD (FL) & 1.156 & 1.166 & 26.824 & 15.517 \\
\hline Port St. Lucie PD (FL) & 4.132 & 0.611 & 31.145 & 6.970 \\
\hline Rochester PD (MN) & 0.781 & 0.000 & 148.733 & 6.716 \\
\hline Flint PD (MI) & 1.527 & 0.000 & 38.736 & 19.608 \\
\hline Savannah-Chatham Metro PD (GA) & 2.852 & 0.726 & 155.422 & 0.932 \\
\hline Henderson PD (NV) & 0.565 & 1.162 & 63.112 & 8.208 \\
\hline Oceanside PD (CA) & 0.510 & 0.000 & 72.110 & 15.764 \\
\hline Covington PD (KY) & 0.000 & 0.000 & 107.907 & 15.534 \\
\hline Albany PD (GA) & 16.578 & 0.000 & 83.941 & 0.167 \\
\hline Pasadena PD (CA) & 0.806 & 0.728 & 38.597 & 13.197 \\
\hline Sanford PD (FL) & 1.575 & 0.000 & 88.182 & 6.452 \\
\hline Palm Bay PD (FL) & 0.000 & 0.000 & 67.111 & 23.874 \\
\hline Fargo PD (ND) & 1.550 & 0.000 & 37.734 & 15.402 \\
\hline Lynchburg PD (VA) & 19.737 & 0.000 & 74.018 & 0.000 \\
\hline Jonesboro PD (AR) & 0.000 & 1.480 & 113.990 & 4.219 \\
\hline Pearland PD (TX) & 1.835 & 1.107 & 46.487 & 4.255 \\
\hline Richmond PD (VA) & 5.142 & 0.000 & 75.969 & 2.054 \\
\hline Murfreesboro PD (TN) & 1.657 & 0.000 & 23.816 & 21.461 \\
\hline Beverly Hills PD (CA) & 1.493 & 0.000 & 84.758 & 5.514 \\
\hline Burbank PD (CA) & 0.629 & 0.000 & 56.082 & 14.035 \\
\hline Lewisville PD (TX) & 1.471 & 1.042 & 43.755 & 5.201 \\
\hline Cape Coral PD (FL) & 0.389 & 0.643 & 49.548 & 10.853 \\
\hline Grand Prairie PD (TX) & 0.463 & 1.145 & 47.529 & 7.492 \\
\hline Bethlehem PD (PA) & 0.676 & 0.000 & 79.983 & 8.277 \\
\hline Tyler PD (TX) & 0.000 & 1.030 & 65.894 & 8.200 \\
\hline Dallas PD (TX) & 5.317 & 1.905 & 10.023 & 5.683 \\
\hline Hollywood PD (FL) & 0.000 & 0.704 & 60.538 & 10.473 \\
\hline Nashville PD (TN) & 2.373 & 0.000 & 54.963 & 5.241 \\
\hline Concord PD (NC) & 2.703 & 0.000 & 87.153 & 2.564 \\
\hline Cranston PD (RI) & 0.662 & 0.000 & 54.695 & 10.274 \\
\hline Franklin PD (TN) & 0.000 & 0.000 & 104.568 & 8.723 \\
\hline Charleston PD (SC) & 1.887 & 0.000 & 247.306 & 0.402 \\
\hline Chandler PD (AZ) & 0.906 & 0.842 & 27.373 & 8.910 \\
\hline Boca Raton PD (FL) & 1.064 & 2.333 & 5.832 & 21.717 \\
\hline Pembroke Pines PD (FL) & 0.000 & 0.643 & 35.352 & 13.853 \\
\hline
\end{tabular}




\begin{tabular}{lcccc}
\hline Police Department (State) & $\begin{array}{c}\text { Complaint } \\
\text { Rate }\end{array}$ & $\begin{array}{c}\text { Death by } \\
\text { Police Rat }\end{array}$ & Force Rate & $\begin{array}{r}\text { Officer } \\
\text { Assault Rate }\end{array}$ \\
\hline Carrollton PD (TX) & 0.621 & 0.000 & 133.359 & 2.863 \\
Greensboro PD (NC) & 0.709 & 0.000 & 106.053 & 3.478 \\
Roseville PD (CA) & 0.000 & 0.837 & 29.280 & 13.978 \\
Sumter PD (SC) & 1.818 & 0.000 & 93.751 & 1.923 \\
North Richland Hills PD (TX) & 0.000 & 1.572 & 50.311 & 4.545 \\
Miami PD (FL) & 2.941 & 0.249 & 9.952 & 13.366 \\
Simi Valley PD (CA) & 1.587 & 0.807 & 8.068 & 17.486 \\
Danbury PD (CT) & 4.054 & 0.000 & 25.908 & 4.139 \\
Bartlett PD (TN) & 1.020 & 0.000 & 66.113 & 3.333 \\
Midland PD (TX) & 4.698 & 0.000 & 44.398 & 1.143 \\
Plantation PD (FL) & 0.000 & 0.000 & 48.921 & 7.900 \\
Norman PD (OK) & 0.000 & 0.000 & 49.216 & 7.520 \\
Livonia PD (MI) & 0.000 & 0.000 & 81.753 & 4.032 \\
Roswell PD (GA) & 4.580 & 1.120 & 33.597 & 0.000 \\
Warwick PD (RI) & 0.000 & 0.000 & 38.695 & 8.687 \\
Alexandria PD (VA) & 1.250 & 0.713 & 30.641 & 1.929 \\
Palm Beach Gardens PD (FL) & 0.877 & 0.000 & 33.100 & 4.207 \\
Boston PD (MA) & 1.890 & 0.968 & 17.752 & 1.729 \\
Conway PD (AR) & 0.962 & 0.000 & 103.915 & 0.000 \\
Marietta PD (GA) & 0.000 & 1.741 & 64.403 & 0.000 \\
Richardson PD (TX) & 1.361 & 0.999 & 5.997 & 2.692 \\
Peoria PD (AZ) & 0.000 & 0.000 & 24.585 & 3.226 \\
Rio Rancho PD (NM) & 0.813 & 0.000 & 24.119 & 0.384 \\
Union City PD (NJ) & 0.000 & 0.000 & 58.518 & 0.000 \\
Hoover PD (AL) & 0.000 & 0.000 & 12.326 & 0.000 \\
\hline
\end{tabular}




\section{APPENDIX D \\ Survey Items Included in Each of the Additive Variety Scores Created}

\section{Table D1}

Items that Comprise the Community-Technology Engagement Additive Variety Score (from LEMAS 2013)

\begin{tabular}{ll}
\hline Question & Individual Items Included \\
\hline $\begin{array}{l}\text { What crime-related information did your } \\
\text { agency provide to the public on its website? }\end{array}$ & $\begin{array}{l}\text { Jurisdiction-wide summaries of crime statistics } \\
\text { Crime statistics by districts, beats, neighborhoods, or } \\
\text { other areas within your jurisdiction } \\
\text { Street-level maps that report the location and nature of a } \\
\text { variety of specific crimes } \\
\text { Street-level maps with details about the residential } \\
\text { location of sex offenders }\end{array}$ \\
& Other types of crime-related information \\
& $\begin{array}{l}\text { Report crime or other problems } \\
\text { Ask questions or provide feedback }\end{array}$ \\
\hline $\begin{array}{l}\text { What kind of information was provided by } \\
\text { the public using your agency's website? }\end{array}$ & File agency or officer complaints \\
& Other types of information \\
\hline $\begin{array}{l}\text { Could the public report crimes or other } \\
\text { problems to your agency by email or texting? }\end{array}$ & Yes or No \\
\hline $\begin{array}{l}\text { Can the public arrange to receive information } \\
\text { about crime or other issues via email, }\end{array}$ & Yes or No \\
recorded phone calls, cell phone texts, or \\
other electronic means from your agency?
\end{tabular}




\section{Table D2}

Items that Comprise the Community-Technology Engagement Additive Variety Score (from LEMAS 2007)

\begin{tabular}{ll}
\hline Question & Individual Items Included \\
\hline Did your agency use technology in any of the & Agency's email address was marketed to citizens \\
following ways to improve contact between & Agency's website included methods for citizens to ask \\
citizens and police? & questions and/or provide feedback \\
& Agency's website provided citizens with direct access to \\
crime maps & Agency's website provided citizens with direct access to \\
crime statistics & Agency hosted a listserv or other electronic means to \\
distribute news and updates & \\
Reverse 9-1-1 system used for emergency community \\
notification \\
System used for non-emergency mass community \\
notification \\
3-1-1 system available to handle police non-emergency \\
calls \\
Electronic crime reporting was available \\
Citizens received crime reports via email \\
Other ways \\
\hline
\end{tabular}




\section{Table D3}

Items that Comprise the Hiring Standards Additive Variety Score (from LEMAS 2007)

\begin{tabular}{ll}
\hline Question & Individual Items Included \\
\hline Which of the following screening & Background investigations \\
techniques are used by your agency & Credit history check \\
in selecting new officer recruits? & Criminal history check \\
& Driving record check \\
& Personal interview \\
& Personality inventory \\
& Polygraph exam \\
& Psychological evaluation \\
& Voice stress analyzer \\
& Written aptitude test \\
& Analytical/problem-solving ability assessment \\
& Assessment of understanding of diverse cultural populations \\
& Mediation/conflict management skills assessment \\
Second language test \\
Volunteer/community service history check \\
Drug test \\
Medical exam \\
Physical agility/fitness test \\
\hline
\end{tabular}




\section{Table D4}

Items that Comprise the Formalization Additive Variety Score (from LEMAS 2007)

\begin{tabular}{ll}
\hline Question & Individual Items Included \\
\hline $\begin{array}{l}\text { Does your agency have written policy } \\
\text { or procedural directives on the }\end{array}$ & Officer conduct pertaining to the use of deadly force/firearm \\
following? & Ofscharge \\
& Officer conduct pertaining to the use of less-than-lethal force \\
& appearance \\
& Officer conduct pertaining to off-duty employment \\
& Officer conduct pertaining to maximum work hours allowed \\
& Officer conduct pertaining to off-duty conduct \\
& Officer conduct pertaining to interacting with the media \\
& Officer conduct pertaining to employee counseling assistance \\
& Dealing with mentally ill persons \\
& Dealing with homeless persons \\
& Dealing with domestic disputes \\
& Dealing with juveniles \\
& Dealing with persons with limited English proficiency \\
& Procedures on collection of information on in-custody deaths \\
& Procedures on racial profiling \\
& Procedures on citizen complaints \\
& Procedures on checking of immigration status by patrol officers \\
Requiring that citizen complaints about use of force receive \\
separate investigation outside the chain of command where the \\
accused officer is assigned
\end{tabular}




\title{
APPENDIX E
}

\author{
Case Study Timeline
}

Weeks from April 30-September 2, 2017

$2^{\text {nd }}$ follow up contact with mutual contact

Phone call and follow up email with Hartford PD

Call with Hartford PD representatives

\section{$1^{\text {st }}$ in person meeting \\ Memoranda of Understanding signed}

7 interviews; 2 observations; 1 ride-along

5 interviews; 2 observations; 2 ride-alongs

16 interviews; 3

observations; 3 ride-alongs

16 interviews; 1 observation; 1 ride-along

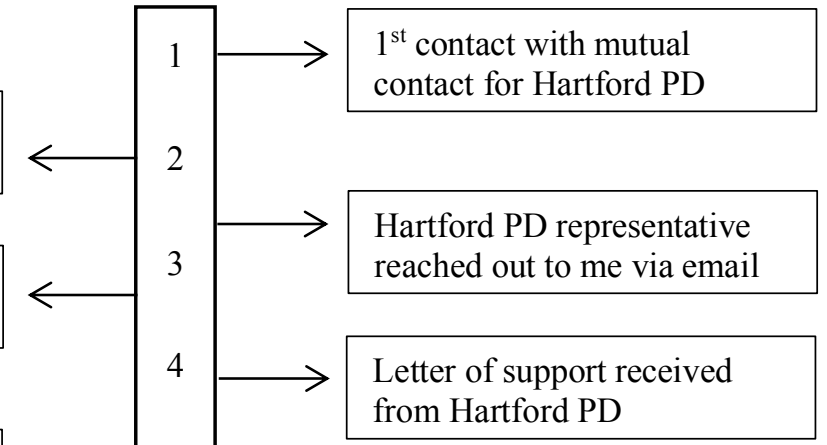

$\leftarrow 5$

6

Started receiving secondary sources from Hartford PD

Arrived in Hartford, CT

7

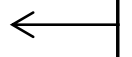

8

$2^{\text {nd }}$ in person meeting

$\longrightarrow \quad 1^{\text {st }}$ interview conducted

9

10

$\leftarrow$

11

Traveled out of the Country

12

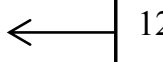

13

16 interviews; 4

observations; 1 ride-along

14

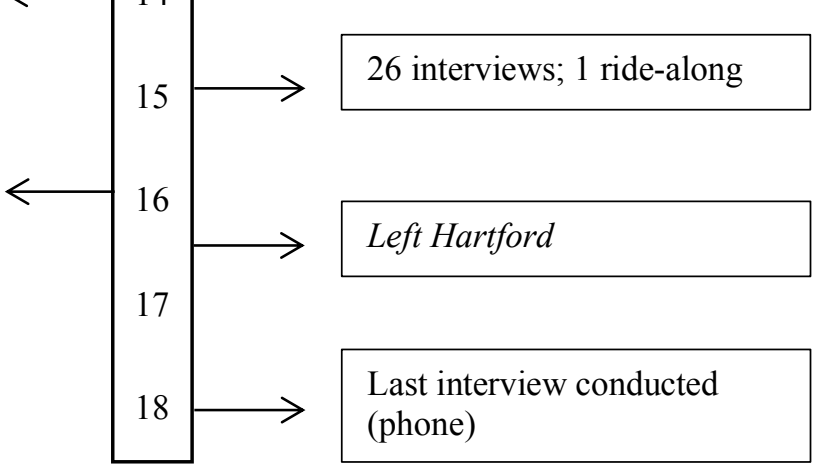




\section{APPENDIX F}

\section{Interview Guide ${ }^{49}$}

\begin{tabular}{|c|c|c|c|c|c|}
\hline Categories & Questions & $\mathbf{C R}$ & FLR & MUM & PUB \\
\hline \multirow{3}{*}{ Background } & $\begin{array}{l}\text { Can you tell me a little about your position and what } \\
\text { you do? }\end{array}$ & $\mathrm{X}$ & $\mathrm{X}$ & $\mathrm{X}$ & $\mathrm{X}$ \\
\hline & What are some things the police department does well? & $\mathrm{X}$ & $\mathrm{X}$ & & \\
\hline & What are some challenges for the police department? & $\mathrm{X}$ & $\mathrm{X}$ & & \\
\hline \multirow{4}{*}{$\begin{array}{l}\text { Overview of } \\
\text { police- community } \\
\text { relations }\end{array}$} & $\begin{array}{l}\text { Can you provide me with your definition of police- } \\
\text { community relations? }\end{array}$ & $\mathrm{X}$ & $\mathrm{X}$ & $\mathrm{X}$ & $\mathrm{X}$ \\
\hline & $\begin{array}{l}\text { Can you tell me about the current state of police- } \\
\text { community relations in Hartford? }\end{array}$ & $\mathrm{X}$ & $\mathrm{X}$ & $\mathrm{X}$ & $\mathrm{X}$ \\
\hline & $\begin{array}{l}\text { What are some of the reasons that you think police- } \\
\text { community relations are this way? }\end{array}$ & & $\mathrm{X}$ & $\mathrm{X}$ & $\mathrm{X}$ \\
\hline & $\begin{array}{l}\text { What have been some of the challenges in promoting } \\
\text { positive police-community relations? }\end{array}$ & & $\mathrm{X}$ & $\mathrm{X}$ & \\
\hline \multirow{5}{*}{$\begin{array}{l}\text { Organizational } \\
\text { Factors }\end{array}$} & $\begin{array}{l}\text { What are the organizational practices that impact police- } \\
\text { community relations? }\end{array}$ & $\mathrm{X}$ & & & \\
\hline & $\begin{array}{l}\text { What has the police department done right in terms of } \\
\text { promoting positive police-community relations (or } \\
\text { trying to improve)? }\end{array}$ & $\mathrm{X}$ & $\mathrm{X}$ & $\mathrm{X}$ & $\mathrm{X}$ \\
\hline & $\begin{array}{l}\text { What are the reasons you think these police practices } \\
\text { impact the relationships with the community? }\end{array}$ & $\mathrm{X}$ & $\mathrm{X}$ & $\mathrm{X}$ & $\mathrm{X}$ \\
\hline & $\begin{array}{l}\text { What can/could the police department do better or } \\
\text { different in regards to police-community relations? }\end{array}$ & $\mathrm{X}$ & $X$ & $X$ & $X$ \\
\hline & $\begin{array}{l}\text { What do you think the reasons are that certain } \\
\text { organizational practices lead to negative police- } \\
\text { community relations? }\end{array}$ & $X$ & & & $X$ \\
\hline \multirow{3}{*}{$\begin{array}{l}\text { Community } \\
\text { Engagement }\end{array}$} & $\begin{array}{l}\text { Can you tell me what specific community policing } \\
\text { efforts are done well in Hartford in terms of impacting } \\
\text { police-community relations? }\end{array}$ & $X$ & $X$ & & $X$ \\
\hline & $\begin{array}{l}\text { What made these efforts have a positive impact on } \\
\text { police-community relations? }\end{array}$ & $X$ & $X$ & & $X$ \\
\hline & $\begin{array}{l}\text { Can you tell me about what community } \\
\text { policing/engagement efforts could be done differently to } \\
\text { better impact police-community relations? }\end{array}$ & $X$ & $X$ & & \\
\hline $\begin{array}{l}\text { Diversity (Gender } \\
\text { and Race) }\end{array}$ & $\begin{array}{l}\text { Can you tell me about gender differences related to } \\
\text { policing in Hartford? (e.g. behavior differences) }\end{array}$ & $X$ & $X$ & $X$ & $\mathrm{X}$ \\
\hline
\end{tabular}

${ }^{49}$ This is a summarized and condensed version of the interview guide created for this study (excluding other statements, explanations, and probes). For the purposes of reporting results and concealing identities, public officials and community respondents were grouped. The semi-structured nature of the interview format allowed for deviations from and/or additions to questions. 


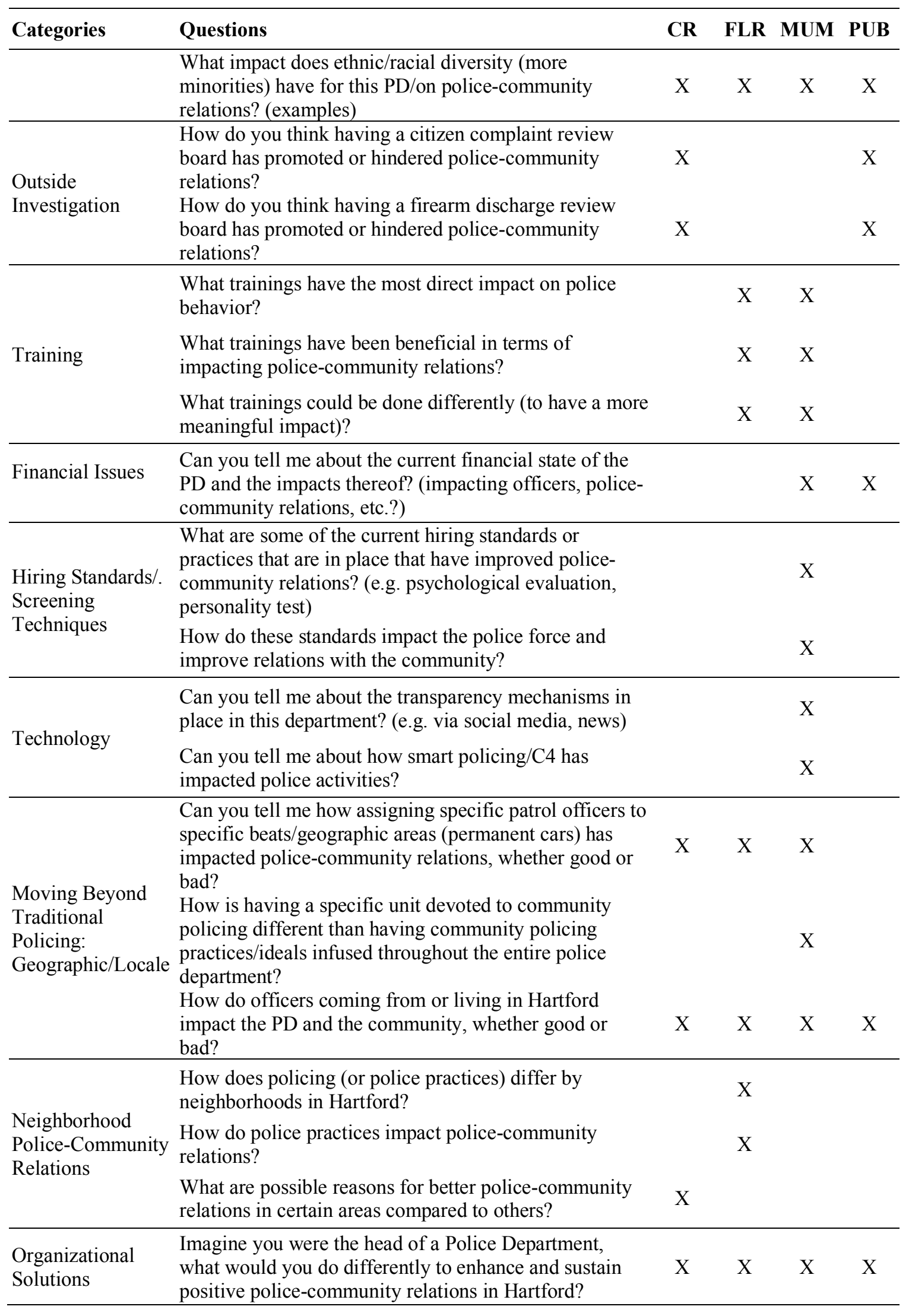




\begin{tabular}{llcccc}
\hline Categories & Questions & CR & FLR & MUM & PUB \\
\hline Wrap Up & $\begin{array}{l}\text { Do you have any final thoughts you would like to share, } \\
\text { maybe something that I have not thought to ask about? }\end{array}$ & X & X & X & X \\
\hline
\end{tabular}

Note. $\mathrm{CR}=$ Community Respondents; FLR = Front-line Respondent; MUM = Mid-to-Upper Management Respondents; PUB $=$ Public Official Respondents 


\title{
APPENDIX G
}

\author{
Transcription Protocol
}

\section{Format:}

- In the beginning of every transcript write:

o File:

○ Duration:

- Date:

- Times New Roman 12 point font;

- One-inch top, bottom, right, and left margins

- All text shall begin at the left-hand margin (with indents); Entire document shall be left justified

- Number the pages

\section{End of Transcription:}

- When the transcription of a single interview is complete, write END OF INTERVIEW in uppercase letters on the last line of the transcript.

\section{Content:}

- There is one person (female) who is the interviewer, who asks questions and then says things like, "Yeah.", "Wow", "Okay." while the Respondent, the person being interviewed, answers the questions. Please distinguish between what the Interviewer and Respondent say by typing what they say on separate lines, and labeling one person "Interviewer" and the other "Respondent."

- Verbatim Transcription (i.e. recorded word for word, exactly as said), including any nonverbal or relevant background sounds the express emotion (e.g. laughter, sighs, claps, etc.; however, car horns, sirens, barking, phone rings and the like are not important), respondent affirmative sounds (yep, yea, yes) and all respondent filler words should be included (mhmm, hmm, uh huh, ahah etc.), the tone of the respondent (where relevant), type out repetition (however stuttering is not needed).

- Repetition words (double-doubled words) for stuttering of single words specifically does not need to be included. The only time repetition should be included is when it is more than a single word (not stuttering) but the speaker is repeating for emphasis.

- Incorrect Example:

- Respondent: I was coming through the ranks, you know, I-I-I saw effects of that. And it was really good. There's - there's times that when we're coming around the corner, the guys see-see-see us, you know.

- Correct Example:

- Respondent: I was coming through the ranks, you know, I saw effects of that. And it was really good. There's times that when we're coming around the corner, the guys see us, you know. 
- Use quotation marks if someone refers to them saying something specific.

- The interviewer's fillers (female voice) should not be included after asking the question. Thus, the affirmative "yea" "okay" or filler "wow" etc. should not be included when the interviewer says it. Only transcribe what the interviewer says when they ask a question or say more than one or two words. Otherwise, keep going with what the Respondent is saying and ignore these vocal fillers by the interviewer in the transcription.

- Good Example:

- Interviewer: Describe your current living situation?

- Respondent: Well, I grew up in section 8 housing, then when I was 10 my dad got a better job in another town.

- Bad Example:

- Interviewer: Describe your current living situation?

- Respondent: Well, I grew up in section 8 housing

- Interviewer: Okay

- Respondent: Then when I was 10 my dad got a better job in another town

- Mispronunciations:

- If interviewers or interviewees mispronounce words, these words shall be transcribed as the individual said them. The transcript shall not be "cleaned up" by removing foul language, slang, grammatical errors, or misuse of words or concepts.

- If an incorrect or unexpected pronunciation results in difficulties with comprehension of the text, the correct word shall be typed in square brackets. A forward slash shall be placed immediately behind the open square bracket and another in front of the closed square bracket.

- Example: I thought that was pretty pacific [/specific/], but they disagreed.

- Inaudible Information

- The transcriber shall identify portions of the audiotape that are inaudible or difficult to decipher. If a relatively small segment of the tape (a word or short sentence) is partially unintelligible, the transcriber shall type the phrase "inaudible segment" and add a time stamp. This information shall appear in square brackets.

- Example: The process of identifying missing words in an audiotaped interview of poor quality is [inaudible segment; TIME STAMP].

- If a lengthy segment of the tape is inaudible, unintelligible, or is "dead air" where no one is speaking, the transcriber shall record this information in square brackets. In addition, the transcriber shall provide a time estimate as well as a time stamp for information that could not be transcribed.

- Example: [Inaudible/Dead Air/Unintelligible: TIME STAMP; about 2 minutes of interview missing] 
- However, if there is a word that cannot be understood but the phonetic version can be provided, please do so.

- Overlapping Speech

- If individuals are speaking at the same time (i.e., overlapping speech) and it is impossible to distinguish what each person is saying, the transcriber shall place the phrase "cross talk" in square brackets immediately after the last identifiable speaker's text and pick up with the next audible speaker. Include in the parenthesis, the approximate time stamp for the cross talk as well.

- Example: Turn taking may not always occur. People may simultaneously contribute to the conversation; hence, making it difficult to differentiate between one person's statement [cross talk at 2:55]. This results in loss of some information

- Interruption Breaks/Pauses

○ Use (inter.) where an interruption break happens

- If an individual pauses briefly between statements or trails off at the end of a statement, the transcriber shall use three ellipses. A brief pause is defined as a two- to five second break in speech.

- Example: Sometimes, a participant briefly loses . . . a train of thought or . . pauses after making a poignant remark. Other times, they end their statements with a clause such as but then . . . .

- If a substantial speech delay occurs at either beginning or the continuing a statement occurs (more than two or three seconds), the transcriber shall use "long pause" in parentheses.

- Example: Sometimes the individual may require additional time to construct a response. (Long pause) other times, he or she is waiting for additional instructions or probes.

- Questionable Text

- If the transcriber is unsure of the accuracy of a statement made by a speaker, this statement shall be placed inside parentheses and a question mark is placed in front of the open parenthesis and behind the close parenthesis with a time stamp.

- Example: I wanted to switch to ?(Kibuli Hospital)? [TIME STAMP] if they have a job available for me because I think the conditions would be better.

- Sensitive Information

- If an individual uses his or her own name during the discussion, or provides others' names, locations, organizations, and so on, the transcriber shall enter an equal sign immediately before and after the named information. Analysts will use this labeling information to easily identify sensitive information that may require substitution.

- Example: My colleague = John Doe = was very unhappy in his job so he started talking to the hospital administrator at $=$ Kagadi Hospital = about a different job.

- Multiple Respondents

$\circ$ If there is more than one respondent to a question by the interviewer, 
please note the change in respondent when it is apparent by a voice change.

- Example: Interviewer, Respondent 1, Respondent 2

\section{Reviewing for Accuracy:}

- The transcriber/proofreader shall check (proofread) all transcriptions against the audiotape and revise the transcript file accordingly before it is submitted. All transcripts shall be audited for accuracy by the interviewer who conducted the interview or by the study data manager.

* Please italicize anything in parenthesis/brackets e.g. (laughter) (long pause) [inaudible information...]. Generally, parenthesis will be used when describing something in the interview (e.g. pause, emotions, noise, etc.), whereas brackets will be used for identifying the transcribers notes specifically [e.g. inaudible information or correct spelling]; 


\section{APPENDIX H}

\section{Observation Sites and Types}

\begin{tabular}{|c|c|c|c|}
\hline Observation Site & $\begin{array}{l}\text { Estimated } \\
\text { Hours }\end{array}$ & Who was observed & $\begin{array}{l}\text { Examples of what was } \\
\text { observed }\end{array}$ \\
\hline Ride-alongs $(n=9)$ & 43.17 & $\begin{array}{l}\text { police; community members; } \\
\text { local business owners; } \\
\text { homeless people }\end{array}$ & $\begin{array}{l}\text { Police-citizen } \\
\text { interactions; people } \\
\text { getting arrested and } \\
\text { booked; police interacting } \\
\text { with other officers; police } \\
\text { writing reports; different } \\
\text { parts of the city both } \\
\text { affluent areas and blighted } \\
\text { areas; parks; community } \\
\text { businesses; libraries; car } \\
\text { chases; people receiving } \\
\text { tickets; people's living } \\
\text { areas }\end{array}$ \\
\hline Roll Calls $(n=4)$ & 1 & $\begin{array}{l}\text { police management; patrol } \\
\text { officers }\end{array}$ & $\begin{array}{l}\text { Police management going } \\
\text { over key events from the } \\
\text { shift prior, checking who } \\
\text { is in attendance }\end{array}$ \\
\hline $\begin{array}{l}\text { Police-Community } \\
\text { Events }(n=4)\end{array}$ & 8.5 & $\begin{array}{l}\text { police; youth; community } \\
\text { leaders and members; state } \\
\text { police; local politicians; } \\
\text { business representatives }\end{array}$ & $\begin{array}{l}\text { Positive interactions } \\
\text { between police and the } \\
\text { community; shoe drive; } \\
\text { athletic outdoors day with } \\
\text { youth; basketball event } \\
\text { where police and youth } \\
\text { played together }\end{array}$ \\
\hline Police meetings $(n=3)$ & 9 & $\begin{array}{l}\text { police recruits; police } \\
\text { command staff; police } \\
\text { administration }\end{array}$ & $\begin{array}{l}\text { Interactions between } \\
\text { police command staff and } \\
\text { new recruits; new real } \\
\text { time crime center; casual } \\
\text { conversations occurring in } \\
\text { command staff offices or } \\
\text { front desk/lobby area }\end{array}$ \\
\hline $\begin{array}{l}\text { Community meetings } \\
(n=5)\end{array}$ & 6 & $\begin{array}{l}\text { community leaders and } \\
\text { volunteers, city government } \\
\text { officials, police } \\
\text { representatives }\end{array}$ & $\begin{array}{l}\text { Community members } \\
\text { having informal } \\
\text { discussions over coffee; } \\
\text { civilian police review } \\
\text { board meeting; city } \\
\text { commission meeting; } \\
\text { mayor town hall meeting; } \\
\text { live viewing of local news } \\
\text { segment with community } \\
\text { members }\end{array}$ \\
\hline
\end{tabular}




\section{APPENDIX I}

\section{Statement of Reflexivity}

While I was not initially interested in conducting research on policing when I entered into my doctoral degree program, I did know that I wanted to use my research to aid in the development of solutions to societal problems. Thus, this study was partially motivated by current events across the country surrounding police-community relations. The numerous incidents of violence between police and citizens that erupted in 2014 put a spotlight on the tensions that existed between marginalized communities and the police. These incidents led to various demonstrations, dialogues, and police reform proposals at the local, state, and national levels of government. These incidents also revealed the lack of data and empirical research dedicated to understanding the impacts of organizational reform strategies on police outcomes. This confluence of events provided a call and an opportunity for research to investigate this topic and potentially make a difference in both policy and practice.

Apart from the salience of this research to practice, there are both personal characteristics and experiences that have influenced me as a researcher and subsequently this research topic. These experiences and characteristics have shaped me as I embarked upon this research project, while in the field conducting this research, and also while interpreting and making sense of the data and overall findings. First, my age, gender, and racial identity all influence my perspective as well as others' perceptions of me. Of most salience, my bi-racial identity has allowed me to understand and empathize with arguments and/or perspectives raised by both Black and White community members pertaining to police-community relations. While conducting field research in a majority- 
minority city, being bi-racial allowed me to identify with and relate to the community directly despite not being from the city or having any ties to the city. Being a young female conducting field research in a male-dominant environment (i.e., police departments) may have also allowed for gender imbalances and/or power dynamics to be present. I was very conscious of potential gender issues and thus was very careful in how I presented myself in terms of etiquette as well as clothing. Nonetheless, there were still some comments made throughout my field research pertaining to my physical appearance and aesthetics, albeit those were few. Second, conducting research on often politicized and high profile topics with police officers while neither having a law enforcement background nor coming from the community I was studying posed some challenges in the field. For instance, there were some police interviewees that were particularly guarded and made their position very clear during the interview. I tried to overcome some of these barriers by embedding myself in the community (e.g., attending community events) and in the police department (e.g., going on ride-alongs).

I have had personal as well as vicarious experiences with police officers and police departments that have ranged the spectrum from positive to negative interactions (some of which occurred during the process of this research). The more positive personal interactions with police officers occurred when I was a child with my elementary School Resource Officer (SRO). However, my SRO was shot and killed while off-duty shortly after I graduated from elementary school. Subsequent to this I have had numerous memorable encounters with law enforcement officers, some of which have been positive or neutral and others which have been negative interactions. For instance, I have family members and friends that were involved with the criminal justice system and I have 
witnessed incidents where arrests have been made. I have also had relatives share with me first-hand accounts of personal experiences where officers used excessive force. On the other hand, I have also had family members share stories of more positive encounters with law enforcement officers, where officers let them off or gave them a break despite clear culpability. However, these latter recounts of stories occurred much less than the former. All of these experiences have shaped my perspective towards police-civilian interactions and police-community relations more generally. While I recognize the value of positive non-enforcement police-civilian encounters I also understand and relate with the fears and risks associated with negative police-civilian interactions. The negative experiences I have had made me very cognizant of the racial tensions that undergird policing in America. Thus, upon embarking in this research, I was somewhat wary of police departments.

In regards to my professional experience, my educational background, the funding support received, and the concurrent internship and research opportunities undertaken each have influenced this research. First, prior to embarking upon my doctoral degree, I received my Bachelor of Science in Education while double-majoring in community and program development and criminology and minoring in communication studies. My educational background instilled within me the importance of the community, equity, and developing transformative solutions to problems. It is my belief that the community as a whole matters as well as all groups and/or sub-groups within the community. The community is central to discussions surrounding public goods and services and the equitable provisions thereof. Thus, my educational background directed my research towards understanding the dynamic and mutual relationship between the police and the 
community, rather than solely focusing on police departments. Likewise, my minor in communication studies helped to refine my interpersonal and written and oral communication skills, all of which aided during the interviewing process. I was also very mindful of the need to incorporate diverse perspectives throughout my research. For instance, I made a concerted effort to ensure that there were a broad array of individuals interviewed across various identity affiliations including but not limited to age, race, ethnicity, national origin, creed, sexual orientation, and professional experience.

Second, I received funding from the U.S. Department of Justice, Bureau of Justice Statistics to conduct this research. The Department of Justice did not direct or guide this research neither does it represent, endorse, nor is it responsible for this research. However, I made it clear to the police department during my initial meetings where the funding support was coming from. During the field research, I found out that some of the police officers believed that I was from the Department of Justice and represented their interests. I tried to communicate that this was an inaccurate assumption and/or belief and to correctly explain the process behind the grant funding. However, I do believe that this could have impacted the delivery and depth of information given by some interviewees. Also, I gained approval with and from the upper administration and leadership of the Hartford Police Department prior to interviewing the front-line police officers. Thus, some front-line officers initially expressed reservations with participating and being audio recorded due to internal police department politics and/or strains between the frontline officers and upper level administration and leadership. Knowing this, I made an effort to build rapport with the front-line officers and supervisors by partaking in police 
ride-alongs. I also tried to clearly reinforce to my interviewees that their identify would be protected.

Lastly, I conducted other projects and program evaluations in conjunction with police departments that were outside the scopes of this dissertation research. For instance, throughout the course of my doctoral program, but prior to starting my dissertation research, I interned with the U.S. Department of Justice, Community Relations Service. In this capacity, I helped to identify areas of community conflict, perform outreach activities to facilitate collaboration between various entities, and assist in the provision of mediation and training as needed. During my internship, I was involved in various situations revolving around police-community relations, which broadened my understanding of the issues. Similarly, prior to embarking on the field research component of my dissertation, I conducted a police body-worn camera program evaluation in which I spent a significant amount of time surveying officers. These experiences provided me the opportunity to engage with and interact with both law enforcement and various communities, all of which helped to prepare me as I entered into the field to conduct the qualitative component of my dissertation research.

As a result of this dissertation research and the experiences that I have gained throughout the research process, I have become much more understanding of the work environment of policing and work demands placed on officers. While, I still remain firm as it pertains to my beliefs around social justice, equity, and fairness in police-civilian interactions specifically (and the criminal justice system more generally), my understanding of and perspective towards police-community relations has broadened. I went into this research believing that there was a need to understand the organizational 
aspects of policing solely. As a result of the knowledge gained, I now seek to also

understand the implementation of organizational solutions as well as the decision-making processes of individual police officers. 
VITA

ANDREA MARIE HEADLEY

Born, Brooklyn, New York

2013

B.S.Ed., Human and Social Development and Criminology University of Miami

Coral Gables, Florida

2013

McKnight Doctoral Fellowship, Florida Education Fund

2015

M.S., Criminal Justice

Florida International University

Miami, Florida

2015

Graduate Research Fellowship Program for Criminal Justice

Statistics, U.S. Department of Justice, Bureau of Justice Statistics

2016

The Hanes Walton, Jr. Award for Quantitative Methods Training, National Conference of Black Political Scientists

2016

Graduate Academic Excellence Award, FIU Department of Criminal Justice

2016

Best Paper Award, American Society for Public Administration, International Young Scholars Workshop

Founders Fellowship, American Society for Public Administration

2017

Outstanding Student Award, American Society of Criminology, Division of People of Color and Crime

2017

Harrell Rodgers Graduate Student Scholarship, Midwest Political Science Association

2017

Equity and Inclusion Fellowship, Association for Public Policy Analysis and Management

2018

Ph.D., Public Affairs

Florida International University

Miami, Florida 


\section{PUBLICATIONS}

Evans, S.D., Malhotra, K. \& Headley, A.M. (2013). Promoting learning and critical reflexivity through an organizational case study project. Journal of Prevention and Intervention in the Community, 41(2), 105-112. (DOI: 10.1080/10852352.2013.757986)

Headley, A. \& Garcia-Zamor, J.C. (2014). The privatization of prisons and its impact on transparency and accountability in relation to maladministration. International Journal of Humanities Social Sciences and Education, 1(8), 23-34.

Goddard, T. \& Headley A. (2015). Community-Based Organization and Crime Prevention. Oxford Handbooks Online in Criminology and Criminal Justice. New York: Oxford University Press. (DOI: 10.1093/oxfordhb/9780199935383.013.81)

Headley, A.M. (2015). Book Review of Policing and Media: Public Relations, Simulations, and Communications by M. Lee and A. McGovern, Punishment \& Society, 18, 122-125. (DOI:10.1177/1462474515602078)

Headley A.M. (2016). Dilemmas faced when contracting out public services. Reprinted In J.J. Gonzalez III \& R.L. Kemp (Eds.) Corruption and American Cities: Essays and Case Studies in Ethical Accountability (p. 15-17). Jefferson, North Carolina: McFarland \& Company.

Guerette, R. T. \& Headley, A. (2016). Kidnapping. In Beth M. Huebner (Ed.) Oxford Bibliographies in Criminology. New York: Oxford University Press. (DOI: 10.1093/OBO/9780195396607-0195)

Headley, A. \& Alkadry, M. G. (2016). The flight or fight response: A look at stand your ground. Ralph Bunche Journal of Public Affairs, 5(1), Article 3, 1-13.

Headley, A.M. (2017). Bureaucratic race-making and place-making through the lens of policing. Book review of Pulled Over: How Police Stops Define Race and Citizenship by Charles R. Epp, Steven Maynard-Moody, and Donald Haider-Markel, Journal of Public Administration Research \& Theory, 27(3), 537-539. (DOI:10.1093/jopart/mux004)

Headley, A.M., Guerette, R.T., \& Shariati, A. (2017). A field experiment of the impact of body worn cameras (BWCs) on police officer behavior and perceptions. Journal of Criminal Justice, 53, 103-109. (DOI: https://doi.org/10.1016/j.jcrimjus.2017.10.003)

Headley, A.M., D'Alessio, S., \& Stolzenberg, L. (2017). The effect of a complainants race on dispositional outcome in police misconduct cases in Chicago. Race and Justice. (DOI:10.1177/17726829) 